PNNL-11549

UC-600

\title{
Tanks Focus Area Site Needs Assessment
} FY 1997

April 1997

Prepared for

the U.S. Department of Energy

under Contract DE-AC06-76RLO 1830

Pacific Northwest National Laboratory

Richland, Washington 99352

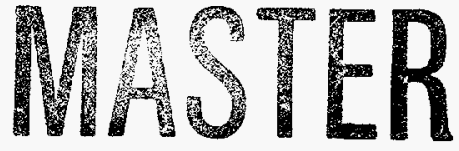




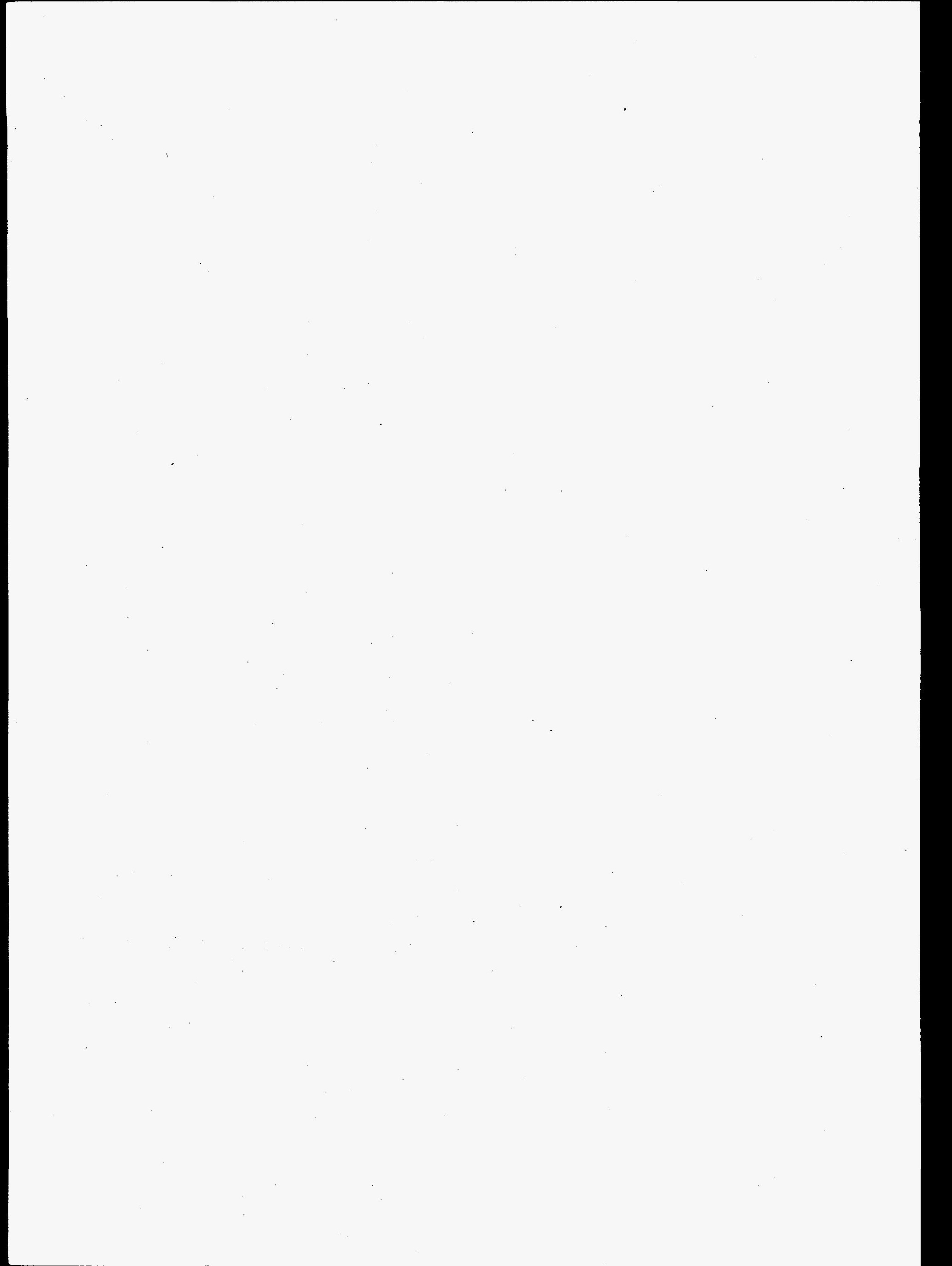




\section{DISCLAMMER}

Portions of this document may be illegible in electronic image products. Images are produced from the best available original document. 


\section{Executive Summary}

The Tanks Focus Area's (TFA's) mission is to manage an integrated technology development program that results in the application of technology to safely and efficiently accomplish tank waste remediation across the U.S. Department of Energy (DOE) complex. The TFA uses a systematic process for developing its annual program that draws from the tanks technology development needs expressed by four DOE tank waste sites - Hanford Site, Idaho National Engineering and Environmental Laboratory (INEEL), Oak Ridge Reservation (ORR), and Savannah River Site (SRS). The process is iterative and involves six steps:

- Site needs identification and documentation

- Site communication of priority needs

- Technical response development

- Review technical responses

- Develop program planning documents

- Review planning documents.

This document describes the outcomes of the first two steps: site needs identificaion and documentation, and site communication of priority needs. It also describes the initial phases of the third and fourth steps: technical response development and review technical responses.

Each site's Site Technology Coordination Group (STCG) was responsible for developing and delivering priority tank waste needs. This was accomplished using a standardized needs template developed by the National STCG. The standard template helped improve the needs submission process this year. The TFA received the site needs during December 1996 and January 1997.

The TFA gathered and cataloged a total of 90 needs from the four sites. The needs were analyzed and potential technical responses drafted and prioritized. Again this year, the TFA used its problem element structure to categorize the needs. Further, the TFA matched the needs to one of six functions: safety, characterization, pretreatment, immobilization, retrieval, and closure. Operationally, the TFA has combined the retrieval and closure functions under one Technology Integration Manager. A summary of the needs submitted and the TFA's assignment of the needs is shown in Table ES.1. To prioritize the technical responses, the TFA used four rating criteria:

- broad-based benefit - This criterion rated whether the technical responses could satisfy needs at multiple sites or with multiple tanks at a single site (complex-wide impact).

- cost reduction potential - This assessed the mortgage reduction potential possible in employing a technical response. 
- support to TFA goals - This criterion measured the technical responses' support or attainment of the four TFA strategic goals.

- user commitment to deploy - The TFA assessed the user's commitment based on interest expressed in the needs description and present or future co-funding of development and/or deployment.

Before the TFA Midyear Technical Review held March 4-7, 1997, draft technical responses and draft FY 1998-FY 1999 funding priorities were provided to TFA Site Representatives and members of the TFA User Steering Group and the TFA Technical Advisory Group. These were then discussed in detail at the midyear review. The Site Representatives finalized the priority listing in preparation for input to the DOE Office of Science and Technology budget process. At the time of publication of this document, the TFA continues to clarify intended work scopes for FY 1998 and FY 1999 tasks, fine tune task priorities, and finalize funding estimates. Currently, the TFA has developed and prioritized 67 technical responses that address 84 of the 90 needs submitted. The remaining six needs were either screened out or retracted by the sites. The TFA screened out needs that were not considered within the TFA mission area, did not have a technology development component, or for which a response was not feasible in cost or schedule. The final results will be summarized in the publication of the next TFA Multiyear Program Plan in the summer of 1997.

Table ES.1. Summary of Site Needs Submitted to Tanks Focus Area

\begin{tabular}{||l|c|c|c|c|c||}
\hline Functional Area & Hanford & INEEL & ORR & SRS & Total \\
\hline Safety & 6 & 0 & 0 & 3 & 9 \\
\hline Characterization & 6 & 1 & 2 & 1 & 10 \\
\hline Pretreatment & 5 & 6 & 2 & 7 & 20 \\
\hline Immobilization & 10 & 3 & 1 & 9 & 23 \\
\hline Retrieval and Closure & 10 & 8 & 4 & 6 & 28 \\
\hline Total & 37 & 18 & 9 & 26 & 90 \\
\hline
\end{tabular}

This year's needs assessment process yielded a few lessons learned. First, work must be done to standardize the sites' measurement of needs priorities. The sites differed in their methodologies, which made comparisons between sites difficult. Also, improvements in the detail and completeness of needs' cost reduction potential would have improved the TFA's prioritization outcomes. Lastly, there is a need to better coordinate STCG submittal schedules with the TFA's development and DOE-Headquarter's budget development cycles. With improved schedule coordination, the TFA and the sites would have had better opportunity for more beneficial technical and programmatic discussions. Nevertheless, this year's needs assessment process produced results superior to those of any previous year. 


\section{Contents}

Executive Summary

.iii

Section 1 - Introduction

Section 2 - Site Needs Assessment and Technical Response Development Process.........2.1

2.1 Site Needs Identification and Documentation .......................................... 2.1

2.2 Site Communication of Priority Needs ................................................. 2.1

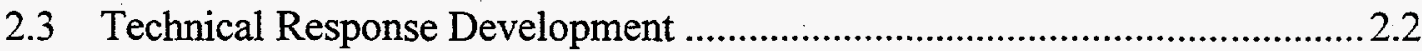

2.3.1 Program Planning Framework Development..............................2.2

2.3.2 Technical Response Evaluation Criteria ......................................2.3

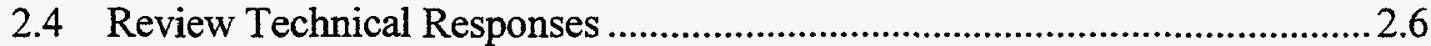

2.5 Develop Program Planning Documents ............................................... 2.6

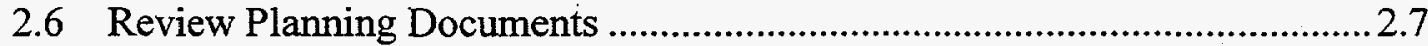

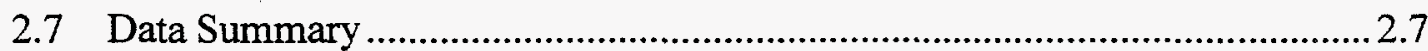

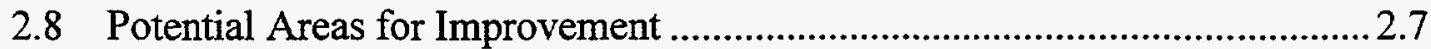

Section 3 - The Next Process Steps..................................................................... 3.1

3.1 Prepare and Submit FY 1999 Input to OST Budget Process ........................ 3.1

3.2 Finalize FY 1998 and FY 1999 Task Priority Listing............................... 3.1

3.3 Prepare and Submit FY 1998 Program Execution Documents ...................... 3.2

3.4 Finalize FY 1998 Technical Activities and Proposed FY 1999 Technical Activities

3.5 Document in the Multiyear Program Plan.................................................. 3.2

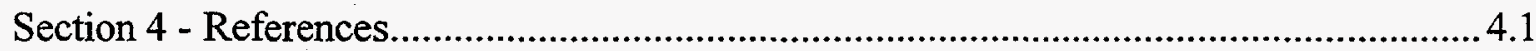

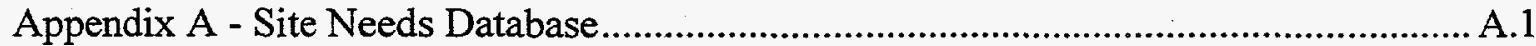




\section{List of Figures}

1.1 FY 1997 Tanks Focus Area Program Development Process .............................. 1.3

2.1 Tanks Focus Area Organization.................................................................. 2.2

\section{List of Tables}

ES.1 Summary of Site Needs Submitted to Tanks Focus Area.....................................iv

$2.1 \quad$ Problem Element Structure .......................................................................... 2.9

2.2 Summary of Site Needs Submitted to Tanks Focus Area...................................2.10

A.1 Tanks Focus Area Needs Submitted by Sites .............................................. A.2

A.2 Tanks Focus Area Site Needs Distributed within the Problem Element Structure ............................................................................ . 5

A.3 Tanks Focus Area FY 1998-FY 1999 Priority Listing .................................... A.11 


\section{Acronyms}

CLN Community Leaders Network

DOE U.S. Department of Energy

DOE-HQ U.S. Department of Energy - Headquarters

DWPF Defense Waste Processing Facility

EM DOE's Office of Environmental Management

HLW high-level waste

INEEL Idaho National Engineering and Environmental Laboratory

IRB Internal Review Budget

LLW low-level waste

MYPP multiyear program plan

ORR Oak Ridge Reservation

OST DOE's Office of Science and Technology

PEG Program Execution Guidance

RL U.S. Department of Energy, Richland Operations Office

SRS Savannah River Site

STCG Site Technology Coordination Group

TAG (TFA's) Technical Advisory Group

TFA Tanks Focus Area

TIM Technology Integration Manager

TRU transuranic (waste)

TTP technical task plan

USG (TFA's) User Steering Group 


\section{Section 1 - Introduction}

Annually, the Tanks Focus Area (TFA) completes a technical program development cycle. This cycle involves the collection of site needs, development of technical responses, refinement of the program for the next fiscal year, formulation of the program budget for the current fiscal year plus two outyears, and revision of the multiyear program plan (MYPP). This document describes the TFA's process of collecting site needs, analyzing them, and creating technical responses to the sites. It also summarizes the information contained within the TFA needs database, portraying information provided by four major U.S. Department of Energy (DOE) sites with tank waste problems.

This is the third edition of the TFA site needs assessment. The FY 1995 version (TFA 1995) described the TFA's initial work in collecting and analyzing tank remediation technology development needs from across the DOE complex. The analysis of last year's needs, described in the FY 1996 TFA Site Needs Assessment (TFA 1996a), served as the basis for formulation of the FY 1997-FY 1999 TFA program. This FY 1997 version serves as the basis for formulation of the FY 1998-FY 2000 TFA program.

The TFA goal remains unchanged - to provide integrated solutions that will accelerate safe and cost-effective cleanup and closure of DOE's tank system. The TFA focused mainly on the four major DOE sites with tank waste problems: Hanford Site, Idaho National Engineering and Environmental Laboratory (INEEL), Oak Ridge Reservation (ORR), and Savannah River Site (SRS). At these four sites, the TFA is responsible for 273 tanks that contain approximately $380,000 \mathrm{~m}^{3}$ of high-level waste (HLW), low-level waste (LLW), and transuranic (TRU) waste. There are a number of smaller tanks at these sites that are outside of the TFA's purview at this time. The varying tank structure, construction, and capacity, as well as the different waste types themselves, have provided extraordinary challenges to the formation of an integrated tanks technology development program. The varying programmatic, institutional, and regulatory issues across the four sites add to the complexwide challenge of remediation.

The overall TFA program objective is to deliver a tanks technology program that reduces the current cost, and the operational and safety risks of tank remediation. The TFA's relationship with each site has matured, with solid working relationships established at many key levels. However, further work is required in several areas. As site technology needs change, the TFA must be prepared to amend its program in response. Additionally, as the results of technology development are not $100 \%$ guaranteed, the TFA must be able to work with the sites to find appropriate alternative solutions if development results do not meet expectations. This year's needs collection and technical response development process, because of the teaming required between the TFA and the sites, provided a forum for the exchange of complex-wide issues. 
Since its inception, the TFA continues to cite four tanks technology program attributes essential for TFA success. These attributes continue to guide the TFA's service to the user, such that the program is

- $\quad$ applicable - addresses users' needs and can be implemented within budget, schedule, and regulatory constraints. This year's consensus-driven site needs collection and technical response process enhanced greatly a deeper understanding of the interrelationships of the needs. Through this process, the TFA was able to develop a priority listing of FY 1998 and FY 1999 proposed activities far earlier in the planning cycle than previously possible. With concurrence from the sites, this priority listing will provide a program that can more quickly respond to changes.

- integrated - leverages relevant activities across the DOE Environmental Management (EM) system and, later, across the DOE complex and beyond. The TFA is part of a technology development network that has formed within the focus areas and at each site. The awareness of related work between sites and focus areas continues to grow. The TFA continues to develop this awareness by leveraging opportunities.

- acceptable - has broad involvement of key stakeholders and incorporates expertise from outside the laboratory system, e.g., from industry and universities as appropriate. The TFA has made special efforts to involve stakeholders. These stakeholders include the Site Technology Coordination Groups (STCGs), the TFA User Steering Group (USG), and the Community Leaders Network (CLN).

- accountable - performs within budget, on schedule, and produces a clear benefit. The TFA continues to execute its mission with a high degree of accuracy, both fiscally and within milestone schedules. Due to this, the TFA has gained the confidence of users and sites.

The TFA accomplishes its objective by executing an iterative approach to program development that involves site users and stakeholders through the STCGs at each site. The needs assessment forms the basis for TFA program definition. The program development process involves six major steps (Figure 1.1):

- Site needs identification and documentation

- Site communication of priority needs

- Technical response development

- Review technical responses

- Develop program planning documents

- Review planning documents. 


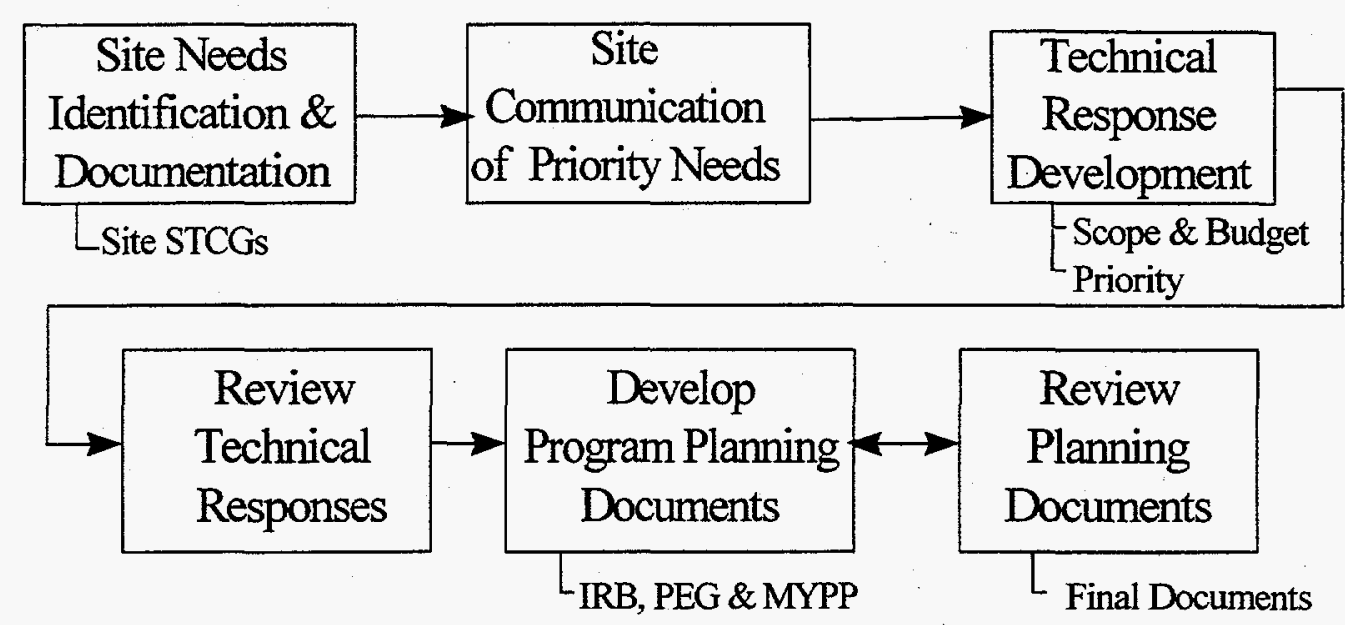

Figure 1.1. FY 1997 Tanks Focus Area Program Development Process

This document reports on the outcomes of the first two steps: site needs identification and documentation, and site communication of priority needs steps. It also describes the initial phases of the third and fourth steps: technical response development and review technical responses. At the time of this document's publication, work is underway for steps three and four. The remainder of those steps, plus the final two steps, develop program planning documents and review planning documents, will be described in more detail in the TFA FY 1998-FY 2000 MYPP. The MYPP is scheduled for publication during the fourth quarter of FY 1997.

Section 2 of this site needs assessment describes the needs collection and technical response process employed by the TFA this year. Section 3 describes the follow-on program development activities the TFA will use to complete this year's program development process. Appendix A contains descriptions of the needs submitted by the sites and the TFA's initial prioritization of the technical responses to them. 


\section{Section 2 - Site Needs Assessment and Technical Response Development Process}

The TFA modified its site needs assessment and technical response development process from last year. The modified process is based on experience gained during the last two program development cycles, and discussions at the TFA Kickoff Meeting held in Atlanta, Georgia, on October 8, 1996. The six step process serves to foster

- Continuous assessment of needs

- Increased dialog and communication

- Broader technical input in developing the TFA technical program

- Improved expression of needs

- Better understanding of the prioritization process

- Increased duration for developing technical responses.

The process steps are (see Figure 1.1)

- Site needs identification and documentation

- Site communication of priority needs

- Technical response development

- Review technical responses

- Develop program planning documents

- Review planning documents

\subsection{Site Needs Identification and Documentation}

Each site used its own internal process to determine and prioritize as necessary their site needs. This year the National STCG developed standard site needs and needs response templates that were endorsed by the TFA Site Representatives. See Figure 2.1, Tanks Focus Area Organization. The TFA took advantage of the opportunity to provide input to the structure of the templates, and, as a result, the TFA agreed fully with the final versions. During its October 8, 1996, meeting in Atlanta, the TFA agreed to supplement the needs response template with additional details.

\subsection{Site Communication of Priority Needs}

The TFA Site Representatives agreed to describe and submit needs using the new STCGdeveloped template. Proper completion of the template for each need provided the TFA the greatly improved quality input required for a comprehensive needs analysis. In addition, the completed templates permitted the TFA to develop higher quality technical responses sooner 


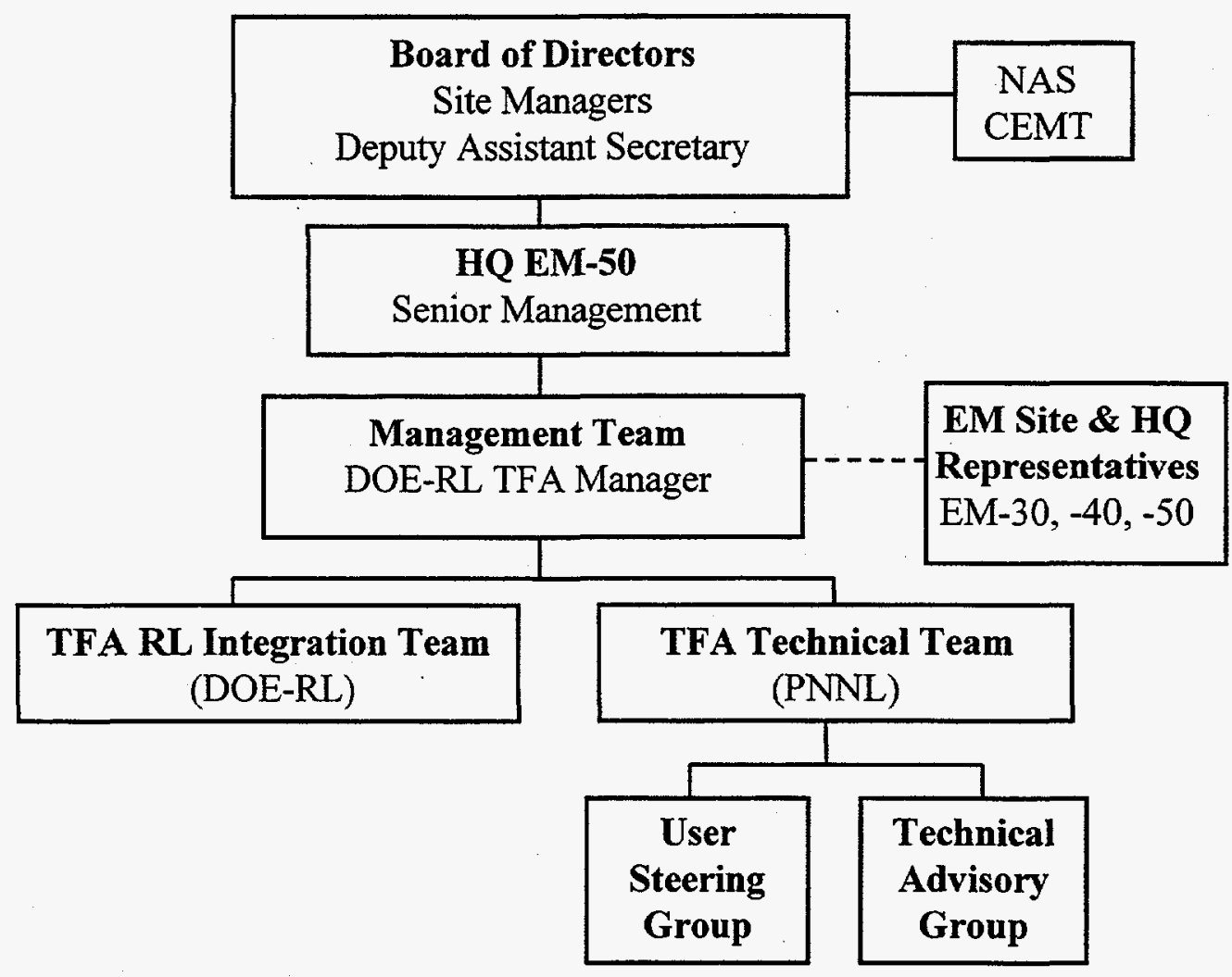

Figure 2.1. Tanks Focus Area Organization

than in the past. The TFA received site needs during the December 1996-January 1997 period.

\subsection{Technical Response Development}

Technical response development began with the analysis of each need. Upon receipt, each need was screened, reviewed for completeness, tentatively placed within the TFA problem element structure, and assigned to a TFA Technology Integration Manager (TIM) according to function. The six TFA functions for which a TIM is assigned are safety, characterization, pretreatment, immobilization, retrieval, and closure. Retrieval and closure are assigned to the same TIM and his deputy, and thus are considered together for the sake of convenience.

\subsubsection{Program Planning Framework Development}

Last year, the TFA established a standard framework to begin the annual program planning process. This framework groups similar or related site needs and the TFA's technical responses and allows for technical integration across functions to solve specific problems, as opposed to consolidating needs by technical focus. This activity begins the transition from 
needs collection and analysis to TFA program development. The results of the program development process will be addressed in the upcoming revision to the MYPP.

To establish and maintain this program planning framework, the TFA uses its problem element structure. The problem elements

- Provide an updated method to logically group site needs and TFA technical responses

- Assist in sequencing and scheduling integrated technical solutions

- Identify the problem elements and the needs within them as baseline, enhancements, or alternatives.

The problem element structure appears in Table 2.1.

\subsubsection{Technical Response Evaluation Criteria}

The TFA studied each need and developed potential integrated technical responses. As necessary, the TFA contacted the specific need technical point of contact for further clarification. During the initial stages of technical response development, each need was subjected to an initial needs screening. The purpose of this screening was to assess whether the

- Need and possible technical response was within the TFA mission area

- Need and possible technical response required a technology development component

- Development, first-time hot demonstration or deployment, re-engineering, etc., was required

- Technology was available, and no technology development was required

- Response was technically feasible (schedule or cost).

From mid-January 1997 through February 1997, the TFA prepared an initial draft response for each need. The composite set of technical responses was rated against criteria intended to rank order them for further program development activities. The criteria included the following:

- Broad-based benefit

- Cost reduction potential

- Support to TFA strategic goals

- User commitment to deploy.

Broad-Based Benefit (multi-site). This criterion remained unchanged from last year, and rated whether technical responses may be deployed at multiple sites or with multiple tanks at a single site. The ratings were defined as follows: 
a) High

- Technical response satisfied a high priority need at one site and similar or related medium priority needs at two or more sites

- Technical response satisfied high priority needs at two or more sites

b) Medium

- Technical response satisfied a high priority need at one site and similar or related medium priority needs at one other site

- Technical response satisfied medium priority needs at two or more sites

c) Low

- Technical response satisfied a medium priority need at one site and low priority needs at other sites

- Technical response satisfied low priority needs at one or more sites.

Cost Reduction (mortgage reduction) Potential. This assessment of mortgage reduction used criteria designed into last year's Risk Data Sheet process. The site needs input should have contained cost savings information pertinent to the submitting site, and the TFA's task was to estimate complex-wide cost savings potential.

a) High

- Without the technical response, there was a very high or high likelihood that DOE could not achieve moderate to significant savings in infrastructure, management systems, or program implementation, accident-related capital, or operational costs

- Technical response could avoid probable costly delays in ongoing remediation; magnitude of cost savings provided in needs statement(s)

b) Medium

- Without the technical response, there was a medium likelihood that DOE could not achieve moderate to significant savings in infrastructure, management systems, or program implementation, accident-related capital, or operational costs

- Technical response could avoid possible costly delays in ongoing remediation; magnitude of cost savings was described, not quantified, in needs statement(s)

c) Low

- Without the technical response, there was a low likelihood that DOE could not achieve moderate savings in infrastructure, management systems, or program implementation, accident-related capital, or operational costs 
- Technical response may have reduced the risks of less costly or less central remediation functions; magnitude of cost savings not provided in needs statement(s).

Support to the TFA Strategic Goals. The sites prioritized their needs for the benefit of the particular site; the TFA's task was to assess the technical responses' complex-wide impact. The TFA's strategic goals provided a framework for this complex-wide assessment. The goals are

- Demonstrate, deploy, and provide performance data for four tank waste retrieval systems to meet EM's FY00 requirements

- Provide tank waste treatment technologies that can efficiently pretreat and immobilize $80 \%$ of HLW

- Demonstrate compact processing units for HLW treatment and immobilization as an effective alternative to large-scale functions

- Provide subsystems necessary to support the closure of 16 radioactive waste storage tanks.

The TFA applied the following scale:

a) High - technical response to this need will achieve a goal

b) Medium - technical response to this need supports a goal

c) Low - technical response to this need does not achieve or support a goal.

User Commitment to Deploy. The TFA assessed the user's commitment based on interest expressed in the needs description and present or future co-funding. Other influencing factors included regulatory justification and consequences of not satisfying the need. All of these factors were included within the site needs template.

a) High - site(s) co-fund development and deployment; is in site baseline

b) Medium - site(s) may co-fund development costs; monies committed to co-fund deployment are not guaranteed

c) Low - no indication of site co-funding.

The criteria were applied to the initial draft technical responses in TFA meetings held in February 1997. The prioritization process was accomplished in a group consensus of TIMs, monitored by DOE's Richland Operations Office (RL), based on available information stated in the needs. During the remainder of February, the TFA developed the final draft technical responses. The TFA's intent was to ensure that technical responses would 
- Be provided for each need received

- Contain an explanation of the priority of the response according to either

- Screening criteria

- Prioritization criteria

- Describe multiyear intent

- 4 year budget estimate (current +3 years)

- Basis of estimate

- Describe the intended scope ( 2 to 3 paragraphs)

- Identify the relationship or benefit to other site needs.

\subsection{Review Technical Responses}

From mid-February through the first of March 1997, the TFA prepared its draft technical responses for TFA Site Representatives' review. The draft technical responses were provided to the Site Representatives and the Technical Advisory Group (TAG) in sufficient time for their review before the TFA Midyear Technical Review, held on March 4-7, 1997, in - Richland, Washington. Draft technical responses and funding priorities were reviewed on March 6 and 7,1997, which allowed a full technical and programmatic interchange with the Site Representatives and USG.

In prioritizing the potential tasks, the TFA found that the four criteria as outlined above, when weighted equally, did not provide enough differentiation between several tasks. A more distinct differentiation was required, especially where the TFA funding line was anticipated. Therefore, the TFA weighted User Commitment the most important, followed by Broad-Based Benefit, Cost Reduction, and Support to the TFA Strategic Goals. This reflects the TFA philosophy that technology deployments are more successful when the user participates by sharing development and deployment costs. Using the weighted criteria, the TFA was able to improve the clarity of its priority listing. Subsequently, the TFA Site Representatives finalized the prioritization of proposed FY 1998-1999 tasks on March 7, 1997. As of the publication date of this document, the TFA was continuing to prepare responses to written comments submitted by the Site Representatives and the TAG subsequent to the midyear meeting. The final version of the technical responses will be summarized in the next edition of the TFA MYPP.

\subsection{Develop Program Planning Documents}

Successful completion of the previous four steps significantly simplifies the development of follow-on program development documents and processes. These include the Office of Science and Technology (OST) budget process, Program Execution Guidance (PEG) document, and MYPP document. In the past, these program requirements largely consisted of technical responses to the needs which were basically developed during the budget process without complete site buy-in. In this improved process, full site buy-in is expected before the development of the program planning documents. 


\subsection{Review Planning Documents}

The TFA's intent is that when full site buy-in is accomplished, final document reviews by the sites would only need to highlight changes proposed or required. During program execution, the inevitable changes caused by either technical or programmatic factors require that the TFA remain flexible. The TFA's method of program development and acceptance greatly enhances program flexibility based on a common understanding of the program's strategies and tactics.

\subsection{Data Summary}

In all, the sites submitted 90 needs. The TFA assigned each need to one of the TFA's five functional areas based on the major subject of the need. A summary of the submitted needs and the TFA's assignment of the needs is shown in Table 2.2.

In general, the Hanford Site needs stressed waste retrieval, pretreatment of sludges, and waste form product acceptance to support the multiple phases of privatization. The needs at the INEEL support data requirements to prepare for Title 1 design. For the ORR, the needs support tank cleanup, waste transfer, and closure to meet accelerated schedules described in their 10-year plan. The SRS needs reflect the importance of preparation of tank wastes and to prepare feed for treatment by private vendors for feed to the Defense Waste Processing Facility (DWPF), efficiency enhancement to the DWPF, and reduction of low-level waste (LLW) volume.

\subsection{Potential Areas for Improvement}

The TFA learned a few lessons from the execution thus far of this year's program development process. Through the National STCG, sites have greatly standardized their needs submissions. As a result, the needs analysis process became much easier. However, the TFA noted three areas that still require improvement. First, each site expressed site priorities differently. While the TFA expected this, it was still difficult to compare priorities across the DOE complex. A standard method of expressing priorities would be helpful for next year.

Secondly, the TFA considered the sites' opinion on potential cost savings for technical solutions a very important element of the needs submittal. Cost reduction potential was one of the TFA's needs response rating criteria. Unfortunately, application of this criterion was difficult because the sites were not consistent in the detail and completeness of estimated cost savings potential.

Lastly, the TFA moved its planning time schedule up one month earlier than in previous years. This was done to permit more thorough planning to support budget formulation requirements and obtain site consensus on TFA technical responses and priorities. Unfortunately, the STCG needs were received later than expected, and the DOE-HQ budget 
cycle was initiated earlier than expected. This resulted in the TFA's efforts being further condensed rather than extended to improve the product. Although the TFA's Site

Representatives provided extraordinary support in coordinating their site's interactions with the TFA, there is still a need to better coordinate the STCG submittal schedule with the TFA's development and DOE-HQ's budget development program cycles. Overall, even with these difficulties, this year's needs assessment process produced results superior to those of any previous year. 
Table 2.1. Problem Element Structure

\begin{tabular}{|c|c|c|}
\hline$\underline{\text { WBS\# }}$ & Problem Element & $\underline{\text { WBS\# }}$ \\
\hline 1.0 & Remediate Tanks & 1.2 .3 \\
\hline 1.1 & Store Waste & 1.2.3.1 \\
\hline 1.1.1 & Extend Tank Life & 1.2.3.1.1 \\
\hline 1.1.1.1 & Monitor Tank Integrity & 1.2.3.1.2 \\
\hline 1.1 .1 .2 & Avoid Tank Corrosion & 1.2.3.1.3 \\
\hline 1.1.1.3 & Remediate Loss of Tank Integrity & 1.2.3.1.4 \\
\hline 1.1 .2 & Ventilate Tanks & 1.2.3.2 \\
\hline 1.1 .3 & Characterize Waste & 1.2.3.2.1 \\
\hline 1.1.3.1 & Characterize Waste In Situ & 1.2 .3 .2 .2 \\
\hline 1.1.3.2 & Sample Waste & \\
\hline 1.1 .3 .3 & Analyze Waste & 1.2.3.2.3 \\
\hline 1.1 .4 & Reduce Waste Volume & 1.2.3.2.4 \\
\hline 1.1.4.1 & Reduce Source Streams & 1.2.3.2.5 \\
\hline 1.1 .4 .2 & Reduce Recycle Streams & 1.3 \\
\hline 1.2 & Process Waste & 1.3 .1 \\
\hline 1.2 .1 & Retrieve Waste & 1.3.1.1 \\
\hline 1.2.1.1 & Deploy Equipment & 1.3.1.2 \\
\hline 1.2.1.2 & Mobilize Bulk Waste & 1.3.1.3 \\
\hline 1.2.1.3 & Mix Waste & 1.3.1.4 \\
\hline 1.2.1.4 & Transfer Waste & 1.3.1.5 \\
\hline 1.2.1.5 & Detect and Mitigate Leaks & 1.3.1.6 \\
\hline 1.2.1.6 & Monitor \& Control Retrieval Process & 1.3.1.7 \\
\hline \multirow[t]{2}{*}{ 1.2.1.7 } & Integrate Retrieval and Pretreatment & 1.3.1.8 \\
\hline & Technology Systems & 1.3.2 \\
\hline 1.2.1.8 & Mobilize Heel & 1.3.2.1 \\
\hline 1.2 .2 & Pretreat Waste & 1.3.2.2 \\
\hline 1.2.2.1 & Calcine Waste. & \\
\hline 1.2.2.2 & Dissolve Waste & 1.3.2.3 \\
\hline 1.2 .2 .3 & $\begin{array}{l}\text { Prepare Retrieved Waste for Transfer } \\
\text { and Pretreatment }\end{array}$ & $\begin{array}{l}1.3 .3 \\
1.3 .3 .1\end{array}$ \\
\hline 1.2.2.4 & Clarify Liquid Stream & 1.3.3.2 \\
\hline 1.2.2.5 & Remove Radionuclides & \\
\hline 1.2.2.6 & $\begin{array}{l}\text { Integrate Pretreatment and LLW } \\
\text { Immobilization Technology Systems }\end{array}$ & \\
\hline 1.2.2.7 & Process Sludge & \\
\hline 1.2.2.8 & $\begin{array}{l}\text { Prepare Pretreated Waste for } \\
\text { Immobilization }\end{array}$ & \\
\hline 1.2.2.9 & Monitor \& Control Process & \\
\hline
\end{tabular}

Problem Element

Immobilize Waste

Process LLW

Monitor \& Control Process

Prepare Feed

Immobilize LLW Stream

Treat Offgas

Process HLW

Monitor \& Control Process

Prepare Secondary Waste from

Pretreatment

Prepare Sludge Feed

Immobilize HLW Stream

Treat Offgas

Store Waste Forms and Close Tanks

Close Tanks

Monitor Tank

Characterize Heels

Define Closure Criteria

Interface with Pretreatment

Treat Heel in Place

Detect Leaks

Stabilize Tank for Closure

Monitor Site

Dispose of LLW

Monitor Waste for Acceptance

Determine Performance of Waste

Form

Provide Disposal System

Store and Dispose HLW

Provide Interim Storage HLW

Provide Shipping Facilities 
Table 2.2. Summary of Site Needs Submitted to Tanks Focus Area

\begin{tabular}{|l|c|c|c|c|c||}
\hline Functional Area & Hanford & INEEL & ORR & SRS & Total \\
\hline Safety & 6 & 0 & 0 & 3 & 9 \\
\hline Characterization & 6 & 1 & 2 & 1 & 10 \\
\hline Pretreatment & 5 & 6 & 2 & 7 & 20 \\
\hline Immobilization & 10 & 3 & 1 & 9 & 23 \\
\hline Retrieval and Closure & 10 & $\mathbf{8}$ & 4 & 6 & 28 \\
\hline Total & 37 & 18 & 9 & 26 & 90 \\
\hline
\end{tabular}




\section{Section 3 - The Next Process Steps}

The TFA considers the needs assessment the starting point for the annual refinement and redefinition of its technical program. The grouping of needs within the problem element structure permits a problem-oriented analysis from a complex-wide perspective. When matched with present and ongoing technical activities related to each of the needs, as well as the schedule drivers for the needs, the TFA expects likely technology targets to emerge. As noted earlier, this document reports only on the initial program development steps. Formulation of the final detailed technical response for each submitted need is presently in progress. The purpose of this section is to describe how the activities covered in this site needs assessment fit into the overall program development process. Within the program development process depicted in Figure 1.1, the following major tasks and schedule remain for this year's program development cycle:

- Prepare and submit FY 1999 input to OST budget process (April 1997)

- Finalize FY 1998 and FY 1999 task priority listing (May 1997)

- Prepare and submit FY 1998 program execution documents (June-August 1997)

- Finalize FY 1998 technical activities and proposed FY 1999 technical activities (August 1997)

- Document in the MYPP (August 1997).

\subsection{Prepare and Submit FY 1999 Input to OST Budget Process}

The TFA has already submitted its initial FY 1999 budget input based on draft work scope and budget estimates for each proposed task. These work scopes and budget estimates were reviewed at the FY 1997 TFA Midyear Technical Review. Additionally, the proposed tasks were prioritized as noted earlier.

\subsection{Finalize FY 1998 and FY 1999 Task Priority Listing}

Prior to the FY 1997 TFA Midyear Technical Review, TFA Site Representatives and TAG reviewed each proposed technical response and the TFA Technical Team's recommended priority listing of them. The Site Representatives finalized the priority listing, which was required for the TFA to meet schedule milestones for the submission of the program's FY 1999 IRB. We expect, however, that priorities are subject to change via a change control process executed by DOE. For example, priorities may change due to changing schedules at the sites, or as a result of Site Representatives' review of TFA responses to their questions and comments on preliminary work scope definitions for FY 1998 and FY 1999. 


\subsection{Prepare and Submit FY 1998 Program Execution Documents}

Each year, the TFA uses two documents to provide for program execution. The first, the PEG, is the TFA's guidance to the selected work perfomer and is tied to the users' commitment and priority. This guidance states the mandatory technical and programmatic requirements needed. Upon receipt of the PEG, the performer develops the second document, the Technical Task Plan (TTP). The TTP is the performer's response to the PEG. An approved TTP constitutes a contractual arrangement between the TFA, the performing DOE Field Office, and the performing organization. Both documents are generally required before work initiation and funding authorization.

\subsection{Finalize FY 1998 Technical Activities and Proposed FY 1999 Techncial Activities}

The TFA Site Representatives and TAG reviewed draft technical activities scheduled for FY 1998 and FY 1999. For work ongoing in FY 1997 that was proposed to continue in FY 1998, the midyear review provided the opportunity for amendments to FY 1998 work based on results thus far. All proposed work for FY 1999 was reviewed as a draft. The TFA continues its review of all of these activities until all questions, both programmatic and technical, have been answered. Agreement on the work scopes for FY 1998 is central to the preparation of program execution documents scheduled for May through September 1997.

\subsection{Document in the Multiyear Program Plan}

The companion document to this one is the TFA MYPP. It documents the results of the preceding planning steps and is the basis for complementary planning between EM-30, EM-40, and EM-50 in future years, which is reflected in the OST budget process. This approach is consistent with the TFA goal of defining and implementing an integrated technical program. The MYPP describes the TFA's technical strategies and the actions being taken to address the site needs within the strategies. The FY 1998-FY2000 MYPP is expected to be published during the summer of 1997.

Based on the FY 1997 STCGs' needs submittal, the FY 1998-FY 2000 MYPP will likely reflect several changes to the TFA's multiyear program, relative to that described in the FY 1997-FY 1999 MYPP. In FY 1998-FY 2000, there is greater emphasis on support to privatization (Hanford and ORR); enhancement of operations (SRS) for mortgage reduction; and support to Title 1 design (INEEL). Each year, the MYPP is updated to reflect the changing emphasis of the sites and the subsequent changes in the TFA's technical focus. 


\section{Section 4 - References}

Tanks Focus Area (TFA). 1995. FY1995 TFA Site Needs Data Assessment, PNL-10649. Pacific Northwest Laboratory, Richland, Washington.

Tanks Focus Area (TFA). 1996a. FY 1996 TFA Site Needs Data Assessment, PNNL-11091. Pacific Northwest National Laboratory, Richland, Washington.

Tanks Focus Area (TFA). 1996b. Tanks Focus Area Multiyear Program Plan FY97-FY99, PNNL-11272. Pacific Northwest National Laboratory, Richland, Washington. 


\section{Appendix A - Site Needs Database}

This appendix contains the specifics of each of the 90 needs submitted by the sites. Three tables precede the presentation of these needs. First, Table A.1 lists a summary of the needs submitted by each site. In developing technical responses to the needs, the Tanks Focus Area (TFA) found it necessary to split apart some needs into more specific elements. Each year, the TFA assigns an identification number, called a "Need ID\#" to each submitted need. Needs that were split show a letter following the NeedID\#. For example, Table A.1 shows needs 678A, 678B and 678C. This means the TFA split need \#678 into three parts.

Within each site's listing in Table A.1, the needs are presented in TFA FY 1998-FY 1999 priority order. Some needs show a priority order indicator of "N/A," meaning "not applicable." There are several reasons why the TFA did not assign a priority to a need. For example, a need may have been consolidated with another need under a single technical response.

The next table, Table A.2, shows those same needs organized into the TFA's problem element structure. The TFA uses this structure to help show what functional areas concern the sites.

Lastly, Table A.3 lists the TFA's responses to the site needs in its priority listing for FY 1998 and FY 1999. Technical responses that were not prioritized by the TFA appear at the end of the table with short explanations for their non-rating. Table A.3 shows that the TFA developed and prioritized 67 technical responses that addressed 84 of the 90 needs submitted. The remaining six needs were either screened out or retracted by the sites. The TFA screened out needs that were not considered within the TFA mission area, did not have a technology development component, or were not feasible in cost or schedule.

The remainder of the appendix is devoted to the individual site needs. Each need is described, followed by a short explanation of the TFA's proposed action in response to the need. The purpose of this site needs assessment is to report on the conduct of the needs assessment and initial results from the analysis. More detailed information may be found in other upcoming TFA program development documents, such as the Multiyear Program Plan, Program Execution Guidance, and Technical Task Plans.

For ease of use, the detailed needs descriptions appear in TFA Need ID\# order. The need and the proposed technical response are tracked with this number. For audit trail purposes, this number remains with the need and response, and the number is not duplicated. Therefore, needs submitted last year retained their own distinctive Need ID\#, and new needs submitted this year were assigned a unique number.

A separate list of acronyms for this appendix appears after the tables. 
Table A.1 Tanks Focus Area Needs Submitted by Sites (sorted by site in TFA priority order)

TFA

Need ID\#

Site

ID\#

Hanford Sitc

$\begin{array}{llll}679 & \text { Retr I } & 5 & \text { High } \\ 662 & \text { OP1 } & 6 & \text { High } \\ 675 & \text { PW10 } & 7 & \text { High } \\ 671 & \text { PW6 } & 11 & \text { High } \\ 672 & \text { PW7 } & 12 & \text { High } \\ 679 \text { A } & \text { Retr 1 } & 13 & \text { High } \\ 674 & \text { PW9 } & 21 & \text { High } \\ 670 & \text { PW5 } & 31 & \text { Medium } \\ 673 & \text { PW8 } & 32 & \text { Medium } \\ 678 \text { A } & \text { PW13 } & 33 & \text { Medium } \\ 678 C & \text { PW13 } & 34 & \text { Medium } \\ 684 & \text { SD1 } & 35 & \text { Low } \\ 686 & \text { SD3 } & 36 & \text { High } \\ 663 & \text { OP2 } & 45 & \text { Medium } \\ 664 & \text { Saf 1 } & 46 & \text { High } \\ 683 & \text { Retr 13 } & 47 & \text { Medium } \\ 658 & \text { Char 4 } & 51 & \text { High } \\ 679 B & \text { Retr 1 } & 52 & \text { High } \\ 667 & \text { PW2 } & 54 & \text { Medium } \\ 678 B & \text { PW13 } & 60 & \text { Medium } \\ 680 & \text { Retr 2 } & 61 & \text { Medium } \\ & & & \\ 681 & \text { Retr 4 } & 62 & \text { High } \\ 682 & \text { Retr 11 } & 63 & \text { Medium } \\ 657 & \text { Char 3 } & 64 & \text { Medium } \\ 659 & \text { Char 5 } & 65 & \text { Medium } \\ 665 & \text { Saf 2 } & 66 & \text { High } \\ 691 & \text { SD8 } & 67 & \text { Low } \\ 660 & \text { Cliar 7 } & \text { N/A } & \text { High } \\ 661 & \text { Char 8 } & \text { N/A } & \text { Low } \\ 676 & \text { PW11 } & \text { N/A } & \text { Medium } \\ 669 & \text { PW4 } & \text { N/A } & \text { Low } \\ 666 & \text { PW1 } & \text { N/A } & \text { High } \\ 677 & \text { PW12 } & \text { N/A } & \text { High } \\ 685 & \text { SD2 } & \text { N/A } & \text { Medium } \\ & & & \\ 675 & & & \end{array}$

Establish Retrieval Performance Evaluation Criteria [Retr-1]

DST Corrosion Monitoring

ILAW Product Acceptance Inspection and Test Methods

Avoidance of Formation of Solids in Phase I Liquid Tank Wastes

Prediction of Gel and Precipitate Formation in Hanford Tank Waste Solutions

SST Retrieval Equipment/System Development

Representative Sampling and Associated Analysis to Support Operations and Disposal

Standard Method for Determining Waste Form Release Rate

Enhanced Sludge Wash Process Data for Extended Operations of Phase I and for Phase II RFP

Settle Decant

SLS Hanford (CUF)

Multi-phase Moisture Flow in Arid Conditions

Glass Monolith Surface Area

Remote Inspection of High-Level Waste Tanks

Criticality Basis - Actinide Studies

High Accuracy Psychrometric/Flow Measurements for Determining Tank Evaporation Rates [Retr 13]

Technetium-99 Analysis in Low Level Waste Feed

Waste Conditioning for Tank Heel Transfer

Hanford Capsule Initiative ( $\mathrm{HCl}$ ): A Processing Demonstration of $\mathrm{Cs} / \mathrm{Sr}$ Capsules for Final Disposition Pilot Plant

Initial Waste Mobilization Methods Needed to Enhance Advanced Design Mixer Pump Retrieval for DST Waste Not Affected by Existing Mixing Pump Performance [Retr-2]

Tank Leak Mitigation Systems for Underground Single-Shell Waste Storage Tanks (SSTs) [Retr-4]

Alternative to Baseline Tank Waste Mixing Systems [Retr-11]

Large Sample Hot Cell DSC/TGA Based Energetics Measurement

Rapid Speciation of Organic Acids and Complexants

Safety Related Transport Properties of Fuel Rich Organics

In-Situ Testing of Glass Release

In-Tank Core Sampling...Off-Riser Capability

Large Volume (3-5 liter) Sludge and Supernate Sampler

IHLW Product Acceptance Inspection and Test Methods

Formulation of Reference Glass for Immobilized LAW

Identification and Management of Chromium and Other Problem Constituents for HLW Vitrification

Secondary Products Acceptance luspection and Test Methods

Standard Method for Determining Waste Form Release Rate 
Table A.1 Continued

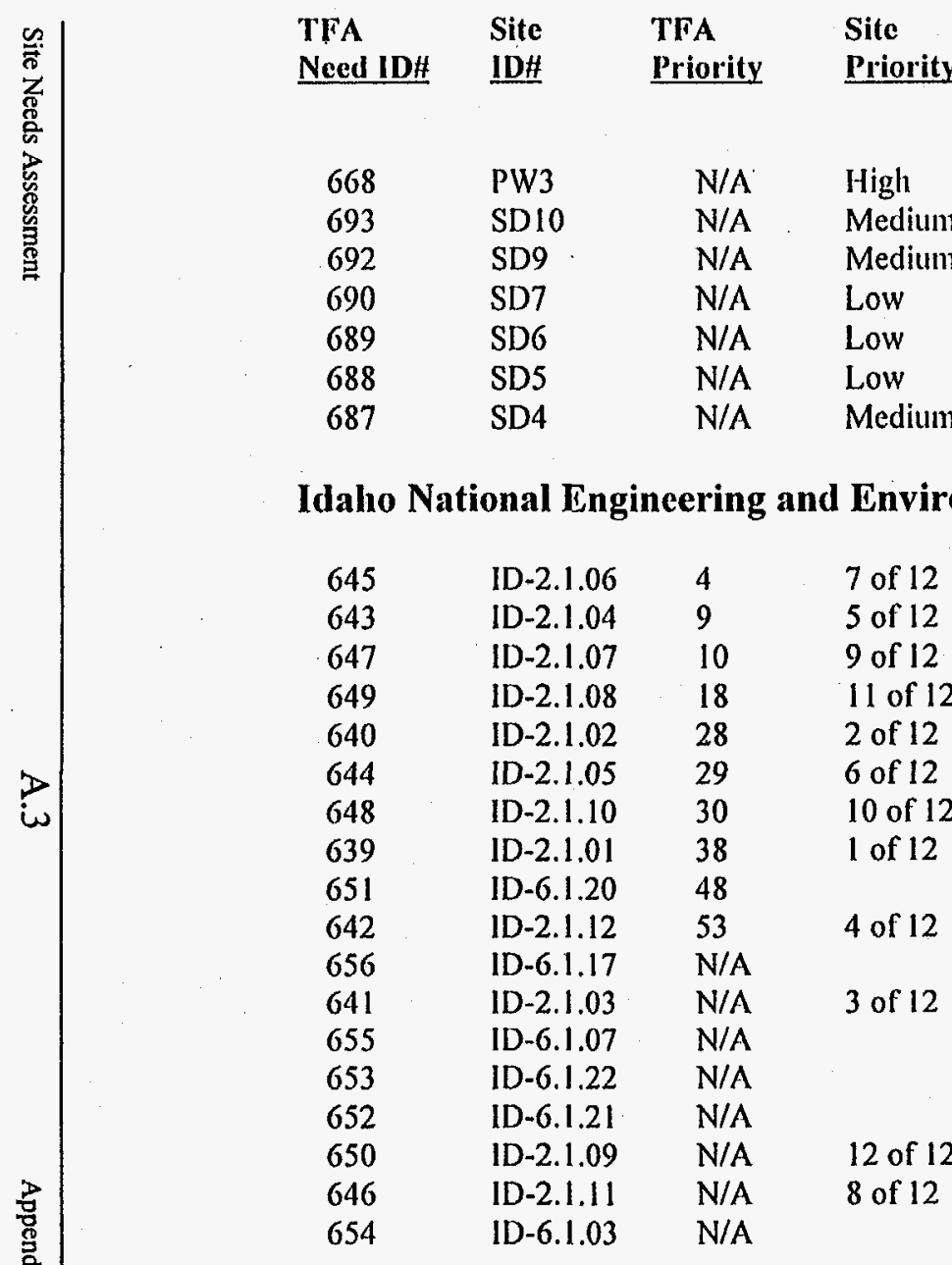

Advanced Methods for Achieving LLW Volume Minimization

Distribution of Recharge Rates

Field Measurements of Vadose Zone Hydraulic Properties

Getter Materials

Moisture Dependence of Kd

Testing of Sand-Gravel Capillary Barrier

Long-Term Testing of Surface Barrier

\section{Oak Ridge Reservation}

$\begin{array}{lll}607 & \text { TK-04 } & 2 \\ 612 & \text { TK-09 } & 3 \\ 609 & \text { TK-05 } & 8 \\ 608 & \text { TK-06 } & 14 \\ 606 & \text { TK-03 } & 16 \\ 604 & \text { TK-10 } & 22\end{array}$

Oak Ridge National Laboratory Sludge Mixing and Slurry Transport Oak Ridge National Laboratory Tank Closure

Oak Ridge National Laboratory Tank Sludge and Supernatant Separations

Oak Ridge National Laboratory Tank Sludge and Supernatant Immobilization

Oak Ridge National Laboratory Sludge Mixing and Mobilization

Oak Ridge National Laboratory Remediated Tank Isolation and Removal

Solvent Extraction \& Ion-Exchange to Remove TRU, Sr, Tc \& Cs from ICPP Tank Farm Method to Separate Undissolved Solids from Sodium-Bearing Waste \& Dissolve Calcine

igh Activity Waste Form

Process Flow Sheet to Process Sodium-Bearing Waste

(ution of Future Calcines

Tanks - New 3 - In-situ Decontamination of Buried 'Tank Contents

Denitrate and Solidify the High Activity Fraction

Removal of Small to Medium Buried Tanks

On-Line Process Monitor for Elemental Amalysis of Calcine Product

Tanks - New 1 - In-Situ Homogenization of Buried Tank Waste

Tanks - New 2 - Removal and Consolidation of Waste from Buried Tanks

\& Transport Calcine

Remove RCRA Listed Wastes from High \& Low Activity Fractions

In-Situ Treatment of Mixed TRU Tank Wastes

$$
\text { Oak Ridge National Laboratory Remediated Tank Isolation and Removal }
$$


Table A.1 Continued

\begin{tabular}{|c|c|c|c|c|}
\hline 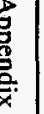 & $\begin{array}{l}\text { TFA } \\
\text { Need ID\# }\end{array}$ & $\begin{array}{l}\text { Site } \\
\text { ID\# }\end{array}$ & $\begin{array}{l}\text { TFA } \\
\text { Priority }\end{array}$ & $\begin{array}{l}\text { Site } \\
\text { Priority }\end{array}$ \\
\hline & $605 \mathrm{~A}$ & TK-11 & 23 & \\
\hline & 610 & TK-02 & 24 & \\
\hline & 611 & TK-01 & 25 & \\
\hline & 605B & TK-11 & 56 & \\
\hline & \multicolumn{4}{|c|}{ Savannal River Site } \\
\hline \multirow{19}{*}{$\stackrel{P}{D}$} & 623 & SR-2011 & 1 & 11 of 26 \\
\hline & 614 & SR-2002 & 15 & 2 of 26 \\
\hline & 613 & SR-2001 & 17. & 1 of 26 \\
\hline & 625 & SR-2013 & 19 & 13 of 26 \\
\hline & 629 & SR-2017 & 20 & 17 of 26 \\
\hline & 633 & $S R-2121$ & 26 & 21 of 26 \\
\hline & 636 & SR-2024 & 27 & 24 of 26 \\
\hline & 618 & SR-2006 & 37 & 6 of 26 \\
\hline & 637 & SR-2025 & 39 & 25 of 26 \\
\hline & 615 & SR-2003 & 40 & 3 of 26 \\
\hline & 619 & SR-2007 & 41 & 7 of 26 \\
\hline & 632 & SR-2020 & 42 & 20 of 26 \\
\hline & 617 & SR-2005 & 43 & 5 of 26 \\
\hline & 620 & SR-2008 & 44 & 8 of 26 \\
\hline & 616 & SR-2004 & 49 & 4 of 26 \\
\hline & 631 & SR-2019 & 50 & 19 of 26 \\
\hline & 638 & SR-2026 & 55 & 26 of 26 \\
\hline & 622 & SR-2010 & 57 & 10 of 26 \\
\hline & 624 & SR-2012 & 58 & 12 of 26 \\
\hline \multirow[t]{7}{*}{ 然 } & 628 & SR-2016 & 59 & 16 of 26 \\
\hline & 621 & SR-2009 & N/A & 9 of 26 \\
\hline & 626 & SR-2014 & N/A & 14 of 26 \\
\hline & 627 & SR-2015 & N/A & 15 of 26 \\
\hline & 630 & SR-2018 & N/A & 18 of 26 \\
\hline & 634 & SR-2022 & N/A & 22 of 26 \\
\hline & 635 & SR-2023 & N/A & 23 of 26 \\
\hline
\end{tabular}

\section{$\underline{\text { Need Title }}$}

ORNL Cs Removal Closeout

Oak Ridge National Laboratory Tank Solid Waste Retrieval

Oak Ridge National Laboratory Tank Waste Characterization

Oak Ridge National Laboratory Tank Sludge and Supernatant Pretreatment

Optimize Waste Loading for DWPF Glass

Alternative Salt Removal Techniques

Tank Heel Removal

Passive Waste Tank Ventilators

Demonstrate Use of Sintered Metal Filters in Place of HEPA Filters and Faper Filters on Air Sampling

Systems

Enhance Equipment Design and Operability of the DWPF Melter System; Improved Melter Pour Spout

Cleaning Techniques

Upgrade DWPF Liquid Level and Density Measurements

Evaluate Alternative Precipitating Agents and Ion Exchange Media for Decontamination of High Level

Waste Salt Solutions

Caustic Recovery \& Recycle

In-Situ Methods for Characterization of Tank Wastes

Provide Alternative Processing and/or Concentration Methods for DWPF Recycle Aqueous Streams

Process Improvements to Maximize Saltstone Waste Loading

Annulus Space Cleaning

Develop Counter-Current Decantation Process for Sludge Washing

Methods to Unplug Waste Transfer Lines

Alternatives for DWPF Melter Feed REDOX Adjustment

Alternate DWPF Canister Decon Techniques

Solids Size Reduction in Waste Tanks

Develop Lower Cost Higher Capacity Melters for DWPF Which are Consistent with Remote Operability Requirements.

Demonstrate STPB Hydroxide Flowsheet to Reduce Nittite Addition, Thereby Reducing ITP Washing

Requirements

Enhanced Clemical Cleaning Methods for High Level Waste Tank Closure

Develop DWPF Analytical Methods to Improve Attainment

In-Tank Corrosion Probe Development

Develop Alternatives to Monosodium Titanate for Alkaline Strontium and Actinide Removal

Enhance Equipment Design and Operability of the DWPF Melter System; Characterize Causes of Pour

Spout Pluggage

Enhance Equipment Design and Operability of the DWPF Melter System; Increase Melt Rate in DWPF Melter 
Table A.2. Tanks Focus Area Site Needs Distributed within the Problem Element Structure

PE\# Problem Element Title

1.0 Remediate Tanks

$1.1 \quad$ Store Waste

665 Safety Related Transport Properties of Fuel Rich Organics

664 Criticality Basis - Actinide Studies

\subsubsection{Extend Tank Life}

\subsubsection{Monitor Tank Integrity}

662 DST Corrosion Monitoring

627 In-Tank Corrosion Probe Development

663 Remote Inspection of High-Level Waste Tanks

\subsubsection{Avoid Tank Corrosion}

\subsubsection{Remediate Loss of Tank Integrity}

681 Tank Leak Mitigation Systems for Underground Hanford Single-Shell Waste Storage Tanks (SSTs) [Retr-4]

\subsubsection{Ventilate Tanks}

625 Passive Waste Tank Ventilators

Hanford

Hanford

Hanford

$$
\begin{aligned}
& \text { High } \\
& \text { High } \\
& \text { High }
\end{aligned}
$$

$\begin{array}{cc}\text { Hanford } & \text { High } \\ \text { SRS } & 15 \text { of } 26 \\ \text { Hanford } & \text { Medium }\end{array}$

Safety

Safety

Safety

Safety

Safety

Safety

13 of 26

Safety

High

Safety

629 Demonstrate use of sintered metal filters in place of SRS

HEPA filters and paper filters on air sampling systems

17 of 26

Safety

\subsubsection{Characterize Waste}

648 Characterize Tank Farm Heels

611 Oak Ridge National Laboratory Tank Waste Characterization

$\begin{array}{ccc}\text { Idaho } 10 \text { of } 12 & \begin{array}{l}\text { Characterization } \\ \text { Characterization }\end{array} \\ \text { Oak Ridge } & & \end{array}$

\subsubsection{Characterize Waste In Situ}

615 In-Situ Methods for Characterization of Tank Wastes SRS

655 In-Situ Characterization of Tank Contents Idaho

3 of 26 Characterization

Characterization

\subsubsection{Sample Waste}

661 Large Volume (3-5 liter) Sludge and

Hanford

Low

Characterization

660 In-Tank Core Sampling...Off-Riser Capability

Hanford

High

Characterization

\subsubsection{Analyze Waste}

657 Large Sample Hot Cell DSC/TGA Based Energetics Measurement

Hanford Medium Characterization

659 Rapid Speciation of Organic Acids and Complexants

658 Technetium-99 Analysis in Low Level Waste Feed Hanford

\subsubsection{Reduce Waste Volume}

\subsubsection{Reduce Source Streams}

639 Reduction in Liquid HLW

Idaho

1 of 12 Retrieval \& Closure

668 Advanced Methods for Achieving LLW Volume Hanford Minimization 
Table A.2. Continued

PE\# Problem Element Title

$\underline{\text { Site }}$

Priority

Function

1.1.4.2 Reduce Recycle Streams

619 Provide Alternative Processing and/or Concentration SRS

7 of 26

Pretreatment Methods for DWPF Recycle Aqueous Streams

637 Caustic Recovery \& Recycle

SRS $\quad 25$ of 26

Pretreatment

1.2 Process Waste

1.2.1 Retrieve Waste

622 Solids Size Reduction in Waste Tanks

SRS

10 of 26

Retrieval \& Closure

617 Annulus Space Cleaning

SRS

5 of 26

Retrieval \& Closure

1.2.1.1 Deploy Equipment

1.2.1.2 Mobilize Bulk and Heel Wastes

606 Oak Ridge National Laboratory Sludge Mixing Oak Ridge and Mobilization

679A SST Retrieval Equipment/System Development Hanford

650 Remove \& Transport Calcine

614 Alternative Salt Removal Techniques

610 Oak Ridge National Laboratory Tank Solid Waste Oak Ridge

1.2.1.3 Mix Waste

653 Tanks - New 1 - In-Situ Homogenization of Idaho Buried Tank Waste

682 Alternative to Baseline Tank Waste Mixing Systems [Retr-11]

Hanford

616 Methods to Unplug Waste Transfer Lines

652 Tanks - New 2 - Removal and Consolidation of Waste from Buried Tanks

607 Oak Ridge National Laboratory Sludge Mixing Oak Ridge and Slurry Transport

674 Representative Sampling and Associated Analysis to Support Operations and Disposal

679B Waste Conditioning for Tank Heel Transfer

\subsubsection{Detect and Mitigate Leaks}

\subsubsection{Monitor \& Control Retrieval Process}

683 High Accuracy Psychrometric/Flow Measurements Hanford For Determining Tank Evaporation Rates [Retr 13]

\subsubsection{Integrate Retrieval and Pretreatment Technology}

\section{Hanford Capsule Initive (HCI): A Process}

Demonstration of Cs/Sr Capsules for Final Disposition

\subsubsection{Mobilize Heel}

613 Tank Heel Removal

621 Enhanced Chemical Cleaning Methods for High Level Waste Tank Closure

680 Initial Waste Mobilization Methods Needed to Enhance Advanced Design Mixer Pump Retrieval For DST Waste Not Affected by Existing Mixing Pump Performance [Retr-2]
Idaho

SRS

SRS

Idaho

Hanford

Hanford

Retrieval \& Closure

High Retrieval \& Closure

12 of 12 Retrieval \& Closure

2 of 26 Retrieval \& Closure

Retrieval \& Closure

Retrieval \& Closure

Medium Retrieval \& Closure

4 of 26 Retrieval \& Closure Retrieval \& Closure

Characterization

High Characterization

High Retrieval \& Closure

Medium

Safety

Medium Immobilization

1 of 26 Retrieval \& Closure

9 of 26 Retrieval \& Closure

Hanford Medium Retrieval \& Closure 
Table A.2. Continued

$\underline{\text { PEF }}$

1.2.2 Pretreat Waste

632 Process Improvements to Maximize Saltstone Waste Loading

Pretreatment

\subsubsection{Calcine Waste}

640 Process Flow Sheet to Process Sodium-Bearing Waste

Idaho

2 of 12

Pretreatment

\subsubsection{Dissolve Waste}

644 Dissolution of Future Calcines

Idaho

6 of 12

Pretreatment

\subsubsection{Prepare Retrieved Waste for Transfer and Pretreatment}

\subsubsection{Clarify Liquid Stream}

609 Oak Ridge National Laboratory Tank Sludge and Supernatant Separations

671 Avoidance of Formation of Solids in Phase I Hanford High Pretreatment Liquid Tank Wastes

643 Method to Separate Undissolved Solids from Idaho 5 of 12 Pretreatment Sodium-Bearing Waste \& Dissolve Calcine

672 Prediction of Gel and Precipitate Formation in Hanford High Pretreatment Hanford Tank Waste Solutions

678C SLS Hanford (CUF)

Hanford Medium Pretreatment

\subsubsection{Remove Radionuclides}

605A ORNL Cs Removal Closeout

Oak Ridge

618 Evaluate Alternative Precipitating Agents and Ion

$$
\text { SRS }
$$

Exchange Media for Decontamination of High Level Waste Salt Solutions

630 Develop Alternatives to Monosodium Titanate for Alkaline Strontium and Actinide Removal

SRS 18 of $26 \quad$ Pretreatment

645 Solvent Extraction \& Ion-Exchange To Remove TRU, Sr, Tc \& Cs from ICPP Tank Farm

646 Characterize \& Remove RCRA Listed Wastes Idaho 8 of 12 Pretreatment from High \& Low Activity Fractions

\subsubsection{Integrate Pretreatment and LLW Immobilization}

\subsubsection{Process Sludge}

605B Oak Ridge National Laboratory Tank Sludge and Supernatant Pretreatment

678B Pilot Plant

654 In-Situ Treatment of Mixed TRU Tank Wastes

Oak Ridge

Pretreatment

673 Enhanced Sludge Wash Process Data for Extended

Hanford Medium

Pretreatment

Idaho

Pretreatment Operations of Phase I and for Phase II RFP

620 Develop Counter-Current Decantation Process for Sludge Washing .

SRS 8 of 26 . Pretreatment

678A Settle Decant

Hanford Medium

Pretreatment 
Table A.2. Continued

PE\# Problem Element Title

1.2.2.8 Prepare Pretreated Waste for Immobilization

628 Demonstrate STPB Hydroxide Flowsheet to

Reduce Nitrate Addition, Thereby Reducing

ITP Washing Requirements
Site

SRS

Priority

Function

16 of 26

Pretreatment

Idaho

3 of 12

Characterization

\subsubsection{Immobilize Waste}

\subsubsection{Process LLW}

\subsection{Monitor \& Control LLW Immobilization Process}

\subsection{Prepare LLW Feed}

\subsection{Immobilize LLW Stream}

608 Oak Ridge National Laboratory Tank Sludge and Oak Ridge

Supernatant Immobilization

647 Immobilize ICPP Low Activity Wastes

Idaho

9 of 12

Immobilization

\subsection{Treat LLW Offgas}

\subsection{Dispose of LLW}

\subsubsection{Process HLW}

\subsection{Monitor \& Control HLW Immobilization Process}

626 Develop DWPF Analytical Methods to Improve

SRS

14 of 26

Immobilization Attainment

636 Upgrade DWPF Liquid Level and Density

SRS

24 of 26

Immobilization

1 2.3.2.2 Prepare Secondary Waste from Pretreatment

677 Secondary Products Acceptance Inspection and Test Methods

Hanford

High

Immobilization

\subsection{Prepare Sludge Feed}

631 Alternatives for DWPF Melter Feed REDOX

SRS

19 of 26

Immobilization

\subsection{Immobilize HLW Stream}

649 High Activity Waste Form

623 Optimize Waste Loading for DWPF Glass

Idaho 11 of 12

Immobilization

SRS 11 of 26

Immobilization

624

Develop Lower Cost Higher Capacity Melters

SRS

12 of 26

Immobilization

Operability Requirements

666

Identification and Management of Chromium

Hanford

High

Immobilization

642 Denitrate and Solidify the High Activity Fraction

Idaho

4 of 12

Immobilization

633

Enhance equipment design and operability of

SRS

21 of 26

Immobilization Spout Cleaning Techniques 
Table A.2. Continued

634 Enhance equipment design and operability of the DWPF Melter System; Characterize Causes of Pour Spout Pluggage

635 Enhance equipment design and operability of the DWPF Melter System; Increase Melt Rate in DWPF Melter.

\subsection{Treat HLW Offgas}

$\begin{array}{ccc}\frac{\text { Site }}{\text { SRS }} & \frac{\text { Priority }}{22 \text { of } 26} & \begin{array}{c}\text { Function } \\ \text { Immobilization }\end{array} \\ \text { SRS } & 23 \text { of } 26 & \text { Immobilization }\end{array}$

1.3 Store Waste Forms and Close Tanks

1.3.1 Close Tanks

651 Tanks - New 3 - In-Situ Decontamination of Buried Tank Contents

Idaho

Retrieval \& Closure

\subsubsection{Monitor Tank}

\subsubsection{Characterize Heels}

679 Establish Retrieval Performance Evaluation Criteria Hanford High Retrieval \& Closure

\subsubsection{Define Closure Criteria}

679 Establish Retrieval Performance Evaluation Criteria Hanford High Retrieval \& Closure

\subsubsection{Treat Supernate in Place}

\subsubsection{Treat Heel in Place}

\subsubsection{Detect Leaks}

\subsubsection{Stabilize Tank for Closure}

656 Removal of Small to Medium Buried Tanks Idaho

604 Oak Ridge National Laboratory Remediated Oak Ridge Tank Isolation and Removal

612 Oak Ridge National Laboratory Tank Closure Oak Ridge

688 Testing of Sand-Gravel Capillary Barrier

Hanford

687 Long-Term Testing of Surface Barrier

Hanford

690 Getter Materials

Hanford

Low

Retrieval \& Closure

Retrieval \& Closure

Retrieval \& Closure

1.3.1.8 Monitor Site

692 Field Measurements of Vadose Zone

Hydraulic Properties

693 Distribution of Recharge Rates

689 Moisture Dependence of Kd

Hanford

Medium

Retrieval \& Closure

Retrieval \& Closure

Low Retrieval \& Closure

1.3.2 Dispose of LLW

Hanford Medium Retrieval \& Closure

Hanford Low Retrieval \& Closure

\subsubsection{Monitor Waste for Acceptance}

\subsubsection{Determine Performance of Waste Form}

676 IHLW Product Acceptance Inspectio and Test Methods

675 ILAW Product Acceptance Inspection and Test Methods

$\begin{array}{lll}\text { Hanford } & \text { Medium } & \text { Immobilization } \\ \text { Hanford } & \text { High } & \text { Immobilization }\end{array}$


Table A.2. Continued

PE\#

Problem Element Title

669 Formulation of Reference Glass for Immobilized LAW

691 In-Situ Testing of Glass Release

685 Standard Method for Determining Waste Form Release

684 Multi-phase Moisture Flow in Arid Conditions

686 Glass Monolith Surface Area

670 Standard Method for Determining Waste Form Release

\subsubsection{Provide Disposal System} 638 Alternate DWPF Canister Decon Techniques

\subsubsection{Store and Dispose HLW}

1.3.3.1 Provide Interim Storage HLW

1.3.3.2 Provide Shipping $\underline{\text { Site }}$

Hanford

Priority

Low

Function

Immobilization

Hanford Low Immobilization

Hanford Medium Immobilization

Hanford Low Retrieval \& Closure

Hanford High Immobilization

Hanford Medium Immobilization

SRS

26 of 26

Immobilization 


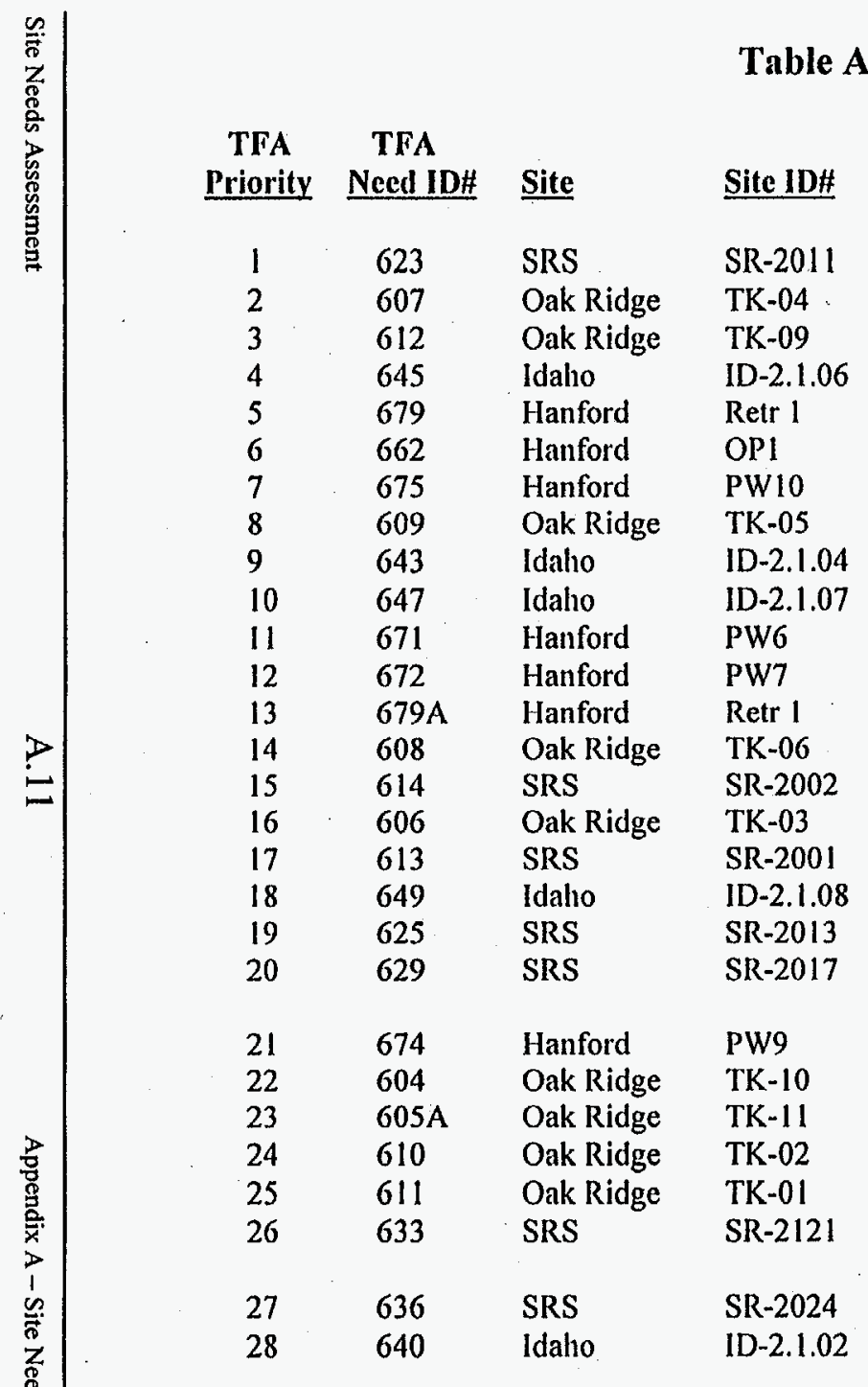

\section{Need Title}

Optimize Waste Loading for DWPF Glass

Oak Ridge National Laboratory Sludge Mixing and Slurry Transport

Oak Ridge National Laboratory Tank Closure

Solvent Extraction \& Ion-Exchange To Remove TRU, Sr, Tc \& Cs from ICPP Tank Farm Establish Retrieval Performance Evaluation Criteria [Retr-1]

DST Corrosion Monitoring

ILAW Product Acceptance Inspection and Test Methods

Oak Ridge National Laboratory Tank Sludge and Supernatant Separations

Method to Separate Undissolved Solids from Sodium-Bearing Waste \& Dissolve Calcine

Immobilize ICPP Low Activity Wastes

Avoidance of Formation of Solids in Phase I Liquid Tank Wastes

Prediction of Gel and Precipitate Formation in Hanford Tank Waste Solutions

SST Retrieval Equipment/System Development

Oak Ridge National Laboratory Tank Sludge and Supernatant Immobilization

Alternative Salt Removal Techniques

Oak Ridge National Laboratory Sludge Mixing and Mobilization

Tank Heel Removal

High Activity Waste Form

Passive Waste Tank Ventilators

Demonstrate Use of Sintered Metal Filters in Place of HEPA Filters and Paper Filters on Air Sampling Systems

Representative Sampling and Associated Analysis to Support Operations and Disposal

Oak Ridge National Laboratory Remediated Tank Isolation and Removal

ORNL Cs Removal Closeout

Oak Ridge National Laboratory Tank Solid Waste Retrieval

Oak Ridge National Laboratory Tank Waste Characterization

Enhance Equipment Design and Operability of the DWPF Melter System; Improved Melter Pour Spout Cleaning Tecluniques

Upgrade DWPF Liquid Level and Density Measurements

Process Flow Sheet to Process Sodium-Bearing Waste 
Table A.3. Continued

TFA TFA Priority Need ID\# Site

\begin{tabular}{|c|c|c|c|}
\hline 29 & 644 & Idaho & ID-2.1.05 \\
\hline 30 & 648 & Idaho & ID-2.1.10 \\
\hline 31 & 670 & Hanford & PW5 \\
\hline 32 & 673 & Hanford & PW8 \\
\hline 33 & $678 \mathrm{~A}$ & Hanford & PW13 \\
\hline 34 & $678 \mathrm{C}$ & Hanford & PW13 \\
\hline 35 & 684 & Hanford & SDI \\
\hline 36 & 686 & Hanford & SD3 \\
\hline 37 & 618 & SRS & SR-2006 \\
\hline 38 & 639 & Idaho & $1 D-2.1 .01$ \\
\hline 39 & 637 & SRS & SR-2025 \\
\hline 40 & 615 & SRS & SR-2003 \\
\hline 41 & 619 & SRS & SR-2007 \\
\hline 42 & 632 & SRS & SR-2020 \\
\hline 43 & 617 & SRS & SR-2005 \\
\hline 44 & 620 & SRS & SR-2008 \\
\hline 45 & 663 & Hanford & OP2 \\
\hline 46 & 664 & Haıford & Saf 1 \\
\hline 47 & 683 & Hanford & Retr 13 \\
\hline 48 & 651 & Idaho & ID-6.1.20 \\
\hline 49 & 616 & SRS & SR-2004 \\
\hline 50 & 631 & SRS & SR-2019 \\
\hline 51 & 658 & Hanford & Char 4 \\
\hline 52 & $679 \mathrm{~B}$ & Hanford & Retr 1 \\
\hline 53 & 642 & Idaho & ID-2.1.12 \\
\hline 54 & 667 & Hanford & PW2 \\
\hline 55 & 638 & SRS & SR-2026 \\
\hline 56 & $605 B$ & Oak Ridge & TK-11 \\
\hline 57 & 622 & SRS & SR-2010 \\
\hline 58 & 624 & SRS & SR-2012 \\
\hline
\end{tabular}

\section{$\underline{\text { Need Title }}$}

Dissolution of Future Calcines

Characterize Tank Farm Heels

Standard Method for Determining Waste Form Release Rate

Enhanced Sludge Wash Process Data for Extended Operations of Phase I and for Phase II RFP

Settle Decant

SLS Hanford (CUF)

Multi-phase Moisture Flow in Arid Conditions

Glass Monolith Surface Area

Evaluate Alternative Precipitating Agents and Ion Exchange Media for Decontanination of Higl Level Waste Salt Solutions

Reduction in Liquid HLW

Caustic Recovery \& Recycle

In-Situ Methods for Characterization of Tank Wastes

Provide Alternative Processing and/or Concentration Methods for DWPF Recycle Aqueous Streams

Process Improvements to Maximize Saltstone Waste Loading

Annulus Space Cleaning

Develop Counter-Current Decantation Process for Sludge Washing

Remote Inspection of High-Level Waste Tanks

Criticality Basis - Actinide Studies

High Accuracy Psyclırometric/Flow Measurements For Determining Tank Evaporation Rates [Retr 13]

Tanks - New 3 - In-Situ Decontamination of Buried Tank Contents

Methods to Unplug Waste Transfer Lines

Alternatives for DWPF Melter Feed REDOX Adjustment

Technetium-99 Analysis in Low Level Waste Feed

Waste Conditioning for Tank Heel Transfer

Denitrate and Solidify the High Activity Fraction

Hanford Capsule Initiative $(\mathrm{HCl})$ : A Processing Demonstration of $\mathrm{Cs} / \mathrm{Sr}$ Capsules for Final Disposition

Alternate DWPF Canister Decon Techniques

Oak Ridge National Laboratory Tank Sludge and Supernatant Pretreatment

Solids Size Reduction in Waste Tanks

Develop Lower Cost Higher Capacity Melters for DWPF Which are Consistent with Remote Operability Requirements 
Table A.3. Continued

TFA

59

60

61

6781

62

63

64

65

66

67
680

681

682

657

659

665

691
Site

SRS

Hanford Hanford

Hanford

Hanford

Hanford

Hanford

Hanford

Hanford

\section{Site ID\# Need Title}

SR-2016

PW13

Retr 2

Retr 4

Retr 11

Char 3

Char 5

Saf 2

SD8

Pilot Plant
Demonstrate STPB Hydroxide Flowsheet to Reduce Nitrite Addition, Thereby Reducing ITP Washing Requirements

Initial Waste Mobilization Methods Needed to Enhance Advanced Design Mixer Pump Retrieval for DST Waste Not Affected by Existing Mixing Pump Performance [Retr-2]

Tank Leak Mitigation Systems for Underground Single-Shell Waste Storage Tanks (SSTs) [Retr-4] Alternative to Baseline Tank Waste Mixing Systems [Retr-11]

Large Sample Hot Cell DSC/TGA Based Energetics Measurement

Rapid Speciation of Organic Acids and Complexants

Safety Related Transport Properties of Fuel Rich Organics

In-Situ Testing of Glass Release 
Table A.3. Continued

TFA

Priority Need ID

$\underline{\text { Site }}$

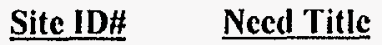

Comment

The following technical responses were not prioritized by the TFA. Please see comments and individual needs descriptions.

\begin{tabular}{|c|c|c|c|}
\hline N/A & 621 & SRS & SR-2009 \\
\hline N/A & 626 & SRS & SR-2014 \\
\hline$N / A$ & 627 & SRS & SR-2015 \\
\hline N/A & 630 & SRS & SR-2018 \\
\hline N/A & 634 & SRS & SR-2022 \\
\hline N/A & 635 & SRS & SR-2023 \\
\hline N/A & 641 & Idaho & ID-2.1.03 \\
\hline N/A & 646 & Idaho & ID-2.1.11 \\
\hline N/A & 650 & Idaho & ID -2.1 .09 \\
\hline$N / A$ & 652 & Idaho & ID-6.1.21 \\
\hline N/A & 653 & Idaho & ID-6.1.22 \\
\hline N/A & 654 & Idalıo & ID-6.1.03 \\
\hline$N / A$ & 655 & Idaho & ID-6.1.07 \\
\hline N/A & 656 & Idaho & ID- 6.1 .17 \\
\hline N/A & 660 & Hanford & Char 7 \\
\hline $\mathrm{N} / \mathrm{A}$ & 661 & Hanford & Char 8 \\
\hline N/A & 666 & Hanford & PWI \\
\hline N/A & 669 & Hanford & PW4 \\
\hline $\mathrm{N} / \mathrm{A}$ & 676 & Hanford & PW11 \\
\hline N/A & 677 & Hanford & PW12 \\
\hline N/A & 685 & Hanford & SD2 \\
\hline N/A & 687 & Hanford & SD4 \\
\hline
\end{tabular}

Enhanced Chemical Cleaning Methods for High Level

Included in response for Need ID\# 613 Waste Tank Closure

Develop DWPF Analytical Methods to Improve Attainment

In-Tank Corrosion Probe Development

Develop Alternatives to Monosodium Titanate for Alkaline Included in response for Need ID\# 618 Strontium and Actinide Removal

Enhance Equipment Design and Operability of the DWPF Included in response for Need ID\# 633

Melter System; Characterize Causes of Pour Spout Pluggage

Enhance Equipment Design and Operability of the DWPF Included in reponse for Need IDH 633

Melter System; Increase Melt Rate in DWPF Melter

On-Line Process Monitor for Elemental Analysis of Calcine Site withdrew support for technology

Product

Characterize \& Remove RCRA Listed Wastes from

High \& Low Activity Fractions

Remove \& Transport Calcine

ID-2.1.09

Tanks - New 2 - Removal and Consolidation of Waste

Tanks - New 1 - In-Situ Homogenization of Buried

Tank Waste

D-6.1.03 In-Situ Treatment of Mixed TRU Tank Wastes

In-Situ Characterization of Tank Contents

Removal of Small to Mediun Buried Tanks

In-Tank Core Sampling...Off-Riser Capability

Large Volume (3-5 liter) Sludge and Supernate Sampler

Identification and Management of Clromium and Other

Problem Constituents for HLW Vitrification

Formulation of Reference Glass for Immobilized LAW

IHLW Product Acceptance Inspection and Test Methods

Secondary Products Acceptance Inspection and

Included in response for Need ID\# 645

Test Methods

Standard Method for Determining Waste Form Release Rate Included in response for Need ID\# 670

Long-Term Testing of Surface Barrier

Need date does not require response now Included in response for Need ID\# 651 Included in response for Need ID\#651

Not in TFA mission area

Included in response for Need ID\# 651 Included in response for Need ID\# 651 Included in response for Need ID\#679

TFA believes solution already exists

Not feasible due to cost and risk

lucluded in response for Need ID\# 675 Included in response for Need ID\# 675 Included in response for Need ID\# 675 Included in response for Need ID\#.684 
Table A.3. Continued

TFA TFA

Priority Need ID\# Site

N/A $668 \quad$ Hanford

N/A $\quad 688$

N/A 689

N/A $\quad 690$

N/A $\quad 692$

N/A $\quad 693$

Hanford

Hanford

Hanford

Hanford

Hanford

\section{Site ID\# Need Title}

PW3

SD5

SD6

SD7

SD9

SD10
Advanced Methods for Achieving LLW.Volume Testing of Sand-Gravel Capillary Barrier

Moisture Dependence of $\mathrm{Kd}$

Getter Materials

Field Measurements of Vadose Zone Hydraulic Properties Distribution of Recharge Rates Minimization

\section{Comment}

Included in response for Need ID\# 637 lncluded in response for Need ID\# 684

Included in response for Need ID\# 684

Included in response for Need ID\# 684

Included in response for Need ID\# 684 Included in response for Need ID\# 684 


\section{Appendix A - Acronyms}

ALARA as low as reasonably achievable

ALV

allowable leak volume

ANS

American Nuclear Society

ARA-1

Auxiliary Reactor Area

BDAT

Best Demonstrated Available Technology

BNFL

British Nuclear Fuels, Ltd.

BNL

Brookhaven National Laboratory

BUSS

Beneficial Uses Shipping System

BVEST

Bethel Valley Evaporator Service Tank

$\mathrm{CAB}$ Citizens Advisory Board

CCD

countercurrent decantation

CDC-

cobalt dicarbollide ion

CERCLA Comprehensive Environmental Response, Compensation and Liability Act

CFR

Code of Federal Regulations

CSA

CSSF

CST

Criticality Safety Analyses

Calcine Solids Storage Facility

CUF

crystalline silicotitanate

CZE

cells unit filter

capillary zone electrophoresis

D\&D

DNFSB

DOE

decontamination and decommissioning

Defense Nuclear Facilities Safety Board

DOE-EM

U.S. Department of Energy

DOE-HQ

U.S. Department of Energy's Office of Environmental Management

DOE-ID

U.S. Department of Energy-Headquarters

DOE-RL

DSC

DST

U.S. Department of Energy's Idaho Operations Office

U.S. Department of Energy's Richland Operations Office

differential scanning calorimetry

double shell tank

EA environmental assessment

Ecology Washington Department of Ecology

EDTA ethylenediaminetetraacetic acid

EIS environmental impact statement

EM Office of Environmental Management

EM-30 Office of Waste Management

EM-50 Office of Science and Technology

EPA U.S. Environmental Protection Agency

ESP Extended Sludge Processing 


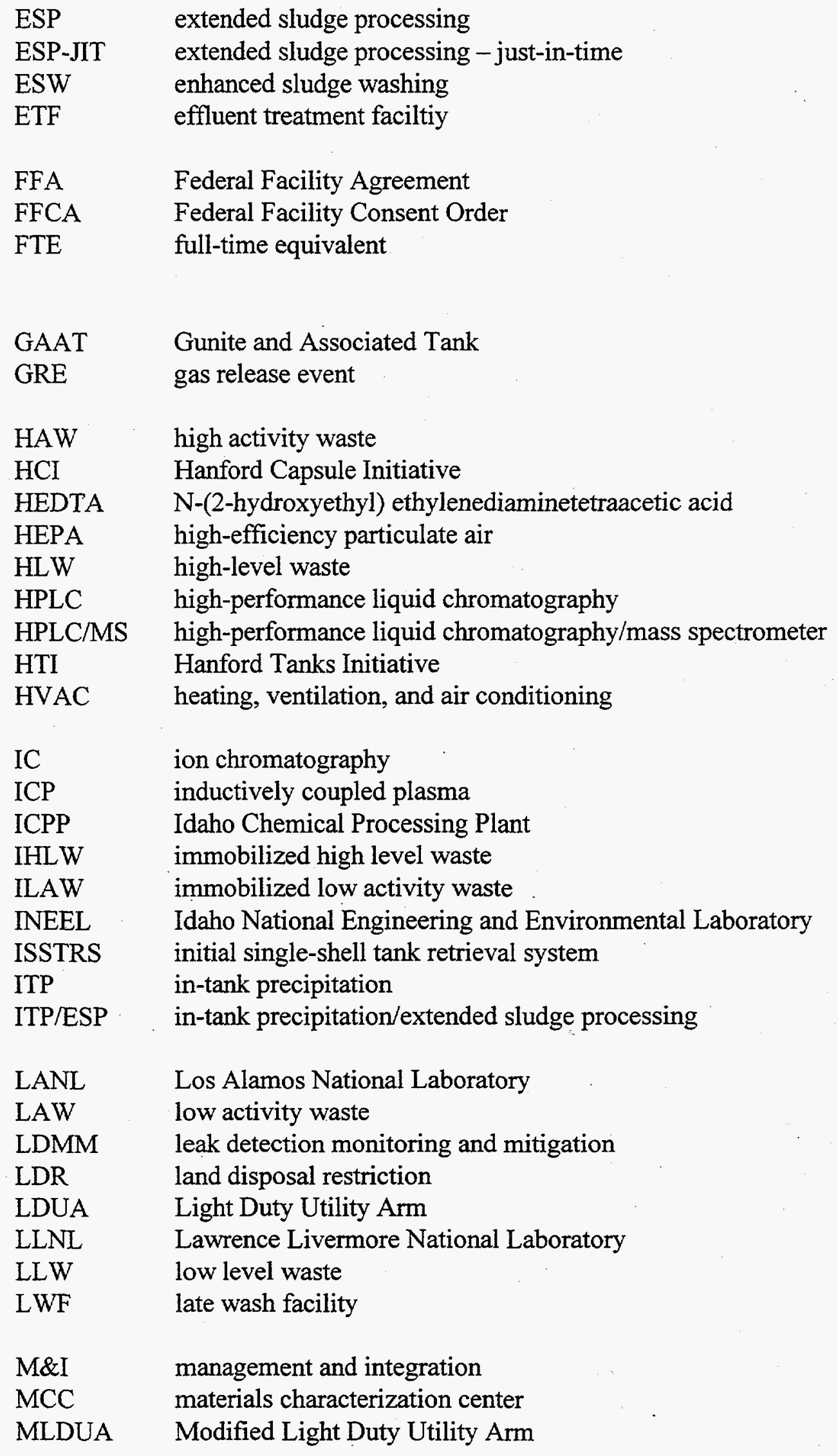




$\begin{array}{ll}\text { MST } & \text { monosodium titanate } \\ \text { MVST } & \text { Melton Valley Storage Tank } \\ \text { N/A } & \text { not applicable } \\ \text { NDE } & \text { non-destructive examination } \\ \text { NRC } & \text { U.S. Nuclear Regulatory Commission } \\ \text { NTS } & \text { Nevada Test Site } \\ \text { NWCF } & \text { New Waste Calcine Facility } \\ & \\ \text { OHF } & \text { Old Hydrofracture Tank } \\ \text { ORNL } & \text { Oak Ridge National Laboratory } \\ \text { ORR } & \text { Oak Ridge Reservation } \\ & \\ \text { PCB } & \text { polychlorinated biphenyl } \\ \text { PCT } & \text { product consistency test } \\ \text { PEW } & \text { process evaporator waste } \\ \text { PHA } & \text { precipitate hydrolysis aqueous } \\ \text { PHMC } & \text { Project Hanford Management Contractor } \\ \text { PNNL } & \text { Pacific Northwest National Laboratory } \\ \text { PUF } & \text { Pressurized Unsaturated Flow } \\ & \\ \text { QC } & \text { quality control } \\ \text { R\&D } & \text { research and development } \\ \text { RCRA } & \text { Resource Conservation and Recovery Act } \\ \text { REDOX } & \text { reduction-oxidation } \\ \text { RFP } & \text { Request for Proposal } \\ \text { RH-TRU } & \text { remote handled-transuranic (waste) } \\ \text { RI/FS } & \text { remedial investigation/feasibility study } \\ \text { RL } & \text { U.S. Department of Energy's Richland Operations Office } \\ \text { RSD } & \text { relative standard deviation } \\ & \\ \text { SBW } & \text { sodium bearing waste } \\ \text { SCC } & \text { stress corrosion cracking } \\ \text { SCDHEC } & \text { South Carolina Department of Health and Environmental Control } \\ \text { SDF } & \text { Saltstone Disposal Facility } \\ \text { SLS } & \text { solid-liquid separation } \\ \text { SRS } & \text { Savannah River Site } \\ \text { SSHT } & \text { Salt Solution Hold Tank } \\ \text { SST } & \text { single shell tank } \\ \text { STPB } & \text { sodium tetraphenylborate } \\ \text { SVOC } & \text { semivolatile organic compound } \\ \text { TAN } & \text { Test Area North } \\ \text { TCA } & \text { trichloroacetic acid } \\ & \end{array}$


TCE

TCLP

TFA

TGA

TPA

TPB-

TRU

TSD

TSR

TWRS

UST

VOC

WAC

WAPS

WC

WDOE

WESF

WIPP

WSRC trichloroethylene

toxicity characteristic leach procedure

Tanks Focus Area

thermogravimetric analysis

Hanford Federal Facility Agreement and Consent Order (also known as the Tri-Party Agreement) tetraphenylborate ion transuranic Treatment, Storage and Disposal Technical Safety Requirement Tank Waste Remediation System

underground storage tank

volatile organic compound

Washington Administrative Code

Waste Acceptance Product Specification

water column

Washington Department of Ecology

Waste Encapsulation Storage Facility

Waste Isolation Pilot Plant

Westinghouse Savannah River Company 


\begin{tabular}{lll}
\hline Tanks Focus Area & \multicolumn{2}{l}{ Need Title: Oak Ridge National Laboratory Remediated Tank } \\
Site Needs & Isolation and Removal & \\
& & \\
& Site: Oak Ridge & TFA Functional Area: Retrieval \& Closure \\
& Site ID\#: TK-10 & TFA Need ID\#: 604 \\
\hline
\end{tabular}

SITE NEED:

Need Description: Remediated tank isolation and removal techniques are needed. Remediated tank/system isolation and removal techniques, which can meet closure acceptance criteria are needed. Isolation of pipelines entering the tanks is needed to eliminate inleakage and meet closure requirements. Surrounding contaminated soils and excavation issues need to be considered.

Waste stream: TRU Waste, Mixed Waste; Gunite and Associated Tanks, Old Hydrofracture Tanks

Functional Performance Requirements: A CERCLA treatability study is underway to obtain characterization data and to demonstrate and evaluate alternative retrieval techniques for the Gunite tanks. The results of the treatability study will be used to determine the functional requirements for remediation and closure of the tanks through the CERCLA process. Closure requirements for the Old Hydrofracture Tanks will also be determined by the CERCLA process.

Schedule Requirements: Tank closures are scheduled from 1998 to 2002.

Problem Description: ORNL has 50 yr old vertical concrete tanks. The largest tank is $50 \mathrm{ft}$ in diameter, $12 \mathrm{ft}$ high at the walls and $18 \mathrm{ft}$ high at the dome. The tank is buried under approximately $6 \mathrm{ft}$ of overburden which is contaminated. The tanks are located on Central Avenue in Waste Area Group 1. This is a high traffic, highly populated area. The OHF tanks are 5 horizontal carbon steel tanks which are rubber lined and not in vaults. They have one 18-in. manhole in the center and a 27 -in. manhole on each end. They contain 6,000 gal of RHTRU sludge. After the sludges are removed, the tanks must be isolated to meet closure requirements. Pipelines entering the tanks must be isolated to eliminate inleakage back into the tanks.

Justifications:

Technical Justification:

Regulatory Justification:

ES\&H Justification:

Cultural/Stakeholder Factors:

Other Justification:

Consequences of Not Filling Need: Tanks may not meet CERCLA closure criteria.

Privatization Potential:

Current Base Technology and Cost:

Current Baseline Timeline:

SUMMARY OF TFA RESPONSE: The TFA rated the priority of the technical response to this need as \#22. The TFA is providing funding for FY97 and proposes to provide funding in FY98-99, given available funding. 


\section{Tanks Focus Area Site Needs}

Need Title: Oak Ridge National Laboratory Tank Sludge and

Supernatant Pretreatment

Site: Oak Ridge

Site ID\#: TK-11
TFA Functional Area: Pretreatment TFA Need ID\#: 605

\section{SITE NEED:}

Need Description: The baseline plan for treatment of ORNL tank waste is to remove cesium from the supernate by ion exchange and grout the waste for disposal at the Nevada Test Site (NTS), and to solidify sludge (most likely by grout or vitrification) for disposal at the NTS or the Waste Isolation Pilot Plant (WIPP). However, pretreatment to remove certain radionuclides and/or to reduce the volume of high-activity transuranic (TRU) waste may be required, particularly if WIPP does not gain approval to accept remote-handled TRU waste.

Waste stream: TRU Waste, Mixed Waste; Gunite and Associated Tanks (GAAT), Bethel Valley Evaporator Service Tanks (BVEST), Melton Valley Storage Tanks (MVST), Old Hydrofracture Tanks (OHF).

Functional Performance Requirements: This waste stream is planned for privatized treatment. The detailed performance requirements will not be known until privatization efforts are further along. However, in general terms, the products from pretreatment processes must meet waste acceptance criteria for on-site disposal at ORNL or disposal at approved waste disposal sites such as NTS, WIPP, or high-level waste repositories. Any pretreatment process considered for ORNL flowsheets must reduce the life cycle costs and/or schedule for treatment and disposal of tank waste compared to the baseline plans in the DOE Ten Year Plan. Emphasis is on the efficiency of the pretreatment process, minimization of secondary waste, stabilization of the separated contaminants, and minimization of total volume of waste requiring disposal.

Schedule Requirements: Supernate treatment is underway, and sludge treatment will begin in 2002 .

Problem Description: Oak Ridge has approximately 180,000 gal of mixed RH-TRU sludge and 800,000 gal of mixed non-TRU supernate stored in underground tanks: The GAAT, OHF, and BVEST waste must be retrieved, consolidated in the MVST, and immobilized to meet transportation and disposal requirements for WIPP or the NTS. The supernate has been historically treated by grouting the waste for disposal, presumably, at the Nevada Test Site. Increasing levels of cesium in the waste (from new research activities and concentration of legacy waste) requires that cesium be removed prior to solidification. A cesium removal demonstration using improved ion exchange materials developed by EM-50 is presently underway. Sludges have not been treated since hydrofracture (deep well injection of grouted waste) was discontinued in 1984. The baseline plan for sludge treatment is to solidify (most likely by grout or vitrification) to meet RCRA Land Disposal Restriction requirements for disposal at the NTS or WIPP. However, the sludge compositions vary considerably from tank farm to tank farm. Pretreatment of some waste streams may be required to meet the feed requirements for the solidification process. In addition, pretreatment to remove certain radionuclides and/or to reduce the volume of high-activity TRU waste may be required, particularly if the WIPP does not gain approval to accept remote-handled TRU waste.

\section{Justifications:}

Technical Justification: Operational drivers include improving efficiency for handling of waste in downstream immobilization processes, minimizing the volume of waste which must be treated for disposal at expensive sites, and minimizing the risk associated with handling of large volumes of high-activity TRU waste during treatment, transportation, and disposal processes.

Regulatory Justification: Operational drivers include improving efficiency for handling of waste in downstream immobilization processes, minimizing the volume of waste which must be treated for disposal at expensive sites, and minimizing the risk associated with handling of large volumes of high-activity TRU waste during treatment, transportation, and disposal processes.

ES\&H Justification: Reduced worker exposure.

Cultural/Stakeholder Factors: 


\section{Tanks Focus Area $\quad$ Need Title: Oak Ridge National Laboratory Tank Sludge and

Site Needs

\section{Other Justification:}

Consequences of Not Filling Need: Waste may not meet feed requirements for solidification processes for baseline treatment plans, or waste may not meet waste acceptance criteria for disposal if WIPP does not accept RH-TRU waste. Considerable cost savings will potentially be lost.

Privatization Potential: Hanford, Savannah River, and Oak Ridge tanks programs and private sector companies could utilize this technology for treatment of waste from underground storage.

Current Base Technology and Cost: The supernate has been historically treated by grouting the waste destined for disposal at the Nevada Test Site. Increasing levels of cesium in the waste (from new research activities and concentration of legacy waste) requires that cesium be removed prior to solidification. A cesium removal demonstration using improved ion exchange materials developed by EM-50 are presently underway. Sludges have not been treated since hydrofracture (deep well injection of grouted waste) was discontinued in 1984. The baseline plan for sludge treatment is to solidify it (most likely by grout or vitrification) to meet RCRA Land Disposal Restriction requirements for disposal at the NTS or WIPP.

Other Technologies Considered: The ongoing cesium removal demonstration indicates that the current ion exchange process will be adequate for cesium removal from supernate. More efficient materials could be considered. Sludge washing to reduce the volume and radioactivity in the sludges requiring disposal at expensive sites could be considered. Initial results from EM-50 development studies indicate much of the beta/gamma and up to $58 \%$ of the sludge volume could be removed by sludge washing processes.

Current Baseline Timeline: Supernate treatment is underway, and sludge treatment will begin in 2002.

SUMMARY OF TFA RESPONSE: In determining a response to this need, the TFA split it in two pieces. One piece, termed "Cesium Removal Demonstration," was assigned a TFA response \#605A. This work was prioritized $\# 23$. The TFA is providing funding for FY 97 and proposes to provide funding in FY98, given available funding.

The second piece was labeled TFA response \#605B, titled "Sludge Processing for ORR," and prioritized as \#56. The TFA is providing funding for FY97 and proposes to provide funding in FY98, given available funding. 


\begin{tabular}{ll}
\hline Tanks Focus Area & Need Title: Oak Ridge National Laboratory Sludge Mixing and \\
Mobilization
\end{tabular}
Site Needs

Site: Oak Ridge

Site ID\#: TK-03

TFA Functional Area: Retrieval \& Closure TFA Need ID\#: 606

\section{SITE NEED:}

Need Description: Systems to mix and mobilize bulk quantities of sludge in ORNL horizontal steel underground tanks with limited access are needed to support waste treatment programs and in some cases to remediate the tanks.

Waste stream: TRU Waste, Mixed Waste; Bethel Valley Evaporator Service Tanks and Old Hydrofracture Tanks

Functional Performance Requirements: In general, the systems must be easy to operate and must be operated remotely. They must be able to reach all areas of the tanks using existing access ports. They must not deteriorate the structural integrity of the tanks. Minimization of secondary waste and worker exposure are key in an effective technique.

For the OHF tanks, the detailed functional requirements for remediation and closure of the tanks will be defined through the CERCLA process.

For the BVEST, the goal is to remove $>90 \%$ of the sludges from the tanks and maintain the structural integrity so that the tanks can remain in long-term use.

Schedule Requirements: Retrieval will begin in 1997 and continue through 2000 . Treatment will begin in 2002.

Problem Description: Mixing and mobilization systems are needed to remove bulk quantities of sludge from ORNL horizontal 50,000-gal stainless steel underground storage tanks which have limited access and internal obstructions (Bethel Valley Evaporator Service Tanks). Systems are also needed to remove bulk quantities of sludge form horizontal 13,000 - 25,000 carbon steel tanks (Old Hydrofracture Tanks). The BVEST will remain in service and the OHF tanks will be remediated after the sludges are retrieved for treatment and disposal.

Oak Ridge has 150,000 gal of RH-TRU sludge stored in thirteen 50,000 -gal horizontal stainless steel tanks (BVEST and MVST) which are located in vaults. The tanks are $12 \mathrm{ft}$ diameter and $61.5 \mathrm{ft}$ long. They have one 19-in. manhole which is located $17 \mathrm{ft}$ from one end and a multitude of internal obstructions located down the center of the tank. The OHF tanks are 5 horizontal carbon steel tanks which are rubber lined and not in vaults. They have one 18-in. manhole in the center and a 27 -in. manhole on each end. They contain 6,000 gal of RHTRU sludge.

Supernatants are mixed wastes, primarily sodium carbonate and nitrate at $\mathrm{pH} 8-12$. Sludges are mixed low level and TRU waste, primarily sodium, uranium and aluminum nitrate. Known contaminants include alpha, Cd, Co, $\mathrm{Cr}, \mathrm{Hg}, \mathrm{Pu}, \mathrm{Ru}$, transuranics (TRU), and $\mathrm{U}$.

\section{Justifications:}

Technical Justification: Operational drivers include the need to empty tanks which are filling to the maximum operational levels, increase efficiency to reduce the amount of secondary waste generated by the operation, minimize penetrations into the tank, and have low maintenance because the system will be in a highly contaminated environment. No retrieval technology has been demonstrated to date which is capable of being inserted through one small access port and can reach all locations in the 50,000-gal tanks.

Regulatory Justification: Operational drivers include the need to empty tanks which are filling to the maximum operational levels, increase efficiency to reduce the amount of secondary waste generated by the operation, minimize penetrations into the tank, and have low maintenance because the system will be in a highly contaminated environment. No retrieval technology has been demonstrated to date which is capable of being inserted through one small access port and can reach all locations in the 50,000-gal tanks. 


\begin{tabular}{lll}
\hline Tanks Focus Area & Need Title: Oak Ridge National Laboratory Sludge Mixing and \\
Site Needs & Mobilization & \\
& Site: Oak Ridge & TFA Functional Area: Retrieval \& Closure \\
& Site ID\#: TK-03 & TFA Need ID\#: 606 \\
\hline
\end{tabular}

ES\&H Justification: Reduced worker exposure and minimization of secondary waste requiring treatment and disposal.

\section{Cultural/Stakeholder Factors:}

Other Justification:

Consequences of Not Filling Need: Programmatic goals to have this waste available for treatment by the private sector will not be met, and waste may not be treated in time to be shipped to WIPP to meet the Commissioner's Order.

Privatization Potential: Equipment will be provided by the private sector and may be operated by the private sector at ORNL for retrieval of waste from the BVEST and OHF. Technologies may be useful in privatized retrieval/treatment of tank wastes at DOE sites such as Hanford, Idaho, and the ORNL Melton Valley Storage Tanks.

Current Base Technology and Cost: Baseline technologies are the AEA Technologies' fluidic jet pump system for the BVEST and single point sluicing or the borehole miner (being developed by the EM-50 Tank Focus Area) for the OHF tanks.

Other Technologies Considered: Enhanced submerged jet systems have been under development by DOE to mix/mobilize bulk quantities of sludge in horizontal tanks for several years. Alternate mobilization systems (e.g., floating pump, pulsed air system, etc.) have been considered for application to these tanks. The baseline technologies are considered to be more desirable for these applications.

Current Baseline Timeline: Retrieval will begin in 1997 and continue through 2000 . Treatment will begin in 2002.

SUMMARY OF TFA RESPONSE: The TFA rated the priority of the technical response to this need as \#16. The TFA is providing funding for FY97 and proposes to provide funding in FY98-99, given available funding. 


\section{Tanks Focus Area Site Needs}

Need Title: Oak Ridge National Laboratory Sludge Mixing and Slurry Transport

Site: Oak Ridge

Site ID\#: TK-04

TFA Functional Area: Characterization TFA Need ID\#: 607

\section{SITE NEED:}

Need Description: A system to transport bulk quantities of sludge from ORNL underground tanks through miles of pipeline to consolidation tanks and treatment facilities is needed. Monitoring is required to eliminate plugging and ensure slurry content.

Waste stream: TRU Waste, Mixed Waste; Gunite and Associated Tanks, Old Hydrofracture Tanks, and Bethel Valley Storage Tanks

Functional Performance Requirements: Operating parameters for slurry transport of waste include specific gravity, slurry viscosity, solid content, particle size, and transport velocity. Solids monitors must be able to monitor these parameters for the range of conditions in the tank farms at the various sites with slurry contents of up to $20 \%$ wt percent solids. Pipeline monitors and/or in situ tank monitors are of potential use. The slurry monitors will also have to be able to withstand radiations fields up to $100 \mathrm{rad} / \mathrm{hr}$.

Schedule Requirements: Retrieval will begin in 1997 and continue through 2000 . Treatment will begin in 2002.

Problem Description: Activities are underway at Oak Ridge and Hanford to retrieve and transport millions of gallons of radioactive sludges and slurries from radioactive waste tanks. At Oak Ridge 90,000 gal of sludge will be transported through a two-inch diameter line for miles to central storage and treatment facilities over a 2 year period. The lines will be susceptible to plugging if the percent solids loading or size of solids are too large. In-line solids monitors can be used to reduce the risk of plugging transport lines and allow the percent solids in the transport slurries to be increased, thereby reducing the amount of secondary liquid waste generated during transport.

Supernatants are mixed wastes, primarily sodium carbonate and nitrate at $\mathrm{pH} 8-12$. Sludges are mixed low level and TRU waste, primarily sodium, uranium, and aluminum nitrate. Known contaminants include alpha, $\mathrm{Cd}, \mathrm{Co}, \mathrm{Cr}, \mathrm{Hg}, \mathrm{Pu}, \mathrm{Ru}$, transuranics (TRU), and $\mathrm{U}$.

\section{Justifications:}

Technical Justification: Previous evaluations of commercially available monitors indicated that no monitors were available which could quantitatively measure particle size distribution of vol $\%$ solids.

Regulatory Justification: Previous evaluations of commercially available monitors indicated that no monitors were available which could quantitatively measure particle size distribution of vol $\%$ solids.

ES\&H Justification: Reduced worker exposure, reduced risk for plugging transfer pipelines, and minimization of secondary waste requiring treatment and disposal.

\section{Cultural/Stakeholder Factors:}

\section{Other Justification:}

Consequences of Not Filling Need: If concentrated slurries are transported with existing technologies, the one pipeline which is available for transport of legacy sludges and newly-generated waste to ORNL storage/treatment facilities may be plugged. Programmatic goals would not be met to have this waste available for treatment by the private sector, and it may not be available in time to be shipped to WIPP to meet the Commissioner's Order. 
Tanks Focus Area Need Title: Oak Ridge National Laboratory Sludge Mixing and Site Needs Slurry Transport

Site: Oak Ridge

Site ID\#: TK-04

TFA Functional Area: Characterization TFA Need ID\#: 607

Privatization Potential: Equipment will be provided by the private sector. Savannah River, Hanford, and Oak Ridge tanks programs and private sector companies could utilize this technology to retrieve waste from underground storage tanks.

Current Base Technology and Cost: Present operations are limited to doing mass balances on tank contents via grab sample analyses prior to transport. This is labor intensive, increases worker exposure, requires sludge conditioning prior to transport, and usually requires the use of an extra sludge consolidation/monitoring tank. The uncertainty in this method requires transport of dilute sludge slurries, increasing the amount of secondary waste generated from the sluice/transport water.

Other Technologies Considered: EM-50 has a project underway to compare commercially available pipeline monitors and those under development by EM-50 in side-by-side tests to determine their suitability for crosssite transfer of high-level and TRU tank sludges via pipelines. These tests will be performed in a cold slurry test system at ORNL to monitor specific gravity, slurry viscosity, \% volume solid content, particle size distribution, and flow velocity during pipeline transport for Oak Ridge and Hanford wastes. No technology development projects are presently underway to evaluate comparable monitors for use in tanks. Promising methods need to be demonstrated with actual waste prior to deployment.

Current Baseline Timeline: Retrieval will begin in 1997 and continue through 2000. Treatment will begin in 2002.

SUMMARY OF TFA RESPONSE: The TFA rated the priority of the technical response to this need as \#2. The TFA is providing funding for FY97 and proposes to provide funding in FY98, given available funding. 
Tanks Focus Area Site Needs
Need Title: Oak Ridge National Laboratory Tank Sludge and Supernatant Immobilization

Site: Oak Ridge

Site ID\#: TK-06
TFA Functional Area: Immobilization TFA Need ID\#: 608

\section{SITE NEED:}

Need Description: The ORNL tank waste must been immobilized and certified to meet the transportation and disposal waste acceptance criteria for Nevada Test Site or the Waste Isolation Pilot Plant.

Waste stream: TRU Waste, Mixed Waste; Gunite and Associated Tanks (GAAT), Bethel Valley Evaporator Service Tanks (BVEST), Melton Valley Storage Tanks (MVST), Old Hydrofracture Tanks (OHF).

Functional Performance Requirements:

Schedule Requirements: Treatment will begin in 2001.

Problem Description:

Justifications:

Technical Justification:

Regulatory Justification:

\section{ES\&H Justification:}

Cultural/Stakeholder Factors:

Other Justification: Oak Ridge Need ID\#: TK-06

NBS: 1.2 .3

Site/Location: Gunite and Associated Tanks; Bethel Valley Evaporator Service Tanks; Melton Valley Storage Tanks; Old Hydrofracture Tanks.

\section{Consequences of Not Filling Need:}

Privatization Potential: Sludge immobilization baseline plans are for privatized treatment.

Current Base Technology and Cost:

Current Baseline Timeline:

SUMMARY OF TFA RESPONSE: The TFA rated the priority of the technical response to this need as \#14. The TFA is providing funding for FY97 and proposes to provide funding in FY98, given available funding. 


\section{Tanks Focus Area Site Needs \\ Need Title: Oak Ridge National Laboratory Tank Sludge and Supernatant Separations \\ Site: Oak Ridge \\ Site ID\#: TK-05 \\ TFA Functional Area: Pretreatment TFA Need ID\#: 609}

\section{SITE NEED:}

Need Description: There is a need to manage the excess water generated during sludge retrieval operations. Sludges and supernate/sluice water must be separated in a fast, cost-effective manner during waste transfer and treatment operations.

Waste stream: TRU Waste, Mixed Waste; Gunite and Associated Tanks (GAAT), Bethel Valley Evaporator Service Tanks (BVEST), Melton Valley Storage Tanks (MVST), Old Hydrofracture Tanks (OHF).

Functional Performance Requirements: This system must be have the capabilities to be remotely operated and must be on-line equipment. It must have a minimum processing rate of $5 \mathrm{gal} / \mathrm{min}$ filtrate and must operate with minimal backwashing and maintenance. It must minimize secondary waste generation and worker exposure. It must effectively separate particulates over the tank sludge particle size range and must be able to treat waste containing $5-20 \%$ wt percent solids. It must operate under moderate pressure (20-40 psi).

Schedule Requirements: Waste consolidation will begin in 1997, and treatment will begin in 2002.

Problem Description: Oak Ridge has approximately 180,000 gal of mixed RH-TRU sludge stored in underground tanks. This waste in the GAAT, BVEST, and OHF must be retrieved, consolidated in the MVST, and immobilized to meet transportation and disposal requirements for WIPP or the Nevada Test Site. Solid liquid separations equipment will be required to manage the excess water generated during sluicing of waste between tank farms and/or to maintain the desired feed composition for the treatment facility.

Supernatants are mixed wastes, primarily sodium carbonate and nitrate at $\mathrm{pH}$ 8-12. Sludges are mixed low level and TRU waste, primarily sodium, uranium, and aluminum nitrate. Known contaminants include alpha, $\mathrm{Cd}, \mathrm{Co}, \mathrm{Cr}, \mathrm{Hg}, \mathrm{Pu}, \mathrm{Ru}$, transuranics (TRU), and $\mathrm{U}$.

\section{Justifications:}

Technical Justification: Operational drivers include improving efficiency for handling of secondary wastewater generated during sludge transfer/treatment operations, minimizing the volume of waste which must be treated for disposal at expensive sites, and maintaining solids content at the desired level in slurries for pipeline transport or for feed to treatment facilities.

Regulatory Justification: Operational drivers include improving efficiency for handling of secondary wastewater generated during sludge transfer/treatment operations, minimizing the volume of waste which must be treated for disposal at expensive sites, and maintaining solids content at the desired level in slurries for pipeline transport or for feed to treatment facilities.

ES\&H Justification: Minimization of worker exposure and secondary waste generated for additional treatment and disposal.

\section{Cultural/Stakeholder Factors:}

\section{Other Justification:}

Consequences of Not Filling Need: Without solid liquid separations capabilities, TRU sludge may be inadvertently transferred to inappropriate facilities. The schedule for transfer of sludges to centralized storage tanks may be delayed past the privatization schedule and the dates required for treatment to meet the Commissioner's Order.

Privatization Potential: Hanford, Idaho, Savannah River, and Oak Ridge tanks programs and private sector companies could utilize this technology for treatment of waste from underground storage tanks. 


\begin{tabular}{lll}
\hline Tanks Focus Area & \multicolumn{2}{l}{ Need Title: Oak Ridge National Laboratory Tank Sludge and } \\
Site Needs & Supernatant Separations & \\
& Site: Oak Ridge & TFA Functional Area: Pretreatment \\
& Site ID\#: TK-05 & TFA Need ID\#: 609 \\
\hline
\end{tabular}

Current Base Technology and Cost: Baseline technology is gravity settling of sludges in storage tanks. This process is slow and cannot be used to maintain solids content in the feed to treatment processes.

Other Technologies Considered: Several technologies have been evaluated by the Tank Focus Area for application at various DOE sites. A cross-flow filtration system has been selected for full-scale demonstration at ORNL in 1997/98.

Current Baseline Timeline: Waste consolidation will begin in 1997, and treatment will begin in 2002.

SUMMARY OF TFA RESPONSE: The TFA rated the priority of the technical response to this need as \#8. The TFA is providing funding for FY97 and proposes to provide funding in FY98-99, given available funding. 


\begin{tabular}{lll}
\hline Tanks Focus Area & $\begin{array}{l}\text { Need Title: Oak Ridge National Laboratory Tank Solid Waste } \\
\text { Retrieval }\end{array}$ \\
Site Needs & $\begin{array}{l}\text { Site: Oak Ridge } \\
\text { Site ID\#: TK-02 }\end{array}$ & TFA Functional Area: Retrieval \& Closure \\
& TFA Need ID\#: 610 \\
\hline
\end{tabular}

SITE NEED:

Need Description: Vertical concrete storage tanks must be remediated. Process heels, hard sludge, and debris from the inside of old concrete storage tanks must be removed in order to remediate the tanks. Concrete walls which are contaminated from contact with radiological materials must be cleaned.

Waste stream: TRU Waste, Mixed Waste; Gunite and Associated Tanks

Functional Performance Requirements: A CERCLA treatability study is underway to obtain characterization data and to demonstrate and evaluate alternative retrieval techniques. The results of the treatability study will be used to determine the functional requirements for remediation and closure of the tanks through the CERCLA process.

Systems are needed for

- Removal of soft sludge heels.

- Removal of hard sludge heels.

- Removal of debris, hardware, and concrete chunks.

- Removal/cleaning of contaminated wall and floor segments.

- Decontamination of in tank hardware.

The systems must be easy to operate and must be operated remotely. They must be able to reach all areas of the tanks using existing limited access ports. They must not further deteriorate the structural integrity of the tanks. Waste must be conditioned to meet pipeline transport requirements. Minimization of secondary waste and worker exposure is key in an effective technique.

Schedule Requirements: Treatability Study and Characterization activities are in progress and are to be completed by FY 1998. Waste retrieval is to begin in FY 1998, and tanks will be closed by 2002 .

Problem Description: ORNL has 50 year old vertical concrete tanks. The first tanks to be remediated are unlined gunite tanks. These tanks contain transuranic (TRU) and non TRU wastes. The tanks are located on Central Avenue in Waste Area Group 1. This is a high traffic, highly populated area. The largest tank is 50 feet in diameter, 12 feet high at the walls and 18 feet high at the dome. The tank is buried under approximately 6 feet of overburden which is highly contaminated.

In the early 1980 's approximately $90 \%$ of the sludge was removed from these tanks by sluicing. A several foot deep supernatant layer of liquid is over the sludge in all but one tank. The total volume of sludge is less than 50,000 gallons. The sludge ranges from very soft silt texture to blocks as hard as concrete. A small amount of debris, hardware, spalled concrete, and chunks of concrete, inside of the tanks also need to be retrieved. Videos indicate a crystalline structure on the top of the sludge. Contaminated equipment in the risers will also have to be retrieved.

\section{Justifications:}

Technical Justification: Operational drivers include improved efficiency and reduced secondary waste generation over conventional technologies such as single point sluicing. Conventional technologies are not expected to be able to meet regulatory requirements for removal of sludge heels and concrete contamination for tank remediation.

Regulatory Justification: Operational drivers include improved efficiency and reduced secondary waste generation over conventional technologies such as single point sluicing. Conventional technologies are not expected to be able to meet regulatory requirements for removal of sludge heels and concrete contamination for tank remediation. 


\section{Tanks Focus Area Need Title: Oak Ridge National Laboratory Tank Solid Waste

Site Needs

TFA Functional Area: Retrieval \& Closure TFA Need ID\#: 610

ES\&H Justification: Reduced worker exposure and minimization of secondary waste requiring treatment and disposal.

\section{Cultural/Stakeholder Factors:}

\section{Other Justification:}

Consequences of Not Filling Need: Programmatic goals will not be met to have this waste available for treatment by the private sector, and it will not be available in time to be shipped to WIPP to meet the FFCA. Fines from CERCLA violations could result.

Privatization Potential: Equipment will be provided by the private sector. It could be considered for use in privatized treatment of tank wastes at DOE sites.

Current Base Technology and Cost: Potential Technology Alternatives: A Modified Light Duty Utility Arm (MLDUA) and remotely-operated vehicle removal systems are currently being evaluated as part of an ongoing treatability study. Remotely operated arm and vehicle equipment using various end effectors will be tested in FY 1997 and 1998 for retrieval of sludge heels, debris, and concrete chunks, and cleaning contaminated concrete floors. .

Other Technologies Considered: Additional technologies may be required to meet regulatory requirements for tank closure. Likely examples include tools for use with the MLDUA or vehicle to scarify tank walls and take core samples of the concrete. A compact processing unit for solids grinding and conditioning may be required to meet pipeline transfer requirements.

Current Baseline Timeline: Treatability Study and Characterization activities are in progress and are to be completed by FY 1998. Waste retrieval is to begin in FY 1998, and tanks will be closed by 2002.

SUMMARY OF TFA RESPONSE: The TFA rated the priority of the technical response to this need as \#24. The TFA is providing funding for FY97 and proposes to provide funding in FY98-99, given available funding. 


\begin{tabular}{lll}
\hline Tanks Focus Area & $\begin{array}{l}\text { Need Title: Oak Ridge National Laboratory Tank Waste } \\
\text { Characterization }\end{array}$ \\
Site Needs & $\begin{array}{l}\text { Site: Oak Ridge } \\
\text { Site ID\#: TK-01 }\end{array}$ & TFA Functional Area: Characterization \\
& TFA Need ID\#: 611 \\
\hline
\end{tabular}

SITE NEED:

Need Description: Waste storage tanks must be emptied, and the tanks must be characterized for closure or return to active service. Characterization technologies are needed to determine the quantity of sludge in the tanks before and after emptying. Characterization technologies are also needed to determine the levels of contamination on tank walls if they are being remediated and to determine the structural integrity if they are to be retumed to long-term service.

Waste stream: TRU Waste, Mixed Waste; Gunite and Associated Tanks, Old Hydrofracture Tanks,.Bethel Valley Evaporator Service Tanks, Melton Valley Storage Tanks.

Functional Performance Requirements: A CERCLA treatability study is underway to obtain characterization data and to demonstrate and evaluate alternative retrieval techniques for the Gunite tanks. The results of the treatability study will be used to determine the functional requirements for remediation and closure of the tanks through the CERCLA process. Closure requirements for the Old Hydrofracture Tanks will also be determined by the CERCLA process.

The systems must be easy to operate and must be operated remotely. They must be able to reach all areas of the tanks using existing limited access ports. They must not further deteriorate the structural integrity of the tanks. Minimization of secondary waste and worker exposure is key in an effective technique. Complete portable characterization equipment including samplers, sensors, controls, analyzers, and data output devices are desirable. Sludge/debris surface mapping equipment capable of profiling surfaces below the supernatant liquid is also needed.

Schedule Requirements: Sludge mapping and structural integrity assessments for the Bethel Valley Evaporator Service Tanks and Melton Valley Storage Tanks will be needed between 1997 and 2000. Old Hydrofracture Tank Sludge Characterization will be needed in 1997//98. Gunite Tank wall characterization will be needed between 1998 and 2001.

Problem Description: ORNL has 50 year old vertical concrete tanks. The largest tank is $50 \mathrm{ft}$ in diameter, 12 $\mathrm{ft}$ high at the walls, and $18 \mathrm{ft}$ high at the dome. The tank is buried under approximately $6 \mathrm{ft}$ of overburden which is contaminated. After the sludges are removed, the amount of contamination in the concrete walls must be determined before closure requirements can be defined.

The OHF tanks are 5 horizontal carbon steel tanks which are rubber lined and not in vaults. They have one 18in. manhole in the center and a 27 -in. manhole on each end. They contain 6,000 gal of RH-TRU sludge. The amount of sludge which is removed by retrieval operations must be determined in order to define closure requirements.

Oak Ridge has 150,000 gal of RH-TRU sludge stored in thirteen 50,000-gal horizontal stainless steel tanks (BVEST and MVST) which are located in vaults. The tanks are $12 \mathrm{ft}$ in diameter and $61.5 \mathrm{ft}$ long. They have one 19-in. manhole which is located $17 \mathrm{ft}$ from one end and a multitude of internal obstructions located down the center of the tank. The waste from the Gunite and Old Hydrofracture Tanks will be consolidated in these tanks prior to treatment via privatization. The amount of sludge in inventory for private sector treatment needs to be better defined. Methods for accurately determining the amount of sludge remaining in the tanks after retrieval are needed. Technologies are needed to determine the structural integrity of the tanks prior to and after sludge retrieval by the private sector in order for the tanks to be put back into active service.

Operating conditions include

- Tanks of questionable structural integrity.

- Supernatant liquid usually several feet to $12 \mathrm{ft}$ deep.

- Equipment ingress to tanks with limited access and small existing risers. 
Supernatants are mixed wastes, primarily sodium carbonate and nitrate at $\mathrm{pH}$ 8-12. Sludges are mixed low level and TRU waste, primarily sodium, uranium and aluminum nitrate. Known contaminants include alpha, $\mathrm{Cd}, \mathrm{Co}$, $\mathrm{Cr}, \mathrm{Hg}, \mathrm{Pu}, \mathrm{Ru}$, transuranics (TRU), and $\mathrm{U}$.

\section{Justifications:}

Technical Justification: Technologies are not presently available to perform the characterization activities in tanks of this size with limited access ports and internal obstructions.

Regulatory Justification: Technologies are not presently available to perform the characterization activities in tanks of this size with limited access ports and internal obstructions.

ES\&H Justification: Reduce worker exposure during tank characterization activities.

\section{Cultural/Stakeholder Factors:}

\section{Other Justification:}

Consequences of Not Filling Need: Unnecessary remediation activities may be performed on the Gunite Tanks to meet regulatory requirements for tank closure due to poor characterization data. Poor sludge characterization data given to the vendors for privatized treatment of tank sludges may result in improper treatment of waste or costly subcontract penalties. Lack of structural integrity data may result in MVST having to be replaced because they cannot be returned to service.

Privatization Potential: Equipment will be provided by the private sector. It could be considered for use in privatized treatment of tank wastes at DOE sites.

Current Base Technology and Cost: Potential Technology Alternatives: A Modified Light Duty Utility Arm (MLDUA) and remotely-operated vehicle removal systems are currently being evaluated as part of an on going treatability study for the Gunite Tanks. Remotely operated arm and vehicle equipment using various end effectors will be tested in FY 1997 and 1998 for retrieval of sludge heels, debris, and concrete chunks, and cleaning contaminated concrete floors. Sludge volumes in tanks are presently determined by grab samples at the vertical location below the manholes. Structural integrity is determined by leak detection evaluations and video inspections in the space above the waste inventory.

Other Technologies Considered: Additional Gunite Tank characterization technologies may be required to meet regulatory requirements for tank closure. Likely examples include tools for use with the MLDUA or vehicle to take core samples of the concrete. Remotely operated sludge surface mapping equipment may be considered for determining sludge volumes and structural integrity of steel tanks.

Current Baseline Timeline: Sludge mapping and structural integrity assessments for the Bethel Valley Evaporator Service Tanks and Melton Valley Storage Tanks will be needed between 1998 and 2000 . Gunite Tank wall characterization will be needed between 1998 and 2001. Old Hydrofracture Tank characterization is needed in 1997/98.

SUMMARY OF TFA RESPONSE: The TFA rated the priority of the technical response to this need as \#25. The TFA proposes to provide funding in FY98, given available funding. 


\begin{tabular}{lll}
\hline Tanks Focus Area & Need Title: Oak Ridge National Laboratory Tank Closure \\
Site Needs & & \\
& Site: Oak Ridge & TFA Functional Area: Retrieval \& Closure \\
& Site ID\#: TK-09 & TFA Need ID\#: 612 \\
\hline
\end{tabular}

SITE NEED:

Need Description: Old deteriorating waste storage tanks exist which contain sludge heels that have been determined to be of negligible risk to health, safety, and environment. However, it will be very costly to remove the waste from tanks with limited access ports. Residual waste in the concrete walls and liners of the waste tanks may also dictate the need for tank closure. A technology is needed to in situ stabilize these sludge heels as part of tank closure. Fill material which can meet acceptance criteria for tank closure is also required.

Waste stream: TRU Waste, Mixed Waste; Gunite and Associated Tanks, Old Hydrofracture Tanks

Functional Performance Requirements: Tank closure processes may include enhanced stabilization processes for residual contaminants, such as in situ heel grouting and/or fill material to structurally stabilize the tanks. Tank closure systems include

- Equipment to fill tanks, piping and systems.

- Monitors to control the filling process.

- Monitors to verify the filled tank system.

Schedule Requirements: The first tank closures begin in 1998, and those requiring in situ stabilization of sludge heels begin in 1999.

Problem Description: ORNL has $50 \mathrm{yr}$ old vertical concrete tanks. The largest tank is $50 \mathrm{ft}$ in diameter, $12 \mathrm{ft}$ high at the walls and $18 \mathrm{ft}$ high at the dome. The tank is buried under approximately $6 \mathrm{ft}$ of overburden which is highly contaminated. The OHF tanks are 5 horizontal carbon steel tanks which are rubber lined and not in vaults. They have one 18 -in. manhole in the center and a 27 -in. manhole on each end. They contain 6,000 gal of RH-TRU sludge. The sludge remaining in the tanks after retrieval operations may require additional stabilization in order to meet tank closure requirements. Small gunite tanks containing low activity waste may be eligible for in situ stabilization without any sludge removal.

\section{Justifications:}

Technical Justification: Techniques are not presently available to remove the sludge heels from these tanks or to stabilize them in situ.

Regulatory Justification: Techniques are not presently available to remove the sludge heels from these tanks or to stabilize them in situ.

ES\&H Justification: Reduced worker exposure and minimization of secondary waste generated during sludge retrieval.

\section{Cultural/Stakeholder Factors:}

Other Justification:

Consequences of Not Filling Need: Oak Ridge Tanks may not meet closure requirements.

Privatization Potential: Equipment will be provided by the private sector. It could be considered for use in privatized treatment of tank wastes at DOE sites.

Current Base Technology and Cost: None.

Current Baseline Timeline: The first tank closures requiring in situ stabilization of sludge heels begin in 1999 . 
Tanks Focus Area $\quad$ Need Title: Oak Ridge National Laboratory Tank Closure Site Needs

Site: Oak Ridge

Site ID\#: TK-09
TFA Functional Area: Retrieval \& Closure TFA Need ID\#: 612

SUMMARY OF TFA RESPONSE: The TFA rated the priority of the technical response to this need as \#3.

The TFA proposes to provide funding in FY98-00, given available funding. 


\begin{tabular}{lll}
\hline Tanks Focus Area & Need Title: Tank Heel Removal \\
Site Needs & & \\
& Site: SRS & TFA Functional Area: Retrieval \& Closure \\
& Site ID\#: SR-2001 & TFA Need ID\#: 613 \\
\hline
\end{tabular}

SITE NEED:

Need Description: Residual heels of sludge and debris remain on the bottoms of some of the waste tanks after bulk waste removal is performed. The tanks are 1 million gallon nominal capacity with a diameter of 75 to 85 feet depending on the type of tank. The types of debris and residual waste include the following:

- Hardened sludge

- Zeolite

- Silica

- Reel Tapes

Conventional waste removal techniques utilizing slurry pumps and transfer jets/pumps do not suspend and remove this type of waste. As much as 40,000 gallons of residue can remain after a conventional waste removal campaign.

Methods must be explored and developed to successfully remove these heels. The older style tanks are committed to be closed within the next 20 years. Bulk waste removal is scheduled to facilitate those goals; however, options to remove the final residue have not been fully considered. Tank closure is not possible unless this residue is removed. For example, Tank 19 is scheduled for closure during FY1998; however, a 25,000 gallon (estimated) residual zeolite heel remains which prevents immediate closure activities.

Waste stream: SRS Waste Tanks, SRS H and F Tank Farm

Functional Performance Requirements: The residual heel must be removed completely from each tank, i.e. no visible evidence of waste. Debris such as pipes and reel tapes may either be removed or cleaned "in place."

Schedule Requirements: Prototypical methods must be presented and tested during FY1997. The first viable technique must be tested successfully during FY1998.

Problem Description: The waste heels can be comprised of hardened sludge, zeolite, and silica. The heels are generally hardened or compacted insoluble particulates with relatively rapid settling velocities. Chemical dissolution generally involves acid cleaning which is not readily compatible with the carbon steel storage tanks. Mechanical or remote cleaning techniques are hampered by numerous interferences created by a network of 2 in. diameter cooling coils laced within the interior of the tanks. Tank access is largely limited to 2-foot diameter openings for the tank tops; however, the newer tanks have larger openings. The heels must be removed in such a manner to leave no waste in the source tank and be transferred ultimately to the Extended Sludge Processing (ESP) Facility.

\section{Justifications:}

Technical Justification: Residual heels of sludge and debris remain on the bottoms of some of the waste tanks after bulk waste removal is performed. The tanks are 1 million gallon nominal capacity with a diameter of 75 to 85 feet depending on the type of tank.

The waste heels can be comprised of hardened sludge, zeolite, and silica. The heels are generally hardened or compacted insoluble particulates with relatively rapid settling velocities. Conventional waste removal techniques utilizing slurry pumps and transfer jets/pumps does not suspend and remove this type of waste. As much as 40,000 gallons of residue can remain after a conventional waste removal campaign.

Chemical dissolution generally involves acid cleaning which is not readily compatible with the carbon steel storage tanks. Mechanical or remote cleaning techniques are hampered by numerous interferences created by a network of 2-in. diameter cooling coils laced within the interior of the tanks. Tank access is largely limited to 2-foot diameter openings for the tank tops; however, the newer tanks have larger openings. The heels must be removed in such a manner to leave no waste in the source tank and be transferred ultimately to the Extended Sludge Processing (ESP) Facility.

Site Needs Assessment

A.36

Appendix A - Site Needs Database 
Methods must be explored and developed to successfully remove these heels. The older style tanks are committed to be closed within the next 20 years. Bulk waste removal is scheduled to facilitate those goals; however, options to remove the final residue have not been fully considered. Tank closure is not possible unless this residue is removed. For example, Tank 19 is scheduled for closure during FY1998; however, a 25,000 gallon (estimated) residual zeolite heel remains which prevents immediate closure activities.

Regulatory Justification: Residual heels of sludge and debris remain on the bottoms of some of the waste tanks after bulk waste removal is performed. The tanks are 1 million gallon nominal capacity with a diameter of 75 to 85 feet depending on the type of tank.

The waste heels can be comprised of hardened sludge, zeolite, and silica. The heels are generally hardened or compacted insoluble particulates with relatively rapid settling velocities. Conventional waste removal techniques utilizing slurry pumps and transfer jets/pumps do not suspend and remove this type of waste. As much as 40,000 gallons of residue can remain after a conventional waste removal campaign.

Chemical dissolution generally involves acid cleaning which is not readily compatible with the carbon steel storage tanks. Mechanical or remote cleaning techniques are hampered by numerous interferences created by a network of 2-in. diameter cooling coils laced within the interior of the tanks. Tank access is largely limited to 2-foot diameter openings for the tank tops, however, the newer tanks have larger openings. The heels must be removed in such a manner to leave no waste in the source tank and be transferred ultimately to the Extended Sludge Processing (ESP) Facility.

Methods must be explored and developed to successfully remove these heels. The older style tanks are committed to be closed within the next 20 years. Bulk waste removal is scheduled to facilitate those goals; however, options to remove the final residue have not been fully considered. Tank closure is not possible unless this residue is removed. For example, Tank 19 is scheduled for closure during FY1998; however, a 25,000 gallon (estimated) residual zeolite heel remains which prevents immediate closure activities.

ES\&H Justification: Removal of the tank heels will significantly reduce the potential for environmental injury and aid in meeting the performance objectives for fate and transport modeling (as dictated by the closure process).

Cultural/Stakeholder Factors: Tank closure and tank cleaning has been discussed at the local level including public meetings and hearings with the Citizens Advisory Board (CAB).

Other Justification: There are no other concerns or justifications.

Consequences of Not Filling Need: The DOE, EPA, and SCDHEC have agreed under the FFA, to eventually close both $\mathrm{F}$ - and $\mathrm{H}$-Area Tank Farms with most of the older tanks to be emptied and cleaned first and closed under an accelerated schedule. Most of these tanks have been in existence for 35 to 40 years. These tanks are physically degrading and are in need of expeditious stabilization. Failure to approve funding for this effort could further delay specific waste removal and closure activities.

Privatization Potential: Privatization of technology development and deployment is highly viable and encouraged. There are numerous vendors and firms capable of performing this work to meet the functional requirements and schedule demands.

Current Base Technology and Cost: None

Current Baseline Timeline: 


\section{Site Needs}

Site: SRS

Site ID\#: SR-2001

TFA Functional Area: Retrieval \& Closure TFA Need ID\#: 613

SUMMARY OF TFA RESPONSE: The TFA rated the priority of the technical response to this need as \#17. The TFA proposes to provide funding in FY98-00, given available funding. Need ID $\$ 621$ is also answered within the technical response. 


\section{SITE NEED:}

Need Description: Saltcake is formed through successive evaporation cycles of alkali waste. Total waste volume is reduced during storage of waste in a less mobile form. However, the saltcake must be redissolved and transferred to the In-Tank Precipitation (ITP) Facility for further processing. Traditional salt removal involves installing large $150 \mathrm{HP}$ slurry pumps into the tank to vigorously mix the contents into solution. The tanks are 1 million gallon nominal capacity with a diameter of 75 to 85 feet depending on the type of tank.

It cost approximately \$6-10 million dollars per tank to perform salt removal on a waste tank using slurry pump method. It is desired to consider less cost intensive and less invasive methods to re-dissolve the salt.

\section{Waste stream: SRS Waste Tank Salt Cake, SRS H and F Tank Farm}

Functional Performance Requirements: Salt must be removed from the tank, leaving only a residual heel.

Schedule Requirements: Prototypical methods must be presented and tested during FY1997. The first viable technique must be tested successfully during FY1998.

Problem Description: Saltcake is comprised of sodium nitrate salts interspersed with sodium nitrite, potassium nitrate, and cesium salts. Cesium-137 is the primary isotope yielding the greatest radioactivity. Controlled salt dissolution using the density gradient method (or enhanced using water jets, steam spargers etc.) must be fully studied and field tested for viability.

\section{Justifications:}

Technical Justification: Saltcake is formed through successive evaporation cycles of alkali waste. Saltcake is comprised of sodium nitrate salts interspersed with sodium nitrite, potassium nitrate, and cesium salts. Cesium137 is the primary isotope yielding the greatest radioactivity. Total waste volume is reduced during storage of waste in a less mobile form. However, the saltcake must be redissolved and transferred to the In-Tank Precipitation (ITP) Facility for further processing. Traditional salt removal involves installing large $150 \mathrm{HP}$ slurry pumps into the tank to vigorously mix the contents into solution.

It costs approximately $\$ 6-10$ million dollars per tank to perform salt removal on a waste tank using slurry pump method. It is desired to consider less cost intensive and less invasive methods to re-dissolve the salt.

Controlled salt dissolution using the density gradient method (or enhanced using water jets, steam spargers etc.) must be fully studied and field tested for viability.

Regulatory Justification: Saltcake is formed through successive evaporation cycles of alkali waste. Saltcake is comprised of sodium nitrate salts interspersed with sodium nitrite, potassium nitrate, and cesium salts. Cesium- 137 is the primary isotope yielding the greatest radioactivity. Total waste volume is reduced during storage of waste in a less mobile form. However, the saltcake must be redissolved and transferred to the InTank Precipitation (ITP) Facility for further processing. Traditional salt removal involves installing large 150 HP slurry pumps into the tank to vigorously mix the contents into solution.

It costs approximately $\$ 6-10$ million dollars per tank to perform salt removal on a waste tank using slurry pump method. It is desired to consider less cost intensive and less invasive methods to re-dissolve the salt. Controlled salt dissolution using the density gradient method (or enhanced using water jets, steam spargers etc.) must be fully studied and field tested for viability.

ES\&H Justification: An alternative salt removal method could potentially reduce personnel radiation exposure and reduce the potential for contamination. 


\begin{tabular}{lll}
\hline Tanks Focus Area & Need Title: Alternative Salt Removal Techniques \\
Site Needs & & \\
& Site: SRS & TFA Functional Area: Retrieval \& Closure \\
& Site ID\#: SR-2002 & TFA Need ID\#: 614 \\
\hline
\end{tabular}

Cultural/Stakeholder Factors: Waste removal, tank closure, and tank cleaning has been discussed at the local level including public meetings and hearings with the Citizens Advisory Board (CAB).

Other Justification: There are no other concerns or justifications.

Consequences of Not Filling Need: The DOE, EPA, and SCDHEC have agreed under the FFA, to eventually close both F- and H-Area Tank Farms with most of the older tanks to be emptied and cleaned first and closed under an accelerated schedule. Most of these tanks have been in existence for 35 to 40 years. These tanks are physically degrading and are in need of expeditious stabilization. Failure to approve funding for this effort could further delay specific waste removal and closure activities.

Privatization Potential: Privatization of technology development and deployment is highly viable and encouraged. There are numerous vendors and firms capable of performing this work to meet the functional requirements and schedule demands.

\section{Current Base Technology and Cost: None}

\section{Current Baseline Timeline:}

SUMMARY OF TFA RESPONSE: The TFA rated the priority of the technical response to this need as \#15. The TFA proposes to provide funding in FY98-00, given available funding. 


\section{SITE NEED:}

Need Description: Develop in-situ methods that provide characterization information without physically removing and transporting material from the waste tanks. Characterization for corrosion chemistry control (i.e., nitrate, nitrite, hydroxide) is one need. Characterization for retrieval and waste pretreatment is also needed (e.g., fissile isotopes of $\mathrm{U}$ and $\mathrm{Pu}, \mathrm{Cs}-137, \mathrm{Sr}-90, \mathrm{Na}+, \mathrm{K}+$, density and weight percent solids).

\section{Waste stream: SRS waste tanks, SRS H and F Tank Farm}

Functional Performance Requirements: In-situ methods need to be able to function in a radiation field and a highly alkaline environment saturated with nitrate, nitrite, carbonate, and aluminate. The solution being characterized may not be colorless and may contain undissolved solids. Target accuracies and precision are $\pm 10 \%$ for solution species present in concentrations ${ }^{3} 0.1 \mathrm{~mole} / \mathrm{L}$, for Cs-137 and Sr-90, density and weight percent solids and $\pm 25 \%$ for solution species present at $<0.1 \mathrm{~mole} / \mathrm{L}$.

Schedule Requirements: None

Problem Description: Characterization of waste tank constituents for corrosion chemistry is important due to the waste being stored in carbon steel tanks. Failure to control the corrosion chemistry can result in tank failure and potential for an environmental release. Failure of a tank would also severely impact operation of the HLW facilities resulting in large production/utility costs.

Sample results of non-corrosion chemistry constituents for characterization purposes impacts processability.

\section{Justifications:}

Technical Justification: Develop a device that provides characterization information without physically sampling material in the waste tanks. Characterization for corrosion chemistry control, cold chemical constituents, and radionuclide characterization is needed. Current sampling and analytical methods for liquid phase characterization are very time consuming and do not provide real-time results.

Regulatory Justification: Develop a device that provides characterization information without physically sampling material in the waste tanks. Characterization for corrosion chemistry control, cold chemical constituents, and radionuclide characterization is needed. Current sampling and analytical methods for liquid phase characterization are very time consuming and do not provide real-time results.

ES\&H Justification: Pulling current samples result in personnel exposure, creation of low level radioactive waste, and cost associated with handling and analysis.

\section{Cultural/Stakeholder Factors: N/A}

Other Justification: N/A

Consequences of Not Filling Need: Continued analytical cost and personnel exposure and waste generation.

\section{Privatization Potential: None}

Current Base Technology and Cost: Dip samples and variable depth samples and traditional analytical techniques.

\section{Current Baseline Timeline:}


Tanks Focus Area Need Title: In-Situ Methods for Characterization of Tank Wastes Site Needs

Site: SRS

TFA Functional Area: Characterization

Site ID\#: SR-2003

TFA Need ID\#: 615

SUMMARY OF TFA RESPONSE: The TFA rated the priority of the technical response to this need as \#40. The TFA proposes to provide funding in FY98-99, given available funding. 
Site: SRS

Site ID\#: SR-2004

SITE NEED:

Need Description: As the tank clean-out and decommissioning program becomes active at SRS, there is an increasing potential that the transfer lines which are in place will become plugged (unable to facilitate waste transfer from one tank to another or from tankage to the DWPF ITP, or Saltstone, etc.).

Waste stream: High level waste from waste tanks, SRS H and F Tank Farm

Functional Performance Requirements: Currently, each tank includes transfer lines for the purpose of emptying the tank. Most transfer lines are permanently installed 3-in. stainless steel pipes within its own carbon steel secondary containment pipe. Most tanks are equipped with 30 to $60 \mathrm{gpm}$ steam operated transfer jets. Some tanks use long shaft electrically driven transfer pumps.

Schedule Requirements: Not known

Problem Description: Transfer systems will potentially become plugged if the solids concentration of the material being transferred increases beyond the capacity of the prime mover which could be a jet or a pump. This can happen due to the solids settling out within the pipe.

\section{Justifications:}

Technical Justification: Pluggage to date has been approached via "brute force", such as the use of water via a high pressure low flow pump.

Regulatory Justification: Pluggage to date has been approached via "brute force", such as the use of water via a high pressure low flow pump.

ES\&H Justification: Excavation of a line for the purpose of unplugging may be impossible due to the high radiation expected at the point of pluggage.

ALARA/OSHA/EPA Concerns: High pressure forcing of pluggage has demonstrated potential to contaminate.

Cultural/Stakeholder Factors: None identified

Other Justification: None identified

Consequences of Not Filling Need: Long time delays will be the results of inability to free a plugged transfer line. Permanent pluggage could require replacement of the line or the installation of alternative means of waste removal.

Privatization Potential: May be other industries pumping clay, sludge iron ore, etc. who may have already solved this problem.

Current Base Technology and Cost: High pressure has been used to force pluggage from jets. Solvents are difficult because of the potential of mixing with the waste and damaging tank and pipe metallurgy.

Current Baseline Timeline:

SUMMARY OF TFA RESPONSE: The TFA rated the priority of the technical response to this need as \#49. The TFA proposes to provide funding in FY98-00, given available funding. 


\begin{tabular}{lll}
\hline Tanks Focus Area & Need Title: Annulus Space Cleaning \\
Site Needs & & \\
& Site: SRS & TFA Functional Area: Retrieval \& Closure \\
& Site ID\#: SR-2005 & TFA Need ID\#: 617 \\
\hline
\end{tabular}

SITE NEED:

Need Description: The Type I, II, and III waste storage tanks are equipped with an annular space between he primary containment wall and the secondary containment wall. Waste has leaked in the tank annulus on several of the waste tanks. Before closing the tank final disposition, waste from the annulus must be removed and the space cleaned. There are no proven methods of removing highly radioactive waste from this type of geometry.

Waste stream: Waste Tank Annulus, SRS H and F Tank Farm.

Functional Performance Requirements: Remove waste from tank annuli such that no visible waste remains.

Schedule Requirements: Prototypical methods must be presented and tested during FY1998. The first viable technique must be tested successfully during FY2000.

Problem Description: The high level waste tanks are 1 million gallon (nominal) carbon steel storage tanks. The tank diameter is between 75-85 feet depending on the type of tank. The secondary wall extends 2 feet (average) beyond the primary wall. The secondary containment concrete wall is lined with welded steel plate to a height of 5 feet for the Type I and II tanks. The secondary wall is lined with steel plate to the full of height of the tank for Type III tanks. Ventilation duct work is routed around the bottom of each annulus. The ventilation ducts occupy much of the lower space of the annulus, thereby limiting access to the annulus floor.

Waste has leaked into the annulus from some of the Type I and II tanks. No waste has leaked from the Type III tanks. For example, Tank 16 has saltcake in its annulus to the height of about 2 feet. This waste must be redissolved and pumped to an acceptable waste tank.

\section{Justifications:}

Technical Justification: The Type I, II, and III waste storage tanks are equipped with an annular space between the primary containment wall and the secondary containment wall. Waste has leaked in the tank annulus on several of the waste tanks. Before closing the tank final disposition, waste from the annulus must be removed and the space cleaned. There are no proven methods of removing highly radioactive waste from this type of geometry.

The high level waste tanks are 1 million gallon (nominal) carbon steel storage tanks. The tank diameter is between 75-85 feet depending on the type of tank. The secondary wall extends 2 feet (average) beyond the primary wall. The secondary containment concrete wall is lined with welded steel plate to a height of 5 feet for the Type I and II tanks. The secondary wall is lined with steel plate to the full of height of the tank for Type III tanks. Ventilation duct work is routed around the bottom of each annulus. The ventilation ducts occupy much of the lower space of the annulus, thereby limiting access to the annulus floor.

Waste has leaked into the annulus from some of the Type I and II tanks. No waste has leaked from the Type III tanks. For example, Tank 16 has saltcake in its annulus to the height of about 2 feet. This waste must be redissolved and pumped to an acceptable waste tank.

Regulatory Justification: The Type I, II, and III waste storage tanks are equipped with an annular space between the primary containment wall and the secondary containment wall. Waste has leaked in the tank annulus on several of the waste tanks. Before closing the tank final disposition, waste from the annulus must be removed and the space cleaned. There are no proven methods of removing highly radioactive waste from this type of geometry.

The high level waste tanks are 1 million gallon (nominal) carbon steel storage tanks. The tank diameter is between 75-85 feet depending on the type of tank. The secondary wall extends 2 feet (average) beyond the primary wall. The secondary containment concrete wall is lined with welded steel plate to a height of 5 feet for 


\section{Site Needs}

Site: SRS

Site ID\#: SR-2005
TFA Functional Area: Retrieval \& Closure TFA Need ID\#: 617

the Type I and II tanks. The secondary wall is lined with steel plate to the full of height of the tank for Type III tanks. Ventilation duct work is routed around the bottom of each annulus. The ventilation ducts occupy much of the lower space of the annulus, thereby limiting access to the annulus floor.

Waste has leaked into the annulus from some of the Type I and II tanks. No waste has leaked from the Type III tanks. For example, Tank 16 has saltcake in its annulus to the height of about 2 feet. This waste must be redissolved and pumped to an acceptable waste tank.

ES\&H Justification: An alternative waste removal method could potentially reduce personnel radiation exposure and reduce the potential for contamination.

Cultural/Stakeholder Factors: Waste removal, tank closure, and tank cleaning has been discussed at the local level including public meetings and hearings with the Citizens Advisory Board (CAB).

Other Justification: There are no other concerns or justifications.

Consequences of Not Filling Need: The DOE, EPA, and SCDHEC have agreed under the FFA, to eventually close both F- and H-Area Tank Farms with most of the older tanks to be emptied and cleaned first and closed under an accelerated schedule. Most of these tanks have been in existence for 35 to 40 years. These tanks are physically degrading and are in need of expeditious stabilization. Failure to approve funding for this effort could further delay specific waste removal and closure activities.

Privatization Potential: Privatization of technology development and deployment is highly viable and encouraged. There are numerous vendors and firms capable of performing this work to meet the functional requirements and schedule demands.

\section{Current Base Technology and Cost: None}

\section{Current Baseline Timeline:}

SUMMARY OF TFA RESPONSE: The TFA rated the priority of the technical response to this need as \#43. The TFA is providing funding for FY97 and proposes to provide funding in FY98-00, given available funding. 


\section{Tanks Focus Area Site Needs}

Need Title: Evaluate Alternative Precipitating Agents and Ion

Exchange Media for Decontamination of High Level Waste Salt
Site: SRS

Site ID\#: SR-2006
TFA Functional Area: Pretreatment TFA Need ID\#: 618

\section{SITE NEED:}

Need Description: The use of the tetraphenylborate ion (TBP-) for precipitation of radioactive cesium from high level waste (HLW) yields high generation of benzene. Other methods of removing radioactive cesium from HLW that avoid use of TPB would eliminate benzene generation. Alternative cesium removal agents may also eliminate the acid hydrolysis and Late Wash processes in the Defense Waste Processing Facility.

Background/general information:

Previous studies examined the use of alternative cesium precipitating agents. The research focused on carbaborane compounds such as the cobalt dicarbollide ion (CDC-). Numerous closely related compounds were also examined. The research was terminated when it was discovered that the solubility of the cesium salt of CDC was approximately ten times higher than that of TPB and that the CDC decomposed in strong caustic. Decomposition of CDC limited the temperature and processing windows. Issues identified at the end of the research program that remain unresolved include cost of the material, possible hydrogen gas generation at high temperature $(>400 \mathrm{C})$, and compatibility with the DWPF glass formulation.

A derivative of $C D C$ that acts as an ion exchange material was identified during the research program. This material, "poly-CDC" is an insoluble, stable inorganic solid that preferentially exchanges cesium for sodium and potassium. Optimization of the synthesis of this material was not completed, but decontamination factors similar to those for crystalline silicotitanate were observed with the preliminary material. The poly-CDC material should exhibit a high solubility in DWPF glass. It is unlikely that poly-CDC could be used as a "batchand-stir" additive to HLW, but could be useful in an ion exchange column. Although significant fundamental research is needed on this material, WSRC is pursuing a patent.

Other ion exchange materials that would remove cesium from HLW fall into two categories: elutable and nonelutable. Elutable resins, such as resorcinol-formaldehyde resin and several other organic polymer resins, are available. The cost of implementing the elution system is prohibitive. Non-elutable resins, such as crystalline silicotitanate (CST) show high efficiency for treatment of HLW. The CST "would be used in a "once-through" mode until saturated with cesium. The CST would then be mixed directly with the DWPF sludge and vitrified. The current limitation is the extremely high radiation field on the loaded resin (>3000 Ci/gal Cs-137) and the solubility of titania in the DWPF glass. Modifying the formulation of the DWPF glass may permit higher titania limits, reducing the required loading of cesium on the CST and the radiation field of the loaded resin. It is impractical to use CST in a "batch-and-stir" mode due to the need to repeatedly contact the HLW to achieve the high decontamination factor $(40,000)$. The use of CST would require construction of ion exchange columns, but would not require the expensive elution equipment. Sluicing equipment would be needed to remove the resin from the columns. The HLW would also require prefiltration to remove insoluble solids prior to treatment. The current In-Tank Precipitation filter equipment could not be used for this prefiltration unless significant shielding is added to the filtrate piping and the filtrate routed to the ion exchange columns.

Ongoing/Approved Program:

The use of CST for treatment of HLW at SRS has been under study for 2 years, funded by the DOE Office of Science and Technology Efficient Separations and Processes Crosscutting Program. The material was first developed as a fine powder and then as an engineered inorganic "resin" for use in ion exchange columns. Initial . tests with the powdered form of CST indicated that cesium was selectively removed from simulated SRS waste. Testing has not yet been completed on the engineered form of CST. This process remains under study at SRS in FY97, although the primary focus of the research shifts to another waste stream (DWPF recycle).

Magnitude of the Problem:

There are over 35 million gallons of HLW at SRS requiring treatment.

Waste stream: ITP Tank 48 


\begin{tabular}{ll}
\hline Tanks Focus Area & Need Title: Evaluate Alternative Precipitating Agents and Ion \\
Exchange Media for Decontamination of High Level Waste Salt
\end{tabular}

Site Needs

Site: SRS

Site ID\#: SR-2006

TFA Functional Area: Pretreatment TFA Need ID\#: 618

Functional Performance Requirements: A cesium-specific precipitating agent is needed. Using a precipitating agent avoids the need for system reconfiguration required for ion exchange. The precipitating agent must exhibit a cesium salt solubility at ambient temperature sufficient to produce a decontamination factor of 40,000 . The decontamination factor must be achieved using a solution that is initially $30 \mathrm{mg} / \mathrm{L}$ cesium, $500 \mathrm{mg} / \mathrm{L}$ potassium, and $5.0 \mathrm{M}$ sodium ions. Less than $10 \%$ of the precipitated solids can be sodium salts, but the potassium may be precipitated and carried with the cesium solids. The precipitating agent must not significantly impact the Saltstone process. The precipitating agent must be stable in strong caustic ( $1 \mathrm{M}$ hydroxide ion), nitrate $(3 \mathrm{M})$, and nitrite ions ( $1 \mathrm{M})$ to $65 \mathrm{C}$ for a period of at least 60 days. The agent must tolerate radiation fields exceeding $10 \mathrm{Ci} / \mathrm{L}$ of $\mathrm{Cs}-137$ for 2 years. The solids formed must be filterable at reasonable flow rates $\left(0.25 \mathrm{gpm} / \mathrm{ft}^{2}\right.$ at 30 psi with $1 \mathrm{wt} \%$ solids $)$ and semi-soluble in dilute oxalic acid to permit filter cleaning. The precipitating agent must decompose by a process readily adaptable to a highly radioactive environment or prove compatible with DWPF vitrification.

Schedule Requirements: No applicable schedule tie.

Problem Description: Benzene can form deflagrable mixtures with air. Technical Safety Requirements in place are cumbersome and costly to administer.

\section{Justifications:}

Technical Justification: The use of the TPB ion for precipitation of radioactive cesium from HLW yields high generation of benzene. Other methods of removing radioactive cesium from HLW that avoid use of TPB would eliminate benzene generation. Alternative cesium removal agents may also eliminate the acid hydrolysis and Late Wash processes in the Defense Waste Processing Facility.

Regulatory Justification: The use of the tetraphenylborate (TPB-) ion for precipitation of radioactive cesium from HLW yields high generation of benzene. Other methods of removing radioactive cesium from HLW that avoid use of TPB would eliminate benzene generation. Alternative cesium removal agents may also eliminate the acid hydrolysis and Late Wash processes in the Defense Waste Processing Facility.

ES\&H Justification: Improvements in the process will reduce benzene emissions, thereby decreasing pollution and health hazards for the immediate employee and the local population.

Cultural/Stakeholder Factors: Extensive interactions with the Defense Nuclear Facility Safety Board, with the DOE, with numerous external consultants and with the local public occur. These interactions ensure the safe operation of the facility.

Other Justification: None identified

Consequences of Not Filling Need: Timely completion of waste removal activities for the Savannah River Site centers on success of this program.

Privatization Potential: DOE encourages efforts by commercial firms to treat waste of this nature. Advances in individual program elements offer high potential for commercialization.

Current Base Technology and Cost: NaTPB precipitation of cesium.

Current Baseline Timeline:

SUMMARY OF TFA RESPONSE: The TFA rated the priority of the technical response to this need as \#37. The TFA proposes to provide funding in FY98-99, given available funding. The response to this need also covers the TFA's response to Need ID\# 630. 
Tanks Focus Area Need Title: Provide Alternative Processing and/or Concentration Site Needs Methods for DWPF Recycle Aqueous Streams

Site: SRS

Site ID\#: SR-2007
TFA Functional Area: Pretreatment TFA Need ID\#: 619

SITE NEED:

Need Description: At design rates, DWPF recycles about $7.5 \mathrm{gpm}$ aqueous stream to the tanks farms for evaporation. The stream consists of the following average composition: $\mathrm{H}_{2} \mathrm{O}-94.7 \% ; \mathrm{NaOH} 4.0 \% ; \mathrm{NaNO}_{3}$ $0.3 \% ; \mathrm{NaNO}_{2}-0.6 \% ; \mathrm{NH}_{3} 300 \mathrm{PPM} ;$ Misc. inorganics $0.3 \%$; Misc. Organics $700 \mathrm{PPM}$. Curie content is approximately 2 curies/gal primarily Cs-137. Incremented cost of processing this material in the Tank Farm is 78 cents per gal. Loss of storage capacity at the Tank Farm or extended outage of tank evaporators will cause DWPF to stop operations.

Waste stream: DWPF Recycle

Functional Performance Requirements: The above DWPF recycle stream must be processed in such a manner that approximately $95 \%$ of the stream is decontaminated to a level of $\sim 2 \times 10^{-4} /$ gal curies (a df of approximately 104) so that it can be processed by the Effluent Treatment Facility. The remaining $5 \%$ will be transferred to the high level waste tank farm.

Schedule Requirements: Not critical if Replacement High Level Waste Evaporator remains on schedule.

Problem Description: An aqueous recycle stream (approx. $7.5 \mathrm{gpm}$ ) from DWPF will be separated into two streams:

$\begin{array}{llll} & \text { FEED } & \text { A(To Tank Farm) } & \text { B(To ETF) } \\ \text { Flow } & 7.5 \text { gpm } & 0.4 \text { gpm } & 7.1 \text { gpm } \\ \text { Curie Content } & 2 \text { curies/gal } & 37.5 \text { curies } / \text { gal } & 2 \times 10^{-4} \text { curies/gal } \\ \text { Curie/min. } & 15 & 14.99 & 14.2 \times 10^{-4}\end{array}$

Justifications:

Technical Justification: At design rates, DWPF recycles about $7.5 \mathrm{gpm}$ aqueous stream to the tanks farms for evaporation. The stream consists of the following average composition: $\mathrm{H}_{2} \mathrm{O}-94.7 \% ; \mathrm{NaOH} 4.0 \% ; \mathrm{NaNO}_{3}$ $0.3 \% ; \mathrm{NaNO}_{2}-0.6 \% ; \mathrm{NH}_{3} 300 \mathrm{PPM}$; Misc. inorganics $0.3 \%$; Misc. Organics $700 \mathrm{PPM}$. Curie content is approximately 2 curies/gal primarily Cs-137. Incremented cost of processing this material in the Tank Farm is 78 cents per gal. Loss of storage capacity at the Tank Farm or extended outage of tank evaporators will cause DWPF to stop operations.

Regulatory Justification: At design rates, DWPF recycles about $7.5 \mathrm{gpm}$ aqueous stream to the tanks farms for evaporation. The stream consists of the following average composition: $\mathrm{H}_{2} \mathrm{O}-94.7 \% ; \mathrm{NaOH} 4.0 \% ; \mathrm{NaNO}_{3}$ $0.3 \% ; \mathrm{NaNO}_{2}-0.6 \% ; \mathrm{NH}_{3} 300$ PPM; Misc. inorganics $0.3 \%$; Misc. Organics 700 PPM. Curie content is approximately 2 curies/gal primarily Cs-137. Incremented cost of processing this material in the Tank Farm is 78 cents per gal. Loss of storage capacity at the Tank Farm or extended outage of tank evaporators will cause DWPF to stop operations.

ES\&H Justification: Reducing the volume of DWPF recycle will reduce the storage and processing burden on the tank farm.

Cultural/Stakeholder Factors: None identified

Other Justification: None identified

Consequences of Not Filling Need: Higher costs will be incurred if potentially lower cost treatment methods are not utilized. 
Tanks Focus Area Site Needs
Need Title: Provide Alternative Processing and/or Concentration Methods for DWPF Recycle Aqueous Streams

Site: SRS

Site ID\#: SR-2007
TFA Functional Area: Pretreatment TFA Need ID\#: 619

Privatization Potential: Potential solution may be applicable to other high level aqueous waste at WSRC and other DOE sites.

Current Base Technology and Cost: The current baseline technology is decontamination and concentration by evaporation.

\section{Current Baseline Timeline:}

SUMMARY OF TFA RESPONSE: The TFA rated the priority of the technical response to this need as \#41. The TFA proposes to provide funding in FY98-00, given available funding. 


\begin{tabular}{ll}
\hline Tanks Focus Area & Need Title: Develop Counter-Current Decantation Process for \\
Site Needs & Sludge Washing
\end{tabular}

Site: SRS

TFA Functional Area: Pretreatment

Site ID\#: SR-2008 TFA Need ID\#: 620

\section{SITE NEED:}

Need Description: CCD is a common process used in the solids processing industries for washing sludge. $\mathrm{CCD}$ uses thickeners as the unit operation. Filters, cyclones, and centrifuges can also be used in this process, when they have advantages. The proposed CCD circuit uses 6 thickeners of 7-ft diameter each. The slurry feed rate is $3 \mathrm{gal} / \mathrm{min}$ and the wash water feed rate is $5 \mathrm{gal} / \mathrm{min}$. The entire circuit is contained within either a $40 \mathrm{ft}$ diameter shielded cell or a square cell $40 \mathrm{ft}$ on a side. The CCD circuit will process sludge in batches of 8,000 gallons to supply DWPF on an as-needed basis or just-in-time.

\section{Waste stream: HLW sludge, ITP Extended Sludge Processing}

Functional Performance Requirements: The CCD circuit uses six thickeners (estimated 7-ft diameter), one feed and one product tank (9,000 gal each, $15-\mathrm{ft}$ diameter by $7-\mathrm{ft}$ high). The feed tank may be equipped to do Al dissolution. The sludge treatment rate is $3 \mathrm{gal} / \mathrm{min}$. The process steps are

- Sludge recovered by waste removal is transferred to Tank 51 for storage, blending and decanting.

- Sludge is transferred from Tank 51 to the ESP-JIT feed tank to make a batch sized to be one transfer to DWPF $(8,000 \mathrm{gal})$.

- If required, the sludge is reacted in the JIT feed tank by stirring with $\mathrm{NaOH}+$ steam to leach the easy-todissolve alumina (gibbsite). Reaction conditions are expected to be 10-12 hours@85 degrees C.

- After leaching, the sludge is fed to the CCD circuit @3 gal/min for washing. In the CCD circuit, the advancing wash water moves by gravity, the sludge by pumping. The wash water product is pumped to Tank 51.

- The washed sludge is accumulated in the product tank until it is full and the feed tank is empty. The washed sludge is transferred to DWPF.

The cycle is repeated.

AEA Technology fluidic pumps and samplers are used throughout the circuit.

Schedule Requirements: The CCD circuit can be installed at any time because it can be installed and demonstrated in parallel with operation of the present ESP operation. The project is estimated to require no more than 3 years to design, build, and demonstrate after start of capital funding.

Problem Description: The CCD circuit was described thoroughly in a special presentation to the Office of Science and Technology on 2 Oct 96.

\section{Justifications:}

Technical Justification: Releases 2 tanks, T40 \& T42, for return to tank farm duty.

All stainless steel circuit - eliminates $\mathrm{NaOH}$ inhibitor additions in ESP tanks.

Because the wash is JIT and because no $\mathrm{NaOH}$ corrosion inhibition is required, no $\mathrm{CO} 2$ is absorbed by the water phase. Because the solubility of carbonates is relatively high, any carbonates accumulated in the sludge prior to washing will be removed by dissolution during the wash. The feed to DWPF will, therefore, contain no carbonates. Thus foaming due to $\mathrm{CO} 2$ release is eliminated.

ESP wash solution volume greatly reduced (1/5 of the volume versus present with 1 cowash, $1 / 10$ of the volume versus present with no cowash).

Recycle wash water without evaporation - recycle direct to ITP-ESP feed preparation.

May eliminate need for Al dissolution, thus eliminating project to install Al dissolution equipment on Tank 42

If $\mathrm{Al}$ dissolution required, then cost of $\mathrm{Al}$ dissolution is decreased by $50-100 \%$.

Guaranteed control of soluble Na content to $0.1 \mathrm{M}$, or any other value

Guaranteed control of nitrate and nitrite to negligible levels

Improves DWPF operation and allows larger amounts of ITP precipitate per canister, thereby reducing the total number of canisters, because of negligible nitrites \& nitrates and tailored Al \& Na levels.

Can be installed and the operation demonstrated in parallel and reversibly with the existing ESP circuit and without needing a major outage to ESP.

Site Needs Assessment

A.50

Appendix A - Site Needs Database 


\section{Tanks Focus Area $\quad$ Need Title: Develop Counter-Current Decantation Process for \\ Sludge Washing}

Site Needs

Site: SRS

Site ID\#: SR-2008
TFA Functional Area: Pretreatment TFA Need ID\#: 620

Reduce number of slurry mix pumps for sludge processing by $2 / 3$ rds, from 12 to 4 .

$C C D$ circuit uses no moving parts in the radiation environment; thus, very little to no maintenance will be required.

Regulatory Justification: Releases 2 tanks, T40 \& T42, for return to tank farm duty. All stainless steel circuit - eliminates $\mathrm{NaOH}$ inhibitor additions in ESP tanks.

Because the wash is JIT and because no $\mathrm{NaOH}$ corrosion inhibition is required, no $\mathrm{CO} 2$ is absorbed by the water phase. Because the solubility of carbonates is relatively high, any carbonates accumulated in the sludge prior to washing will be removed by dissolution during the wash. The feed to DWPF will, therefore, contain no carbonates. Thus foaming due to $\mathrm{CO}_{2}$ release is eliminated.

ESP wash solution volume greatly reduced (1/5 of the volume versus present with 1 cowash, $1 / 10$ of the volume versus present with no cowash).

Recycle wash water without evaporation - recycle direct to ITP-ESP feed preparation.

May eliminate need for $\mathrm{Al}$ dissolution, thus eliminating project to install Al dissolution equipment on Tank 42

If $\mathrm{Al}$ dissolution required, then cost of $\mathrm{Al}$ dissolution is decreased by $50-100 \%$.

Guaranteed control of soluble $\mathrm{Na}$ content to $0.1 \mathrm{M}$, or any other value

Guaranteed control of nitrate and nitrite to negligible levels

Improves DWPF operation and allows larger amounts of ITP precipitate per canister, thereby reducing the total number of canisters, because of negligible nitrites \& nitrates and tailored $\mathrm{Al} \& \mathrm{Na}$ levels.

Can be installed and the operation demonstrated in parallel and reversibly with the existing ESP circuit and without needing a major outage to ESP.

Reduce number of slurry mix pumps for sludge processing by $2 / 3 \mathrm{rds}$, from 12 to 4 .

$\mathrm{CCD}$ circuit uses no moving parts in the radiation environment, thus very little to no maintenance will be required.

ES\&H Justification: Inherently safe transfers to DWPF (no siphoning) because each transfer is an entire tankful. Improves ESP and DWPF operability, dramatically decreases maintenance required for ESP and the associated secondary waste and decontamination + disposal of failed equipment

Cultural/Stakeholder Factors: There are no known stakeholder concerns of a non-regulatory nature.

Other Justification:

Consequences of Not Filling Need: The indicated improvements and savings will not be obtained.

Privatization Potential: The process demonstration and the equipment are standard technology and can be supplied by established commercial vendors.

Current Base Technology and Cost: Bulk water wash in SRS waste tank.

\section{Current Baseline Timeline:}

SUMMARY OF TFA RESPONSE: The TFA rated the priority of the technical response to this need as \#44. The TFA is providing funding for FY97 and proposes to provide funding in FY98-99, given available funding. 


\begin{tabular}{lll}
\hline Tanks Focus Area & Need Title: Enhanced Chemical Cleaning Methods for High \\
Site Needs & Level Waste Tank Closure \\
& Site: SRS & TFA Functional Area: Retrieval \& Closure \\
& Site ID\#: SR-2009 & TFA Need ID\#: 621 \\
\hline
\end{tabular}

\section{SITE NEED:}

Need Description: The technology needed is that which will allow waste high level waste tanks to be closed as a Class $\mathrm{C}$ waste. In order for this to occur the bulk of the waste in the tanks will be emptied by processing through the various waste treatment facilities. The remaining waste, most likely small quantities but difficult to remove, will have to be treated in such a way as to remove it from the tanks. It is possible that 40 or more of the high level waste tanks will have to be treated in order to meet the Class $\mathrm{C}$ requirements.

Waste stream: SRS High Level Waste Tanks, SRS H and F Tank Farm

Functional Performance Requirements: The method of cleaning must result in a high level waste tank being declared a Class $\mathrm{C}$ waste.

Schedule Requirements: An enhanced cleaning method is necessary in FY97 if it is necessary for the closure of Tank 20.

Problem Description: The problem is how to clean remaining waste out of a high level waste tank after bulk removal of the waste has occurred. The inside wall of the tank, cooling coils, annulus, etc. will most probably be contaminated with some type of waste. There will be some small amount of insoluble particles remaining in the bottom of the tank. A method for removing this remaining waste is necessary in order for the tanks to be declared Class $\mathrm{C}$ waste. It is presently envisioned to use oxalic acid as the medium to remove this remaining waste.

In 1980 a demonstration was conducted to show the efficacy of using oxalic acid washes in conjunction with water washes to reduce the remaining waste in a tank to extremely low limits. The test successfully demonstrated that a combination of the two washes was effective in cleaning the tanks. Although oxalic acid proved to be an effective cleaning agent, there might be a better one available. The method by which the oxalic acid or water wash is used might be done in a better manner. The purpose of this Technology Need is to determine if we are cleaning the tanks in the most efficient manner possible.

\section{Justifications:}

Technical Justification: The technology needed is that which will allow waste high level waste tanks to be closed as a Class $C$ waste. In order for this to occur the bulk of the waste in the tanks will be emptied by processing through the various waste treatment facilities. The remaining waste, most likely small quantities but difficult to remove, will have to be treated in such a way as to remove it from the tanks. It is possible that 40 or more of the high level waste tanks will have to be treated in order to meet the Class $C$ requirements.

Regulatory Justification: The technology needed is that which will allow waste high level waste tanks to be closed as a Class $\mathrm{C}$ waste. In order for this to occur the bulk of the waste in the tanks will be emptied by processing through the various waste treatment facilities. The remaining waste, most likely small quantities but difficult to remove, will have to be treated in such a way as to remove it from the tanks. It is possible that 40 or more of the high level waste tanks will have to be treated in order to meet the Class $\mathrm{C}$ requirements.

ES\&H Justification: An alternative salt removal method could potentially reduce personnel radiation exposure and reduce the potential for contamination.

Cultural/Stakeholder Factors: Waste removal, tank closure, and tank cleaning has been discussed at the local level including public meetings and hearings with the Citizens Advisory Board (CAB).

Other Justification: There are no other concerns or justifications. 
Tanks Focus Area Site Needs
Need Title: Enhanced Chemical Cleaning Methods for High Level Waste Tank Closure

Site: SRS

Site ID\#: SR-2009
TFA Functional Area: Retrieval \& Closure TFA Need ID\#: 621

Consequences of Not Filling Need: The DOE, EPA, and SCDHEC have agreed under the FFA, to eventually close both F- and H-Area Tank Farms with most of the older tanks to be emptied and cleaned first and closed under an accelerated schedule. Most of these tanks have been in existence for 35 to 40 years. These tanks are physically degrading and are in need of expeditious stabilization. Failure to approve funding for this effort could further delay specific waste removal and closure activities.

Privatization Potential: Privatization of technology development and deployment is highly viable and encouraged. There are numerous vendors and firms capable of performing this work to meet the functional requirements and schedule demands.

Current Base Technology and Cost: None

Current Baseline Timeline:

SUMMARY OF TFA RESPONSE: The TFA did not prioritize this need separately. Instead, this need will be addressed in TFA's response to Need ID\# 613. 


\begin{tabular}{lll}
\hline Tanks Focus Area & Need Title: Solids Size Reduction in Waste Tanks \\
Site Needs & & \\
& Site: SRS & TFA Functional Area: Retrieval \& Closure \\
& Site ID\#: SR-2010 & TFA Need ID\#: 622 \\
\hline
\end{tabular}

SITE NEED:

Need Description: There are numerous waste deposits in the tank farm waste storage tanks that cannot be dissolved or broken up into suspension. These deposits, also known as "clinkers," possess significant radioactive source term. Therefore, it is desirable to remove these deposits from the waste tanks prior to closure, however, there are no viable methods to remove these artifacts.

Waste stream: Tank Farm Tanks, SRS H and F Tank Farm

Functional Performance Requirements: Successfully remove these deposits from the waste storage tanks.

Schedule Requirements: Prototypical methods must be presented and tested during FY1998. The first viable technique must be tested successfully during FY2000.

Problem Description: The high level waste tanks are 1 million gallon (nominal) carbon steel storage tanks. The tank diameter is between 75-85 feet depending on the type of tank. Solids deposits ranging in size from a few inches to a few feet form during the long term storage of sludge material. High temperatures from decay heat fuses the sludge particles together in a rock-like form. These "clinkers" are apparently impervious to vigorous agitation and erosion from experience with past waste removal efforts.

\section{Justifications:}

Technical Justification: The high level waste tanks are 1 million gallon (nominal) carbon steel storage tanks. The tank diameter is between 75-85 feet depending on the type of tank. There are numerous waste deposits in the tank farm waste storage tanks that cannot be dissolved or broken up into suspension. Solids deposits ranging in size from a few inches to a few feet form during the long term storage of sludge material. High temperatures from decay heat fuses the sludge particles together in a rock-like form. These deposits, also known as "clinkers," are apparently impervious to vigorous agitation and erosion from experience with past waste removal efforts. These "clinkers" possess significant radioactive source term. Therefore, it is desirable to remove these deposits from the waste tanks prior to closure, however, there are no viable methods to remove these artifacts.

Regulatory Justification: The high level waste tanks are 1 million gallon (nominal) carbon steel storage tanks. The tank diameter is between 75-85 feet depending on the type of tank. There are numerous waste deposits in the tank farm waste storage tanks that cannot be dissolved or broken up into suspension. Solids deposits ranging in size from a few inches to a few feet form during the long term storage of sludge material. High temperatures from decay heat fuses the sludge particles together in a rock-like form. These deposits, also known as "clinkers," are apparently impervious to vigorous agitation and erosion from experience with past waste removal efforts. These "clinkers" possess significant radioactive source term. Therefore, it is desirable to remove these deposits from the waste tanks prior to closure, however, there are no viable methods to remove these artifacts.

ES\&H Justification: Removal of the tank solids will significantly reduce the potential for environmental injury and aid in meeting the performance objectives for fate and transport modeling (as dictated by the closure process).

Cultural/Stakeholder Factors: Waste removal, tank closure, and tank cleaning has been discussed at the local level including public meetings and hearings with the Citizens Advisory Board (CAB).

Other Justification: There are no other concerns or justifications.

Consequences of Not Filling Need: The DOE, EPA, and SCDHEC have agreed under the FFA, to eventually close both F- and H-Area Tank Farms with most of the older tanks to be emptied and cleaned first and closed 
Site Needs

Site: SRS

Site ID\#: SR-2010
TFA Functional Area: Retrieval \& Closure TFA Need ID\#: 622

under an accelerated schedule. Most of these tanks have been in existence for 35 to 40 years. These tanks are physically degrading and are in need of expeditious stabilization. Failure to approve funding for this effort could further delay specific waste removal and closure activities.

Privatization Potential: Privatization of technology development and deployment is highly viable and encouraged. There are numerous vendors and firms capable of performing this work to meet the functional requirements and schedule demands.

\section{Current Base Technology and Cost: None}

Current Baseline Timeline:

SUMMARY OF TFA RESPONSE: The TFA rated the priority of the technical response to this need as \#57. The TFA proposes to provide funding in FY98-00, given available funding. 


\section{Tanks Focus Area}

Need Title: Optimize Waste Loading for DWPF Glass

\section{Site Needs}

Site: SRS

Site ID\#: SR-2011

TFA Functional Area: Immobilization TFA Need ID\#: 623

\section{SITE NEED:}

Need Description: The total number of canisters required to vitrify all of the current and future inventory of SRS high level waste can be reduced by reducing the uncertainty of models used to ensure the glass produced meets all quality and processing constraints. DWPF control program is based on statistical process control and narrowing the error bands on the constraints will allow the waste / glass former blends at compositions nearer to the constraints.

Waste stream: SRS DWPF melter feed

Functional Performance Requirements: Provide new or improved version of exiting property models for liquidus temperature and durability. Identify the model tolerances. These models should be applicable to the entire range of plausible glass compositions produced from glass formers (frits) and washed sludge waste ("sludge only glass") or glass formers, sludge and processed washed precipitate ("PHA" or precipitate hydrolysis aqueous).

Schedule Requirements: No applicable schedule tie.

Problem Description: DWPF's complies with Waste Acceptance Product Specifications and process control requirements control by demonstrating, to a high confidence, that melter feed will produce glass meeting all quality and processing requirements. This method requires that uncertainties associated with sampling, sample analysis and models used to estimate properties be determined and that sufficient allowance is made for these uncertainties when controlling feed composition.

The existing model for liquidus temperature has a large uncertainty associated and its application has lead to reduction in allowable waste loading. Some constraints on the application of the durability model can cause acceptable glassed to be rejected, because the durability is indeterminate (i.e., the applicability of the model is not certain).

\section{Justifications:}

Technical Justification: The total number of canisters required to vitrify all of the current and future inventory of SRS high level waste can be reduced by reducing the uncertainty of models used to ensure the glass produced meets all quality and processing constraints. DWPF control program is based on statistical process control and narrowing the error bands on the constraints will allow the waste / glass former blends at compositions nearer to the constraints. Reducing uncertainty in the Liquidus Model and increasing the range of applicability of the durability model will result in larger acceptable composition ranges and increased waste loadings.

Regulatory Justification: The total number of canisters required to vitrify all of the current and future inventory of SRS high level waste can be reduced by reducing the uncertainty of models used to ensure the glass produced meets all quality and processing constraints. DWPF control program is based on statistical process control and narrowing the error bands on the constraints will allow the waste/glass former blends at compositions nearer to the constraints. Reducing uncertainty in the Liquidus Model and increasing the range of applicability of the durability model will result in larger acceptable composition ranges and increased waste loadings.

ES\&H Justification: Potential for reducing number of canisters sent to repository

Cultural/Stakeholder Factors: No known concerns.

Other Justification: 
Tanks Focus Area Need Title: Optimize Waste Loading for DWPF Glass

Site Needs

Site: SRS

Site ID\#: SR-2011

TFA Functional Area: Immobilization TFA Need ID\#: 623

Consequences of Not Filling Need: If these improvements are not made, there will be an increase in the false rejection and subsequent costly remediation of feed batches and missed a opportunity to increase waste loading in canister with the concomitant reduction in canisters produced to vitrify the HLW inventory.

Loss of production due to false rejection of a good feed batch is about 3 days (of 14) per batch. Avoiding this could increase the DWPF attainment by about $2 \%-5 \%$ per year. The improvement in the liquidus model could increase waste loading by up to $5 \%$, with the same reduction in total canister produced to vitrify the HLW inventory ( -300 canister over the DWPF life cycle with over $\$ 100$ million emplacement cost in the Federal Waste Repository). This also would enable DWPF to shut down sooner and reduce ingredient cost.

Privatization Potential: These studies can be performed by outside laboratories.

Current Base Technology and Cost: Existing models allow operation of the DWPF.

Current Baseline Timeline:

SUMMARY OF TFA RESPONSE: The TFA rated the priority of the technical response to this need as \#1. The TFA is providing funding for FY97 and proposes to provide funding in FY98, given available funding. 


\section{Tanks Focus Area $\quad$ Need Title: Develop Lower Cost Higher Capacity Melters for Site Needs \\ DWPF Which are Consistent with Remote Operability \\ Site: SRS \\ TFA Functional Area: Immobilization \\ Site ID\#: SR-2012 TFA Need ID\#: 624}

SITE NEED:

Need Description: The cost of a DWPF melter to vitrify $220 \mathrm{lbs} / \mathrm{hr}$ of an aqueous high level waste stream is approximately $\$ 20$ million. Melter changeout requires long periods of outage time. A lower cost long life melter is desirable.

Waste stream: DWPF melter

Functional Performance Requirements: The melter must vitrify a waste stream with an approximate composition of $45 \mathrm{wt} . \%$ solids in a water slurry with a density of 1.4 . The major elements present in the solids are Al@ 2 wt.\% elemental, B@ 2 wt.\% elemental, Fe@8wt.\% elemental, and Si@24 wt.\% elemental. The calcine factor for the waste solids is approximately 0.87 . Melter temperature, other than those in the cold cap, must not be less than $1050^{\circ} \mathrm{C}$ to assure that glass quality requirements are met. Maximum temperature is $1200^{\circ} \mathrm{C}$ to assure that DWPF off-gas systems are not overloaded (i.e., Cs volatility) and materials of construction limitations (electrode surface temperature) are not exceeded.

Schedule Requirements: Schedule is driven primarily by potential cost savings and available funding.

Problem Description: The melter is one of the most expensive and most complicated components in the DWPF. In the future, it could also become the production rate limiting component in the plant. A simpler, lower cost melter could result in significant lower life cycle costs for the DWPF.

\section{Justifications:}

Technical Justification: The cost of a DWPF melter to vitrify $220 \mathrm{lbs} / \mathrm{hr}$ of an aqueous high level waste stream is approximately $\$ 20$ million. Melter changeout requires long periods of outage time. A lower cost long life melter is needed.

Regulatory Justification: The cost of a DWPF melter to vitrify $220 \mathrm{lbs} / \mathrm{hr}$ of an aqueous high level waste stream is approximately $\$ 20$ million. Melter changeout requires long periods of outage time. A lower cost long life melter is needed.

ES\&H Justification: A longer life melter will reduce occupational exposure incurred during melter changeout.

Cultural/Stakeholder Factors: N/A

Other Justification: N/A

Consequences of Not Filling Need: Higher capital and operating costs may be incurred if potential lower cost melters are not evaluated.

Privatization Potential: Improvements would probably also be applicable at other DOE sites where vitrification of high level waste is planned for the future, e.g., Hanford and Idaho.

Current Base Technology and Cost: The current baseline technology, joule-heated melter is being successfully operated at DWPF.

\section{Current Baseline Timeline:}

SUMMARY OF TFA RESPONSE: The TFA rated the priority of the technical response to this need as \#58. The TFA proposes to provide funding in FY98-00, given available funding. 


\section{Site Needs}

Site: SRS

Site ID\#: SR-2013
TFA Functional Area: Safety

TFA Need ID\#: 625

\section{SITE NEED:}

Need Description: Develop a passive device that ventilates the waste tank interior. A tank top device is needed to purge the waste tank atmosphere of accumulated hydrogen gas and organic vapor. Such a device would save capital investment for the upgrades scheduled for the old style tanks. In addition, savings would be gained by the avoidance of operation and maintenance cost associated with tank ventilation upkeep.

Functional Performance Requirements: Provide a HEPA barrier between the tank atmosphere and the environment. Provide an air exchange for a filled waste tank (362") air space every 9 days. This volume is approximately 16,000 cubic feet. Device must be passive in nature (e.g. no electricity).

Schedule Requirements: None

\section{Problem Description:}

\section{Justifications:}

Technical Justification: Existing ventilation systems are very old and need replacement.

Regulatory Justification: Existing ventilation systems are very old and need replacement.

ES\&H Justification: Improvements in passive ventilation will reduce the potential for accumulation of flammable vapors in SRS waste tanks.

Cultural/Stakeholder Factors: Extensive interactions with the Defense Nuclear Facility Safety Board, with the Department of Energy, with numerous external consultants and with the local public occur. Changes to the waste tank ventilation design will need to satisfy the safety perspective of these groups.

Other Justification: None identified.

Consequences of Not Filling Need: Maintain the existing active HVAC system until waste removal. Such a device would be a cost avoidance.

\section{Privatization Potential: None}

Current Base Technology and Cost: Simple exhaust fan purging the waste tank air space at a nominal 150$300 \mathrm{cfm}$. The inlet plenum is HEPA filtered and the exhaust plenum is dried and the air is condensed to keep the exhaust HEPA filter dry.

\section{Current Baseline Timeline:}

SUMMARY OF TFA RESPONSE: The TFA rated the priority of the technical response to this need as \#19. The TFA proposes to provide funding in FY98-00, given available funding. 


\begin{tabular}{lll}
\hline Tanks Focus Area & $\begin{array}{l}\text { Need Title: Develop DWPF analytical methods to improve } \\
\text { attainment }\end{array}$ \\
Site Needs & Site: SRS & TFA Functional Area: Immobilization \\
& Site ID\#: SR-2014 & TFA Need ID\#: 626 \\
\hline
\end{tabular}

\section{SITE NEED:}

Need Description: Currently, the DWPF requires the sampling of its feed streams for elemental analysis at several points during the preparation of a waste batch for melter pouring. These analyses require very lengthy and laborious sample preparation steps in remote shielded cells prior to lab elemental analysis by ICP atomic emission spectrometry. Depending on sample type and analytical methodology employed, a single set of these analyses require from 24 to 72 hours to complete. Since the process is a batch process with no "hold" tanks, most of this analysis time is "critical path" time for the process. Thus, a reduction in this analytical time translates directly into process attainment improvement. Ideally, the need is for elemental analysis system which can be operated in a remote cell with very little, if any, pretreatment or preparation of waste slurry samples for analysis.

In addition to SRS, this technology improvement has direct applicability to West Valley Nuclear Services Vitrification Plant, Hanford, and INEEL waste processing analytical processes.

Waste stream: SRS HLW Sludge and Slurry, DWPF

Functional Performance Requirements: System/methodology must have the ability to measure the following components in SRS waste slurries at 10 to $25 \mathrm{wt} \%$ total solids and waste slurry (25\%)/glass frit (75\%) mixtures at 40 to $60 \mathrm{wt} \%$ total solids:

(Waste Slurries)

Component Nominal Concentration (Wt \% on dried solids basis)

$\begin{array}{ll}\mathrm{Al} & 6 \\ \mathrm{Ca} & 2 \\ \mathrm{Cr} & 0.1 \\ \mathrm{Cu} & 1 \\ \mathrm{Fe} & 23 \\ \mathrm{~K} & 1 \\ \mathrm{Li} & 0.1 \\ \mathrm{Mg} & 1 \\ \mathrm{Mn} & 3 \\ \mathrm{Na} & 7 \\ \mathrm{Ni} & 0.3 \\ \mathrm{Si} & 0.7 \\ \mathrm{Ti} & 1 \\ \mathrm{U} & 3 \\ \mathrm{Zr} & 0.1\end{array}$


Tanks Focus Area Site Needs
Need Title: Develop DWPF analytical methods to improve attainment

Site: SRS

Site ID\#: SR-2014
TFA Functional Area: Immobilization TFA Need ID\#: 626

\section{(Waste/Frit Mixtures) \\ Component Nominal Concentration (Wt \% on glass)}

$\begin{array}{ll}\mathrm{Al} & 2 \\ \mathrm{Ca} & 1 \\ \mathrm{Cr} & 0.1 \\ \mathrm{Cu} & 0.3 \\ \mathrm{Fe} & 8 \\ \mathrm{~K} & 1 \\ \mathrm{Li} & 2 \\ \mathrm{Mg} & 1 \\ \mathrm{Mn} & 1 \\ \mathrm{Na} & 9 \\ \mathrm{Ni} & 0.1 \\ \mathrm{Si} & 23 \\ \mathrm{Ti} & 0.5 \\ \mathrm{U} & 1 \\ \mathrm{Zr} & 0.1\end{array}$

Measurements must exhibit a precision on four replicate measurements of $<8 \% \mathrm{RSD}$. Accuracy as compared against consensus Corning or PNNL glass standards should be within $8 \%$ of theoretical values.

Schedule Requirements: Needed within next 1 to 3 years to minimize attainment impacts on DWPF.

Problem Description: This task will likely require a combination of new R\&D and the application of existing technologies. Experience in radioactive remoting of equipment and instrumentation is essential.

\section{Justifications:}

Technical Justification: Currently, the DWPF requires the sampling of its feed streams for elemental analysis at several points during the preparation of a waste batch for melter pouring. These analyses require very lengthy and laborious sample preparation steps in remote shielded cells prior to lab elemental analysis by ICP atomic emission spectrometry. Depending on sample type and analytical methodology employed, a single set of these analyses require from 24 to 72 hours to complete. Since the process is a batch process with no "hold" tanks, most of this analysis time is "critical path" time for the process. Thus, a reduction in this analytical time translates directly into process attainment improvement.

Regulatory Justification: Currently, the DWPF requires the sampling of its feed streams for elemental analysis at several points during the preparation of a waste batch for melter pouring. These analyses require very lengthy and laborious sample preparation steps in remote shielded cells prior to lab elemental analysis by ICP atomic emission spectrometry. Depending on sample type and analytical methodology employed, a single set of these analyses require from 24 to 72 hours to complete. Since the process is a batch process with no "hold" tanks, most of this analysis time is "critical path" time for the process. Thus, a reduction in this analytical time translates directly into process attainment improvement.

\section{ES\&H Justification: N/A}

\section{Cultural/Stakeholder Factors: N/A}

Other Justification: None

Consequences of Not Filling Need: If DWPF attainment is impacted by lab throughput and canister production is lower than required, waste could potentially remain in storage tanks for a longer period than expected.

\begin{tabular}{lll}
\hline Site Needs Assessment & A.61 Appendix A-Site Needs Database
\end{tabular}




\section{Tanks Focus Area $\quad$ Need Title: Develop DWPF analytical methods to improve attainment}

Site Needs TFA Need ID\#: 626

Privatization Potential: There is not a large commercial market, but there would a substantial market within DOE sites.

Current Base Technology and Cost: (Stated in Needs Description)

Current Baseline Timeline:

SUMMARY OF TFA RESPONSE: The TFA did not develop a technical response to this need and did not rate it since the TFA believes the stated problem has been solved. 


\section{SITE NEED:}

Need Description: Savannah River Site (SRS) has had, for twenty some years, a successful corrosion program for its waste tanks and their cooling coils, using tank chemistry control. Through continuous research, judicious application of research results, and disciplined and vigilant adherence to its corrosion program, SRS has successfully contained nitrate stress corrosion cracking (SCC) in older tanks, from the late '50's through the early '70's. Now, the mechanism of SCC is fairly well understood for our waste system. The newer Type III fully contained tanks designed and built based on site research, have not had any SCC or leaks or any indication of one in some 474 tank-years of service. SRS will continue to rely on its tank chemistry program as its primary means of corrosion control.

However, the in-situ corrosion probes being tested at Hanford may add to our capability to fine tune the amount of tank inhibitor needed, and the response time necessary. It will also enhance our understanding of the mechanism of pitting and general corrosion for our system in the vapor-liquid interface. This new probe with faster response may also help in controlling corrosion for site processing tanks, e.g., ITP/ESP, and evaporator feed tanks, where tank chemistry can undergo rapid changes.

Waste stream: High Level Waste Tanks, SRS F and H Tank Farms

\section{Functional Performance Requirements:}

1. Test probe in simulants to demonstrate correlation with corrosion mechanisms.

2. Demonstrate confidence and reliability of probe signal.

3. Test probe in actual waste tanks: one that is well inhibited and in storage mode, and one undergoing rapid changes and in processing mode.

4. Test the probe's materials of construction for durability and service life estimates.

5. Develop in-tank deployment technique for the probe at the interfacial region.

\section{Schedule Requirements: None}

Problem Description: Characterization of waste tank constituents for corrosion chemistry is important due to the waste being stored in carbon steel tanks. Failure to control the corrosion chemistry can result in tank failure and potential for an environmental release. Failure of a tank would also severely impact operation of the HLW facilities resulting in large production/utility costs.

\section{Justifications:}

Technical Justification: Develop a corrosion probe that provides characterization information without physically sampling material in the waste tanks. Current sampling and analytical methods for liquid phase characterization are very time consuming and do not provide real-time results. A corrosion probe could be of great help in fine tuning SRS tank corrosion chemistry program both in amounts of inhibitors needed and the response time necessary, especially in waste processing tanks. It will also help SRS having a better control on the pitting corrosion in the vapor-liquid interface.

Regulatory Justification: Develop a corrosion probe that provides characterization information without physically sampling material in the waste tanks. Current sampling and analytical methods for liquid phase characterization are very time consuming and do not provide real-time results. A corrosion probe could be of great help in fine tuning SRS tank corrosion chemistry program both in amounts of inhibitors needed and the response time necessary, especially in waste processing tanks. It will also help SRS having a better control on the pitting corrosion in the vapor-liquid interface.

ES\&H Justification: Pulling current samples result in personnel exposure, creation of low level radioactive waste, and cost associated with handling and analysis. 
Tanks Focus Area Need Title: In-Tank Corrosion Probe Development Site Needs

Site: SRS

Site ID\#: SR-2015
TFA Functional Area: Safety TFA Need ID\#: 627

Cultural/Stakeholder Factors: N/A

Other Justification: N/A

Consequences of Not Filling Need: Continued analytical cost and personnel exposure and waste generation.

Privatization Potential: The potential for a working system would be very good for similar liquid containing systems.

Current Base Technology and Cost: Dip samples and variable depth samples and traditional analytical techniques.

Current Baseline Timeline:

SUMMARY OF TFA RESPONSE: The TFA is responding to this need through the response to Need ID\#662. 


\section{Tanks Focus Area Site Needs}

Need Title: Demonstrate STPB Hydroxide Flowsheet to Reduce Nitrite Addition, Thereby Reducing ITP Washing Requirements

Site: SRS

Site ID\#: SR-2016

TFA Functional Area: Pretreatment TFA Need ID\#: 628

SITE NEED:

Need Description: A second stage of washing is required to remove the nitrites from the ITP precipitate before feeding to DWPF. The total amount of wash water between the ITP wash and the LWF wash should be minimized for least cost operation. The High Hydroxide process option for ITP simplifies and reduces the precipitate washing step. The original flowsheet is designed to provide a feed to DWPF with a low Na concentration. Washing to the low $\mathrm{Na}$ level requires supplemental addition of $\mathrm{NaOH}$ and $\mathrm{NaNO}_{2}$ to inhibit corrosion. When DWPF changed to acid hydrolysis, it was found necessary to remove the $\mathrm{NaNO}_{2}$ to low levels. This requirement resulted in adding the Late Wash process. The Late Wash process can remove the $\mathrm{NaNO}_{2}$ because it uses stainless steel equipment. The High Hydroxide option recognizes that, during the ITP wash step, the solution is self-inhibiting as long as the hydroxide concentration is high (@2M hydroxide). In this scheme ITP washes only to the lower limit for self-inhibition, which requires no $\mathrm{NaNO}_{2}$ addition. Late Wash, then, completes the wash to the Na level required by DWPF. This will simultaneously lower the $\mathrm{NaNO}_{2}$ level to less than required by DWPF. The ITP wash cycle time will shorten to about one-half the original design time with this scheme, while Late Wash will continue doing the same amount of washing. Late Wash will be washing $\mathrm{Na}$ rather than $\mathrm{NaNO}_{2}$.

This scheme may also reduce the amount of excess STPB required in ITP and LWF. This will reduce the potential amount of benzene released during processing.

Waste stream: SRS HLW Salt and Supernate, In-Tank Processing Facility

Functional Performance Requirements: ITP precipitate transferred to Tank 49 must be corrosion inhibited by high $\mathrm{OH}$ levels plus minimal NaNO2. ITP precipitate must be washed to a solution specific gravity such that the precipitate sinks (s.g. $<1.16-1.18$ ). LWF must continue to wash precipitate to DWPF requirements for $\mathrm{Na}$ and $\mathrm{NO} 2$ levels.

Schedule Requirements: The first opportunity to implement the High Hydroxide Flowsheet is probably for ITP Cycle 2. ITP Cycle 1 is committed presently to following the design flowsheet. Implementing the High Hydroxide Flowsheet at this early opportunity gives many benefits, especially minimum wash water volume $(<1 / 2$ as much) and less operating time for washing in both ITP and Late Wash because of improved filter fluxes and lower total wash water volume.

Problem Description: The High Hydroxide Flowsheet has been described thoroughly in the following three documents:

1. QISS \#316856, approved 4-19-95 by A.H. Scott, submitted by Brooke, Walker \& Hobbs.

2. All-In-1, J.N. Brooke to D.J. McCabe, et.al., 4/23/93, "Comparison of Two Sequences for Adding Chemicals \& Solutions to Tank 48 ".

3. Presentation, D.D. Walker, 11/93, "In-Tank Precipitation Process -- Hydroxide Inhibited Flowsheet".

4. D.D. Walker \& D.T. Hobbs, 30 Oct 92, "Alternative Washing Strategy during In Tank Precipitation

Processing," report \#WSRC-RP-92-1259

Document 4 contains a complete description of the proposed washing strategy plus complete material balances with comparison to the design flowsheet. The potential benefit for lowering benzene levels must be determined by-laboratory testing.

\section{Justifications:}

Technical Justification: The High Hydroxide process option for ITP simplifies and reduces the precipitate washing step. The original flowsheet is designed to provide a feed to DWPF with a low Na concentration. Washing to the low $\mathrm{Na}$ level requires supplemental addition of $\mathrm{NaOH}$ and $\mathrm{NaNO} 2$ to inhibit corrosion. When DWPF changed to acid hydrolysis, it was found necessary to remove the NaNO2 to low levels. This requirement resulted in adding the Late Wash process. The Late Wash process can remove the NaNO2 because 


\begin{tabular}{ll}
\hline Tanks Focus Area & Need Title: Demonstrate STPB Hydroxide Flowsheet to Reduce \\
Nitrite Addition, Thereby Reducing ITP Washing Requirements
\end{tabular}

Site: SRS

TFA Functional Area: Pretreatment

Site ID\#: SR-2016 TFA Need ID\#: 628

it uses stainless steel equipment. The High Hydroxide option recognizes that, during the ITP wash step, the solution is self-inhibiting as long as the hydroxide concentration is high (@2M hydroxide). In this scheme ITP washes only to the lower limit for self-inhibition, which requires no $\mathrm{NaNO}_{2}$ addition. Late Wash, then, completes the wash to the $\mathrm{Na}$ level required by DWPF. This will simuitaneously lower the $\mathrm{NaNO}_{2}$ level to less than required by DWPF. The ITP wash cycle time will shorten to about one-half the original design time with this scheme, while Late Wash will continue doing the same amount of washing. Late Wash will be washing Na rather than $\mathrm{NaNO}_{2}$.

This scheme may also reduce the amount of excess STPB required in ITP and LWF. This will reduce the potential amount of benzene released during processing.

Regulatory Justification: The High Hydroxide process option for ITP simplifies and reduces the precipitate washing step. The original flowsheet is designed to provide a feed to DWPF with a low Na concentration. Washing to the low $\mathrm{Na}$ level requires supplemental addition of $\mathrm{NaOH}$ and $\mathrm{NaNO}_{2}$ to inhibit corrosion. When DWPF changed to acid hydrolysis, it was found necessary to remove the $\mathrm{NaNO}_{2}$ to low levels. This requirement resulted in adding the Late Wash process. The Late Wash process can remove the NaNO2 because it uses stainless steel equipment. The High Hydroxide option recognizes that, during the ITP wash step, the solution is self-inhibiting as long as the hydroxide concentration is high (@2M hydroxide). In this scheme ITP washes only to the lower limit for self-inhibition, which requires no $\mathrm{NaNO}_{2}$ addition. Late Wash, then, completes the wash to the $\mathrm{Na}$ level required by DWPF. This will simultaneously lower the $\mathrm{NaNO}_{2}$ level to less than required by DWPF. The ITP wash cycle time will shorten to about one-half the original design time with this scheme, while Late Wash will continue doing the same amount of washing. Late Wash will be washing $\mathrm{Na}$ rather than $\mathrm{NaNO}_{2}$.

This scheme may also reduce the amount of excess STPB required in ITP and LWF. This will reduce the potential amount of benzene released during processing.

ES\&H Justification: Potential for lowered benzene emissions.

Cultural/Stakeholder Factors: There are no known stakeholder concerns of a non-regulatory nature.

\section{Other Justification:}

Consequences of Not Filling Need: The design flowsheet will be continued at the present levels and costs.

Privatization Potential: N/A

Current Base Technology and Cost: The design flowsheet as described in the ITP operating procedures.

Current Baseline Timeline:

SUMMARY OF TFA RESPONSE: The TFA rated the priority of the technical response to this need as \#59. The TFA proposes to provide funding in FY98, given available funding. 


\section{Tanks Focus Area Site Needs}

Need Title: Demonstrate Use of Sintered Metal Filters in Place

of HEPA Filters and Paper Filters on Air Sampling Systems

Site: SRS

Site ID\#: SR-2017
TFA Functional Area: Safety TFA Need ID\#: 629

\section{SITE NEED:}

Need Description: HEPA filters are used throughout the SRS complex to assure that air emissions to the environment are free of radioactive particulates. Filters are generally constructed of a 0.013 inch thick glass fiber material. Required minimum HEPA standards include $99.97 \%$ capture of 0.3 micrometer diameter aerosol particles.

Typical of the filters in use at SRS is the Flanders Super-Flow® II type GG-F filter. It is constructed of 'fan folded' borosilicate glass fiber paper. HEPA filters in service at SRS waste management have the following typical attributes:

- Two year average life (limited by filter media failure)

- Replaced when any of the following conditions are exceeded

- Pressure drop exceeds 6" wc

- Gamma radiation becomes excessive (due to collected particles)

- Fails $99.97 \%$ DOP test

- Pressure drop limit is determined by the strength of the $0.013 "$ thick filter media

- Water is principal problem encountered with existing HEPAs.

Preheater are installed in the air ducts upstream of most waste management HEPAs in an effort to prevent condensation and subsequent damage to the HEPA.

Use of a HEPA filter constructed of sintered stainless steel will provide a HEPA filter which is not subject to water damage, and can be installed with built in water jets which will be used to wash the filter to reduce radiation and to eliminate to dirt accumulation. Preliminary tests indicate that use of sintered metal filter material eliminates the release of particulates to the atmosphere with the same efficiency as filtration with a fiberglass filter medium, but can be cleaned with water, and is not subject to water damage.

\section{Waste stream: SRS High Level Waste Tanks, SRS H and F Tank Farm}

Functional Performance Requirements: This new development is intended to eliminate failure problems associated with wetting of the filter, and provide a filter whose design includes permanently installed spray wash nozzles which would be used to restore flow to a plugged or partially plugged filter.

Experiments using Mott Metallurgical Co. one micron sintered stainless steel filter media suggest that a waterproof HEPA filter could be manufactured to replace our existing HEPA filters.

The medium is sintered stainless steel whose particle size is 1 micrometer diameter. SRS testing of the sintered metal filter resulted in data indicating that the material passes the $99.97 \%$ capture requirement using DOP 0.3 micrometer diameter aerosol. Water spray experiments have shown that the medium in unharmed by total immersion, and that water spray is effective at restoring flow through material which was plugged by accumulated atmospheric borne dirt. Water sprayed on the dirty side of a vertical filter appears to flush the accumulated "dirt" down the "dirty" side. Previous experiments by Lawrence Livermore National Laboratory [LLNL] researchers attempting to clean steel filters by backpulsing air (from the clean side of the filter) failed due to high moisture. The LLNL filters were constructed of 2 micron diameter stainless steel fibers whereas the proposed sintered filter would be constructed of 1 micron particles which are formed into a 0.013 inches thick plate.

SRS experimental evidence suggests that use of $36 " \mathrm{n}$. 36" flat Mott Corp. $1 \mu$ material will provide $555 \mathrm{cfm}$ flow at 157 inches water column of vacuum. Waste tank installation will require replacement of the $1 \mathrm{hp}$ exhaust fan with a $15 \mathrm{hp}$ exhaust fan.

1) Very thin [0.013 inch] filter medium stops particle transmission at the exposed surface of the medium. The particles collected are more easily removed from the relatively smooth surface of the filter than particles collected within the bulk of a thicker filter medium such as stainless steel wire mesh. Use of thin sheet of sintered stainless steel makes the filter washable from dirty side. 


\section{Tanks Focus Area Site Needs}

Need Title: Demonstrate Use of Sintered Metal Filters in Place of HEPA Filters and Paper Filters on Air Sampling Systems

Site: SRS

Site ID\#: SR-2017
TFA Functional Area: Safety

TFA Need ID\#: 629

2) Relatively rigid [not flexible] stainless steel construction makes the filter resistant to mechanical damage.

3) Material will tolerate higher pressure drop than glass paper type HEPA.

4) Material could withstand high temperatures without damage or fire hazard.

The 51 SRS waste tanks each use $500 \mathrm{cfm}$ rated glass/paper HEPA filters to prevent radioactive contamination of the environment from the tank's purge off gas. Standard requirement is that a HEPA block $99.97 \%$ of 0.3 micrometer diameter particles.

\section{Schedule Requirements:}

Problem Description:

Justifications:

Technical Justification: HEPA filter replacement is an issue with respect to personnel radiation exposure and contamination, and HEPA filter disposal cost. All waste tank purge HEPA systems include a preheater in an attempt to prevent condensation of water on the HEPA. The sintered steel HEPA will not be damaged when wetted.

Regulatory Justification: HEPA filter replacement is an issue with respect to personnel radiation exposure and contamination, and HEPA filter disposal cost. All waste tank purge HEPA systems include a preheater in an attempt to prevent condensation of water on the HEPA. The sintered steel HEPA will not be damaged when wetted.

ES\&H Justification: N/A

Cultural/Stakeholder Factors: None

Other Justification: None identified

Consequences of Not Filling Need:

Privatization Potential: Pall Filter Company and Nuclear Filter Technology Co. have strong interest in sintered metal filter technology for use on a HEPA filter. They have constructed sintered wire type filters. The Mott filter material has not been used for HEPA application because of the high pressure drop required to maintain flow. The Mott sintered particle filter has very smooth surface compared to the surface of the sintered wire type filters. SRS testing to date has focused of the Mott material.

Current Base Technology and Cost: SRS currently employs conventional borosilicate glass paper filters.

Current Baseline Timeline:

SUMMARY OF TFA RESPONSE: The TFA rated the priority of the technical response to this need as \#20. The TFA proposes to provide funding in FY98-00, given available funding. 


\section{Tanks Focus Area Site Needs}

Need Title: Develop Alternatives to Monosodium Titanate for

Alkaline Strontium and Actinide Removal

Site: SRS

Site ID\#: SR-2018
TFA Functional Area: Pretreatment TFA Need ID\#: 630

\section{SITE NEED:}

Need Description: Monosodium titanate (MST) is used for removal of radioactive strontium and actinides from alkaline high level waste (HLW) in the In-Tank Precipitation process. The vendor that supplies MST has had difficulty in producing material that meets the specification for both particle size and radionuclide removal. Establishing multiple vendors to supply the material would ensure a reliable supply. Also, the MST causes a $50 \%$ decrease in the filter flow rate due to the presence of fine particulates. Increasing the particle size of MST to avoid impacting the filter performance is not an option because settling may occur in Tank $48 \mathrm{H}$, and may reduce the radionuclide removal efficiency.

\section{Waste stream: ITP Tank 48}

Functional Performance Requirements: A strontium-specific ion exchange material is needed. There are currently no specifications for actinide removal because the current formulation is adequate. If the formulation were modified, the new material must be proven to meet the Saltstone acceptance criteria for actinides. An improvement in the preference for removing plutonium vs. uranium would be advantageous. The material must exhibit a strontium decontamination factor at ambient temperature of 150 using a standardized test. The decontamination factor must be achieved using a solution that contains $5.0 \mathrm{M}$ sodium ions as a mixture of hydroxide, nitrate, and nitrite salts, and is saturated with strontium. The material must be completely insoluble and must not significantly impact the Saltstone process. The material must be stable in strong caustic (1 M hydroxide ion), nitrate $(3 \mathrm{M})$, and nitrite ions ( $1 \mathrm{M})$ to $65 \mathrm{C}$ for a period of at least 60 days. The agent must tolerate radiation fields exceeding $10 \mathrm{Ci} / \mathrm{L}$ of $\mathrm{Cs}-137$ for two years. The material, when mixed with potassium tetraphenylborate precipitate, must be filterable at reasonable flow rates $(0.25 \mathrm{gpm} / \mathrm{ft} 2$ at $30 \mathrm{psi}$ with $1 \mathrm{wt} \%$ solids and 0.5 micron filters). The material must be soluble in dilute oxalic acid to permit filter cleaning and in concentrated formic acid to be compatible with DWPF vitrification.

\section{Schedule Requirements: No applicable schedule tie}

Problem Description: Previous studies focused on use of MST for strontium removal. This material has proven to be suitable for ITP, but improvements in the filter flow rate would dramatically improve the process throughput.

\section{Justifications:}

Technical Justification: Monosodium titanate (MST) is used for removal of radioactive strontium and actinides from alkalineHLW in the In-Tank Precipitation process. The vendor that supplies MST has had difficulty in producing material that meets the specification for both particle size and radionuclide removal. Establishing multiple vendors to supply the material would ensure a reliable supply. Also, the MST causes a $50 \%$ decrease in the filter flow rate due to the presence of fine particulates. Increasing the particle size of MST to avoid impacting the filter performance is not an option because settling may occur in Tank $48 \mathrm{H}$, and may reduce the radionuclide removal efficiency.

Regulatory Justification: Monosodium titanate (MST) is used for removal of radioactive strontium and actinides from alkaline HLW in the In-Tank Precipitation process. The vendor that supplies MST has had difficulty in producing material that meets the specification for both particle size and radionuclide removal. Establishing multiple vendors to supply the material would ensure a reliable supply. Also, the MST causes a $50 \%$ decrease in the filter flow rate due to the presence of fine particulates. Increasing the particle size of MST to avoid impacting the filter performance is not an option because settling may occur in Tank $48 \mathrm{H}$, and may reduce the radionuclide removal efficiency.

\section{ES\&H Justification: N/A}




\begin{tabular}{lll}
\hline Tanks Focus Area & \multicolumn{2}{l}{ Need Title: Develop Alternatives to Monosodium Titanate for } \\
Site Needs & Alkaline Strontium and Actinide Removal \\
& & \\
& Site: SRS & TFA Functional Area: Pretreatment \\
& Site ID\#: SR-2018 & TFA Need ID\#: 630 \\
\hline
\end{tabular}

Cultural/Stakeholder Factors: Extensive interactions with the Defense Nuclear Facilities Safety Board, with the Department of Energy, with numerous external consultants and with the local public occur. These interactions ensure the safe operation of the facility.

Other Justification: None identified

Consequences of Not Filling Need: Timely completion of waste removal activities for the Savannah River Site centers on success of this program.

Privatization Potential: Department of Energy encourages efforts by commercial firms to treat waste of this nature. Advances in individual program elements offer high potential for commercialization.

Current Base Technology and Cost: NaTPB precipitation of cesium.

Current Baseline Timeline:

SUMMARY OF TFA RESPONSE: The TFA did not prepare a separate technical response to this need. Instead, it has been covered within the response to Need ID\# 618. 
Tanks Focus Area Site Needs
Need Title: Alternatives for DWPF Melter Feed REDOX

Adjustment

Site: SRS

Site ID\#: SR-2019
TFA Functional Area: Immobilization TFA Need ID\#: 631

SITE NEED:

Need Description: DWPF can reduce operating risk and level of Technical Safety Requirement (TSR) control by eliminating hydrogen and ammonia production during feed preparation.

Waste stream: SRS DWPF melter feed

Functional Performance Requirements: Identify an alternative to formic acid for adjusting the redox potential of melter feed so as not to produce hydrogen or ammonia. This reductant must reduce mercury to its elemental form and not reduce noble metals or copper. The REDOX state of the feed must be with iron partially reduced such that $0-20 \%$ of it is in the ferrous state.

Schedule Requirements: No applicable schedule tie.

Problem Description: Hydrogen can make explosive mixtures with air. Ammonia can react with nitrate (always present) in vents and produce solid ammonium nitrate, which is can be explosive, under certain conditions. The Technical Safety Requirements in place are cumbersome and costly to meet.

Justifications:

Technical Justification: DWPF would enhance its intrinsic safety posture and eliminate the time, money and effort required to administer the TSRs for hydrogen and ammonia control.

Regulatory Justification: DWPF would enhance its intrinsic safety posture and eliminate the time, money and effort required to administer the TSRs for hydrogen and ammonia control.

ES\&H Justification: N/A

Cultural/Stakeholder Factors: N/A

Other Justification: None identified

Consequences of Not Filling Need: DWPF will continue to operate with the hydrogen and ammonia TSRs and their attendant cost and administrative burden.

Privatization Potential: The literature review, bench testing and evaluation of potential new reductants could be done by a private concern.

Current Base Technology and Cost: DWPF Uses formic acid as a reductant. Its process performance is satisfactory, but hydrogen and ammonia are produces. DWPF has Technical Safety Requirements and engineered controls in place to control this hazard, but the administration and equipment maintenance and operation is burdensome.

Current Baseline Timeline:

SUMMARY OF TFA RESPONSE: The TFA rated the priority of the technical response to this need as \#50. The TFA proposes to provide funding in FY98-99, given available funding. 


\begin{tabular}{lll}
\hline Tanks Focus Area & $\begin{array}{l}\text { Need Title: Process Improvements to Maximize Saltstone Waste } \\
\text { Loading }\end{array}$ \\
Site Needs & $\begin{array}{l}\text { Site: SRS } \\
\text { Site ID\#: SR-2020 }\end{array}$ & $\begin{array}{l}\text { TFA Functional Area: Pretreatment } \\
\text { TFA Need ID\#: } 632\end{array}$ \\
& &
\end{tabular}

SITE NEED:

Need Description: Saltstone, as currently formulated, has been demonstrated to produce an acceptable waste form using salt solution containing 10 to $32 \mathrm{wt} \%$ soluble sodium salts, corresponding to as high as $6.5 \mathrm{Molar}$ sodium salts in the waste stream to be treated, based on the average composition of the salt contaminants. Salt solution is processed to produce saltstone based on the water content of the salt solution processed, since the hydration of the dry materials used in the production of saltstone leads to the formation of a stable solid suitable for disposal. Processing salt solution containing salt concentrations near the upper end of the demonstrated concentration range is desirable to minimize the volume of saltstone produced, since each gallon of liquid waste generates approximately 1.8 gallons of solid saltstone that must be disposed in the saltstone disposal vaults located in the SDF. Present upstream processes (ITP and ETF) project up to 130 million gallons of salt solution containing 20 to $25 \mathrm{wt} \%$ sodium salts (4 to 5 Molar sodium) will be generated from processing existing HLW in the $\mathrm{F}$ - and $\mathrm{H}$-Area Tank Farms, requiring about 120 vault cells (ten 12 -cell vaults in the present vault configuration) for ultimate disposal in the SDF. Projected treatment and disposal costs for salt solution converted to saltstone is $\$ 4$ to $\$ 5$ per gallon of solution (about $\$ 2.50$ per gallon of saltstone). By simply evaporating the existing salt solution from the current approximate specific gravity of 1.23 to a specific gravity of 1.30 the volume of saltstone generated could be reduced by as much as $20 \%$, effectively eliminating the need for at least one of the disposal vaults in the SDF and the processing of at least 12 million gallons of waste into saltstone, corresponding to a direct cost savings of $\$ 40$ to $\$ 60$ million dollars in direct disposal costs for saltstone.

Waste stream: Decontaminated Salt Solution/ETF Bottoms/Saltstone, SRS/Z-Area Saltstone Disposal Facility (SDF).

Functional Performance Requirements: Provide an intermediate treatment process to receive aqueous salt solutions from ITP and/or ETF to produce salt solution at a specific gravity of about 1.30 suitable for transfer to the existing Salt Solution Hold Tank located in Z-Area. Sprint capacity to handle up to 650,000 gallons of influent salt solution (sp. g. of 1.2 to 1.25 ) in a two-week period at an influx rate of up to 120 gallons per minute, and an annual receipt capacity of up to 8 million gallons per year. In this same two-week period, Z-Area shall be able to receive salt solution at a comparable rate from this intermediate treatment facility. Ramping up to this influent capacity over a 2-year period is acceptable. This treatment process shall reduce the annualized volumetric flow to Z-Area by at least $10 \%$, based on the current projections of salt solution compositions from ITP and/or ETF. Total sodium concentration in the solution shall not exceed 6.5 moles/Liter, specific gravity shall be in the range of 1.26 to $1.32, \mathrm{pH}$ of the solution shall be greater than 10 , and temperature of the solution at the time of delivery to the SSHT shall be less than 350C. Concentrations of hazardous contaminants and radioactive contaminants shall be within the current Waste Acceptance Criteria for Z-Area, which assure that saltstone will meet disposal criteria as non-hazardous, low-level radioactive waste. Secondary waste streams (aqueous effluents or vapor emissions) generated by this intermediate treatment shall either be suitable for direct release to the general environment or be suitable for treatment in an existing facility at the SRS (for example, aqueous condensate could be transferred to the ETF for treatment prior to release to the environment).

Schedule Requirements: Not applicable. Present saltstone production process is acceptable, but improvements to reduce salt solution volume to be processed is desirable as a route to reduce overall cost of saltstone production and disposal. Implementation prior to FY2000 is desirable.

Problem Description: Potential cost savings provide the incentive for this interim treatment using proven technology.

\section{Justifications:}

Technical Justification: Saltstone, as currently formulated, has been demonstrated to produce an acceptable waste form using salt solution containing 10 to $32 \mathrm{wt} \%$ soluble sodium salts, corresponding to as high as 6.5 Molar sodium salts in the waste stream to be treated, based on the average composition of the salt contaminants.

$\begin{array}{lll}\text { Site Needs Assessment } & \text { A.72 Appendix A - Site Needs Database }\end{array}$




\section{Tanks Focus Area Need Title: Process Improvements to Maximize Saltstone Waste \\ Loading}

Site Needs

Site: SRS

Site IDH: SR-2020
TFA Functional Area: Pretreatment TFA Need ID\#: 632

Salt solution is processed to produce saltstone based on the water content of the salt solution processed, since the hydration of the dry materials used in the production of saltstone leads to the formation of a stable solid suitable for disposal. Processing salt solution containing salt concentrations near the upper end of the demonstrated concentration range is desirable to minimize the volume of saltstone produced, since each gallon of liquid waste generates approximately 1.8 gallons of solid saltstone that must be disposed in the saltstone disposal vaults located in the SDF. Present upstream processes (ITP and ETF) project up to 130 million gallons of salt solution containing 20 to $25 \mathrm{wt} \%$ sodium salts ( 4 to 5 Molar sodium) will be generated from processing existing HLW in the F-and H-Area Tank Farms, requiring about 120 vault cells (ten 12 -cell vaults in the present vault configuration) for ultimate disposal in the SDF. Projected treatment and disposal costs for salt solution converted to saltstone is $\$ 4$ to $\$ 5$ per gallon of solution (about $\$ 2.50$ per gallon of saltstone). By simply evaporating the existing salt solution from the current approximate specific gravity of 1.23 to a specific gravity of 1.30 the volume of saltstone generated could be reduced by as much as $20 \%$, effectively eliminating the need for at least one of the disposal vaults in the SDF and the processing of at least 12 million gallons of waste into saltstone, corresponding to a direct cost savings of $\$ 40$ to $\$ 60$ million dollars in direct disposal costs for saltstone.

Regulatory Justification: Saltstone, as currently formulated, has been demonstrated to produce an acceptable waste form using salt solution containing 10 to $32 \mathrm{wt} \%$ soluble sodium salts, corresponding to as high as 6.5 Molar sodium salts in the waste stream to be treated, based on the average composition of the salt contaminants. Salt solution is processed to produce saltstone based on the water content of the salt solution processed, since the hydration of the dry materials used in the production of saltstone leads to the formation of a stable solid suitable for disposal. Processing salt solution containing salt concentrations near the upper end of the demonstrated concentration range is desirable to minimize the volume of saltstone produced, since each gallon of liquid waste generates approximately 1.8 gallons of solid saltstone that must be disposed in the saltstone disposal vaults located in the SDF. Present upstream processes (ITP and ETF) project up to 130 million gallons of salt solution containing 20 to $25 \mathrm{wt} \%$ sodium salts ( 4 to 5 Molar sodium) will be generated from processing existing HLW in the F- and H-Area Tank Farms, requiring about 120 vault cells (ten 12-cell vaults in the present vault configuration) for ultimate disposal in the SDF. Projected treatment and disposal costs for salt solution converted to saltstone is $\$ 4$ to $\$ 5$ per gallon of solution (about $\$ 2.50$ per gallon of saltstone). By simply evaporating the existing salt solution from the current approximate specific gravity of 1.23 to a specific gravity of 1.30 the volume of saltstone generated could be reduced by as much as $20 \%$, effectively eliminating the need for at least one of the disposal vaults in the SDF and the processing of at least 12 million gallons of waste into saltstone, corresponding to a direct cost savings of $\$ 40$ to $\$ 60$ million dollars in direct disposal costs for saltstone.

ES\&H Justification: Changes to the composition/loading of saltstone could impact the potential for exposure and contamination.

Cultural/Stakeholder Factors: The saltstone facility has been discussed at the local level including public meetings and hearings with the Citizens Advisory Board (CAB).

Other Justification: There are no other concerns or justifications.

Consequences of Not Filling Need: Cost of treatment and disposal of saltstone depends directly on the volume of salt solution processed. Higher volumes of saltstone waste require more disposal units (vaults) and costs related to a larger landfill needed for disposal.

\section{Privatization Potential: High}

Current Base Technology and Cost: Existing technology would be applied. Installation and operation of an evaporator was included as part of one proposal in the recent vendor forum. Projected time of installation and operation was estimated to be less than 2 years in the proposal for a turnkey installation, with an option have the facility operated by the vendor included in the proposal. 


\section{Tanks Focus Area Need Title: Process Improvements to Maximize Saltstone Waste \\ Loading}

Site Needs

Site: SRS

Site ID\#: SR-2020

TFA Functional Area: Pretreatment TFA Need ID\#: 632

\section{Current Baseline Timeline:}

SUMMARY OF TFA RESPONSE: The TFA rated the priority of the technical response to this need as \#42. The TFA proposes to provide funding in FY98-99, given available funding. 


\section{Tanks Focus Area} Site Needs
Need Title: Enhance Equipment Design and Operability of the

DWPF Melter System; Improved Melter Pour Spout Cleaning

Site: SRS

Site ID\#: SR-2121

TFA Functional Area: Immobilization TFA Need ID\#: 633

\section{SITE NEED:}

Need Description: The DWPF Melter pour spout accumulates glass and crystalline deposits in three areas. These deposits must be periodically removed from the pour spout to maintain melter operability. Improved cleaning techniques are required to remove these deposits from the pour spout.

\section{Waste stream: DWPF melter}

Functional Performance Requirements: Cleaning techniques are required to remove glass and crystalline deposits from the DWPF Melter pour spout. These techniques must satisfy the following criteria:

(1) Must remove as much of the accumulated material as possible, including that accumulated behind the disengagement points (45o back cut knife edge). This material consists of high level nuclear waste glass and waste glass devitrification (crystalline) products.

(2) Cannot damage or deform the pour spout or associated equipment.

(3) Must be accomplished remotely. A telerobotic manipulator is available which reaches the melter pour spout. Other methods may be acceptable; however, the only access to the melter is via overhead crane hook and impact wrench.

(4) Cannot get stuck in the pour spout. Must be easily removed.

(5) Cannot adversely impact waste form acceptance criteria.

Schedule Requirements: There is a current need for pour spout cleaning. Cleaning techniques should be developed in FY97 to ensure that DWPF melter attainment is maintained sufficiently high to meet production requirements.

Problem Description: The DWPF Melter pour spout is approximately $25^{\prime \prime}$ long. It consists of three vertically oriented cylindrical sections of increasing diameter from top to bottom; 2", 3" and 3.96". The intersections between these sections are 45 o back cut knife edges which are intended to serve as molten glass disengagement points. Under normal operation the first disengagement point (2" diam. cylinder) is where the pour stream begins a free-fall into the glass receiving canister. (The glass stream should not contact anything else after leaving that edge.) The pour spout is externally heated from within approximately 2 " from the top to 3 " from the bottom.

The melter pour spout accumulates glass and crystalline deposits in three areas. The upper (heated) sidewalls, behind the glass disengagement points, and at the bottom. These deposits can adversely impact melter performance by deflecting the melt pour stream and ultimately causing partial or complete pluggage of the melter discharge area. Accumulated material on the upper sidewalls and disengagement points (knife edges) of the pour spout can contribute to a phenomenon referred to as "wicking" of the pour stream where glass flows down the side walls rather than free-falling from the disengagement point into the canister. When wicking occurs, significant glass buildup occurs in the lower (unheated) end of the spout. This causes further diversion of the pour stream which contacts the wall of the bellows assembly which mates the pour spout to the canister. Glass accumulation and resultant pluggage in this section is common.

When pour spout and bellows pluggage occur, much time is required to remove accumulated glass and allow waste glass production to resume. This significantly impacts melter attainment and glass production. Severe pluggage can also jeopardize the glass melter.

Methods are required to periodically clean the pour spout to help minimize glass "wicking", improve pouring behavior, lower the frequency of pluggage incidents, and shorten duration of recovery from pluggage.

\section{Justifications:}




\section{Tanks Focus Area $\quad$ Need Title: Enhance Equipment Design and Operability of the Site Needs \\ DWPF Melter System; Improved Melter Pour Spout Cleaning}

Site: SRS

TFA Functional Area: Immobilization

Site ID\#: SR-2121 TFA Need ID\#: 633

Technical Justification: Improved pour spout cleaning techniques will help minimize the occurrence of glass "wicking", improve pouring behavior, lower the frequency of pluggage incidents, and shorten duration of recovery from pluggage.

Regulatory Justification: Improved pour spout cleaning techniques will help minimize the occurrence of glass "wicking", improve pouring behavior, lower the frequency of pluggage incidents, and shorten duration of recovery from pluggage.

ES\&H Justification: If pluggage occurs which results in replacement of the DWPF Melter, significant personnel radiation exposure will occur during melter change out.

\section{Cultural/Stakeholder Factors: N/A}

Other Justification: None identified

Consequences of Not Filling Need: There will be continued negative impact on DWPF attainment and an increased risk of loss of the melter due to pluggage.

Privatization Potential: Limited, this problem seems to be limited to HLW vitrification processes. Similar problems have occurred in the commercial glass industry; however, their glasses and melters are significantly different and their solutions have been "hands-on".

Current Base Technology and Cost: Existing tools (Telerobotic Manipulator and associated tooling) are being used to mechanically clean the pour spout.

\section{Current Baseline Timeline:}

SUMMARY OF TFA RESPONSE: The TFA rated the priority of the technical response to this need as \#26. The TFA proposes to provide funding in FY98-99, given available funding. The response to this need also satisfies Need ID\# 634 and 635. 
Tanks Focus Area Site Needs
Need Title: Enhance Equipment Design and Operability of the

DWPF Melter System; Characterize Causes of Pour Spout

Site: SRS

Site ID\#: SR-2022
TFA Functional Area: Immobilization TFA Need ID\#: 634

\section{SITE NEED:}

Need Description: The DWPF Melter pour spout accumulates glass and crystalline deposits in three areas. These deposits result in further glass deposition and pluggage in the bellows assembly which couples the glass receiving canister to the melter. The causes of this accumulation and pluggage must be characterized as a part of the effort to eliminate the problem.

\section{Waste stream: DWPF melter}

Functional Performance Requirements: Characterization of the pour spout accumulation/pluggage must include

(1) Evaluation of the importance of glass chemistry including composition, physical properties, redox state, devitrification.

(2) Evaluation of the physics of glass pouring.

(3) Evaluation of the pour spout design including physical configuration, thermal profile and materials aspects.

(4) Evaluation of relationship between melter, pour spout, bellows assembly, and canister.

(5) Evaluation of effect of melter/pour spout pressure control systems.

(6) Recommendations for optimization of items 1-5 above.

Schedule Requirements: For this evaluation to impact re-design and implementation for DWPF Melter-2 it must be complete by end of FY97. For it to impact re-design and implementation for DWPF Melter-3 it must be complete by end of FY98. For DWPF Melter-4 and future melters it must be complete by end of FY99.

Problem Description: The DWPF Melter pour spout is approximately $25^{\prime \prime}$ long. It consists of three vertically oriented cylindrical sections of increasing diameter from top to bottom; 2", 3 " and 3.96". The intersections between these sections are 450 back cut knife edges which are intended to serve as molten glass disengagement points. Under normal operation the first disengagement point (2" diam. cylinder) is where the pour stream begins a free-fall into the glass receiving canister. (The glass stream should not contact anything else after leaving that edge.) The pour spout is externally heated from within approximately 2 " from the top to 3 " from the bottom.

The melter pour spout accumulates glass and crystalline deposits in three areas. The upper (heated) sidewalls, behind the glass disengagement points, and at the bottom. These deposits can adversely impact melter performance by deflecting the melt pour stream and ultimately causing partial or complete pluggage of the melter discharge area. Accumulated material on the upper sidewalls and disengagement points (knife edges) of the pour spout can contribute to a phenomenon referred to as "wicking" of the pour stream where glass flows down the side walls rather than free-falling from the disengagement point into the canister. Another suspected contributor to wicking is the melter/pour spout pressure control system which affects the pour stream size and position. When wicking occurs, significant glass buildup occurs in the lower (unheated) end of the spout. This causes further diversion of the pour stream which contacts the wall of the bellows assembly which connects the pour spout to the canister. Glass accumulation and resultant pluggage in this section is common.

When pour spout and bellows pluggage occur, much time is required to remove accumulated glass and allow waste glass production to resume. This significantly impacts melter attainment and glass production. Severe pluggage can also jeopardize the glass melter.

The pluggage phenomenon must be characterized in order to guide efforts to eliminate it. Suspected contributors to the problem include physical design, glass chemistry/redox, and melter/pour spout pressure control systems.

\section{Justifications:}




\section{Tanks Focus Area Need Title: Enhance Equipment Design and Operability of the Site Needs \\ DWPF Melter System; Characterize Causes of Pour Spout}

Site: SRS

TFA Functional Area: Immobilization

Site ID\#: SR-2022

TFA Need ID\#: 634

Technical Justification: Characterization of the pluggage problem will help guide design and/or process flow sheet changes. This will help minimize the occurrence of glass "wicking", improve pouring behavior, and lower the frequency of pluggage incidents.

Regulatory Justification: Characterization of the pluggage problem will help guide design and/or process flow sheet changes. This will help minimize the occurrence of glass "wicking", improve pouring behavior, and lower the frequency of pluggage incidents.

ES\&H Justification: If pluggage occurs which results in replacement of the DWPF Melter, significant personnel radiation exposure will occur during melter change out.

\section{Cultural/Stakeholder Factors: N/A}

Other Justification: None identified

Consequences of Not Filling Need: There will be continued negative impact on DWPF attainment and an increased risk of loss of melters due to pluggage.

Privatization Potential: Limited, this problem seems to be limited to HLW vitrification processes. Similar problems have occurred in the commercial glass industry; however, their glasses and melters are significantly different and their solutions have been "hands-on".

Current Base Technology and Cost: Existing technology is based on pilot scale experience with different process flowsheets from that in use at DWPF.

\section{Current Baseline Timeline:}

SUMMARY OF TFA RESPONSE: The TFA is responding to this need through its response to Need ID\# 633. 


\section{Tanks Focus Area Site Needs}

Need Title: Enhance Equipment Design and Operability of the

DWPF Melter System; Increase Melt Rate in DWPF Melter

Site: SRS

Site ID\#: SR-2023
TFA Functional Area: Immobilization TFA Need ID\#: 635

SITE NEED:

Need Description: The DWPF Glass Melter has been unable to sustain glass production rate (melt rate) equivalent to that achieved during pilot scale testing. Methods to increase melt rate are required to meet DWPF HLW glass production goals.

Waste stream: DWPF melter

Functional Performance Requirements: Method(s) to increase DWPF melt rate must satisfy the following criteria:

(1) Goal melt rate: $228 \mathrm{lb}$ glass produced per hour $(8 \mathrm{lb} / \mathrm{hr} \mathrm{ft2})$

(2) Cannot adversely impact waste glass acceptance criteria.

(3) Minimal impact to existing feed preparation and delivery equipment.

(4) Minimal impact to melter design.

(5) Melter configuration needs to be accommodated by the present DWPF melt cell geometry.

Schedule Requirements: There is a current need for improving DWPF melt rate. Melt rate improvement methods should be developed during FY97-98 to ensure that DWPF melter attainment is maintained sufficiently high to meet increasing production requirements.

Problem Description: The DWPF Melter has been unable to sustain glass production at the reference rate of $228 \mathrm{lb} / \mathrm{hr}(8 \mathrm{lb} / \mathrm{hr} \mathrm{ft} 2)$. It is important to produce glass at that rate or above to meet production goals and work off $\mathrm{HLW}$ inventories within the projected time frame. Experience to date indicates that "foaming" at the glass/feedstock interface is contributing to the problem by limiting heat transfer from the glass to the feed material. The redox state of the feed/glass may be the cause. Viscosity of the glass and melting feed may also limit the melting rate.

\section{Justifications:}

Technical Justification: The DWPF Glass Melter has been unable to sustain glass production rate (melt rate) equivalent to that achieved during pilot scale testing. Methods to increase melt rate are required to meet DWPF HLW glass production goals.

Regulatory Justification: The DWPF Glass Melter has been unable to sustain glass production rate (melt rate) equivalent to that achieved during pilot scale testing. Methods to increase melt rate are required to meet DWPF HLW glass production goals.

\section{ES\&H Justification: N/A}

Cultural/Stakeholder Factors: Extensive interactions with the Defense Nuclear Facilities Safety Board, with the Department of Energy, with numerous external consultants, and with the local public occur. Changes to the melter design will need to satisfy the safety perspective of these groups.

Other Justification: None identified

Consequences of Not Filling Need: There will be continued negative impact on DWPF attainment.

Privatization Potential: Technology associated with increased glass production rate may have application in other waste glass production including hazardous as well as radioactive wastes. Waste glass melting technology exists throughout the country outside of the DOE complex. It may also have limited application in the commercial glass industry. 


\begin{tabular}{lll}
\hline Tanks Focus Area & Need Title: Enhance Equipment Design and Operability of the \\
Site Needs & DWPF Melter System; Increase Melt Rate in DWPF Melter \\
& Site: SRS & TFA Functional Area: Immobilization \\
& Site ID\#: SR-2023 & TFA Need ID\#: 635 \\
\hline
\end{tabular}

Current Base Technology and Cost: Existing technology is based on pilot scale experience with different process flowsheets from that currently in use at DWPF.

Current Baseline Timeline:

SUMMARY OF TFA RESPONSE: The TFA is responding to this need through its response to Need ID\# 633. 


\section{Tanks Focus Area Site Needs}

Need Title: Upgrade DWPF Liquid Level and Density

Measurements

Site: SRS

Site ID\#: SR-2024
TFA Functional Area: Immobilization TFA Need ID\#: 636

\section{SITE NEED:}

Need Description: The level and density of the contents (both homogenous and slurry) of DWPF process tanks are currently determined by measuring the pressure at several levels in the tanks. The differential pressures are then utilized to determine liquid level and/or liquid density. Knowledge of these variable is necessary for successful operation of the process. Many of the tanks contain solid slurries consisting of glass frit and high level waste sludge solids. Nitrogen or air bubblers are a common means to determine pressure in aqueous tanks at various levels. Such devices have been unsuccessful at DWPF because of pluggage caused by the solid slurries. Because of this, Holledge Gages have been utilized at DWPF with good success. The disadvantage of Holledge Gages are high cost (about 75-100K) for a remotable unit and relatively short useful life (estimated average 2 year life). The DWPF contains 8 remote Holledge gages. Estimated cost for replacement of Holledge Gages is about $\$ 500 \mathrm{~K} /$ year.

Waste stream: DWPF process

Functional Performance Requirements: Equipment must be capable of determining tank level and material density for aqueous homogeneous and solid (glass frit and high level waste sludge solid) mixtures. Specific gravity range from 1.0 to 1.5. Equipment must be remotable and must be capable of operation in radiation fields of up to $105 \mathrm{R} / \mathrm{hr}$ for a period of at least 5 years.

Schedule Requirements: No firm schedule exists. Timing is driven by potential cost reductions and DWPF attainment improvement.

Problem Description: Described under Need Description and Function Performance Requirements.

\section{Justifications:}

Technical Justification: The level and density of the contents (both homogenous and slurry) of DWPF process tanks are currently determined by measuring the pressure at several levels in the tanks. The differential pressures are then utilized to determine liquid level and/or liquid density. Knowledge of these variable is necessary for successful operation of the process. Many of the tanks contain solid slurries consisting of glass frit and high level waste sludge solids. Nitrogen or air bubblers are a common means to determine pressure in aqueous tanks at various levels. Such devices have been unsuccessful at DWPF because of pluggage caused by the solid slurries. Because of this, Holledge Gages have been utilized at DWPF with good success. The disadvantage of Holledge Gages are high cost (about 75-100K) for a remotable unit and relatively short useful life (estimated average 2 year life). The DWPF contains 8 remote Holledge gages.

Regulatory Justification: The level and density of the contents (both homogenous and slurry) of DWPF process tanks are currently determined by measuring the pressure at several levels in the tanks. The differential pressures are then utilized to determine liquid level and/or liquid density. Knowledge of these variable is necessary for successful operation of the process. Many of the tanks contain solid slurries consisting of glass frit and high level waste sludge solids. Nitrogen or air bubblers are a common means to determine pressure in aqueous tanks at various levels. Such devices have been unsuccessful at DWPF because of pluggage caused by the solid slurries. Because of this, Holledge Gages have been utilized at DWPF with good success. The disadvantage of Holledge Gages are high cost (about 75-100K) for a remotable unit and relatively short useful life (estimated average 2 year life). The DWPF contains 8 remote Holledge gages.

ES\&H Justification: No known concerns

Cultural/Stakeholder Factors: No known concerns

Other Justification: No known concerns 


\begin{tabular}{lll}
\hline Tanks Focus Area & Need Title: Upgrade DWPF Liquid Level and Density \\
Site Needs & Measurements & \\
& Site: SRS & TFA Functional Area: Immobilization \\
& Site ID\#: SR-2024 & TFA Need ID\#: 636 \\
\hline
\end{tabular}

Consequences of Not Filling Need: Consequences are primarily higher operating costs for DWPF.

Privatization Potential: Units could be utilized at all DOE complex sites where radioactive slurries are processed. Potential exists for possible use in any facility where tank content of slurries is required information.

Current Base Technology and Cost: High cost remote Holledge Gages are the baseline technology.

Current Baseline Timeline:

SUMMARY OF TFA RESPONSE: The TFA rated the priority of the technical response to this need as \#27. The TFA proposes to provide funding in FY98-00, given available funding. 
Site: SRS

Site ID\#: SR-2025
TFA Functional Area: Pretreatment TFA Need ID\#: 637

SITE NEED:

Need Description: Large quantities of sodium hydroxide (caustic) are present in the low-level liquid waste produced in the In-Tank Precipitation process. This concentrated salt solution is disposed in a cement waste form referred to as Saltstone. Significant savings in disposal costs could be realized if the caustic was recovered and recycled.

Waste stream: SRS Waste Tanks, SRS H and F Tank Farm

Functional Performance Requirements: The caustic recovery process must be cost effective and deliver a product that meets customer requirements for purity and concentration. The facility must be capable of processing low-level radioactive waste at a rate of between 0.94 and 4.7 million gallons per year. Transport, storage and handling of the recovered caustic must be accomplished with minimal changes to the existing customer facilities and equipment.

\section{Schedule Requirements:}

Problem Description: Large quantities of chemicals (chiefly sodium salts of nitrate, nitrite, hydroxide, and aluminate) are present in the liquid phase of high-level waste (HLW). Greater than $99.9 \%$ of the soluble salts will be disposed in Saltstone after removal of radioactive species in the In-Tank Precipitation (ITP) process. Recovery of sodium hydroxide (caustic) from the salt solution could significantly reduce the volume of waste disposed in Saltstone. Electrochemical technology exists to separate salts from aqueous waste streams. An electrochemical salt splitting process has the potential to recover the sodium from salt solution as caustic solution. Recycling caustic reduces the quantity of new chemicals added to the high-level waste system at the Savannah River Site. The recovered caustic could be used to neutralize fresh waste from the Separations canyons, Defense Waste Processing Facility, and the Effluent Treatment Facility, used as a corrosion inhibitor in the Tank Farm, and used to dissolve alumina in Extended Sludge Processing (ESP).

\section{Justifications:}

Technical Justification: Large quantities of sodium hydroxide (caustic) are present in the low-level liquid waste produced in the In-Tank Precipitation process. This concentrated salt solution is disposed in a cement waste form referred to as Saltstone. Significant savings in disposal costs could be realized if the caustic was recovered and recycled.

Regulatory Justification: Large quantities of sodium hydroxide (caustic) are present in the low-level liquid waste produced in the In-Tank Precipitation process. This concentrated salt solution is disposed in a cement waste form referred to as Saltstone. Significant savings in disposal costs could be realized if the caustic was recovered and recycled.

\section{ES\&H Justification:}

Cultural/Stakeholder Factors: No known concerns

Other Justification: No known concerns

Consequences of Not Filling Need: All decontaminated salt solution from SRS waste processing will be disposed in Saltstone.

Privatization Potential: A caustic recovery operation could be implemented into the SRS high-level waste flowsheet in such a manner that a stand alone facility could be built and operated by a private vendor. Decontaminated salt solution would be provided to the facility for treatment. The facility would produce a caustic product for SRS and offsite customers and a caustic depleted salt solution for disposal in Saltstone. 
Tanks Focus Area Need Title: Caustic Recovery \& Recycle

Site Needs

Site: SRS

TFA Functional Area: Pretreatment

Site ID\#: SR-2025

TFA Need ID\#: 637

Electrochemical salt splitting is a well-known technology that has been successfully commercialized for the desalination of water, treatment of pulp and paper wastes and the recovery of chemicals from spent plating baths.

Current Base Technology and Cost: There are currently no onsite facilities for caustic recovery.

Current Baseline Timeline:

SUMMARY OF TFA RESPONSE: The TFA rated the priority of the technical response to this need as \#39. The TFA is providing funding for FY97 and proposes to provide funding in FY98-00, given available funding. The response to this need also includes the response to Need ID\# 668. 


\section{Tanks Focus Area \\ Need Title: Alternate DWPF Canister Decon Techniques \\ Site Needs \\ Site: SRS \\ Site ID\#: SR-2026 \\ TFA Functional Area: Immobilization \\ TFA Need ID\#: 638}

SITE NEED:

Need Description: DWPF canister decontamination is a water-frit slurry blast technique that removes contamination and oxides from the entire canister exterior surface. The waste from this process is in two forms. An off-gas is routed to the facility vessel ventilation system and on to facility controlled ventilation exhaust. A water-frit slurry waste stream is pumped into the facility chemical process and fed into the vitrification process stream, to minimize liquid waste production.

This coupling of canister decontamination with chemical processing is less than optimum and could limit production rates in the future.

Technology development is desired in this area, with the following objectives.

- Minimize actual decontamination time, as well as full cycle time between canister decontaminations

- Simplify decontamination system controls, regarding operations and maintenance functions

- Minimize gas and liquid waste

- Minimize cost

- Minimize or eliminate the couple between canister decontamination and chemical processing

\section{Waste stream: DWPF Decon}

Functional Performance Requirements: A decontamination method is required which will remove the oxide layer from the exterior surface of the DWPF stainless steel canister. The contamination level of the exterior surface must be less than $2200 \mathrm{dpm} / 100 \mathrm{~cm} 2$ beta gamma and $220 \mathrm{dpm} / 100 \mathrm{~cm} 2$ alpha.

Schedule Requirements: There is no direct schedule tie for this item.

Problem Description: There is a potential problem that at near design production rates the DWPF canister decontamination operation could limit plant operating attainment to less than the design $75 \%$. An improved decontamination method as described under Need Description would eliminate this concern.

\section{Justifications:}

Technical Justification: DWPF canister decontamination is a water-frit slurry blast technique that removes contamination and oxides from the entire canister exterior surface. The waste from this process is in two forms. An off-gas is routed to the facility vessel ventilation system and on to facility controlled ventilation exhaust. A water-frit slurry waste stream is pumped into the facility chemical process and fed into the vitrification process stream, to minimize liquid waste production.

This coupling of canister decontamination with chemical processing is less than optimum and could limit production rates in the future.

Technology development is desired in this area, with the following objectives.

- Minimize actual decontamination time, as well as full cycle time between canister decontaminations

- Simplify decontamination system controls, regarding operations and maintenance functions

- Minimize gas and liquid waste

- Minimize cost

- Minimize or eliminate the couple between canister decontamination and chemical processing

Regulatory Justification: DWPF canister decontamination is a water-frit slurry blast technique that removes contamination and oxides from the entire canister exterior surface. The waste from this process is in two forms. An off-gas is routed to the facility vessel ventilation system and on to facility controlled ventilation exhaust. A 


\section{Tanks Focus Area Need Title: Alternate DWPF Canister Decon Techniques Site Needs \\ Site: SRS \\ Site ID\#: SR-2026 \\ TFA Functional Area: Immobilization TFA Need ID\#: 638}

water-frit slurry waste stream is pumped into the facility chemical process and fed into the vitrification process stream, to minimize liquid waste production.

This coupling of canister decontamination with chemical processing is less than optimum and could limit production rates in the future.

Technology development is desired in this area, with the following objectives.

- Minimize actual decontamination time, as well as full cycle time between canister decontaminations

- Simplify decontamination system controls, regarding operations and maintenance functions

- Minimize gas and liquid waste

- Minimize cost

- Minimize or eliminate the couple between canister decontamination and chemical processing

ES\&H Justification: No known concerns

Cultural/Stakeholder Factors: No known concems

Other Justification: No known concerns

Consequences of Not Filling Need: Potential lower attainment for DWPF and higher operating costs for DWPF. Additional operating DWPF experience is required to quantitize the actual cost saving.

Privatization Potential: Potential application at West Valley, Hanford, Idaho and other areas where radioactive decontamination of surface is required.

Current Base Technology and Cost: Additional DWPF operating experience is required to determine potential cost savings.

Current Baseline Timeline:

SUMMARY OF TFA RESPONSE: The TFA rated the priority of the technical response to this need as \#55. The TFA proposes to provide funding in FY98-00, given available funding. 


\begin{tabular}{lll}
\hline Tanks Focus Area & Need Title: Reduction in Liquid HLW \\
Site Needs & & \\
& Site: Idaho & TFA Functional Area: Retrieval \& Closure \\
& Site ID\#: ID-2.1.01 & TFA Need ID\#: 639 \\
\hline
\end{tabular}

SITE NEED:

Need Description: Technology development is needed to reduce the amount of radioactive liquid waste that is generated through ICPP activities. These wastes are currently sent to the ICPP tank farm which adds to the volume which must be treated by 2012 according to the court ordered Settlement Agreement. The volume of radioactive liquid waste generated must be reduced to meet the treatment commitment schedules. A main focus is on decontamination activities which contribute a large volume. More efficient decontamination technologies and alternative operating techniques are currently being investigated as part of the EM-30 funded HLW Development Program (WBS \# 1.2.3.2.4.2, ADS 1008). However, under the DOE-HQ plan, the reductions must be greater and sooner to meet the goals. Currently 100,000 to 150,000 gallons of additional waste (after PEW evaporation) are added to the tank farm each year. In addition, much of this waste contains high sodium or potassium levels which create solutions which must be diluted with cold chemicals to allow calcination thus increasing final waste volumes.

Waste stream: Low and High Level/Mixed Liquid Waste

Functional Performance Requirements: Reduce radioactive liquid waste generation from ICPP activities while meeting requirements of waste handling systems and environmental regulations.

Schedule Requirements: The need is current as each additional year adds extra waste to the tank farm. The Settlement Agreement identifies that the waste must be removed from the tank farm by 2012; therefore, the sooner new practices are implemented the larger the impact and benefit will be. This activity is currently funded for approximately 2.5 FTEs per year through 2002 by the EM-30 HLW Development Program (WBS \# 1.2.3.2.4.2, ADS 1008). Improvements are being implemented as they become available.

Problem Description: The ICPP generates radioactive liquid waste which is routed to the tank farm from a number of sources including 1) Decontamination of operating equipment for maintenance, 2) Decontamination of deactivated facilities, 3) Storm water collection in radiation areas, 4) Operation of calcination and off-gas cleanup facilities, 5) Operation of fuel storage facilities. The liquid waste ranges from slightly contaminated water to highly radioactive waste containing many hazardous components. Current technologies used are chemical cleaning, $\mathrm{CO} 2$ pellet blasting, liquid abrasive blasting, mechanical scabbling, strippable coatings. Additional work is needed on using state of the art systems such as laser ablation and ultra high liquid nitrogen. Most basic research is completed, but application specific development is needed. Additional work is also needed to determine cost effectiveness of other water treatment methods.

\section{Justifications:}

Technical Justification: Technology development is needed to reduce the amount of radioactive liquid waste that is generated through ICPP activities. These wastes are currently sent to the ICPP tank farm which adds to the volume which must be treated by 2012 according to the court ordered Settlement Agreement.

Regulatory Justification: Technology development is needed to reduce the amount of radioactive liquid waste that is generated through ICPP activities. These wastes are currently sent to the ICPP tank farm which adds to the volume which must be treated by 2012 according to the court ordered Settlement Agreement.

ES\&H Justification: Waste minimization/pollution prevention

\section{Cultural/Stakeholder Factors:}

\section{Other Justification:}

Consequences of Not Filling Need: May not meet Settlement Agreement milestone dates. Also additional costs in processing and storing the extra waste generated. 


\begin{tabular}{lll}
\hline Tanks Focus Area & Need Title: Reduction in Liquid HLW \\
Site Needs & & \\
& Site: Idaho & TFA Functional Area: Retrieval \& Closure \\
& Site ID\#: ID-2.1.01 & TFA Need ID\#: 639 \\
\hline
\end{tabular}

Privatization Potential: Technologies used as part of this solution could be marketed commercially for cleaning anything from airplanes to microchips.

Current Base Technology and Cost: Cleaning is currently done primarily with water, chemicals, steam sprays, $\mathrm{CO} 2$ pellet blasting and liquid abrasive blasting. Slightly contaminated water is treated the same as highly radioactive hazardous solutions by evaporation then calcination. All water is not evaporated due to equipment constraints.

\section{Cost:}

How Long it will Take: NA/ Cannot meet commitment dates using current techniques.

\section{Current Baseline Timeline:}

SUMMARY OF TFA RESPONSE: The TFA rated the priority of the technical response to this need as \#38. The TFA proposes to provide funding in FY98-99, given available funding. 


\begin{tabular}{ll}
\hline Tanks Focus Area & Need Title: Process Flow Sheet to Process Sodium-Bearing \\
Site Needs & Waste
\end{tabular}

Site: Idaho

Site ID\#: ID-2.1.02

TFA Functional Area: Pretreatment TFA Need ID\#: 640

SITE NEED:

Need Description: A process flowsheet must be developed to process sodium-bearing wastes (SBW) at the ICPP. There are 1.5 million gallons of SBW currently stored in the ICPP tank farm and an additional 1 million gallons expected to be generated through future decontamination activities. The SBW cannot be efficiently calcined using existing flowsheets due to incomplete conversion of the nitrates to oxides at the $500^{\circ} \mathrm{C}$ operating temperature and the resulting agglomeration of particles. The Consent Order requires that the INEL "cease use" of the tank farm by 2012 because of seismic concerns and noncompliance with RCRA double-containment requirements. The Court Ordered Batt Settlement Agreement requires that this waste be treated via calcination by December 31, 2012.

Waste stream: High Level Waste, Idaho Chemical Processing Plant (ICPP)

Functional Performance Requirements: Major performance objectives that must be achieved to demonstrate a successful flowsheet for calcining SBW are 1) minimize the amount of chemical additives required to process the SBW to improve the calciner processing rate and to conserve calcine solids storage space; 2) demonstrate fluidized-bed calciner operability with respect to bed and system stability and the absence of bed agglomeration; 3) produce a calcine that is pneumatically transportable and retrievable; 4) produce a calcine that is soluble in nitric acid; 5) produce a calcine that is safe to transport, store, and dissolve; 6) control species volatilization and fines generation to an acceptable level; and 7) produce a calcine that is chemically compatible with the waste immobilization process.

Schedule Requirements: Section E5 of the Batt Settlement Agreement requires that the SBW be calcined by December 31,2012 . This requires that the NWCF be modified and operational by FY-06. Process flowsheet development is expected to continue through FY-02 to support the full-scale project to modify the NWCF.

Problem Description: Radioactive liquid waste containing large quantities of sodium has accumulated over the years and is stored in the ICPP tank farm. This waste is referred to as sodium-bearing waste, and was generated as a result of extraction system solvent cleanup and decontamination efforts. Sodium nitrate and potassium nitrate are major components of the SBW. SBW is difficult to calcine due to agglomeration and caking of molten sodium nitrate and potassium nitrate that persist in the calcine product. The pure component decomposition temperatures for sodium nitrate and potassium nitrate are $380^{\circ} \mathrm{C}$ and $400^{\circ} \mathrm{C}$, respectively. However, the thermal decomposition of the nitrates is not fully achieved by calcination at $500^{\circ} \mathrm{C}$ (the normal operating temperature of the NWCF) due to mass transfer and kinetic limitations and due to the formation of eutectic phases during drying. Section E5 of the Settlement Agreement requires that the SBW be calcined by 2012. This commitment cannot be met using the established SBW flowsheet due to the copious quantity of aluminum nitrate that is required. Therefore, to meet the objectives of increased throughput, reduced waste volumes, and reduced cost, alternative calcination schemes must be investigated.

\section{Justifications:}

Technical Justification: An improved process flowsheet must be developed to efficiently calcine SBW and overcome the problems caused by melting of sodium and potassium nitrates.

Regulatory Justification: An improved process flowsheet must be developed to efficiently calcine SBW and overcome the problems caused by melting of sodium and potassium nitrates.

ES\&H Justification: Waste minimization

Cultura/Stakeholder Factors: An improved calcination flowsheet will allow the ICPP to "cease use" of the tank farm sooner, alleviating stakeholder concerns about storing liquid radioactive waste in tanks, over the Snake River aquifer, which do not comply with seismic and/or RCRA requirements. 


\section{Tanks Focus Area Need Title: Process Flow Sheet to Process Sodium-Bearing \\ Waste}

Site Needs

Site: Idaho

Site ID\#: ID-2.1.02

TFA Functional Area: Pretreatment TFA Need ID\#: 640

Other Justification:

Consequences of Not Filling Need: The Batt Settlement Agreement will not be met. Life-cycle cost to process the SBW will be significantly greater than with more efficient, alternative calcination flowsheets.

Privatization Potential: None known

Current Base Technology and Cost: Calcination with cold chemical additives.

Current Baseline Timeline: Calcination with cold chemicals will require the NWCF to run for 10 campaigns; approximately through the year 2020 , assuming campaign cycles of 18 months of operation and 12 months downtime.

SUMMARY OF TFA RESPONSE: The TFA rated the priority of the technical response to this need as \#28. The TFA proposes to provide funding in FY98-00, given available funding. 


\section{Tanks Focus Area Site Needs}

Need Title: On-Line Process Monitor for Elemental Analysis of

Calcine Product

Site: Idaho

Site ID\#: ID-2.1.03
TFA Functional Area: Characterization TFA Need ID\#: 641

\section{SITE NEED:}

Need Description: On-line process monitoring for elemental analysis of calcine product is needed for alternative flowsheet calcination. Alternative calcination flowsheets, including sugar-additive calcination, are being developed to more effectively denitrate the sodium and potassium salts. However, to safely implement sugar-additive calcination, the process must be closely monitored to detect process upset conditions or out-ofspecification combinations of compounds. Development of real-time process control monitoring is needed to measure hydrocarbon and nitrate compounds (as elemental carbon and nitrogen) in the off-gas fines, and elemental species (sodium, aluminum, iron, calcium, fluoride, potassium, and RCRA metals) in the calcine product.

\section{Waste stream: High Level Waste, Idaho Chemical Processing Plant (ICPP)}

Functional Performance Requirements: The process monitor must: 1) provide on-line, real-time calcine product and fines monitoring capabilities; 2) operate in the temperature range of interest $\left(500-650^{\circ} \mathrm{C}\right)$; 3) not require sample acquisition or sample treatment; 4) provide quantitative elemental analysis; 5) have sufficient sensitivity for the elements of interest (0.01-10 wt \% for carbon, $0.1-25 \mathrm{wt} \%$ for sodium, $0.01-5 \mathrm{wt} \%$ for potassium, and $0.0001-1 \mathrm{wt} \%$ for metals); and 6) be able to measure carbon compounds impregnated in the offgas fines and calcine product in the presence of carbon compounds in the gas phase.

Schedule Requirements: Section E5 of the Batt Settlement Agreement requires that the SBW be calcined by December 31,2012 . This requires that the NWCF be modified and operational by FY-06. Process development is expected to continue through FY-02 to support the full-scale project to modify the NWCF. Alternative flowsheets which use sugar as a denitration additive are under development with an objective to provide full-scale calciner operating parameters by September 1999 and begin equipment modifications to the NWCF by January 2001.

Problem Description: Radioactive liquid waste containing large quantities of sodium has accumulated over the years and is stored in the ICPP tank farm. This waste is referred to as sodium-bearing waste, and was generated as a result of extraction system solvent cleanup and decontamination efforts. Sodium nitrate and potassium nitrate are major components of the SBW. SBW is difficult to calcine due to agglomeration and caking of molten sodium nitrate and potassium nitrate that persist in the calcine product. The pure component decomposition temperatures for sodium nitrate and potassium nitrate are $380^{\circ} \mathrm{C}$ and $400^{\circ} \mathrm{C}$, respectively. However, the thermal decomposition of the nitrates is not fully achieved by calcination at $500^{\circ} \mathrm{C}$ (the normal operating temperature of the NWCF) due to mass transfer and kinetic limitations and due to the formation of eutectic phases during drying. Section E5 of the Settlement Agreement requires that the SBW be calcined by 2012. This commitment cannot be met using the established SBW flowsheet due to the copious quantity of aluminum nitrate that is required. Therefore, to meet the objectives of increased throughput, reduced waste volumes, and reduced cost, alternative calcination schemes must be investigated.

Alternative flowsheets which use sugar as a denitration additive are under development with an objective to provide full-scale calciner operating parameters by September 1999 and begin equipment modifications to the NWCF by January 2001. Process monitors are needed to be used in conjunction with the new flowsheet to assure off-gas calciner fines and the calciner product do not exceed safety limit criteria for total organic carbon content and to monitor the product consistency levels of other elements (i.e., sodium, aluminum, iron, calcium, fluoride, potassium, and RCRA metals).

\section{Justifications:}

Technical Justification: Monitoring capabilities meeting the following requirements are currently not available. The process monitor must: 1) provide on-line, real-time calcine product and fines monitoring capabilities; 2) operate in the temperature range of interest $\left.\left(500-650^{\circ} \mathrm{C}\right) ; 3\right)$ not require sample acquisition or sample treatment; 4) provide quantitative elemental analysis; 5) have sufficient sensitivity for the elements of 


\begin{tabular}{lll}
\hline Tanks Focus Area & \multicolumn{2}{l}{$\begin{array}{l}\text { Need Title: On-Line Process Monitor for Elemental Analysis of } \\
\text { Calcine Product }\end{array}$} \\
Site Needs & Site: Idaho & TFA Functional Area: Characterization \\
& Site ID\#: ID-2.1.03 & TFA Need ID\#: 641 \\
\hline
\end{tabular}

interest (0.01-10 wt \% for carbon, 0.1-25 wt\% for sodium, $0.01-5 \mathrm{wt} \%$ for potassium, and $0.0001-1 \mathrm{wt} \%$ for metals); and 6) be able to measure carbon compounds impregnated in the off-gas fines and calcine product in the presence of carbon compounds in the gas phase.

Regulatory Justification: Monitoring capabilities meeting the following requirements are currently not available. The process monitor must: 1) provide on-line, real-time calcine product and fines monitoring capabilities; 2) operate in the temperature range of interest $\left.\left(500-650^{\circ} \mathrm{C}\right) ; 3\right)$ not require sample acquisition or sample treatment; 4) provide quantitative elemental analysis; 5) have sufficient sensitivity for the elements of interest (0.01-10 wt \% for carbon, $0.1-25 \mathrm{wt} \%$ for sodium, $0.01-5 \mathrm{wt} \%$ for potassium, and $0.0001-1 \mathrm{wt} \%$ for metals); and 6) be able to measure carbon compounds impregnated in the off-gas fines and calcine product in the presence of carbon compounds in the gas phase.

ES\&H Justification: On-line, real-time process monitoring is needed in conjunction with alternative calcination flowsheets to assure off-gas calciner fines and the calciner product do not exceed safety limit criteria for total organic carbon content.

Cultural/Stakeholder Factors: An on-line, real-time process monitor will allow safe implementation of alternative calcination flowsheets. An improved calcination flowsheet will allow the ICPP to "cease use" of the tank farm sooner, alleviating stakeholder concerns about storing liquid radioactive waste in tanks, over the Snake River aquifer, which do not comply with seismic and/or RCRA requirements.

\section{Other Justification:}

Consequences of Not Filling Need: Safe implementation of alternative calcination flowsheets cannot be assured. Without an alternative calcination flowsheet, the Batt Settlement Agreement will not be met. Lifecycle costs to process the SBW will be significantly greater than with more efficient alternative calcination flowsheets.

\section{Privatization Potential: None known}

Current Base Technology and Cost: None for the process monitor. Calcination with cold chemical additives is the baseline technology for calcining the waste.

\section{Current Baseline Timeline:}

SUMMARY OF TFA RESPONSE: INEEL withdrew its request for funding to develop an on-line process monitor for elemental analysis of calcine product. Therefore, the TFA did not develop a technical response. 


\section{SITE NEED:}

Need Description: Technology development is needed to denitrate and solidify the high-activity fraction resulting from radionuclide separation of sodium-bearing waste (SBW) and dissolved ICPP calcine. The technology must be capable of stabilizing the waste in a solid form for shipment in NRC-certified casks to an alternate treatment site for vitrification.

\section{Waste stream: High Level Waste, Idaho Chemical Processing Plant (ICPP)}

Functional Performance Requirements: The process must be capable of processing the various compositions that result from radionuclide separation of SBW and dissolved calcine. The product must be a solid which can be placed in moveable storage/shipping containers; transportable in NRC-certified shipping casks to an alternate treatment site; retrievable from the containers; and be compatible with HLW immobilization formulations capable of meeting repository waste acceptance criteria.

Schedule Requirements: A denitration/solidification technology is needed by 2007 to support Title Design of a production facility if solidification and shipping is the alternative chosen.

Problem Description: Radioactive liquid waste containing large quantities of sodium has accumulated over the years and is stored in the ICPP tank farm. This waste is referred to as sodium-bearing waste, and was generated as a result of extraction system solvent cleanup and decontamination efforts. Sodium nitrate and potassium nitrate are major components of the SBW. SBW is difficult to calcine due to agglomeration and caking of molten sodium nitrate and potassium nitrate that persist in the calcine product. The pure component decomposition temperatures for sodium nitrate and potassium nitrate are $380^{\circ} \mathrm{C}$ and $400^{\circ} \mathrm{C}$, respectively. However, the thermal decomposition of the nitrates is not fully achieved by calcination at $500^{\circ} \mathrm{C}$ (the normal operating temperature of the NWCF) due to mass transfer and kinetic limitations and due to the formation of eutectic phases during drying. The Consent Order to the Notice of Noncompliance requires that the ICPP "cease use" of the tank farm by 2015 . This commitment cannot be met using the established SBW calcination flowsheet due to the copious quantity of aluminum nitrate that is required. Therefore, to meet the objectives of increased through-put, reduced waste volumes, and reduced cost, alternative treatment methods must be investigated.

One such scheme is to partition the radionuclides from the SBW and dissolved calcine to generate a small volume of high activity waste to be vitrified and disposed to a HLW repository and a large volume of sodiumrich low activity waste to be grouted. The HAW would then be immobilized through vitrification. The vitrification could take place either at the ICPP or at an off-site location. In the case that vitrification is performed off-site, a means of preparing the waste for transport between locations is needed.

\section{Justifications:}

Technical Justification: HAW produced from radionuclide separation of SBW and dissolved calcine must be solidified for transportation to an off-site treatment facility.

Regulatory Justification: HAW produced from radionuclide separation of SBW and dissolved calcine must be solidified for transportation to an off-site treatment facility.

ES\&H Justification: Waste minimization.

Cultural/Stakeholder Factors: An improved waste processing scheme will allow the ICPP to "cease use" of the tank farm sooner, alleviating stakeholder concerns about storing liquid radioactive waste in tanks, over the Snake River Aquifer, which do not comply with seismic and/or RCRA requirements.

Other Justification: 
Tanks Focus Area Need Title: Denitrate and Solidify the High Activity Fraction

Site Needs

Site: Idaho

Site ID\#: ID-2.1.12

TFA Functional Area: Immobilization TFA Need ID\#: 642

Consequences of Not Filling Need: The Consent Order to the Notice of Noncompliance will not be met. Lifecycle costs to process the SBW will be significantly greater because the intermediate calcination step will continue in addition to the treatment that must eventually take place to render the waste acceptable for disposal.

Privatization Potential: None known

Current Base Technology and Cost: On-site vitrification.

Cost: Not known.

Current Baseline Timeline: Not known.

SUMMARY OF TFA RESPONSE: The TFA rated the priority of the technical response to this need as \#53. The TFA is providing funding for FY97 and proposes to provide funding in FY98-99, given available funding. 


\begin{tabular}{|c|c|}
\hline Tanks Focus Area & $\begin{array}{l}\text { Need Title: Method to Separate Undissolved Solids from } \\
\text { Sodium-Bearing Waste \& Dissolve Calcine }\end{array}$ \\
\hline & $\begin{array}{l}\text { TFA Functional Area: Pretreatment } \\
\text { TFA Need ID\#: } 643\end{array}$ \\
\hline
\end{tabular}

SITE NEED:

Need Description: Methods to remove undissolved solids from tank waste and dissolved calcine are needed. The solids must be removed to ensure the separation processes can achieve NRC Class A LLW criteria.

Waste stream: High Level Waste, Idaho Chemical Processing Plant (ICPP)

Functional Performance Requirements: Unknown at this time.

Schedule Requirements: Need by 2007 to support title design of production facility.

Problem Description: Undissolved solids present in tanks and from calcine dissolution processes must be removed to achieve LLW specifications from separations processes.

\section{Justifications:}

Technical Justification: Undissolved solids present in tanks and from calcine dissolution processes must be removed to achieve LLW specifications from separation processes.

Regulatory Justification: Undissolved solids present in tanks and from calcine dissolution processes must be removed to achieve LLW specifications from separation processes.

\section{ES\&H Justification:}

Cultural/Stakeholder Factors: Unknown

Other Justification:

Consequences of Not Filling Need: Failure to meet Settlement Agreement

Privatization Potential: High, within 3-5 years.

Current Base Technology and Cost:

Current Baseline Timeline:

SUMMARY OF TFA RESPONSE: The TFA rated the priority of the technical response to this need as \#9. The TFA is providing funding for FY97 and proposes to provide funding in FY98, given available funding. 


\begin{tabular}{lll}
\hline Tanks Focus Area & Need Title: Dissolution of Future Calcines \\
Site Needs & & \\
& Site: Idaho & TFA Functional Area: Pretreatment \\
& Site ID\#: ID-2.1.05 & TFA Need ID\#: 644 \\
\hline SITE NEED: & &
\end{tabular}

SITE NEED:

Need Description: Methods to dissolve calcine are needed. The calcine must be dissolved to put it in a form readily amenable to aqueous separation technologies.

Waste stream: High Level Waste, Idaho Chemical Processing Plant (ICPP)

Functional Performance Requirements: Unknown at this time.

Schedule Requirements: Need by 2007 to support title design of production facility.

Problem Description: Calcine must be dissolved to put it in a form that is compatible with radionuclide separation technologies. Parameters affecting dissolution efficiency must be defined and scale-up and design of a calcine dissolver must be completed.

\section{Justifications:}

Technical Justification: Calcine must be dissolved to put it in a form that is compatible with radionuclide separation technologies. Parameters affecting dissolution efficiency must be defined and scale-up and design of a calcine dissolver must be completed.

Regulatory Justification: Calcine must be dissolved to put it in a form that is compatible with radionuclide separation technologies. Parameters affecting dissolution efficiency must be defined and scale-up and design of a calcine dissolver must be completed.

\section{ES\&H Justification:}

Cultural/Stakeholder Factors: Unknown

Other Justification:

Consequences of Not Filling Need: Failure to meet Settlement Agreement

Privatization Potential: Moderate, within 5-7 years.

Current Base Technology and Cost:

Current Baseline Timeline:

SUMMARY OF TFA RESPONSE: The TFA rated the priority of the technical response to this need as \#29. The TFA proposes to provide funding in FY98-99, given available funding. 


\section{Tanks Focus Area Site Needs}

Need Title: Solvent Extraction \& Ion-Exchange To Remove TRU, Sr, Tc \& Cs from ICPP Tank Farm

Site: Idaho

Site ID\#: ID-2.1.06
TFA Functional Area: Pretreatment TFA Need ID\#: 645

\section{SITE NEED:}

Need Description: Removal of TRU, $\mathrm{Sr}$, and $\mathrm{Cs}$ from tank waste and dissolved calcine. Solvent extraction and ion-exchange technologies must be demonstrated on actual INEEL radioactive waste streams to ensure fullscale processes will adequately recover the active constituents to convert the bulk of the waste to LLW.

Waste stream: High Level Waste, Idaho Chemical Processing Plant (ICPP)

Functional Performance Requirements: TRU: $<10 \mathrm{nCi} / \mathrm{g}, \mathrm{Sr}:<0.04 \mathrm{Ci} / \mathrm{m} 3, \mathrm{Cs}:<1 \mathrm{Ci} / \mathrm{m} 3$

Schedule Requirements: Need by 2007 to support title design of production facility.

Problem Description: TRUs, Cs and Sr comprise less than one percent of the total INEEL radioactive waste volume. If these elements can be removed from the bulk (inert) elements in the waste, a significant reduction in the volume of HLW would be realized.

\section{Justifications:}

Technical Justification: TRUs, $\mathrm{Cs}$ and $\mathrm{Sr}$ comprise less than one percent of the total INEEL radioactive waste volume. If these elements can be removed from the bulk (inert) elements in the waste, a significant reduction in the volume of HLW would be realized.

Regulatory Justification: TRUs, Cs and Sr comprise less than one percent of the total INEEL radioactive waste volume. If these elements can be removed from the bulk (inert) elements in the waste, a significant reduction in the volume of HLW would be realized.

ES\&H Justification:

Cultural/Stakeholder Factors: Unknown

Other Justification:

Consequences of Not Filling Need: Failure to meet Settlement Agreement

Privatization Potential: High, within 3-5 years.

Current Base Technology and Cost:

Current Baseline Timeline:

SUMMARY OF TFA RESPONSE: The TFA rated the priority of the technical response to this need as \#4. The TFA is providing funding for FY97 and proposes to provide funding in FY98-99, given available funding. This response will also include the technical response to Need ID\#646. 


\section{Tanks Focus Area Need Title: Characterize \& Remove RCRA Listed Wastes from Site Needs \\ High \& Low Activity Fractions \\ Site: Idaho \\ Site ID\#: ID-2.1.11 \\ TFA Functional Area: Pretreatment TFA Need ID\#: 646}

SITE NEED:

Need Description: Removal of RCRA metals from tank waste and dissolved calcine. Solvent extraction and ion-exchange technologies must be demonstrated on actual INEEL radioactive waste streams to ensure fullscale processes will adequately recover the active constituents to meet RCRA treatment requirements.

Waste stream: High Level Waste, Idaho Chemical Processing Plant (ICPP)

Functional Performance Requirements: Unknown at this time.

Schedule Requirements: Need by 2007 to support title design of production facility.

Problem Description: RCRA metals have BDAT treatment technologies specified. In order to meet the BDAT treatment requirements, and to produce high and low activity waste fractions that will not be classified as mixed waste, RCRA metals must be separated from the radioactive wastes.

\section{Justifications:}

Technical Justification: RCRA metals have BDAT treatment technologies specified. In order to meet the BDAT treatment requirements, and to produce high and low activity waste fractions that will not be classified as mixed waste, RCRA metals must be separated from the radioactive wastes.

Regulatory Justification: RCRA metals have BDAT treatment technologies specified. In order to meet the BDAT treatment requirements, and to produce high and low activity waste fractions that will not be classified as mixed waste, RCRA metals must be separated from the radioactive wastes.

\section{ES\&H Justification:}

Cultural/Stakeholder Factors: Unknown.

Other Justification:

Consequences of Not Filling Need: Failure to meet Settlement Agreement.

Privatization Potential: Moderate, within 5-7 years.

Current Base Technology and Cost:

Current Baseline Timeline:

SUMMARY OF TFA RESPONSE: The TFA did not prepare a separate technical response for this need. Instead, it was consolidated and included under the response for Need ID\# 645. 
Site: Idaho

Site ID\#: ID-2.1.07
TFA Functional Area: Immobilization TFA Need ID\#: 647

SITE NEED:

Need Description: Technology is required for grouting the low-level waste (LLW) generated at ICPP. These wastes include the LLW from separations operations, facility decontamination solutions, and low-level process equipment wastes. LLW from the separation of high activity wastes will be acidic and high in nitrates. Both of these are detrimental to grout chemistry; thus, basic research is needed to develop grout formulations that will solidify and stabilize these wastes. Annually, about 100,000 to 150,000 gallons of liquid waste are added to the tank farm inventory from decontamination and process equipment wastes, much of which could be grouted. Grout formulations and qualified waste forms are also needed for these waste streams.

Waste stream: High Level Waste, Idaho Chemical Processing Plant (ICPP)

Functional Performance Requirements: The grouted "product" will be low-level and/or mixed low-level waste. The waste must meet the stability requirements of 10 CFR Part 61 as noted in the Nuclear Regulatory Commission Low-Level Waste Management Branch Technical Position on Waste Form, January 1991, for structural stability and leach resistance of radionuclides. The waste must also meet the requirements of 40 CFR Part 268 for leach resistance of hazardous components.

Schedule Requirements: Research data is needed by 2007 to support title design of the immobilization facility.

Problem Description: The low-level wastes from the separations process will be acidic and high in nitrates, both of which are detrimental to grout chemistry. The LLW at other DOE sites is basic; therefore, their grout formulations are not applicable to ICPP LLW. Due to the high acidity and nitrates in the waste, waste conditioning is necessary prior to grouting. Grout formulation consists of blending and proportioning the waste with cements such as ordinary Portland cement, blast furnace slag, and coal power plant fly ash. Once the grout formulation is developed for a specific LLW stream, extensive waste form qualification is required to document grout stability and leach resistance. Waste form qualification includes compressive strength after initial curing, immersing, and thermal cycling and leach tests for radionuclides and hazardous components. This is an iterative research process between waste conditioning, grout formulation, and waste form qualification. Equipment is needed to condition the simulated waste, mix grout, prepare full-size waste forms, core drill waste form, and conduct thermal cycle tests.

Current research utilizes thermal calcination to solidify the waste and destroy the nitrates. This denitration process produces significant amounts of off-gas which must be handled. Denitration equipment must be specified, procured, and tested. The corrosive nature of the off-gas must be investigated and materials of construction determined. EM-30 funding covers the basic formulation work; however, other funding is needed to research the denitration process.

\section{Justifications:}

Technical Justification: Conditioning processes and equipment, grout formulations, mixing processes and equipment, and waste form qualification are needed for LLW at ICPP.

Regulatory Justification: Conditioning processes and equipment, grout formulations, mixing processes and equipment, and waste form qualification are needed for LLW at ICPP.

ES\&H Justification: The LLW form must meet the environmental standards contained in the CFRs noted above. The grouting process and facility must maintain the safety and health of the operators and the public.

Cultural/Stakeholder Factors: An area of public concern is the liquid wastes stored at ICPP. Grouting LLW is an internationally accepted process and will solidify the liquid wastes and will stabilize the hazardous material by meeting leach requirements. 


\section{Tanks Focus Area Need Title: Immobilize ICPP Low Activity Wastes Site Needs \\ Site: Idaho \\ TFA Functional Area: Immobilization \\ Site ID\#: ID-2.1.07 TFA Need IDH: 647}

Other Justification: There is a high potential to privatize a LLW grout facility; however, grout research is needed to provide the basis for bid performance specifications and criteria.

Consequences of Not Filling Need: The Batt Settlement Agreement will not be met. Liquid waste will continue to accumulate.

Privatization Potential: A commercial grout facility is feasible for the mixed LLW. The grout formulations should allow sufficient tolerance that vendors could meet the waste conditioning and grout mixing performance specifications.

Current Base Technology and Cost: The grout research is currently spread over 12 years to support design of a waste treatment separations/vitrification/grout facility in 2009. If a grout facility is needed earlier, the grout research would need to be accelerated to support specification/bid preparation. The baseline includes minimal grout research (1 to 2 persons per year) through 2001 ; then, design, construction, and operation of a grout pilot plant from 2002 to 2009.

Cost: Baseline cost from 1997 to 2002 totals about $\$ 5$ million. The pilot plant construction estimate is $\$ 5$ million. Pilot plant operational costs for chemicals, grout, other materials, and labor have not been determined.

Current Baseline Timeline: As noted above the grout research is spread over 12 years. Privatization may accelerate the process. The actual grouting of LLW at ICPP could run 30 to 40 years by processing solutions from separations, continuing process equipment waste, and eventual facility decommissioning wastes.

SUMMARY OF TFA RESPONSE: The TFA rated the priority of the technical response to this need as \#10. The TFA is providing funding for FY97 and proposes to provide funding in FY98-00, given available funding. 


\begin{tabular}{lll}
\hline Tanks Focus Area & Need Title: Characterize Tank Farm Heels \\
Site Needs & & \\
& Site: Idaho & TFA Functional Area: Characterization \\
& Site ID\#: ID-2.1.10 & TFA Need ID\#: 648 \\
\hline
\end{tabular}

SITE NEED:

Need Description: When the ICPP high activity tanks are emptied, a heel may remain. It is proposed to grout any such heel in place upon tank closure. Technology is required to characterize tank farm heel residuals to allow development of grout formulations. The heel characterization must take place in highly radioactive and limited access environments. Methodologies and platforms for deploying heel retrieval equipment are needed for heel mixing, hose deployment, ventilation, shielding, containment, heel sampling, etc.

Waste stream: High Level Waste, Idaho Chemical Processing Plant (ICPP)

Functional Performance Requirements: Sufficient samples must be taken to provide representative components for grout development. Sampling must be done under ALARA considerations.

Schedule Requirements: Need by 2005 to support tank heel grouting.

Problem Description: The tanks are underground and are highly radioactive. No heel sampling or mixing capabilities are installed. If any remaining heel is to be grouted in place, the nature of the heel must be known to provide a grout that will incorporate the heel and set up as a stable solid. The liquids in the tanks are known to be acidic and are high in nitrates, both of which are detrimental to grout chemistry. Other potential problem constituents are borates, phosphates, permanganates, and sulfates. These anions have been specifically identified by vendors as having the potential to cause problems with cement solidification of low-level wastes (see technical reference noted below). Knowledge of the heel composition and physical state is needed to develop a grout that will mix with the heel, solidify, and remain stable.

\section{Justifications:}

Technical Justification: Heel characterization is needed to develop a grout that will solidify and remain stable. A list of waste constituents that may cause problems with cement solidification is noted on page A-20 of the U.S. Nuclear Regulatory Commission Low-Level Waste Management Branch Technical Position on Waste Form, January 1991.

Regulatory Justification: Heel characterization is needed to develop a grout that will solidify and remain stable. A list of waste constituents that may cause problems with cement solidification is noted on page A-20 of the U.S. Nuclear Regulatory Commission Low-Level Waste Management Branch Technical Position on Waste Form, January 1991.

ES\&H Justification: Grouting the tanks in place rather than complete decontamination and demolition will save considerable radiation exposure (estimate not developed).

Cultural/Stakeholder Factors: The grouting of the tanks and leaving the tanks and any heels will need to be presented to the public and approved by the State of Idaho.

\section{Other Justification:}

Consequences of Not Filling Need: Grouted heel may not be stable, i.e., the grout may not "set up." This may allow the grout/heel sludge to corrode the tank.

Privatization Potential: Grout mixing and transport to the tanks could be privatized. Internal heel characterization must be done prior to privatization.

Current Base Technology and Cost: This technology need is not covered in any current budgets.

Cost: Not known

Site Needs Assessment

A. 101

Appendix A - Site Needs Database 


\begin{tabular}{lll}
\hline Tanks Focus Area & Need Title: Characterize Tank Farm Heels \\
Site Needs & & \\
& Site: Idaho & TFA Functional Area: Characterization \\
& Site ID\#: ID-2.1.10 & TFA Need ID\#: 648 \\
\hline
\end{tabular}

Current Baseline Timeline: Not known.

SUMMARY OF TFA RESPONSE: The TFA rated the priority of the technical response to this need as \#30. The TFA is providing funding for FY97 and proposes to provide funding in FY98-99, given available funding. 


\begin{tabular}{lll}
\hline Tanks Focus Area & Need Title: High Activity Waste Form \\
Site Needs & & \\
& Site: Idaho & TFA Functional Area: Immobilization \\
& Site ID\#: ID-2.1.08 & TFA Need ID\#: 649 \\
\hline
\end{tabular}

SITE NEED:

Need Description: Technology is needed to develop a process that immobilizes the HAW fraction from ICPP calcine dissolution and radionuclide separation. Vitrification is considered the "Best Demonstrated Available Technology" (40 CFR 268, Federal Register/Vol. 57, No. 101, pgs 22046-22047, May 26, 1992) for immobilizing highly radioactive wastes. Precedents are established for the use of a vitrification process to immobilize highly radioactive wastes by the operation of the Defense Waste Processing Facility at the Savannah River Site and the West Valley Demonstration Plant at the West Valley Site. Exact vitrification technologies from these sites cannot be transferred for use at the INEEL because of the unique composition of the HAWs. Thus variations in the vitrification process need to be incorporated in order to make the HAW "road ready" by year 2035 as required in Section E. 6 of the Batt Settlement Agreement.

Waste stream: High Level Waste, Idaho Chemical Processing Plant (ICPP)

Functional Performance Requirements: The initial major performance requirement for immobilization is to determine that the HAW composition can be vitrified. Thus vitrification formulation development must first be interfaced with separations development to demonstrate that the HAW product can be vitrified to a useful glass. This synergism may require not only alterations in the vitrification formulation, but also in the HAW product composition meaning consequent alteration of the separations process. Useful vitrification of the HAW product will be achieved when such a product meets all waste form performance specifications for repository storage as established in the 1993 DOE-EM Waste Acceptance Product Specifications (WAPS). The next major performance requirement is that a process must be developed to produce the acceptable vitrified product on a production scale. The product of this process must also meet all the performance specifications established in the WAPS. These include specifications for waste forms, canisters, canistered waste forms, quality assurance and documentation.

Schedule Requirements: Section E.6 of the Batt Settlement Agreement requires that all calcined wastes and liquid sodium bearing wastes will be rendered ready (immobilized) for transport to a suitable repository by December 31,2035 . This requires that DOE evaluate means to suitably immobilize these wastes and issue by the end of year 2009 a treatment plan for meeting the 2035 date.

Problem Description: The HAW product generated by the separations process will be of unique chemical compositions. These compositions will range from those consisting of zirconia, calcium stabilized zirconia, phosphates and fluorides to those consisting mainly of alumina. Thus, although immobilization of high activity radioactive wastes exists as a production scale technology, no vitrifying formulations are readily available for the HAW composition. A technology to develop vitrifying formulations has been defined through years of high level waste management experience at the ICPP. This technology must be applied in order to define vitrifying formulations that can be used in a full scale process to accomplish the basic requirement of Section E. 6 of the Batt Settlement Agreement that all HAW will be rendered ready for transport to a suitable repository by the end of year 2035 .

Justifications:

Technical Justification: Immobilization process not developed for ICPP HAW compositions.

Regulatory Justification: Immobilization process not developed for ICPP HAW compositions.

ES\&H Justification: Eliminate potential for SBW to leak from tanks, immobilize calcine in geologically unsound Bin set 1.

Cultural/Stakeholder Factors: Batt Settlement Agreement is that HLW will be road-ready by year 2035. This removes storage of highly radioactive wastes from over the Snake River Aquifer, especially those in Bin set 1 which does not comply to seismic requirements. 


\begin{tabular}{lll}
\hline Tanks Focus Area & Need Title: High Activity Waste Form \\
Site Needs & & \\
& & TFA Functional Area: Immobilization \\
& Site: Idahỏ & TFA Need ID\#: 649 \\
\hline
\end{tabular}

Other Justification:

Consequences of Not Filling Need: Violate Batt Settlement Agreement, Section E.6.

Privatization Potential: Cost effective only if privatized as part of separations development.

Current Base Technology and Cost: Cost: EM-30: \$1M, EM-50: \$150K

Current Baseline Timeline: Production scale vitrification of HAW may begin by year 2019 and require up to fifteen years to complete.

SUMMARY OF TFA RESPONSE: The TFA rated the priority of the technical response to this need as \#18. The TFA is providing funding for FY97 and proposes to provide funding in FY98-00, given available funding. 
Site: Idaho

Site ID\#: ID-2.1.09
TFA Functional Area: Retrieval \& Closure TFA Need ID\#: 650

SITE NEED:

Need Description: An efficient system for retrieving radioactive calcine from storage bins and transferring it to a future calcine treatment facility must be developed. Retrieval must be performed remotely, due to the high radiation fields generated by the calcine. The equipment required to accomplish this task has not been designed and retrieval was not a major consideration during the design of the storage bins. Calcine retrieval development is needed to support operation of a full scale treatment facility in 2020, as determined through the INEEL EM Integration Effort to meet the court ordered Batt Settlement Agreement.

Waste stream: High Level Waste, Idaho Chemical Processing Plant (ICPP)

Functional Performance Requirements: Major performance objectives that must be achieved to develop a calcine retrieval system are: 1) determine the characteristics of the calcine in the storage bins (e.g. is it all free flowing?); 2) determine design parameters for a calcine retrieval system such as air flow requirements, mechanical functions, line and nozzle sizes, etc; and 3) determine an efficient way to remotely make new penetrations into bins.

Schedule Requirements: The Batt Settlement Agreement requires that a full-scale calcine treatment facility be in operation by 2020 . The first calcine retrieval system must also be operable by that time. Development work should be completed by 2010 to support design.

Problem Description: Radioactive calcine, currently stored in bins, must be retrieved for subsequent treatment and disposal. Retrieval must be performed remotely due to the high radiation levels. The equipment required to accomplish this task has not been designed since retrieval was not a major consideration during design of the storage bins.

\section{Justifications:}

Technical Justification: Initial tests have demonstrated a simple method for retrieving free flowing calcine, but more tests are needed to gather detailed design data, and remote mechanical systems must be developed. No determination has been made as to whether the calcine in the bins is free flowing. Samples from CSSF 2 showed that it was free flowing, but laboratory tests have shown that under more severe conditions, some calcines will form a cake. Retrieval of caked calcine has never been demonstrated.

Regulatory Justification: Initial tests have demonstrated a simple method for retrieving free flowing calcine, but more tests are needed to gather detailed design data, and remote mechanical systems must be developed. No determination has been made as to whether the calcine in the bins is free flowing. Samples from CSSF 2 showed that it was free flowing, but laboratory tests have shown that under more severe conditions, some calcines will form a cake. Retrieval of caked calcine has never been demonstrated.

ES\&H Justification: Development of a simple, efficient retrieval system will minimize radiation exposure to workers and minimize radioactive waste generation during calcine retrieval.

Cultural/Stakeholder Factors: Treatment of calcine would reduce the risk of calcine escaping from storage facilities which are located over the Snake River aquifer. In particular CSSF 1 does not meet current design requirements for seismic or static loads.

\section{Other Justification:}

Consequences of Not Filling Need: May not meet Batt Settlement Agreement milestone dates. Costs of calcine retrieval will be higher, more waste will be generated during retrieval, and workers will receive more radiation exposure. 


\begin{tabular}{lll}
\hline Tanks Focus Area & Need Title: Remove \& Transport Calcine \\
Site Needs & \multicolumn{1}{l}{} \\
& Site: Idaho & TFA Functional Area: Retrieval \& Closure \\
& Site ID\#: ID-2.1.09 & TFA Need ID\#: 650 \\
\hline
\end{tabular}

Privatization Potential: There are companies which specialize in cleaning caked material out of storage bins and silos. This work is often performed remotely to avoid the hazards associated with physically entering a bin filled with caked material, so it is likely that existing technology could be adapted for removing caked calcine from a bin. It is also likely that techniques developed for calcine retrieval could be adapted to other industries where it is becoming more important to reduce emissions of particulate and hazardous materials.

Current Base Technology and Cost: It is generally assumed that a mechanical arm will be required to maneuver throughout a bin to break up caked material with a vibrator and vacuum up the calcine. However, a system with these capabilities has not been adequately demonstrated, nor has it been adequately demonstrated that any of the calcine is caked. None of the commercially available systems for breaking up caked material has been investigated.

Cost: Millions of dollars can potentially be saved by developing a simple retrieval system. Savings may result from minimizing the number of penetrations into bins and by minimizing the complexity of remote mechanical systems required. The total cost of retrieval is estimated to be $\$ 250$ million. The goal of calcine retrieval technology development is to save at least $10 \%$ of this cost.

Current Baseline Timeline: Investigation into retrieving calcine from CSSF 1 demonstrated the potential to save several months.

SUMMARY OF TFA RESPONSE: Schedule requirement did not warrant technical response in FY98-FY00; if needed by 2010 , a development effort could be started in 7-10 years. 


\begin{tabular}{lll}
\hline Tanks Focus Area & Need Title: Tanks - New 3 - In-Situ Decontamination of Buried \\
Site Needs & Tank Contents & \\
& Site: Idaho & TFA Functional Area: Retrieval \& Closure \\
& Site ID\#: ID-6.1.20 & TFA Need ID\#: 651 \\
\hline
\end{tabular}

SITE NEED:

Need Description: A method is needed to in-situ decontaminate buried tanks, including capability of removing small, heavy particles lying on the bottom of tanks (i.e. not suspended in the slurry or sludge). Method should be able to perform at distances of up to 50 feet from tank openings and from regions of the tanks with restricted access, and in sumps or baffles.

Waste stream: Mixed TRU and RCRA tank waste

Functional Performance Requirements: Remote or robotic means of decontaminating underground storage tanks are needed in order to complete this work with minimal personnel exposure. Confined space considerations and contaminant/radiation exposure precludes manual decontamination, particularly for tanks with maximum dimensions exceeding 20 feet or containing internal obstructions such as baffles, etc. The equipment must be capable of operating in tanks containing up to 5 percent residual waste and be capable of deploying a range of sensors to verify adequate decontamination. The equipment should be designed for ease of decontamination following use.

Schedule Requirements: To provide maximum support to the INEEL CERCLA mixed waste tank remediations, the need date is September 1,1997 . The latest date that information derived from this technological development would be useable for INEEL RI/FSs is October 1, 1998. However, the general problem of characterizing storage tanks greatly transcend the boundaries of the INEEL CERCLA USTs; hundreds of small storage tanks exist across the DOE complex that eventually will undergo D\&D and require characterization. Therefore, inability to meet the above need dates should not by itself be a criterion for eliminating this need from consideration.

Problem Description: There are currently 11 buried waste tanks and potentially contaminated soils, containing TRU and mixed waste. Tanks range from 100 to 50,000 gallons. There will be more tanks identified for remediation at the INEEL over the next several years.

\section{Justifications:}

Technical Justification: Existing methods fail to identify tanks sufficiently.

Regulatory Justification: Existing methods fail to identify tanks sufficiently.

ES\&H Justification: Potential risk to human health and the environment.

\section{Cultural/Stakeholder Factors:}

Other Justification:

Consequences of Not Filling Need: Schedule and budget may not be met.

Privatization Potential: High

Current Base Technology and Cost: Cost: \$1-2 Million

Current Baseline Timeline: Approximately 1 year.

SUMMARY OF TFA RESPONSE: The TFA rated the priority of the technical response to this need as \#48. The TFA proposes to provide funding in FY98-00, given available funding. Other needs satisfied under the proposed technical response include Need ID\# 652, 653, 655, and 656. 


\begin{tabular}{lll}
\hline Tanks Focus Area & \multicolumn{2}{l}{ Need Title: Tanks - New 2 - Removal and Consolidation of } \\
Site Needs & Waste from Buried Tanks & \\
& Site: Idaho & TFA Functional Area: Retrieval \& Closure \\
& Site ID\#: ID-6.1.21 & TFA Need ID\#: 652 \\
\hline
\end{tabular}

SITE NEED:

Need Description: A method is needed for the removal of waste from buried tanks including consolidation of waste between tanks, without release of contaminants to the environment. Tanks range from 100 to 50,000 gallons. The method should be capable of being remotely operated.

Waste stream: Mixed TRU and RCRA Contaminated Tank Waste, scattered across the INEEL. Some locations include: ARA-1, TAN, and ICPP.

Functional Performance Requirements: A method is needed to remotely remove waste from buried mixed waste tanks while transferring the waste to DOT approved shipping containers. Risk driving actinides and organics must be removed from tanks. We anticipate that below risk levels will result in only 1 to 4 percent residual product remaining in the tank and that no equipment will be left behind. This technology must also be suitable for use to remotely transfer contents from one tank to another over distances of approximately 100 feet. The technology must be capable of removing from tanks approximately 30 feet below the surface as well as from the sumps of the tanks. The tank access may be up to 20 feet from the end of a tank and the tanks often contain baffles and flanges. The equipment must be easily decontaminated.

Schedule Requirements: To provide maximum support to the INEEL CERCLA mixed waste tank remediations, the need date is October 1,1997 . The latest date that information derived from this technological development would be useable for INEEL RI/FSs is October 1, 1998. However, the general problem of waste removal and consolidation from underground storage tanks transcends the boundaries of the INEEL CERCLA USTs; hundreds of underground storage tanks exist across the DOE complex that eventually will undergo D\&D and require excavation/removal. Therefore, inability to meet the above need dates should not by itself be a criterion for eliminating this need from consideration.

Problem Description: There are currently 11 buried waste tanks and potentially contaminated soils, containing TRU and mixed waste. Tanks range from 100 to 50,000 gallons. There will be more tanks identified for remediation at the INEEL over the next several years.

Justifications:

Technical Justification: Existing methods may leave unacceptable risk or not meet existing schedule and budget.

Regulatory Justification: Existing methods may leave unacceptable risk or not meet existing schedule and budget.

ES\&H Justification: Potential risk to human health and the environment.

\section{Cultural/Stakeholder Factors:}

\section{Other Justification:}

Consequences of Not Filling Need: Existing methods may leave unacceptable risk or not meet existing schedule and budget.

Privatization Potential: High

Current Base Technology and Cost: Cost: \$2-4 Million

Current Baseline Timeline: Approximately 3 years. 


\section{Site Needs}

Site: Idaho

TFA Functional Area: Retrieval \& Closure

Site ID\#: ID-6.1.21 TFA Need ID\#: 652

SUMMARY OF TFA RESPONSE: The technical response to this need is included in the TFA's technical response to Need ID\# 651. 


\begin{tabular}{lll}
\hline Tanks Focus Area & Need Title: Tanks - New 1 - In-Situ Homogenization of Buried \\
Sank Waste & \\
& & \\
& Site: Idaho & TFA Functional Area: Retrieval \& Closure \\
& Site ID\#: ID-6.1.22 & TFA Need ID\#: 653 \\
\hline
\end{tabular}

SITE NEED:

Need Description: Need to determine and potentially improve upon best existing in-situ methods for mixing sludge and liquids in buried tanks.

Waste stream: Mixed TRU, metal, VOC and PCB contaminated tank waste

Functional Performance Requirements: A remotely operated mixing system is required to homogenize tank contents to allow the contents to be pumped from the tank. Tanks range in size from 500 to 10,000 gallons and the mixing equipment must be able to homogenize the entire tank contents, including sumps. Direct access to the tank may be up to 200 feet from the end of the tank. The technology must be capable of mixing the contents in the presence of internal baffles and flanges. The equipment must be easily decontaminated. It is desired that the mixing system be portable (usable at the location of the storage tanks) and that the mixing system be sufficiently robust to mix tank sludge with solid contents ranging up to 90 percent.

Schedule Requirements: To provide maximum support to the INEEL CERCLA mixed waste tank remediations, the need date is September 1,1997 . The latest date that information derived from this technological development would be useable for INEEL RI/FSs is October 1, 1998. However, the general problem of untreatable waste mixtures greatly transcend the boundaries of the INEEL CERCLA USTs; hundreds of mixed waste tanks exist across the DOE complex that eventually will undergo D\&D. Therefore, inability to meet the above need dates should not by itself be a criterion for eliminating this need from consideration.

Problem Description: There are currently 11 buried waste tanks and potentially contaminated soils, containing TRU and mixed waste. Tanks range from 100 to 50,000 gallons. There will be more tanks identified for remediation at the INEEL over the next several years.

Justifications:

Technical Justification: No existing in-situ mixing technology available.

Regulatory Justification: No existing in-situ mixing technology available.

ES\&H Justification: Potential risk to human health and the environment.

Cultural/Stakeholder Factors:

Other Justification:

Consequences of Not Filling Need: Higher cost of remediation.

Privatization Potential: High

Current Base Technology and Cost: Cost: $\$ 5-10$ Million

Current Baseline Timeline: Approximately 3 years.

SUMMARY OF TFA RESPONSE: The technical response to this need is included in the TFA's technical response to Need ID\# 651 . 
Site: Idaho

Site ID\#: ID-6.1.03
TFA Functional Area: Pretreatment TFA Need ID\#: 654

\section{SITE NEED:}

Need Description: In-situ treatment methods for sludge in buried tanks containing TRU isotopes, uranium, fission products, VOCs, SVOCs, metals, and PCBs that will meet LDRs, TCLP, and other applicable regulations. This task matches with High Level Waste Tank needs.

Waste stream: Mixed TRU, metal, VOC, and PCB contaminated tank waste.

INEEL ranked this need 3 out of 10 needs for environmental restoration.

Functional Performance Requirements: The mixture of contaminants in mixed waste tank sludges are often such that at least one constituent exceeds the acceptance criteria of existing Treatment, Storage, and Disposal (TSD) facilities. In most cases, if the organic constituents of the tanks could be substantially reduced or totally eliminated, the remaining contaminants could then be treated or disposed of at existing TSD facilities. An insitu treatment method is desired to minimize personnel exposure and risk of release to the environment. The minimum desired performance requirements is reduction of $\mathrm{PCB}$ concentrations to less than $5 \mathrm{ppm}$ and reduction of other organic contaminants to concentrations compatible TSD acceptance criteria. Further separation of the contaminants into radioactive components and heavy metal components would be desirable, but is of secondary importance to the elimination or reduction of VOCs, SVOCs, and PCBs.

Schedule Requirements: To provide maximum support to the INEEL CERCLA mixed waste tank remediations, the need date is October 1,1997 . The latest date that information derived from this technological development would be useable for INEEL RU/FSs is October 1, 1998. However, the general problem of untreatable waste mixtures greatly transcend the boundaries of the INEEL CERCLA USTs; hundreds of mixed waste tanks exist across the DOE complex that eventually will undergo D\&D. Therefore, inability to meet the above need dates should not by itself be a criterion for eliminating this need from consideration.

Problem Description: Tanks contain a wide variety of RCRA contaminants. Organic contaminants include: PCBs up to $1000 \mathrm{ppm}$, TCE up to $10,000 \mathrm{ppm}$, TCA up to $1000 \mathrm{ppm}$, and acetone. Metals include: $\mathrm{Cd}, \mathrm{Pb}, \mathrm{As}$, $\mathrm{Ag}$, and $\mathrm{Cr}$.

\section{Justifications:}

Technical Justification: No existing in-situ treatment technology available.

Regulatory Justification: No existing in-situ treatment technology available.

ES\&H Justification: Potential risk to human health and the environment.

\section{Cultural/Stakeholder Factors:}

Other Justification:

Consequences of Not Filling Need: Schedule for remediation may not be met.

Privatization Potential: High

Current Base Technology and Cost: Cost: Approximately \$5-10 Million

Current Baseline Timeline: Approximately 3 years.

SUMMARY OF TFA RESPONSE: The TFA program scope has not included treatment of organics such as PCBs or mixed wastes, nor has it included in-situ treatment. The TFA determined that this need did not fall 
Tanks Focus Area Need Title: In-Situ Treatment of Mixed TRU Tank Wastes Site Needs

Site: Idaho

Site ID\#: ID-6.1.03
TFA Functional Area: Pretreatment TFA Need ID\#: 654

within the TFA program mission and recommends that DOE-ID forward this need to the Mixed Waste Focus Area for consideration. 


\begin{tabular}{lll}
\hline Tanks Focus Area & Need Title: In-Situ Characterization of Tank Contents \\
Site Needs & & \\
& Site: Idaho & TFA Functional Area: Retrieval \& Closure \\
& Site ID\#: ID-6.1.07 & TFA Need ID\#: 655 \\
\hline
\end{tabular}

SITE NEED:

Need Description: A method is needed for in-situ characterization of tank contents, including capability of detecting small, heavy particles lying on the bottom of tanks (i.e. not suspended in the slurry or sludge). Method should be able to obtain data at distances of up to 50 feet from tank openings and from regions of the tanks with restricted access, and in sumps or baffles.

Waste stream: Mixed TRU and RCRA tank waste, scattered across the INEEL. Some locations include ARA-1, TAN, and ICPP.

INEL ranked this need 7 of 10 needs for environmental restoration.

Functional Performance Requirements: Remote or robotic means of sampling and examining underground storage tanks are needed in order to perform characterization with minimum personnel exposure. Confined space considerations and contaminant/radiation exposure precludes manual sampling, particularly for tanks with maximum dimensions exceeding ten feet or containing internal obstructions such as baffles, etc. The equipment must be capable of operating in partially or completely filled tanks, obtaining liquid, sludge, and solid samples, and be capable of deploying a range of sensors, including video cameras, laser imaging equipment, ultrasound QC equipment, etc. The equipment should be designed for ease of decontamination following use.

Schedule Requirements: To provide maximum support to the INEEL CERCLA mixed waste tank remediations, the need date is May 1,1997 . The latest date that information derived from this technological development would be useable for INEEL RI/FSs is October 1, 1998. However, the general problem of characterizing storage tanks greatly transcend the boundaries of the INEEL CERCLA USTs; hundreds of small storage tanks exist across the DOE complex that eventually will undergo D\&D and require characterization. Therefore, inability to meet the above need dates should not by itself be a criterion for eliminating this need from consideration.

Problem Description: There are currently 11 buried waste tanks and potentially contaminated soils, containing TRU and mixed waste. Tanks range from 100 to 50,000 gallons. There will be more tanks identified for remediation at the INEEL over the next several years.

\section{Justifications:}

Technical Justification: Existing methods fail to identify tanks sufficiently.

Regulatory Justification: Existing methods fail to identify tanks sufficiently.

ES\&H Justification: Potential risk to human health and the environment.

\section{Cultural/Stakeholder Factors:}

Other Justification:

Consequences of Not Filling Need: Schedule and budget may not be met.

Privatization Potential: High

Current Base Technology and Cost: Cost: $\$ 1$ to 2 Million

Current Baseline Timeline: Approximately 1 year. 


\begin{tabular}{|c|c|c|}
\hline \multirow{2}{*}{$\begin{array}{l}\text { Tanks Focus Area } \\
\text { Site Needs }\end{array}$} & \multicolumn{2}{|c|}{ Need Title: In-Situ Characterization of Tank Contents } \\
\hline & $\begin{array}{l}\text { Site: Idaho } \\
\text { Site ID\#: ID-6.1.07 }\end{array}$ & $\begin{array}{l}\text { TFA Functional Area: Retrieval \& Closure } \\
\text { TFA Need ID\#: } 655\end{array}$ \\
\hline
\end{tabular}

SUMMARY OF TFA RESPONSE: The technical response to this need is included in the TFA's technical response to Need ID\# 651. 


\begin{tabular}{lll}
\hline Tanks Focus Area & Need Title: Removal of Small to Medium Buried Tanks \\
Site Needs & & \\
& Site: Idaho & TFA Functional Area: Retrieval \& Closure \\
& Site ID\#: ID-6.1.17 & TFA Need ID\#: 656 \\
\hline
\end{tabular}

SITE NEED:

Need Description: A method is needed for the removal of 11 buried waste tanks and potentially contaminated soils, containing TRU and mixed waste, without release of contaminants to the environment. Tanks range from 100 to 50,000 gallons. The method should cause minimal risk of damaging the object being excavated, buried piping, or cable runs, and it should be capable of being remotely operated.

Waste stream: Mixed TRU and RCRA Contaminated Tank Waste, scattered across the INEEL. Some locations include: ARA-1, TAN, and ICPP.

INEEL ranked this need 8 of 10 needs for environmental restoration.

Functional Performance Requirements: Underground storage tanks are often located in close proximity to active utility and/or process piping, cable runs, etc. Also, it is not uncommon that undocumented, abandoned piping exists near the tanks undergoing remediation. In addition, the soils surrounding the tanks are often contaminated by spills or leakage. To minimize airborne contamination release and to minimize the risk of contaminant release to the environment, dustless excavation technologies are needed that will not damage or rupture pipes, cables, or structures encountered during the excavation. The technology should be capable of excavating 10 cubic yards of material per hour at depths up to 20 feet. In addition, it should capture and package the excavated material such that it can be removed from the excavation site without direct human contact.

Schedule Requirements: To provide maximum support to the INEEL CERCLA mixed waste tank remediations, the need date is October 1,1997 . The latest date that information derived from this technological development would be useable for INEEL RI/FSs is October 1, 1998. However, the general problem of excavating underground storage tanks greatly transcend the boundaries of the INEEL CERCLA USTs; hundreds of underground storage tanks exist across the DOE complex that eventually will undergo D\&D and require excavation/removal. Therefore, inability to meet the above need dates should not by itself be a criterion for eliminating this need from consideration.

Problem Description: There are currently 11 buried waste tanks and potentially contaminated soils, containing TRU and mixed waste. Tanks range from 100 to 50,000 gallons. There will be more tanks identified for remediation at the INEEL over the next several years.

Justifications:

Technical Justification: Existing methods may leave unacceptable risk or not meet existing schedule and budget.

Regulatory Justification: Existing methods may leave unacceptable risk or not meet existing schedule and budget.

ES\&H Justification: Potential risk to human health and the environment.

\section{Cultural/Stakeholder Factors:}

Other Justification:

Consequences of Not Filling Need: Existing methods may leave unacceptable risk or not meet existing schedule and budget.

Privatization Potential: High 


\begin{tabular}{lll}
\hline Tanks Focus Area & Need Title: Removal of Small to Medium Buried Tanks \\
Site Needs & & \\
& Site: Idaho & TFA Functional Area: Retrieval \& Closure \\
& Site ID\#: ID-6.1.17 & TFA Need ID\#: 656 \\
\hline
\end{tabular}

Current Base Technology and Cost: Cost: \$2-4 Million

Current Baseline Timeline: Approximately 3 years.

SUMMARY OF TFA RESPONSE: The technical response to this need is included in the TFA's technical response to Need ID\# 651. 


\section{Tanks Focus Area $\quad$ Need Title: Large Sample Hot Cell DSC/TGA Based Energetics

Site Needs

\section{SITE NEED:}

Need Description: An instrument is required to estimate the energetics of complex chemical mixtures obtained by sampling Hanford waste tanks. The energetics of wastes when dried is one measure of safety during storage of wastes in Hanford single-shell tanks. Present methods, using milligram aliquots of waste samples produce an uncertainty too high for such safety decisions.

\section{Waste stream: Double Shell Tanks; Single Shell Tanks, Tank Farms \\ Type of Procurement: Industry [Adaptation of Existing Equipment]}

Functional Performance Requirements: The instrumentation needs to be deployable in a hot cell and be capable of measuring energetics (DSC) and moisture (TGA) over the ambient to 500 degree centigrade range on high level waste samples. This system can be modular e.g. only the sample containing module need be located in the hot cell with controller and processor located outside the hot cell. Component modules (cell loading, etc) located inside the hot cell must be operable remotely, with manipulators.

Modules located inside the hot cell must be constructed to withstand a highly corrosive environment, high sodium hydroxide samples.

The unit needs to be suitable for analysis of aliquots of sample greater than 0.5 grams. Reproducibility of measurements are to be better than 20 percent (relative). Methods of testing and maintaining performance need to be available either by replacement of components or easily replaced parts.

Schedule Requirements: Procurement should be made in FY 1998 of a modified or off the shelf instrument identified by technology transfer outreach efforts. Since this is a primary screening measurement for the program, the method must be rapid and performed by technologists in the laboratory. Reruns are frequently requested to bring the precision of measurements within the program specifications. These reruns may require new aliquots to be removed from the hot cell which significantly extends results reporting time.

Problem Description: Several letters have been received from the Waste Tank Safety Program, TWRS, that document deficiencies of the methodology currently used for this measurement. Current instrumentation uses only $10-30 \mathrm{mg}$ of sample and this is insufficient to average microheterogeneities within the waste material. Measurements on waste samples result in variations between duplicate aliquots less precise than required by the program.

\section{Justifications:}

Technical Justification: Safe storage of waste in tanks is in part assured by the non-reactive waste form or it is mitigated to a conditionally safe form. The measure of energetics present in the complex waste form cannot be adequately calculated and must be empirically measured.

Regulatory Justification: Safe storage of waste in tanks is in part assured by the non-reactive waste form or it is mitigated to a conditionally safe form. The measure of energetics present in the complex waste form cannot be adequately calculated and must be empirically measured.

ES\&H Justification: Environmental releases of radioactive and toxic wastes could result from propagating exothermic events inside the waste tanks. These events can be mitigated to preclude the parameters, (e.g. waste dry-out, ignition source, etc.) at a cost to intrusive activities. If mitigation is not required, i.e. waste is not reactive, fewer parameters require monitoring for continued safe storage and processing. 


\begin{tabular}{lll}
\hline Tanks Focus Area & Need Title: Large Sample Hot Cell DSC/TGA Based Energetics \\
Site Needs & Measurement & \\
& Site: Hanford & TFA Functional Area: Characterization \\
& Site ID\#: Char 3 & TFA Need ID\#: 657 \\
\hline
\end{tabular}

Cultural/Stakeholder Factors: Several stakeholder/oversight panels have been established to review and recommend actions based on available information. Energetics data is recognized by these panels to be a basis for classifying the waste tanks.

Other Justification: N/A

Consequences of Not Filling Need:

Privatization Potential:

Current Base Technology and Cost:

Current Baseline Timeline:

SUMMARY OF TFA RESPONSE: The TFA rated the priority of the technical response to this need as \#64. The TFA proposes to provide funding in FY98-99, given available funding. 


\begin{tabular}{lll}
\hline Tanks Focus Area & Need Title: Technetium-99 Analysis in Low Level Waste Feed \\
Site Needs & & \\
& Site: Hanford & TFA Functional Area: Characterization \\
& Site ID\#: Char 4 & TFA Need ID\#: 658 \\
\hline
\end{tabular}

SITE NEED:

Need Description: An accurate, robust production laboratory method for the measurement of technetium-99 concentration in Hanford waste tank material is needed. The measurement methodology needs to be tested for consistency of performance between DOE sites characterizing waste materials (round robin exchange, etc.). This methodology must also be suitable for characterizing soils from the vadose zone which receives any leakage of tank wastes.

\section{Waste stream: Low Level Waste, 222-S Laboratory}

Functional Performance Requirements: A methodology is needed which is appropriate for production laboratory use to routinely measure the concentration of technetium- 99 in waste tank matrices representing any of the waste classifications considered potential feed sources to the vitrification vendors.

1. Candidate methodologies should be tested by round robin exchanges of actual samples selected for variability due to matrix and interferences.

2. Absolute accuracy represented by agreement in the concentration value of better than 10 percent is required.

3. Precision, as measured by the reproducibility of replicate measurements of a sample should be no greater than 15 percent.

4. The methodology demonstrated should be rapid, representing no more than 4 hours to complete.

Schedule Requirements: Waste identification is in progress in 1997, and waste staging for the private vitrification contractor will be initiated by 1999 . Therefore the methodology needs to be available in 1997 or early 1998.

Problem Description: An accurate production laboratory method for establishing the technetium-99 concentration in low level waste and vadose zone soils is needed. Technetium-99 concentration is a critical component of feed to the waste vitrification vendors. The absolute accuracy of these analytical results produced at Hanford has been questioned and found to be in disagreement with results produced at another DOE site. Variability of redox potential and interferences present in Hanford tank wastes produces inconsistent performance of sample preparation methods in use. In addition, the method must be applicable to soils which may receive waste material that leak from the tank. Technetium in the +7 oxidation state is known to be mobile in the soil column and therefore the concentration in tank wastes must be known well to estimate long term effects of waste tank leakage during storage or retrieval operations.

\section{Justifications:}

Technical Justification: Private vendors will receive low level waste, after being characterized and concentrations of analytes documented. If sensitive analyte concentrations are inaccurately represented, the DOE will be responsible for environmental and process rework caused. Without this interlaboratory testing and acceptance, the liability is likely to remain unresolved.

Science: Measurement methodology must be demonstrated acceptable by peer review. This is performed by sample exchange between national laboratories and process control laboratories. The reduction-oxidation potential will be different from tank-to-tank as a result of organic and inorganic components present.

Extractions performed to reduce the effects of radiochemical interferences are only effective when the isotope is in the +7 oxidation state. Therefore the measurement methodology must be robust to overcome the matrix reductants and oxidize all oxidation states of technetium to the pertechnetate form.

Regulatory Justification: Private vendors will receive low level waste, after being characterized and concentrations of analytes documented. If sensitive analyte concentrations are inaccurately represented, the DOE will be responsible for environmental and process rework caused. Without this interlaboratory testing and acceptance, the liability is likely to remain unresolved. 


\section{Tanks Focus Area Need Title: Technetium-99 Analysis in Low Level Waste Feed Site Needs \\ Site: Hanford \\ Site ID\#: Char 4 \\ TFA Functional Area: Characterization TFA Need ID\#: 658}

Science: Measurement methodology must be demonstrated acceptable by peer review. This is performed by sample exchange between national laboratories and process control laboratories. The reduction-oxidation potential will be different from tank-to-tank as a result of organic and inorganic components present.

Extractions performed to reduce the effects of radiochemical interferences are only effective when the isotope is in the +7 oxidation state. Therefore the measurement methodology must be robust to overcome the matrix reductants and oxidize all oxidation states of technetium to the pertechnetate form.

ES\&H Justification: Pertechnetates can be volatilized during processing of waste for vitrification. High concentrations not removed during pretreatment may be disbursed through the gaseous emissions during the vitrification process. Feed to the private vitrification vendor must be properly classified and manifested. Leakage during storage or retrieval operations may deposit waste containing technetium-99 into the soils surrounding the tanks. The mobility and long half-life of the isotope makes the concentration value significant for environmental consequences.

Cultural/Stakeholder Factors: Measurement data will have better credibility with the oversight panels when the measurement methodology has been peer reviewed and accepted. Issues concerning emissions from the pretreatment and vitrification processes should be answerable with documented data.

\section{Other Justification:}

Consequences of Not Filling Need:

\section{Privatization Potential:}

Current Base Technology and Cost:

\section{Current Baseline Timeline:}

SUMMARY OF TFA RESPONSE: The TFA rated the priority of the technical response to this need as \#51. The TFA proposes to provide funding in FY98-99, given available funding. 


\section{Site Needs}

Site: Hanford

Site IDH: Char 5
TFA Functional Area: Characterization TFA Need ID\#: 659

\section{SITE NEED:}

Need Description: A rapid method for quantitation of major organic constituents in Hanford tank wastes is needed to estimate flammability, fuel content, and complexing capacity. Total organic carbon analyses frequently indicate single shell and double shell tanks have high levels of organic material present. At least 80 percent of the total organic content needs to be identified with compounds for evaluation of waste classification as "safe," "conditionally safe," or "unsafe."

\section{Waste stream: Low Level Waste, 222-S Laboratory}

Functional Performance Requirements: Acceptable methodology must be capable of providing analysis of waste tank samples within one week of sample receipt at the work station. The accepted method must also require no more than four hours of instrument time for each sample (assumes duplicate aliquots and quality assurance). The method must provide sufficient sensitivity that major species of organic acids and complexing agents (e.g. EDTA and HEDTA) will account for 80 percent of the organic carbon present if present in a sample at greater than 1 weight percent of the sample as compared to the extensive methodology (HPLC, HPLC/MS, etc.).

Testing will compare data generated between the various methodologies at Hanford and at other DOE sites. The principal focus will be analyses on actual waste samples using ion chromatography, capillary zone electrophoresis, and other suitable technologies available at other sites. Tests should be conducted to determine the effect of matrix interferences on the measurement.

Schedule Requirements: The Waste Tank Safety Program is focussed on closing the organic and organic nitrate issues in fiscal year 1998. Initial characterization of wastes will be primarily by labor intensive methodologies. An improved method is needed to complete the quantitation of major constituents by fiscal year 1998. Preliminary testing will be conducted in 1997, with initial comparisons between IC, CZE, and HPLC methods funded by the EM-30 User Program. The need will continue well beyond the year 2000 for the PHMC contractors to manifest DOE wastes to private contractors for immobilization under contract. This latter need requires measurements to be defensible in contract resolution issues.

Problem Description: Major species of organic carbon present in tanks need to be identified with specific compounds as a test for flammability, fuel content and complexing capacity. Current requirements are derived from TWRS, Waste Tank Safety Program, Organic Issue Resolution negotiations with the Defense Nuclear Facilities Safety Board (DNFSB). The Organic Safety Program needs rapid quantitation of major constituents to fulfill its responsibility for identifying and mitigating conditions, if necessary, that are unacceptable for safe storage and intrusive activities in tanks.

\section{Justifications:}

Technical Justification: The TWRS Organic Safety Program is charged with responsibility for identifying flammable fuel loadings in waste tanks. In addition, organics complex the fissile inventory (e.g., Pu) in waste and can redistribute this material rather than remaining in the sludge. Defensible concentration data must be available to the DNFSB and private immobilization contractors.

Regulatory Justification: The TWRS Organic Safety Program is charged with responsibility for identifying flammable fuel loadings in waste tanks. In addition, organics complex the fissile inventory (e.g., Pu) in waste and can redistribute this material rather than remaining in the sludge. Defensible concentration data must be available to the DNFSB and private immobilization contractors.

ES\&H Justification: In the event a single shell tank containing complexed waste leaks, the waste products can be expected to migrate through the soil column more rapidly and with less driving force than uncomplexed waste. When complexed, "non-mobile" radioactive and nonradioactive constituents can reach groundwater. 
Tanks Focus Area Need Title: Rapid Speciation of Organic Acids and Complexants Site Needs

Site: Hanford Site ID\#: Char 5
TFA Functional Area: Characterization TFA Need ID\#: 659

Cultural/Stakeholder Factors: As discussed above, both scientific and environmental concerns are frequently raised that cannot be dispelled without the knowledge gathered by measurements. This data needs to be available on most tanks remaining on the characterization schedule.

Other Justification:

Consequences of Not Filling Need:

Privatization Potential:

Current Base Technology and Cost:

Current Baseline Timeline:

SUMMARY OF TFA RESPONSE: The TFA rated the priority of the technical response to this need as \#65. The TFA proposes to provide funding in FY98, given available funding. 
Site: Hanford

Site ID\#: Char 7
TFA Functional Area: Characterization TFA Need ID\#: 660

\section{SITE NEED:}

Need Description: There is a need to gather data on single shell and double shell tanks, in areas where conventional core sampling is not effective. Data gathered will support both stabilization and retrieval functions.

\section{Waste stream: Single Shell Tanks and Double Shell Tanks, Tank Farms}

Functional Performance Requirements: Samples must be reviewed from tanks at locations not directly below existing tank risers. Sampling devices can be deployed using existing rotary or push-mode core sample systems, from the Light Duty Utility Arm, or by using other methods that are compatible with the materials and safety requirements of the waste tanks. Samples are needed at various depths to support statistical evaluation of data. However, surface-only sampling capability would be an improvement over existing methods and will be considered. Sample size should be approximately $100 \mathrm{~mL}$. Sampling methods must not contaminate the waste with hydrocarbons, etc. Methods that preserve the physical integrity of the waste material are preferred but not required.

Schedule Requirements: Needed by the Characterization Project in FY1999/2000 time frame, to support completion of the sampling needs, required per DNFSB 93-5.

Problem Description: Currently, the truck core sampling systems (i.e., rotary and push mode core trucks) have difficulty in attaining samples, sometimes. If there are sections (layers) of the tank that waste sample material is not available for analysis, critical information may be missing that is necessary to understand the tank contents, and ultimately dispose of the tank contents.

\section{Justifications:}

Technical Justification: Proposed work scope would be used to gather critical waste sample data on single shell and double shell tanks. This information is needed to understand their contents sufficiently to retrieve them, and ultimately dispose of them. In areas where the core sampling is ineffective this data will be missing unless an alternative is developed.

Regulatory Justification: Proposed work scope would be used to gather critical waste sample data on single shell and double shell tanks. This information is needed to understand their contents sufficiently to retrieve them, and ultimately dispose of them. In areas where the core sampling is ineffective this data will be missing unless an alternative is developed.

ES\&H Justification: Will establish methods to calculate environmental insult due to tank waste.

Cultural/Stakeholder Factors: Resolution of major stakeholder issue related to tank waste characterization of both the DSTs and the SSTs.

\section{Other Justification: N/A}

Consequences of Not Filling Need: Costly core sampling activities will have to be re-run, when voids in characterization information are determined.

Privatization Potential: N/A

Current Base Technology and Cost: Push mode and Rotary Mode Core Sampling.

Current Baseline Timeline: 
Tanks Focus Area $\quad$ Need Title: In-Tank Core Sampling...Off-Riser Capability Site Needs

Site: Hanford

Site ID\#: Char 7
TFA Functional Area: Characterization TFA Need ID\#: 660

SUMMARY OF TFA RESPONSE: The technical response to this need has been included in the TFA's technical response to Need ID\# 679, the Hanford Tanks Initiative. 


\section{SITE NEED:}

Need Description: There is a need to obtain large quantities of material from the tanks for analysis, and testing, to support pretreatment, safety, and retrieval.

Waste stream: Single Shell Tanks and Double Shell Tanks, Tank Farms

Functional Performance Requirements: The system developed must be capable of removing large volumes $(\sim 3-5 \mathrm{~L})$ of sludge, and/or supernate, from the DSTs and the SSTs. This system must be compatible with the current sample casks, supporting transportation, and sample handling systems at Hanford's 222-S Lab.

Schedule Requirements: Needed by the Characterization Project in FY1999/2000 time frame, to support completion of the sampling needs, required per DNFSB 93-5.

Problem Description: There is no system available to aid in attaining large volume sludge and Supernate. The largest volume sampler for this activity, currently, is the $125 \mathrm{~mL}$ "Bottle-on-a-string."

\section{Justifications:}

Technical Justification: Proposed work scope would be used to gather critical waste sludge and supernate samples, for single shell and double shell tanks. This information is needed to understand their contents sufficiently to retrieve them, and ultimately dispose of them.

Regulatory Justification: Proposed work scope would be used to gather critical waste sludge and supernate samples, for single shell and double shell tanks. This information is needed to understand their contents sufficiently to retrieve them, and ultimately dispose of them.

ES\&H Justification: Will establish methods to calculate environmental insult due to tank waste.

Cultural/Stakeholder Factors: Resolution of major stakeholder issue related to tank waste characterization of both the DSTs and the SSTs.

\section{Other Justification: N/A}

Consequences of Not Filling Need: Attaining the large volumes of sludge, and supernate required for the privatization effort would have to be done using existing "technology," the needs in this area will not be completed, or it will take a longer time, and greater exposure.

\section{Privatization Potential:}

Current Base Technology and Cost: $125-\mathrm{ml}$ sampler

\section{Current Baseline Timeline:}

SUMMARY OF TFA RESPONSE: The TFA did not propose a technical response to this need, and felt a solution already exists; no technology development or deployment support was warranted. 


\begin{tabular}{lll}
\hline Tanks Focus Area & Need Title: DST Corrosion Monitoring \\
Site Needs & & \\
& Site: Hanford & TFA Functional Area: Safety \\
& Site ID\#: OP1 & TFA Need ID\#: 662 \\
\hline
\end{tabular}

SITE NEED:

Need Description: Corrosion monitoring of DSTs is currently provided by process knowledge and tank sampling. Tanks found to be within chemistry specification limits are considered to be not at risk for excessive corrosion damage. There have been no direct corrosion monitoring systems for DSTs in use at the Hanford Site. The recent discovery of six low hydroxide (out of corrosion specification) tanks indicates that this system is inadequate to support corrosion control. Tank samples are infrequent and their analysis difficult and expensive. Process knowledge is complicated by waste streams that are exempt from the corrosion control specifications. In-tank, real-time measurement of the corrosive characteristics of the tank wastes is needed to provide an acceptable level of corrosion control information.

Waste stream: Double Shell Tanks, Tank Farms

Functional Performance Requirements:

- Identify the onset of stress corrosion cracking.

- Identify the onset of pitting.

- Order of magnitude quantification of mass loss during pitting and cracking.

- Quantification of uniform corrosion rates.

Schedule Requirements: Work is to be performed in FY 1997 and 1998.

Problem Description: Corrosion control of high level waste DST is currently provided by concentration limits on hydroxide, nitrite, and nitrate. Monitoring of the chemistry is provided by tank samples and process knowledge. As many as six DSTs at Hanford have operated outside of corrosion chemistry limits in the past 2 years. Detection and remediation of these low hydroxide tanks has been slow and costly.

Available technology for corrosion monitoring has progressed to a point where it is now feasible to monitor and control corrosion by on-line monitoring of the corrosion process and direct addition of corrosion inhibitors. The potential benefits of a corrosion monitoring system include:

1. Safer operation and reduced risk of tank liner failure. Corrosion will be monitored directly, versus monitoring chemical species. Assumptions about tank waste homogeneity and accuracy of the corrosion chemistry specification will be reduced or removed.

2. Significant potential for cost reduction: $\$ 100 \mathrm{~K}$ unplanned work scope at Hanford in FY 1996 on sampling and analysis to determine the extent of out of specification conditions.

3. Increased tank life due to more rapid identification and resolution of off-normal conditions.

4. Avoidance of unnecessary chemical additions due to unknown corrosion conditions: More than 10,000 gallons of waste volume added to the tanks at Hanford through FY 1996 through unplanned sodium hydroxide additions. Direct monitoring of the actual tank corrosion conditions may have shown these additions to be unnecessary.

5. Possible cost savings over time as a result of the relaxation of corrosion inhibitor addition requirements as corrosion behavior becomes better understood.

\section{Justifications:}

Technical Justification: Real time corrosion monitoring has been selected for preliminary evaluation at the Hanford Site. The use of such a system in Hanford waste tanks would allow for real-time monitoring of both corrosion processes and corrosion inhibitor addition. Real-time data collection would facilitate identification of the precise time when a corrosion process begins to occur in a tank. This, coupled with corrosion rate information also generated, would help in determining the extent of design life lost due to degradation by abnormal corrosion conditions. Similarly, real-time corrosion monitoring during inhibitor addition would allow one to observe corrosion conditions return to an acceptable level. Therefore, unnecessary inhibitor addition could be eliminated. The current system cannot offer this capability. 


\section{Tanks Focus Area Need Title: DST Corrosion Monitoring Site Needs \\ Site: Hanford \\ Site ID\#: OP1 \\ TFA Functional Area: Safety \\ TFA Need ID\#: 662}

Available techniques offer the ability to distinguish between uniform corrosion, stress corrosion cracking, pitting, and other forms of localized corrosion as they occur. They also generate uniform corrosion rate data identical to what is currently derived from chemical sampling. Some available corrosion monitoring techniques using electrical resistance probes or linear polarization resistance probes are not capable of distinguishing between uniform and localized forms of corrosion. These would not be considered acceptable. The most likely cause of failure in DSTs is degradation due to some form of localized corrosion.

Regulatory Justification: Real-time corrosion monitoring has been selected for preliminary evaluation at the Hanford Site. The use of such a system in Hanford waste tanks would allow for real-time monitoring of both corrosion processes and corrosion inhibitor addition. Real-time data collection would facilitate identification of the precise time when a corrosion process begins to occur in a tank. This, coupled with corrosion rate information also generated, would help in determining the extent of design life lost due to degradation by abnormal corrosion conditions. Similarly, real-time corrosion monitoring during inhibitor addition would allow one to observe corrosion conditions return to an acceptable level. Therefore, unnecessary inhibitor addition could be eliminated. The current system cannot offer this capability.

Available techniques offer the ability to distinguish between uniform corrosion, stress corrosion cracking, pitting, and other forms of localized corrosion as they occur. They also generate uniform corrosion rate data identical to what is currently derived from chemical sampling. Some available corrosion monitoring techniques using electrical resistance probes or linear polarization resistance probes are not capable of distinguishing between uniform and localized forms of corrosion. These would not be considered acceptable. The most likely cause of failure in DSTs is degradation due to some form of localized corrosion.

\section{ES\&H Justification:}

- WHC-SD-WM-OSR-005, Single-Shell Tank Interim Operational Safety Requirements, WHC-SD-WM-OSR004, Aging Waste Facility Interim Operational Safety Requirements, and WHC-SD-WM-OSR-016, DoubleShell Tank Interim Operational Safety Requirements. These support documents contain interim operational safety requirement - administrative controls for corrosion control, cathodic protection, and integrity assessments. Implementation of these administrative controls necessitates corrosion control activities. - WHC-SD-WM-PLN-068, TWRS Life Management Program Plan, identifies stress corrosion cracking, pitting corrosion, and uniform corrosion as the primary aging mechanisms for DSTs. On-line monitoring of DSTs for these mechanisms will provide necessary data for damage prediction models being developed for the DST Life Management Program.

- BNL/DOE-HQ Tank Structural Integrity Panel, Guidelines for Development of Structural Integrity Programs for DOE High-Level Waste Storage Tanks - DRAFT, discusses the important role of corrosion monitoring in the context of a comprehensive structural integrity program.

\section{Cultural/Stakeholder Factors: N/A}

\section{Other Justification: N/A}

Consequences of Not Filling Need: Regulatory Impacts

- The Hanford Operations contractor has previously entered into negotiations with the Washington State Department of Ecology (WDOE) for determination of acceptable compliance with WAC 173-303-640. Completion of this activity was a part of the negotiations. Failure to complete this activity might be construed by WDOE as failure to comply with WAC legal requirements and failure to negotiate compliance in good faith.

- Programmatic impacts

- Corrosion control of double shell tanks is currently provided by process knowledge and tank sampling. The continued operation of four low hydroxide (out of corrosion specification) tanks indicates that this system is inadequate to support corrosion control. Tank samples are infrequent and their analysis difficult and expensive. Process knowledge is complicated by waste streams that are exempt from the corrosion control specifications. In-line, real-time measurement of the corrosive characteristics of the tank wastes will augment the current
Site Needs Assessment
A.127
Appendix A - Site Needs Database 


\begin{tabular}{lll}
\hline Tanks Focus Area & Need Title: DST Corrosion Monitoring \\
Site Needs & & \\
& Site: Hanford & TFA Functional Area: Safety \\
& Site ID\#: OP1 & TFA Need ID\#: 662 \\
\hline
\end{tabular}

system to provide an acceptable level of corrosion control information to satisfy the programmatic drivers above.

Privatization Potential: Modified commercial technology could be marketed back to the private sector.

Current Base Technology and Cost: There is no baseline technology for direct monitoring of corrosion in high level waste tanks.

\section{Current Baseline Timeline:}

SUMMARY OF TFA RESPONSE: The TFA rated the priority of the technical response to this need as \#6. The TFA is providing funding for FY97 and proposes to provide funding in FY98-00, given available funding. This technical response also responds to Need ID\# 627. 


\begin{tabular}{lll}
\hline Tanks Focus Area & \multicolumn{2}{c}{ Need Title: Remote Inspection of High-Level Waste Tanks } \\
Site Needs & & \\
& Site: Hanford & TFA Functional Area: Safety \\
& Site ID\#: OP2 & TFA Need ID\#: 663 \\
\hline
\end{tabular}

SITE NEED:

Need Description: The Tri-Party Agreement (TPA) schedule requires retrieval of waste in the SSTs to begin by 2004 for future vitrification and permanent storage in a waste repository. In order to meet this schedule, a retrieval method needs to be selected to retrieve the waste for processing. A non-destructive examination (NDE) of the tank needs to be performed prior to the selection of the retrieval method to assure successful retrieval of waste from the tank. Inspection methods are needed also to detect the extent of corrosion in the DSTs to assess their integrity for transfer of SST wastes to the DSTs and subsequent waste processing.

Waste stream: Single-Shell and Double-Shell Tanks, Tank Farms

Functional Performance Requirements: There are two categories of flaws to consider, non-through-wall and through-wall. Non-through-wall (partial penetration) need to be evaluated to estimate the time to wall penetration. The through-wall flaws need to be evaluated to determine the potential for tank rupture and estimate rates of leaks that have occurred (SSTs) or may occur in the future (SSTs and DSTs) to assess appropriate corrective actions.

According to the acceptance criteria for NDE of DSTs, the allowable flaw sizes are:

Through-wall crack length

Maximum allowable crack depth

Thinnest allowable wall section

(where $t$ is the original thickness) and

Maximum allowable pit depth $-12^{\prime \prime}$

$-3 / 16^{\prime \prime}$

$-0.8 \mathrm{t}$

$-0.5 \mathrm{t}$.

The selected remote inspection method needs to be demonstrated in a SST with very little waste. Leakage rates from detected through-wall cracks have to be estimated to assess sluicing feasibility of the SSTs. The knowledge and experience gained on SSTs should be applied for inspecting the DSTs. The DST inspection needs to be prioritized on the basis of the DST Useful Life Estimate Analyses.

Schedule Requirements: Functional systems must be deployed prior to December 31, 2000, in order to successfully meet the TPA schedule for retrieval of wastes from the SSTs to begin by 2004 . In addition, knowledge gained from SST examination must be applied to inspecting the DSTs. Inspection of DSTs should be performed to assure a) that the DST Useful Life Estimates are fairly accurate and b) that the integrity of the DSTs is sound until the waste in the DSTs is disposed of in the year 2028.

Problem Description: Initially, SSTs that have little or no waste need to be selected for NDE of tank wall/floor. If necessary, destructive metallurgical examination of small isolated sections of the SSTs may need to be performed to obtain a thorough understanding of the operating corrosion mechanisms. The number and size of cracks that led to the leakage of waste from the leaking SSTs need to be determined. Waste leakage rates should be estimated based on the defect information, and the acceptability of sluicing for retrieval operations needs to be evaluated for each selected SST. The technology, once successful with the SSTs, should be applied to perform NDE of DSTs to assess the integrity of the DSTs.

In order to be able to meet the TPA SST waste retrieval schedule, initially only one tank from a group of tanks containing similar wastes should be studied. The retrieval decision made for this one tank should be extended to the remaining tanks in the group. The information obtained from the SST examination and the technology utilized needs to be applied to the DSTs in order to accurately assess their integrity until disposal of wastes in the year 2028.

Every effort should be made to perform the examination with a remote device such as the Light Duty Utility Arm (LDUA) or similar robotic equipment more efficiently to minimize costs.

The potential benefits of NDE evaluation (and possible destructive evaluation of some of the SSTs) include: 1. Determination of feasibility of sluicing as a waste retrieval method for the SSTs. 


\title{
Tanks Focus Area Need Title: Remote Inspection of High-Level Waste Tanks
} Site Needs

\author{
Site: Hanford \\ Site ID\#: OP2 \\ TFA Functional Area: Safety \\ TFA Need ID\#: 663
}

2.Assessment of integrity of the DSTs to more accurately determine the remaining life for successful completion of waste disposal by the year 2028 .

3.Validation of DST Remaining Useful Life Estimates.

4. Prioritization of tanks for waste retrieval and processing.

\section{Justifications:}

Technical Justification: Sluicing is the baseline approach for SST retrieval and as such we need to know early on whether or not it is feasible to use this method. Currently, it is assumed that the DSTs will be sound and none will fail prior to the final disposal in the year 2028. The examination will provide an accurate assessment of the corrosion damage and will serve as an early warning for those DSTs that show higher than expected corrosion rates.

Regulatory Justification: Sluicing is the baseline approach for SST retrieval and as such we need to know early on whether or not it is feasible to use this method. Currently, it is assumed that the DSTs will be sound and none will fail prior to the final disposal in the year 2028. The examination will provide an accurate assessment of the corrosion damage and will serve as an early warning for those DSTs that show higher than expected corrosion rates.

ES\&H Justification: WHC-SD-WM-OSR-005, Single-Shell Tank Interim Operational Safety Requirements, WHC-SD-WM-OSR-004, Aging Waste Facility Interim Operational Safety Requirements, and WHC-SD-WMOSR-016, Double-Shell Tank Interim Operational Safety Requirements. These support documents contain interim operational safety requirement - administrative controls for corrosion control, cathodic protection, and integrity assessments. Implementation of these administrative controls necessitates corrosion control activities. WHC-SD-WM-PLN-068, TWRS Life Management Program Plan, identifies stress corrosion cracking, pitting corrosion, and uniform corrosion as the primary aging mechanisms for DSTs. Physical inspection of SST and DST liners will provide assurance of tank integrity. BNL/DOE-HQ Tank Structural Integrity Panel, Guidelines for Development of Structural Integrity Programs for DOE High-Level Waste Storage Tanks - DRAFT, discusses the important role of corrosion monitoring in the context of a comprehensive structural integrity program.

\section{Cultural/Stakeholder Factors: N/A}

\section{Other Justification: N/A}

Consequences of Not Filling Need: Regulatory Impacts

The DOE has previously entered into a Tri-Party Agreement with the Washington State Department of Ecology (WDOE) and the EPA to begin retrieval of SST wastes by the year 2004. Completion of this activity was a part of the negotiations. Failure to complete this activity might be construed by WDOE as failure to comply with WAC legal requirements and failure to negotiate compliance in good faith.

\section{Programmatic Impacts}

Sluicing is considered to be one of the primary methods to retrieve waste from the SSTs. It is possible that sluicing may not be a viable retrieval method for some of the SSTs due to the extensive nature of corrosion experienced by these tanks. Therefore, it is important to initiate tank inspection to rule out sluicing at an early stage in order to have adequate time to pursue other retrieval methods prior to the 2004 deadline to initiate retrieval of SST wastes. At the present time, it is assumed that the DSTs will not fail prior to the final waste disposal in year 2028. However, the possibility still exists that there may be a few localized regions within the DSTs where the waste is not in total compliance with the DST waste specifications. In addition, it is probable that some of these same regions may also be under large residual tensile stresses, which could lead to failure by pitting and/or cracking. Early inspection of the DSTs will isolate the tanks with questionable integrity for either immediate waste composition adjustment or bringing a new tank on-line to meet the TPA milestones on schedule. 
Tanks Focus Area Need Title: Remote Inspection of High-Level Waste Tanks Site Needs

Site: Hanford

Site ID\#: OP2

TFA Functional Area: Safety TFA Need ID\#: 663

Privatization Potential: Remote inspection capabilities may be applicable to pulp/paper and other process industries.

Current Base Technology and Cost: There is no baseline technology for in-situ inspection of high-level waste tanks for assessing corrosion damage. End effectors have been developed in conjunction with the LDUA for inspection of petrochemical and marine facilities.

\section{Current Baseline Timeline:}

SUMMARY OF TFA RESPONSE: The TFA rated the priority of the technical response to this need as \#45. The TFA proposes to provide funding in FY98-99, given available funding. 


\section{Tanks Focus Area Need Title: Criticality Basis - Actinide Studies Site Needs \\ Site: Hanford \\ Site ID\#: Saf 1 \\ TFA Functional Area: Safety TFA Need ID\#: 664}

SITE NEED:

Need Description: Although the Unreviewed Safety Question related to Tank Farm Criticality has been closed, the nuclear criticality technical basis report (Bratzel et al, 1996) is currently being reviewed by DOE to approve closure of the nuclear criticality safety issue. However, even though the safety analysis has proven that the waste tank contents are highly subcritical, there are several remaining chemical and physical characteristics of the behavior of the actinides in Hanford HLW that are not fully understood. Additional technical analysis of these characteristics are required in support of future waste management activities (e.g., retrieval and pretreatment) to ensure a technically defensible safety basis.

Waste stream: Double Shell Tanks, Tank Farms

Type of Procurement: Science Need

Functional Performance Requirements: Definition of actual range of solubility, sorption, solid solution, phase characteristics, solids aging and particle size distribution of Pu precipitates in HLW need to be better defined.

Schedule Requirements: Results are needed to Support Retrieval and Phase 2 Pretreatment Specification Development.

Problem Description: Serne et al (1996) and Whyatt et al (1996) presented a detailed review of plutonium chemistry as it relates to criticality issues. All the available data reviewed indicated that plutonium in Hanford Site fuel reprocessing waste streams can potentially undergo three different types of reactions. These are precipitation as a distinct solid phase; precipitation as a solid solution with other components that are present in certain specific process-dependent waste streams (lanthanum, bismuth, and zirconium); and adsorption onto major hydroxide and/or oxyhydroxide components such as aluminum, iron, chromium, and manganese, etc. The available tank characterization data does not contain details on the speciation of plutonium in the waste phases (supernate, saltcake, and sludge). Therefore, the waste stream analyses were even less detailed, subsequent changes during aging in the tanks are largely uncharacterized, and no definite conclusion could be reached about the dominant chemical reactions and phase partitioning of plutonium in current waste tank environments. In addition to the chemistry and physics of plutonium, there is also an interest (at a lower priority) in the related chemistry and physics of americium and curium.

The review of plutonium chemistry relevant to waste tank environment raised the following questions: 1. During neutralization of the waste (for typical compositions of Hanford Site waste, see Agnew 1996), does plutonium form chemical bonds with the neutron absorbers (mainly iron and aluminum hydroxides) through mainly adsorption reactions?

2. To what extent does plutonium form solid solutions with compatible components such as lanthanum, bismuth, and zirconium on neutralization of waste streams?

3. Because Hanford Site waste streams were apparently oversaturated with respect to $\mathrm{PuO}_{2} \mathrm{xH}_{2} \mathrm{O}$ did plutonium precipitate as a distinct solid phase (coagulated by the large masses of iron and aluminum hydroxides)?

4. Does aging of the sludge solids release plutonium from neutron absorbers into separate solid phases that could settle out during retrieval?

5. What is the nature of aged solid phases (i.e., the extent to which iron and aluminum hydroxides have converted to oxyhydroxides and/or oxides) during decades of higher temperature aging in waste tanks?

6. What are the likely particle size distributions of neutron absorbing aluminum and iron solid phases and, if present, the distinct particles of $\mathrm{PuO}_{2} \mathrm{xH}_{2} \mathrm{O}$ ?

\section{References:}

Serne, R. J. et al, Whyatt, G.A. et al, G. S. Barney, S. Y. Mattigod, Y. Onishi, M. R. Powell, L. M. Liljegren, J. H. Westsik, jr., N. J. Aimo, K. P. Recknagle, G. R. Golcar, T. B. Miley, G. R. Holdren, and R. K. Biyani; Fluid Dynamics, Particle Segregation, Chemical Processes, Natural Ore Analog and Tank Inventory Discussions that 


\section{Site Needs}

Site: Hanford

Site ID\#: Saf 1
TFA Functional Area: Safety

TFA Need ID\#: 664

Relate to the Potential for Criticality in Hanford Tanks, WHC-SD-TL-757, Rev 0; Westinghouse Hanford Co, September 1996.

Whyatt, G. A., R. J. Serne, S. Y. Mattigod, Y. Onishi, M. R. Powell, J. H. Westsik, jr., L. M. Liljegren, G. R. Golcar, K. P. Recknagle, P. G. Doctor, V. G. Zhirnov, and J. Dixon, Potential for Criticality in Hanford Tanks Resulting from Retrieval of Tank Wastes, PNNL-11304, September 1996, Pacific Northwest National Laboratory.

Agnew, S.F., 1996, "Hanford Tank Chemical and Radionuclide Inventories: HDW Model," Rev. 2, LA-UR-96858, Los Alamos National Laboratory, Los Alamos, New Mexico.

\section{Justifications:}

Technical Justification: This effort is required to ensure that Criticality Safety Analysis [CSA] for retrieval and actinide related specification for sludge-washing and enhanced sludge washing for Phase 2 privatization can be developed.

Regulatory Justification: This effort is required to ensure that Criticality Safety Analysis [CSA] for retrieval and actinide related specification for sludge-washing and enhanced sludge washing for Phase 2 privatization can be developed.

\section{ES\&H Justification: N/A}

Cultural/Stakeholder Factors: N/A

Other Justification: N/A

Consequences of Not Filling Need: Lower reliability for both CSA and Phase 2 Privatization specification could lead to costly future delays in retrieval should characterization data identify a waste stream outside of the bounds of the safety documentation.

Privatization Potential: N/A

Current Base Technology and Cost: See references.

Current Baseline Timeline:

SUMMARY OF TFA RESPONSE: The TFA rated the priority of the technical response to this need as \#46. The TFA proposes to provide funding in FY98-00, given available funding. 


\section{Tanks Focus Area Site Needs}

Need Title: Safety Related Transport Properties of Fuel Rich

Organics

Site: Hanford

Site ID\#: Saf 2

TFA Functional Area: Safety

TFA Need ID\#: 665

\section{SITE NEED:}

Need Description: Characterization of waste hydraulic properties is needed, in support of Organic Safety Issue and Continued Tank Farm Operations (e.g., salt-well pumping), to predict the long-term distribution of moisture and soluble chemical species in stabilized single shell tanks, which must be maintained in safe conditions until the contained radionuclides can be processed into a safer storage system. Measurements of waste hydraulic properties such as permeability and capillary liquid retention are needed in modern numerical fluid flow simulators, which can be used to predict the potential drying of waste and the possible redistribution of soluble chemicals within a waste. Constitutive models of waste that connect the measurements of a waste's hydraulic properties to chemical characteristics and grain-size information would facilitate use of advanced simulators to evaluate the safety of stabilized tanks and to design appropriate moisture remediation strategies, if so required to maintain safe waste storage conditions. Better estimates of hydraulic properties can also help assess through modeling the effectiveness of pumping tanks that are not yet stabilized.

Waste stream: Single Shell Tanks, Tank Farms

Type of Procurement: Science Need: Predictive pore-scale models for hydraulic properties needed as data input into advanced simulators required to manage tank conditions.

Functional Performance Requirements: Moisture in single shell tanks must be maintained at sufficient levels to eliminate any possibility of exothermic chemical reactions, while during the same period, the remaining interstitial liquid in stabilized single shell tanks must not leak into the groundwater environment. Waste in single shell tanks must be contained safely while waiting transfer into double shell tank storage.

Schedule Requirements: Results are needed presently to model the long-term distribution of moisture and soluble chemical species in stabilized SSTs.

Problem Description: Modern advanced numerical simulators of fluid flow and solute transport in drained tank waste cannot be accurately applied, because there is currently a lack of hydraulic property characterization information. It is logistically difficult and usually unsafe to handle waste samples to directly obtain measurements of hydraulic properties. Therefore, estimation of such properties based on grain-size and chemical composition information obtained from core samples would considerably improve the usefulness of existing numerical simulators for calculating fluid flow in porous waste forms. Because waste hydraulic properties may change over time in a tank, new constitutive models would also be useful to predict long-term waste storage behavior, such as drying out or the concentrating of soluble chemicals.

A further justification for this study is that there have been no recent documented efforts to obtain hydraulic properties of tank waste forms since the studies of Metz (1976). These old estimates are of questionable accuracy, because the conceptualization of the waste physics was only approximate or even incomplete. Simmons (1996) discussed what is currently available about the estimated values of hydraulic properties for sludge and saltcake waste. Today, it is recognized that stabilized waste will be an unsaturated porous material; and consequently, the hydraulic properties have a complicating factor that depends on the local liquid content in the waste medium, which varies over the waste's depth. Moreover, sludge is subject to the physical rules of a consolidating porous medium, which is highly deformable when pumped. Past characterization of waste hydraulic properties are therefore inadequate to evaluate present tank waste conditions.

Development of constitutive grain-scale models for waste hydraulic properties would contribute to answering certain questions about the long-term conditions of waste storage in SSTs as stated below:

Can a particular SST be effectively pumped to put it in a safe stabilized condition that precludes potential leakage? 


\begin{tabular}{ll}
\hline Tanks Focus Area & Need Title: Safety Related Transport Properties of Fuel Rich \\
Site Needs & Organics
\end{tabular}

Site: Hanford

Site ID\#: Saf 2

TFA Functional Area: Safety

TFA Need ID\#: 665

Does the moisture evaporation and condensation cycle within a tank waste profile maintain the surface in a safe condition, under the particular ventilation control plan?

Are dissolved chemicals leached downward or accumulated at the surface over time as a result of the moisture transport cycle within a waste profile, as driven by the prevailing heat load transfer? That is, will the waste surface dry out?

Is there sufficient permeability of the drained waste to allow the continual safe diffusive escape through ventilation of flammable gases such as hydrogen?

What specific quantity of water at what rate should be applied to a waste profile of a certain height to maintain it as safely moist at the surface or to leach unwanted accumulations of chemicals there?

References:

Metz, W. P. 1976. "A topical report on interstitial liquid removal from Hanford salt cakes." ARH-CD-545, Atlantic Richfield Hanford Company, Richland, Washington.

Simmons, C. S. 1996. "Modeling water retention of sludge simulants and actual saltcake tank wastes." PNNL10831, Pacific Northwest National Laboratory, Richland, Washington.

\section{Justifications:}

Technical Justification: Improved prediction and management of tank waste conditions. Support for Resolution of the Organic Safety Issue and Continued Tank Farm Operations.

Regulatory Justification: Improved prediction and management of tank waste conditions. Support for Resolution of the Organic Safety Issue and Continued Tank Farm Operations.

ES\&H Justification: The potential for enrichment of soluble organic fuel rich waste on the more accessible (to initiators) surface of stored saltcake waste creates uncertainty about the interim safe storage of wastes in Hanford saltcake and organic complexant containing HLW tanks. Safety evaluation on about 12 to 18 tanks would add to a requirement for greater controls under a potential soluble fuel enrichment scenario. Completing the proposed work will increase our confidence in our safety assessments relative to ongoing storage of the wastes prior to disposal and allow for reduced intrusion controls.

\section{Cultural/Stakeholder Factors: N/A}

Other Justification: N/A

Consequences of Not Filling Need: Current safety assessments (related to organic safety issue) supporting operations of SSTs will be scientifically under justified in achieving the required long-term cost effective management and safety operations.

\section{Privatization Potential: None}

Current Base Technology and Cost: Available measurements of hydraulic properties for waste were obtained over 20 years ago and potentially do not describe the wide range of variation in waste properties that impact the distribution of moisture in stabilized SSTs.

\section{Current Baseline Timeline:}

SUMMARY OF TFA RESPONSE: The TFA rated the priority of the technical response to this need as \#66. The TFA proposes to provide funding in FY98-00, given available funding.

$\begin{array}{lll}\text { Site Needs Assessment } & \text { A.135 } & \text { Appendix A-Site Needs Database }\end{array}$




\begin{tabular}{lll}
\hline Tanks Focus Area & \multicolumn{2}{l}{ Need Title: Identification and Management of Chromium and } \\
Other Problem Constituents for HLW Vitrification \\
Site Needs & Site: Hanford & TFA Functional Area: Immobilization \\
& Site ID\#: PW1 & TFA Need ID\#: 666 \\
\hline
\end{tabular}

SITE NEED:

Need Description: Currently, HLW glasses are formulated to assure that little or no insoluble phases exist in the HLW melter. Insoluble phases are caused by such problem constituents as chrome minerals, spinels, and noble metals. An alternative method for handling problem constituents in HLW glasses is needed. The volume of HLW glass that will be produced from the sludges at Hanford is dependent on the ability to solubilize or dilute problem constituents that make up a very small fraction of the overall waste. Minimizing the impact of the problem constituents is important for formulating a strategy and staging the wastes to be treated during the Phase II privatization effort. Diluting the problem constituents usually involves blending of waste types and/or increasing the volume of glass waste forms. Both of these alternatives are expensive.

An alternative for handling problem constituents is to allow them to remain insoluble in the glass matrix. This approach is acceptable as long as the insoluble phase does not adversely affect the processing of the waste or the quality of the waste form. Usually, the concentration of the insoluble constituents in the final waste form would be very low (less than $2 \%$ ).

Information is needed on the technical viability of producing HLW glasses with insoluble phases. Information such as settling rates and rheological properties is needed for insoluble phases to determine if the phases will settle in a HLW melter and, if so, whether the settled sludge can be discharged through a bottom drain or by other means. Information is also needed to determine the impact of the insoluble phases on the durability of the waste form. Ultimately, new HLW glass formulations can be produced that reduce the overall glass volume for various waste types and reduce the blending requirements at Hanford. Based on the results of this study, the cost and risk of producing waste forms with insoluble phases will have to be compared with other options such as blending or diluting to determine the best path forward. This information is needed to formulate a strategy for the Phase II privatization effort at Hanford. This includes waste blending requirements for the DOE, waste volume minimization requirements for the Contractors, and overall contracting strategy.

\section{Waste stream: High Level Waste, Tank Farms}

Functional Performance Requirements: Based on current HLW feed processability reports, identify physical (particle size, particle morphology, and settling rate) and chemical (composition and crystalline structure) characteristics for insoluble phases in HLW glass formulations with high waste loadings. If applicable, determine the physical characteristics of settled layers of insoluble particles (sludges). Evaluate the methods for removing the settled sludge layers either continuously or periodically. Evaluate the processability of the new glass formulations.

\section{Schedule Requirements:}

\section{Problem Description:}

Justifications:

Technical Justification:

Regulatory Justification:

\section{ES\&H Justification:}

Cultural/Stakeholder Factors:

Other Justification:

Consequences of Not Filling Need:

Site Needs Assessment 


\section{Tanks Focus Area Need Title: Identification and Management of Chromium and

Site Needs

\section{Privatization Potential:}

\section{Current Base Technology and Cost:}

\section{Current Baseline Timeline:}

SUMMARY OF TFA RESPONSE: The TFA did not address this need because of cost and the uncertainty of success. Based on the extensive development experience for the DWPF, the vitrification process is greatly complicated by the presence of crystalline material. Melter life is reduced, either because the melter "silts up" blocking access to pouring conduits, or because of excessive corrosion. In addition, qualification of a multiphase waste form will be much more difficult and expensive than for a single-phase glass. Thus, while it is not inconceivable that a viable process and product could be developed, the likelihood of success without very large expenditures is not great, and is questionable even with unlimited funding. 


\section{Tanks Focus Area Need Title: Hanford Capsule Initiative (HCI): A Processing Site Needs \\ Demonstration of Cs/Sr Capsules for Final Disposition \\ Site: Hanford \\ Site ID\#: PW2 \\ TFA Functional Area: Immobilization TFA Need ID\#: 667}

\section{SITE NEED:}

Need Description: To develop and demonstrate a concept for disassembling and processing the cesium and strontium capsules that will condition the halide salts for blending with other HLW feeds prior to vitrification. The effort is required to ensure the vitrification of capsule contents can be performed safely and efficiently.

\section{Waste stream: Cesium and Strontium Capsules, High-Level Waste Vitrification Facility}

Functional Performance Requirements: Using previous experience with the disassembly and processing of capsule contents, develop and demonstrate a concept that provides for the remote disassembly of a capsule. The processes needed include: removal of the capsule contents; separation of the capsule contents from the encapsulating materials; pulverize the $\mathrm{SrF} 2$ and transport it as slurry to a holding tank; dissolution of $\mathrm{CsCl}$ and removal of the chlorides.

All operations must be performed reliably and without excessively contaminating the surrounding hot cell.

The HCI will be performed in two phases. The first phase will be focused on process development and cold testing and will be performed at Hanford. The second phase will be a hot small-scale demonstration of the process at the Savannah River Site, using capsules currently stored in Hanford's 300 Area and SRS's vitrification capabilities.

Schedule Requirements: A proven concept is required by 1999 to enable it to be incorporated into the design of a private HLW vitrification facility at Hanford.

Problem Description: The disassembly of these capsules is a messy operation that results in gross contamination of a hot cell. There is a need to develop and demonstrate methods for performing the disassembly without creating a significant contamination problem. The demonstration of a remote disassembly concept will make vitrification more acceptable as the final disposition of these capsules, and will provide sufficient confidence in the process so that requirements for capsule processing can be included in the privatization work scope.

\section{Justifications:}

Technical Justification: Past experience with the disassembly of capsules is that the process results in the significant contamination of equipment and facilities. Contamination is a significant issue with the vitrification of the capsule contents. However, the vitrification option is attractive because it: 1) eliminates the repository disposal fee, i.e. blending the capsule contents with other HLW feeds does not increase the overall volume of vitrified product; and 2) the vitrified waste form is much more acceptable to the public than the soluble salt.

Regulatory Justification: Past experience with the disassembly of capsules is that the process results in the significant contamination of equipment and facilities. Contamination is a significant issue with the vitrification of the capsule contents. However, the vitrification option is attractive because it: 1) eliminates the repository disposal fee, i.e. blending the capsule contents with other HLW feeds does not increase the overall volume of vitrified product; and 2) the vitrified waste form is much more acceptable to the public than the soluble salt.

ES\&H Justification: The hot demonstration will require the transport of capsules from Hanford to the Savannah River Site. The current Safety Analysis Reports for the Beneficial Uses Shipping System (BUSS) cask is in place.

Cultural/Stakeholder Factors: This effort would be viewed positively by all stakeholders in that it enables further cleanup at Hanford to proceed.

Other Justification:

Site Needs Assessment

A.138

Appendix A - Site Needs Database 
Tanks Focus Area Site Needs
Need Title: Hanford Capsule Initiative (HCI): A Processing Demonstration of Cs/Sr Capsules for Final Disposition

Site: Hanford

Site ID\#: PW2
TFA Functional Area: Immobilization TFA Need ID\#: 667

Consequences of Not Filling Need: If this need is not filled, then the closure of Hanford's 324 Building will wait until the capsules can be repackaged and returned to the WESF for indefinite storage, or an alternative solution is found. Insufficient data will be available for inclusion in the Phase II privatization RFP; vendors may be unable or unwilling to respond to this part of the RFP.

Privatization Potential: The results of this effort will be privatized if Hanford follows through on its concept of HLW privatization.

\section{Current Base Technology and Cost:}

Cost: $\$ 5$ million for development, cold testing and hot demonstration Waste: Shredded metal alloy - one drum of remote-handled solid waste.

Inorganic resin - one drum of slightly radioactive resin. Liquid waste from the decontamination of hot-cell equipment

Current Baseline Timeline: The expected duration of this development is 2 years.

SUMMARY OF TFA RESPONSE: The TFA rated the priority of the technical response to this need as \#54. The TFA proposes to provide funding in FY98-00, given available funding. 


\begin{tabular}{lll}
\hline Tanks Focus Area & Need Title: Advanced Methods for Achieving LLW Volume \\
Site Needs & Minimization & \\
& & \\
& Site: Hanford & TFA Functional Area: Pretreatment \\
& Site ID\#: PW3 & TFA Need ID\#: 668 \\
\hline SITE NEED: & &
\end{tabular}

SITE NEED:

Need Description: There is a need to minimize the volume of the low-level waste. This is both prudent from an overall cost standpoint as well as a requirement when dealing with any RCRA waste. More specifically, there is a need to develop and demonstrate a concept for significant reduction in the volume of low level waste.

Waste stream: Double and Single Shell Tanks, LLW Pretreatment

Functional Performance Requirements: The approach should be definitized enough to provide a suitable basis for scale up to Phase II production scale and allow a detailed engineering, business, and environmental evaluations of the approach for Phase II. The low-level waste minimization should be cost effective on a lifecycle cost basis.

Schedule Requirements: This effort needs to be completed in FY 2001 to support trade studies which will be completed in FY 2002 in the Phase 2 RFP Planning (Multi-Year Work Plan Schedule Identification Number $\mathrm{H} 2343$ ) and subsequent RFP completion and bid evaluation.

Problem Description: Currently, the amount of tank waste is so large that enormous quantities of immobilized low activity waste will be generated and require appropriate low level waste disposal. By removal of essentially nonradioactive constituents from the waste by innovative chemical processes, the volume of low level waste requiring disposal can be significantly reduced.

One approach to minimize the volume of low level waste is to recover the sodium nitrate sufficiently decontaminated to permit a portion to be converted to sodium hydroxide for recycle. Further decontamination of the bulk of the sodium nitrate and conversion to sodium carbonate would permit a grouted form of the carbonate to be used as a fill material for decontaminated facilities. Alternatively, the sodium carbonate could be disposed in shallow land burial if it is decontaminated to a level that is below regulatory concern. This technology needs to be demonstrated first with simulated waste and then with actual waste. To date, successful laboratory call process development tests of sodium nitrate recrystallization have shown the concept to be feasible. However, sufficient engineering scale information for this or alternate LLW minimization processes is lacking to support engineering alternatives analyses and analyses of environmental impacts.

\section{Justifications:}

Technical Justification: This effort is required to ensure that reasonable incentives for LLW minimization are developed so that they can be included in the Phase II RFP. This effort will also provide a technical basis for a fair cost estimate as well as for writing a meaningful RFP for Phase II.

Regulatory Justification: This effort is required to ensure that reasonable incentives for LLW minimization are developed so that they can be included in the Phase II RFP. This effort will also provide a technical basis for a fair cost estimate as well as for writing a meaningful RFP for Phase II.

\section{ES\&H Justification:}

Cultural/Stakeholder Factors: LLW minimization has the potential to minimize land use for on site disposal of LLW.

Other Justification: The byproducts of the waste minimization activity could be useful either in pursuing the cleanup at Hanford, other DOE sites, or for non DOE application. Examples could include materials for road construction, facility decommissioning, and site closure. 
\begin{tabular}{ll}
\hline Tanks Focus Area & Need Title: Advanced Methods for Achieving LLW Volume \\
Minimization
\end{tabular} Site Needs

Site: Hanford

Site ID\#: PW3

TFA Functional Area: Pretreatment TFA Need ID\#: 668

Consequences of Not Filling Need: The lack of technical understanding of Phase II will cause the Phase II Vendors facilities to be more expensive due to an inexact RFP and a lack of understanding upon which to do a bid evaluation. LLW will not be minimized.

Privatization Potential: It is fully expected that addressing this technical need will stimulate private industries to incorporate the resulting technology development in conjunction with their own related expertise when they respond to the Phase 2 Privatization Request for Proposal.

Current Base Technology and Cost: The current technical baseline has limited, yet-to-be-defined incentives for low level waste minimization. For Phase 2 it is estimated that about $4.4 \times 10^{5}$ metric tons of LLW glass will be produced. About $20 \%$ of this glass is composed of sodium oxide which could be eliminated with the removal of sodium nitrate prior to vitrification. Since the LLW glass is limited by the sodium in it, for each ton of sodium reduced, greater than one ton of LLW would be avoided.

\section{Current Baseline Timeline:}

SUMMARY OF TFA RESPONSE: The TFA did not rate this need separately. The response to this need is covered within the TFA's response to Need ID\# 637. 


\section{Tanks Focus Area Need Title: Formulation of Reference Glass for Immobilized Site Needs LAW \\ Site: Hanford \\ TFA Functional Area: Immobilization \\ Site ID\#: PW4 TFA Need ID\#: 669}

\section{SITE NEED:}

Need Description: A standard reference material for immobilized low-activity waste (ILAW) applications must be identified for use in inter- and intralaboratory comparisons between the private contractor and DOE to verify the accuracy of reported results. The identification, development, and qualification of ILAW form reference materials is required. These materials must have appropriate compositions typical of expected ILAW forms so that the reference materials have utility for verifying ILAW compositional and durability specifications and comparing inter- and intralaboratory test results.

Waste stream: Immobilized Low-Activity Waste, TWRS

Functional Performance Requirements:

- Identify and select ILAW material(s) as reference standard(s)

- Prepare samples and characterize chemical and physical properties

- Determine inter- and intralaboratory variability

- Document reference properties and statistical variability

Schedule Requirements: Reference materials are needed for private contractor qualification testing and DOE verification testing beginning in approximately FY 1999.

Problem Description: Identify and qualify ILAW reference materials that have compositional and durability characteristics that allow comparative measurements with the ILAW product specifications stated in the RFP. The RFP specifies compositional limits as well as durability requirements as determined by the PCT method. These reference materials may be an adaptation of an existing ILAW form or development of a specific formulation if required by the DOE complex. For Hanford purposes it should include surrogates for some of the more mobile radionuclides that typically are accumulated in LAW and are specifically mentioned in the RFP. An example of a surrogate may be rhenium for technetium. Characterization of the reference materials should include the mean response and variability for both within lab and between lab data sets which will probably require a limited round-robin approach.

\section{Justifications:}

Technical Justification: Provides a reference point for identifying intra- and inter-laboratory variability among Hanford laboratories and private contractor laboratories.

Regulatory Justification: Provides a reference point for identifying intra- and interlaboratory variability among Hanford laboratories and private contractor laboratories.

\section{ES\&H Justification: None}

\section{Cultural/Stakeholder Factors: None}

\section{Other Justification:}

Consequences of Not Filling Need: Increases time required to resolve conflicts due to variability in testing and analytical results.

Privatization Potential: Low unless large quantities (tons) of the reference materials are needed.

Current Base Technology and Cost: No reference standard has been established for ILAW. The EA glass is a standard for IHLW.

\section{Current Baseline Timeline:}




\begin{tabular}{|c|c|c|}
\hline \multirow{2}{*}{$\begin{array}{l}\text { Tanks Focus Area } \\
\text { Site Needs }\end{array}$} & \multicolumn{2}{|c|}{$\begin{array}{l}\text { Need Title: Formulation of Reference Glass for Immobilized } \\
\text { LAW }\end{array}$} \\
\hline & $\begin{array}{l}\text { Site: Hanford } \\
\text { Site ID\#: PW4 }\end{array}$ & $\begin{array}{l}\text { TFA Functional Area: Immobilization } \\
\text { TFA Need ID\#: } 669\end{array}$ \\
\hline
\end{tabular}

SUMMARY OF TFA RESPONSE: The TFA did not rate the response to this need separately. This is covered in the TFA's technical response to Need ID\# 675. 


\section{Tanks Focus Area Need Title: Standard Method for Determining Waste Form Site Needs \\ Release Rate \\ Site: Hanford \\ Site ID\#: PW5 \\ TFA Functional Area: Immobilization TFA Need ID\#: 670}

\section{SITE NEED:}

Need Description: The release of radionuclides from a waste form and package to the environment results from the interactions between the waste form and water in the disposal system. Waste forms are typically developed to minimize the rate of release as measured by a variety of test methods. Current ILAW product specifications require PCT testing and ANS 16.1 testing of the waste forms. These test methods may not be representative of the expected disposal system environment at Hanford. A release rate test method yielding results that can be related to the waste form release rate under expected service conditions is needed as a basis for Phase 2 ILAW product specifications.

Waste stream: Immobilized Low-Activity Waste

Functional Performance Requirements:

- Develop and standardize a waste form release rate method

- Conduct sufficient tests to provide data to form a basis for Phase 2 waste form release rate specification

- Coordinate efforts with Hanford Low-Level Tank Waste Performance Assessment

Schedule Requirements: A standard method for determining waste form release rate and supporting data is needed to prepare the ILAW product specifications for Phase 2 of the TWRS privatization beginning in approximately 2003 .

Problem Description: Develop a standard waste form release rate test method that is relevant to expected performance in the disposal environment and that can be used as a ILAW product specification. The test method must provide usable results within a 90-day time period such that the compliance of the waste form to the product specifications can be confirmed and payment to the private contractor authorized. The test method will be implemented in a production environment.

\section{Justifications:}

Technical Justification: Numerous test methods including the MCC test, PCT, and ANS 16.1 have been used to determine waste form release rates. Current methods for measuring release rates from a waste form do not mimic the conditions that the waste form will experience in the disposal environment.

Regulatory Justification: Numerous test methods including the MCC test, PCT, and ANS 16.1 have been used to determine waste form release rates. Current methods for measuring release rates from a waste form do not mimic the conditions that the waste form will experience in the disposal environment.

ES\&H Justification: Radionuclide release rates are driving factors in determining the human health and environmental impact from the disposal of ILAW at Hanford.

\section{Cultural/Stakeholder Factors:}

Other Justification: A more relevant release rate specification will make interpretation of the product specifications easier in the performance assessment.

Consequences of Not Filling Need: Inadequate specification of release rates could lead to future environmental impacts. Interpretation of specifications in performance assessment will be more difficult.

\section{Privatization Potential: Limited}

Current Base Technology and Cost: PCT test and ANS 16.1 test

Current Baseline Timeline: 
Tanks Focus Area Site Needs
Need Title: Standard Method for Determining Waste Form Release Rate

Site: Hanford

Site ID\#: PW5
TFA Functional Area: Immobilization TFA Need ID\#: 670

SUMMARY OF TFA RESPONSE: The TFA rated the priority of the technical response to this need as \#31. The TFA proposes to provide funding in FY98-99, given available funding. The response to this need also includes the response to Need ID\#685. 


\begin{tabular}{lll}
\hline Tanks Focus Area & Need Title: Avoidance of Formation of Solids in Phase I Liquid \\
Site Needs & Tank Wastes & \\
& Site: Hanford & TFA Functional Area: Pretreatment \\
& Site ID\#: PW6 & TFA Need ID\#: 671 \\
\hline SITE NEED: &
\end{tabular}

SITE NEED:

Need Description: During Phase I of privatization, TWRS will be retrieving double shell tank supernate/saltcake. The current plan is to dissolve the saltcake/precipitated salts by the addition of water. While these precipitated salts are expected to go back into solution, this has not been verified with actual wastes. If solids remain undissolved, they can cause operational difficulties during transfer and can result in the transferred stream being greater than $5 \%$ solids, which is the contractual maximum specified in the privatization contracts. In addition, the chemistry of these concentrated supernates is quite complex, and the dilution itself may cause additional precipitation. For example dilution may aid dissolution of sodium nitrate, but may cause gibbsite (aluminum hydroxide) to precipitate. Thus it becomes important to understand the conditions which avoid precipitation. This task will verify thermodynamic models which help predict the occurrence of this precipitation.

Waste stream: Double Shell Tanks, Tank Farms

Functional Performance Requirements: The LLW privatization vendors feed must be less than 5 volume percent solids. These tests need to be completed by Marcy 1999 so that the LLW plan update can incorporate these findings in FY99, any necessary field modifications such as caustic addition capabilities can be completed in FY00, feed staging can begin in FY01, and delivery of feed to the Privatization Contractors' feed tanks can occur prior to hot start-up in FY02.

\section{Schedule Requirements:}

\section{Problem Description:}

Justifications:

Technical Justification: This effort is required to ensure that the feed to the Privatization Contractors is within the envelopes specified in the two contracts.

Regulatory Justification: This effort is required to ensure that the feed to the Privatization Contractors is within the envelopes specified in the two contracts.

ES\&H Justification: N/A

\section{Cultural/Stakeholder Factors: N/A}

Other Justification: N/A

Consequences of Not Filling Need: Privatization Contractors' feed will not be delivered by DOE on the schedule agreed to in the contract and DOE will be forced to pay the Privatization Contractors for idle facilities.

Privatization Potential: N/A

Current Base Technology and Cost: Satisfying this technical need is required to meet the current baseline.

\section{Current Baseline Timeline:}

SUMMARY OF TFA RESPONSE: The TFA rated the priority of the technical response to this need as \#11. The TFA proposes to provide funding in FY98-99, given available funding. 


\section{SITE NEED:}

Need Description: Information is needed on the solubility of various components in the complex solid and liquid matrices of the Hanford tank wastes. This information is needed to predict when solids will precipitate or when gels will form in retrieval, wash, and leach solutions, and to supplement empirical water wash and caustic leach data from enhanced sludge wash testing of Hanford tank sludge and saltcake samples.

Much information is available from past solubility chemistry work at Hanford and from other DOE sites. Available information needs to be compiled for easier use, missing data need to be identified, and work performed to supply the missing data. The information will be used to support the planning for and performance of the Hanford tank waste remediation. This remediation involves pretreating almost $150,000 \mathrm{~m} 3$ of sludge and saltcake solids and 60,000 m3 of supernatants from 177 waste tanks (Hanlon 1996).

\section{Waste stream: Single Shell Tanks and Double Shell Tanks, Tank Farms}

Functional Performance Requirements: A compilation of available solubility data in the form of charts, figures, correlations, and calculational methods that can be easily used to predict solids precipitation or gel formation in processing solutions, or can be used to predict wash and leach efficiencies based on key sludge or saltcake composition data. The compilation should accurately and efficiently predict solubilities for the major problem species expected in the complex solid and liquid matrices expected in the Hanford tank wastes. Examples of problem species are aluminates, phosphates, fluorophosphates, silicates, and chromates. The information should be suitable for inclusion in the Aspen software program and the Environmental Simulation Program, both of which are in use at Hanford. The work should identify what solubility data are missing and identify what experimental work is needed to provide the missing data. The identified experiments should be performed and the resulting data included in the compilation.

Schedule Requirements: This effort needs to be initiated in FY1999 to feed the preparation of the Phase II privatization RFP (H2343). It provides needed information for specifying the interface between the Retrieval Contractor and the High-Level Waste Contractor.

Problem Description: Solids and gels are known to form in the Hanford tank wastes when the solution ionic strength is decreased. Transfer lines have been plugged when solids or gels inadvertently formed. Knowledge of the solubility envelope for the waste is necessary to avoid unwanted precipitation or gel formation in supernatants. Sludge washing and leaching performance and saltcake dissolution evaluations are based on empirical data extrapolated from individual tanks to groups of tanks based on waste types. Improvements in processing efficiency are expected if the wash, leach, and dissolution processes are based on an understanding of the dissolution thermodynamics and kinetics rather than just empirical data. Water usage and makeup chemical addition can also be reduced which together with the improvement in efficiency can reduce the amount of HLW glass produced.

\section{Justifications:}

Technical Justification: This effort will provide a basis for writing a meaningful RFP for Phase II.

Regulatory Justification: This effort will provide a basis for writing a meaningful RFP for Phase II.

\section{ES\&H Justification: N/A}

\section{CulturalStakeholder Factors: N/A}

\section{Other Justification: N/A}

Consequences of Not Filling Need: The lack of technical understanding of Phase II wastes will cause the Phase II vendors' estimated costs to be to be higher due to an inexact RFP being written. 


\begin{tabular}{lll}
\hline Tanks Focus Area & \multicolumn{2}{l}{ Need Title: Prediction of Gel and Precipitate Formation in } \\
Site Needs & Hanford Tank Waste Solutions \\
& Site: Hanford & TFA Functional Area: Pretreatment \\
& Site ID\#: PW7 & TFA Need ID\#: 672 \\
\hline
\end{tabular}

Privatization Potential: N/A

Current Base Technology and Cost: A thermodynamic model known as the Environmental Simulation Program has been only partially validated with actual waste solubility data.

\section{Current Baseline Timeline:}

SUMMARY OF TFA RESPONSE: The TFA rated the priority of the technical response to this need as \#12. The TFA is providing funding for FY97 and proposes to provide funding in FY98-99, given available funding. 


\section{Tanks Focus Area Site Needs}

Need Title: Enhanced Sludge Wash Process Data for Extended

Operations of Phase I and for Phase II RFP

Site: Hanford

Site ID\#: PW8

TFA Functional Area: Pretreatment

TFA Need ID\#: 673

SITE NEED:

Need Description: Enhanced sludge wash (ESW) process data are needed to prepare enough feed to satisfy the maximum order quantity for Phase I preparation of the Phase II privatization request for proposal, and for bid evaluation of vendors proposals.

Currently only about 70 to 80 percent of the maximum order quantity for phase I sludge washing has been identified. Additional feeds must be identified that can satisfy Envelope D after pretreatment to ensure that the Private Contractors will be able to operate through 2011.

By March 1998 a decision will have been made whether ESW produces a reasonable number of HLW glass canisters. Assuming that ESW is successful in producing a reasonable number of glass canisters, additional data on ESW performance are required to provide a sound basis for the second phase of privatization. A strategy was developed for ESW testing based on obtaining 47 SST and 10 DST sludge samples (Kupfer 1996). Not all of that sampling and testing will have been completed before the March 1998 decision. Completion of that strategy is necessary to craft the Phase II RFP and to provide enough definitive information for a fair cost estimate for bid evaluation purposes.. A high emphasis needs to be placed on obtaining information on the $\mathrm{Cr}$ chemistry in the sludges and saltcakes. Chromium removal is needed to reduce the impact of $\mathrm{Cr}$ on the HLW glass volume. This is a continuation of the ESW testing program currently in progress. Additional data on the affect of varying temperature and caustic concentration on leach performance would be beneficial.

Waste stream: Single Shell Tanks, Tank Waste Pretreatment

Functional Performance Requirements: Enhanced sludge wash process data representing $90+\%$ of the SST sludge volume and $70+\%$ of the DST sludge volume. An understanding of the $\mathrm{Cr}$ removal chemistry that allows reduction of the impact of Cr on HLW glass by $50 \%$.

Schedule Requirements: The identification of Phase I candidate feed tanks is needed in the middle of FY 1999 to provide information to the HLW feed staging plan update in FY 1999 (H1233) and allow enough time to install the needed retrieval equipment and pretreatment equipment to extend the HLW Privatization Contractor's Phase I operation to FY 2001. For Phase II, this effort needs to be initiated in FY 1999 to feed the preparation of the Phase II privatization RFP (H2343) and subsequent bid evaluation.

Problem Description: The cost of pretreatment facilities may be higher than needed because of the design conservatism used to reduce the risk associated with uncertainties in the ESW data. Additional ESW process data will allow more accurate projections of ESW performance. Facility design contingency factors can be reduced by using the more accurate data.

\section{Justifications:}

Technical Justification: This effort will allow additional feeds to be identified as candidate feeds to the Phase I Privatization Contractor for HLW. For Phase II it provides a basis for a fair cost estimate and the writing of a meaningful RFP.

Regulatory Justification: This effort will allow additional feeds to be identified as candidate feeds to the Phase I Privatization Contractor for HLW. For Phase II it provides a basis for a fair cost estimate and the writing of a meaningful RFP.

ES\&H Justification: N/A

Cultural/Stakeholder Factors: N/A

Other Justification: N/A 


\section{Tanks Focus Area $\quad$ Need Title: Enhanced Sludge Wash Process Data for Extended Operations of Phase I and for Phase II RFP}

Site Needs

Site: Hanford Site ID\#: PW8
TFA Functional Area: Pretreatment TFA Need ID\#: 673

Consequences of Not Filling Need: 1) The use of the Phase I HLW facility will be less than planned due to inadequate feed. 2) The lack of technical understanding of Phase II will cause the Phase II Vendors facilities to be more expensive due to an inexact RFP and a lack of understanding upon which to do a bid evaluation

Privatization Potential: N/A

Current Base Technology and Cost: Satisfying this technical need is required to meet the current baseline.

\section{Current Baseline Timeline:}

SUMMARY OF TFA RESPONSE: The TFA rated the priority of the technical response to this need as \#32. The TFA proposes to provide funding in FY98-99, given available funding. 


\section{Tanks Focus Area Site Needs}

Need Title: Representative Sampling and Associated Analysis to

Support Operations and Disposal

Site: Hanford

Site ID\#: PW9

TFA Functional Area: Characterization TFA Need ID\#: 674

\section{SITE NEED:}

Need Description: To develop and demonstrate a concept for taking representative samples and associated rapid analysis of feeds which are to be staged for cross site transfer or are to be staged as feed for the Privatization Contractors. Feed for Privatization Phase I immobilization demonstrations must be shown to be within the RFP feed Envelope A, B, and C specifications.

To accomplish this, the intermediate waste feed staging tank contents must be sampled while being mixed for transfer to the Private Contractors feed staging tank. A variable depth sampling system is needed that can be operated in conjunction with the active mixing system to certify that the tank contents meet the specified waste envelopes. (Reference: "Alternatives Generation and Analysis for the Phase I Intermediate Waste Feed Staging System Design Requirements, WHC-SD-TWR-AGA-001, Rev.0).

Waste stream: Double Shell Tanks, Tank Farms

Related Technology Needs/Opportunities Statement: "Real Time Waste Property Measurement System for Waste Transfer"

Functional Performance Requirements: The sampling and analytical capabilities should be able to provide representative samples and measure the parameters needed to support successful cross site transfers and needed as specified in the Privatization Contract for envelopes A, B, and C and envelope D. The Privatization Phase 1 supernate solutions to be sampled are targeted to be dilute slurry/supernate solutions with a maximum of $5 \%$ solids by volume. The samples will be drawn from the tank with a lift distance of up to $50 \mathrm{ft}$. The system to be provided will need to be deployed using existing spare tank penetrations or be installed into an existing process pit located in the tank farm. The sampling system shall provide required support subsystems as necessary to meet safety and operational requirements. The feed needs to be sampled and analyzed for these activities consistent with ALARA principles.

Schedule Requirements: The cross site transfer line from Tank 102-SY will be operational in FY 1998; this sampling and analysis capability would be beneficially employed any time thereafter. To support the privatization this method needs to be developed by March 1999 so that the LLW plan update can incorporate this method in FY99, and these methods can be installed in FY00, feed staging can begin in FY01, and delivery of feed to the Privatization Contractors' feed tanks can occur prior to hot start-up in FY02.

Problem Description: A representative, and preferably also rapid, sampling and analysis system has to be developed and demonstrated so that feeds to the cross site transfer line and to both the LLW and HLW Privatization Contractors can be staged successfully with a minimum impact on tank space. Current grab samplers consisting of "bottle-on-a-string" are used for slurry/supernate sampling. This system of sampling has been found to be cross contaminated with material from higher elevations above the desired sample depth as it is withdrawn from the tank. Although this cross contamination is proportional, it could skew the sample results. Also, this method cannot be performed during active mixing system operation, therefore allowing time for intank stratification to re-establish before the sampling can be performed. The sampling is a manual operation performed thorough an existing riser using a portable "glove bag" for containment control that has potential for personnel contamination and exposure. With Hanford's existing capabilities it takes weeks or even months to sample and analyze a tank.

As the disposal program activities involving 200 Area waste retrieval and privatization proceed, Hanford will need the capability to sample and analyze much more rapidly in order to ensure that DOE provides feeds in accordance with its privatization contracts and with a minimum use of tank space. Representative sampling involving potentially nonhomogeneous waste feed is definitely needed. Long sample and analysis times will cause operations to tie up tanks until analytical results are available to determine how the waste should be staged. Quicker sample/analytical responses will provide more flexibility to the tank system. 


\section{Tanks Focus Area Site Needs}

Need Title: Representative Sampling and Associated Analysis to

Support Operations and Disposal

Site: Hanford

Site ID\#: PW9

TFA Functional Area: Characterization TFA Need ID\#: 674

Possible concept: On-line sampling and analysis could satisfy this need. AEA has developed the capability of obtaining representative samples of slurries of waste with a fluidics sampling pump, and this concept is being adapted for Savannah River Site waste tank use. If this device were combined with on-line analytical methods, this need could be satisfied.

\section{Justifications:}

Technical Justification: This effort is required to ensure that feed is delivered to the cross site transfer line and to Privatization Contractors in a timely manner with the use of minimum double shell tank space. This activity will seek improved sampling systems that support ALARA goals and can be operated at variable depths while the DST mixing system is operating.

Regulatory Justification: This effort is required to ensure that feed is delivered to the cross site transfer line and to Privatization Contractors in a timely manner with the use of minimum double shell tank space. This activity will seek improved sampling systems that support ALARA goals and can be operated at variable depths while the DST mixing system is operating.

ES\&H Justification: Using on-line instrumentation will reduce the exposure of personnel during taking of the samples in the field and analysis the samples in the laboratory. This will also help in avoiding plugged cross site transfer lines, and the increased exposure of personnel in taking the necessary actions to clear the plugging. The transportation of samples to the 222-S Analytical Lab would be avoided.

\section{Cultural/Stakeholder Factors: N/A}

Other Justification: The Office of Science and Technology, EM-50, has funded the transfer of some non radioactive demonstrations of the sampling technology using power fluidics, and has developed the laser ablation/mass spectrometer and installed a prototype unit in the 222-S Analytical laboratory in late FY 1996. These technologies could be integrated in a demonstration relevant to the feed staging applications identified.

Consequences of Not Filling Need: Greater risk of plugging the cross site transfer lines; increased delay in making transfers; possible slippage of retrieval schedules. Privatization Contractors' feed may not be delivered by DOE on schedule agreed to in the contract and DOE will be forced to pay the Privatization Contractors for idle facilities. PHMC staff will experience greater radiation exposure both in the field taking samples by current methods, and in the analytical laboratory handling the additional samples. Less accurate grab samples will be used which may result in feed that doesn't initially meet specifications (i.e., requires rework prior to transfer to the Private Contractors feed staging tank).

Privatization Potential: The representative sampler could be supplied and possibly also installed by AEA Technology, or possibly BNFL, or possibly Numatec or SGN Systems, or the Russians since this technology or variations thereof have been used by these foreign organizations in their waste management and waste processing activities. A laser ablation/mass spectrometer has been developed by Pacific Northwest National Laboratory under EM-50 funding; this work could be made available with suitable contractual arrangements for privatization. The sample distribution manifold system is available through British Columbia Research Inc., a Canadian technology development firm. The measurement of rheological properties associated with the representative samples would need to be made with analyzer equipment commercially available and adapted to the sample distribution manifold system. The analysis requirements would be different for the feed staging for the cross site transfer where the emphasis would be on ensuring pumpability through the cross site transfer pipe and waste compatability of what is being transferred versus what is in the receiver tank. On the other hand, for the requirements for the intermediate feed staging tanks for privatization, the emphasis is to ensure the tank contents comply with the desired feed envelope: A, B, or C for supernatants, and envelope D for sludges. 
Tanks Focus Area Site Needs
Need Title: Representative Sampling and Associated Analysis to Support Operations and Disposal

Site: Hanford

Site ID\#: PW9
TFA Functional Area: Characterization TFA Need ID\#: 674

Current Base Technology and Cost: Current plans for feed staging tank sampling and analysis involve trying to mix the waste and take "bottle on the string" or other grab samples followed by analysis in the 222-S Laboratory. It takes weeks or even months to analyze a tank of waste.

\section{Current Baseline Timeline:}

SUMMARY OF TFA RESPONSE: The TFA rated the priority of the technical response to this need as \#21. The TFA proposes to provide funding in FY98-00, given available funding. 


\section{Tanks Focus Area Site Needs}

Need Title: ILAW Product Acceptance Inspection and Test

Methods

Site: Hanford

Site ID\#: PW10

TFA Functional Area: Immobilization TFA Need ID\#: 675

SITE NEED:

Need Description: The U.S. Department of Energy (DOE), Richland Operations Office (RL) is proceeding with a two-phased approach to privatize the treatment and immobilization of Hanford's low-activity and highlevel wastes currently in storage in underground tanks. DOE will provide the tank wastes to the private contractors who will treat and immobilize the wastes and then return the final products to DOE for storage and final disposal. DOE will pay the private contractors for each waste package received that meets the product specifications. Acceptance of the immobilized wastes will be based on a combination of private contractor activities to qualify, verify, document, and certify the product and DOE activities to audit, review, inspect, and test the processes and products.

The immobilization contractors will provide to DOE the immobilized low-activity waste (ILAW) and immobilized high-level waste (IHLW) products in sealed containers, process and product grab samples, and the appropriate product certification which may include pertinent process data. The DOE may conduct nondestructive testing of the sealed immobilized waste containers and destructive and non-destructive testing of the process and product samples. Specific parameters of interest may include chemical composition of the waste forms, fillers, and containers phase composition, radiochemical composition thermal history and surface temperature, waste form volume and void space, waste form and container weight container dimensions, including wall thickness effectiveness of container closure or seal (leak tightness), presence of prohibited materials including free liquids and explosive, pyrophoric or combustible materials, dose rate, surface contamination, waste form homogeneity, and waste form release rates. The IHLW product is expected to be a glass waste form in a 61-cm diameter by 3- to 5-m long cylindrical stainless steel canister. The ILAW is expected to be a glass, ceramic, or metal waste form in a $1.2 \mathrm{~m} \mathrm{x} 1.2 \mathrm{~m} \mathrm{x} 1.8 \mathrm{~m}$ rectangular metal box.

Generally, the inspection and test methods should not require opening or otherwise breaching the seal of the waste form containers. The appropriate sampling and analysis strategies should provide the basis for making statistically based statements with respect to the confidence with which the products meet specifications. The inspection and test methods must be shown to be relevant to the expected performance parameters of the ILAW and IHLW.

Waste stream: Immobilized High-Level Waste/Immobilized Low-Activity Waste, TWRS

Functional Performance Requirements: Demonstrate non-destructive examination techniques on full-scale prototypic ILAW and IHLW waste packages. Techniques must have the required sensitivity, precision, and accuracy to make decisions regarding the acceptability of the products. Techniques must have reliability for application in production type environment.

Schedule Requirements: Early indications of the adequacy of the inspection and test methods is needed early as input to product acceptance strategy revisions, Phase 1B contract negotiations, and inspection facility design. Inspection and test methods must be selected by September 2000 such that operating procedures can be prepared and implemented. Inspection operations will begin in June 2002.

Problem Description: Non-destructive examination techniques are currently being used at commercial and DOE operated disposal facilities to verify that packaged wastes meet acceptance criteria. Radiography, including real-time radiography, digital radiography, and X-ray computed tomography, is used to identify gross inhomogeneities and free liquids within waste containers. Gamma spectroscopy is a common technique for determining the concentration of gamma-emitting radionuclides $(60 \mathrm{Co}, 137 \mathrm{Cs}, 152 \mathrm{Eu}$, and $154 \mathrm{Eu})$ within a waste drum. Passive/active neutron assay is used to determine the quantity of neutron-emitting and fissile material in waste packages. It is used to differentiate between LLW and TRU wastes. Application of these techniques to the larger ILAW boxes and more dense glass waste forms proposed for the current low-activity waste will need to be demonstrated. Other nondestructive techniques such as eddy current methods, and ultrasonic techniques may have application to the inspection of waste containers and their contents. Acoustics 
Site: Hanford

Site ID\#: PW10
TFA Functional Area: Immobilization TFA Need ID\#: 675

and optics based measuring devices are commercially available and would need to be adapted for measuring package dimensions. Similar inspection methods are needed for IHLW packages.

Justifications:

Technical Justification: Product acceptance inspection and test results will provide part of the basis for justifying payment to private contractors. Methods must be technically defensible in case of litigation.

Regulatory Justification: Product acceptance inspection and test results will provide part of the basis for justifying payment to private contractors. Methods must be technically defensible in case of litigation.

ES\&H Justification: The IHLW and ILAW product specifications were developed in part to protect the safety of operators and to protect the environment. Failure to detect non-conforming products could lead to adverse environmental, safety and health impacts.

Cultural/Stakeholder Factors: Stakeholders continue to have concerns for the storage and disposal of radioactive wastes at Hanford.

\section{Other Justification:}

Consequences of Not Filling Need: Potential increases for inadequate waste packages slipping through acceptance process and later failing, causing safety and environmental impacts. Technically undefensible inspection and test techniques could lead to losses should payments to private contractors be contested in courts.

Privatization Potential: High. Private companies have systems that can be adapted to Hanford applications.

Current Base Technology and Cost: None established. Non-destructive examination techniques including radiography, gamma spectroscopy, and passive/active neutron assay are currently used for LLW and TRU solid wastes.

\section{Current Baseline Timeline:}

SUMMARY OF TFA RESPONSE: The TFA rated the priority of the technical response to this need as \#7. The TFA is providing funding for FY97 and proposes to provide funding in FY98-00, given available funding. The TFA intends to satisfy the additional following needs within this technical response: $\# 669,676$, and 677 . 


\section{Tanks Focus Area Need Title: IHLW Product Acceptance Inspection and Test Site Needs \\ Methods \\ Site: Hanford \\ Site ID\#: PW11 \\ TFA Functional Area: Immobilization TFA Need ID\#: 676}

SITE NEED:

Need Description: The U.S. Department of Energy (DOE), Richland Operations Office (RL) is proceeding with a two-phased approach to privatize the treatment and immobilization of Hanford's low-activity and highlevel wastes currently in storage in underground tanks. DOE will provide the tank wastes to the private contractors who will treat and immobilize the wastes and then return the final products to DOE for storage and final disposal. DOE will pay the private contractors for each waste package received that meets the product specifications. Acceptance of the immobilized wastes will be based on a combination of private contractor activities to qualify, verify, document, and certify the product and DOE activities to audit, review, inspect, and test the processes and products.

The immobilization contractors will provide to DOE the immobilized high-level waste (IHLW) products in sealed canisters, process and product grab samples, and the appropriate product certification which may include pertinent process data. The DOE may conduct non-destructive testing of the sealed immobilized high-level waste canisters and destructive and non-destructive testing of the process and product samples. Specific parameters of interest may include chemical composition of the waste forms, fillers, and containers, phase composition, radiochemical composition, thermal history and surface temperature, waste form volume and void space, waste form and container weight, container dimensions including wall thickness, effectiveness of container closure or seal (leak tightness), presence of prohibited materials including free liquids and explosive, pyrophoric or combustible materials, dose rate, surface contamination, waste form homogeneity, and waste form release rates. The IHLW product is expected to be a glass waste form in a $61-\mathrm{cm}$ diameter by $3-$ to $5-\mathrm{m}$ long cylindrical stainless steel canister.

Generally, the inspection and test methods should not require opening or otherwise breaching the seal of the waste form containers. The appropriate sampling and analysis strategies should provide the basis for making statistically based statements with respect to the confidence with which the products meet specifications. The inspection and test methods must be shown to be relevant to the expected performance parameters of the IHLW.

Waste stream: Immobilized High-Level Waste, TWRS

Functional Performance Requirements: Demonstrate non-destructive examination techniques on full-scale prototypic IHLW waste packages. Techniques must have the required sensitivity, precision, and accuracy to make decisions regarding the acceptability of the products. Techniques must have reliability for application in production type environment.

Schedule Requirements: Early indications of the adequacy of the inspection and test methods is needed early as input to product acceptance strategy revisions, Phase $1 \mathrm{~B}$ contract negotiations, and inspection facility design. Inspection and test methods must be selected by September 2000 such that operating procedures can be prepared and implemented. Inspection operations will begin in June 2002.

Problem Description: Non-destructive examination techniques are currently being used at commercial and DOE operated LLW and TRU disposal facilities to verify that packaged wastes meet acceptance criteria. Radiography, including real-time radiography, digital radiography, and X-ray computed tomography, is used to identify gross inhomogeneities and free liquids within waste containers. Gamma spectroscopy is a common technique for determining the concentration of gamma-emitting radionuclides $(60 \mathrm{Co}, 137 \mathrm{Cs}, 152 \mathrm{Eu}$, and $154 \mathrm{Eu}$ ) within a waste drum. Passive/active neutron assay is used to determine the quantity of neutronemitting and fissile material in waste packages. It is used to differentiate between LLW and TRU wastes. Application of these techniques to the more radioactive and more dense IHLW glass forms will need to be demonstrated. Other nondestructive techniques such as eddy current methods and ultrasonic techniques may have application to the inspection of waste containers and their contents. Acoustics and optics based measuring devices are commercially available and would need to be adapted for measuring IHLW canister dimensions

Justifications:

Site Needs Assessment

A.156

Appendix A - Site Needs Database

TFA Need ID\#: 676 
Tanks Focus Area Site Needs
Need Title: IHLW Product Acceptance Inspection and Test Methods

Site: Hanford

Site ID\#: PW11
TFA Functional Area: Immobilization TFA Need ID\#: 676

Technical Justification: Product acceptance inspection and test results will provide part of basis for justifying payment to private contractors. Methods must be technically defensible in case of litigation.

Regulatory Justification: Product acceptance inspection and test results will provide part of basis for justifying payment to private contractors. Methods must be technically defensible in case of litigation.

ES\&H Justification: The IHLW product specifications were developed in part to protect the safety of operators and to protect the environment. Failure to detect non-conforming products could lead to adverse environmental, safety and health impacts.

Cultural/Stakeholder Factors: Stakeholders continue to have concerns for the storage and disposal of radioactive wastes at Hanford.

\section{Other Justification:}

Consequences of Not Filling Need: Potential increases for inadequate IHLW canisters slipping through acceptance process and later failing, causing safety and environmental impacts. Technically indefensible inspection and test techniques could lead to losses should payments to private contractors be contested in courts.

Privatization Potential: High. Private companies have systems that can be adapted to Hanford applications.

Current Base Technology and Cost: None established. Non-destructive examination techniques including radiography, gamma spectroscopy, and passive/active neutron assay are currently used for LLW and TRU solid wastes.

\section{Current Baseline Timeline:}

SUMMARY OF TFA RESPONSE: The TFA did not rate the technical response to this need separately. The TFA intends to satisfy this need through the technical response to Need ID\# 675. 


\begin{tabular}{lll}
\hline Tanks Focus Area & Need Title: Secondary Products Acceptance Inspection and Test \\
Site Needs & Methods & \\
& Site: Hanford & TFA Functional Area: Immobilization \\
& Site ID\#: PW12 & TFA Need ID\#: 677 \\
\hline
\end{tabular}

SITE NEED:

Need Description: The U.S. Department of Energy (DOE), Richland Operations Office (RL) is proceeding with a two-phased approach to privatize the treatment and immobilization of Hanford's low-activity and highlevel wastes currently in storage in underground tanks. DOE will provide the tank wastes to the private contractors who will treat and immobilize the wastes and then return the final products to DOE for storage and final disposal. The private contractors are to separate entrained solids, $137 \mathrm{Cs}$, $99 \mathrm{Tc}$; $90 \mathrm{Sr}$, and TRU from the low-activity waste stream for later immobilization as HLW. DOE will pay the private contractors for the separated secondary waste products that meet the product specifications. Acceptance of the secondary waste products will be based on a combination of private contractor activities to qualify, verify, document, and certify the products and DOE activities to audit, review, inspect, and test the processes and products.

The private contractors will provide to DOE the secondary waste products as liquids or solids depending on the specifications and the appropriate product certification which may include pertinent process data. The DOE may conduct destructive and non-destructive testing of the process and product samples. Specific parameters of interest may include

- chemical composition of the secondary waste products

- radiochemical composition

- thermal history and surface temperature of secondary waste containers

- weight and/or volume of secondary product

- container dimensions including wall thickness

- effectiveness of container closure or seal (leak tightness)

- presence of prohibited materials including free liquids and explosive, pyrophoric or combustible materials

- dose rate

- surface contamination

- flow properties of liquid secondary waste products

The separated cesium-137 product will be a dry, free flowing product in a container with a 50-year storage capability. The entrained solids, strontium-90, transuranics, and technetium-99 will be in a liquid or slurry form with the technetium a distinctly separate product stream.

Generally, the inspection and test methods should not require opening or otherwise breaching the seal of the separated cesium-137 product containers. In-tank or in-pipeline inspection and test methods may be needed for the liquid wastes. The appropriate sampling and analysis strategies should provide the basis for making statistically based statements with respect to the confidence with which the products meet specifications.

Waste stream: Entrained Solids, Cs-137, Tc-99, Sr-90, and TRU, TWRS

Functional Performance Requirements: Demonstrate destructive and non-destructive examination techniques and chemical and radiochemical analysis techniques for inspecting and testing expected secondary waste products. Techniques must have the required sensitivity, precision, and accuracy to make decisions regarding the acceptability of the products. Techniques must have reliability for application in production type environment.

Schedule Requirements: Early indications of the adequacy of the inspection and test methods is needed early as input to product acceptance strategy revisions, Phase 1B contract negotiations, and inspection facility design. Inspection and test methods must be selected by September 2000 such that operating procedures can be prepared and implemented. Inspection operations will begin in June 2002.

Problem Description: Chemical and radiochemical analytical techniques must be demonstrated to have the required sensitivity, precision, and accuracy to characterize the composition and radionuclide content of the entrained solids, $137 \mathrm{Cs}, 99 \mathrm{Tc}, 90 \mathrm{Sr}$, and TRU waste products. Techniques to verify that the solutions and 


\section{Tanks Focus Area Need Title: Secondary Products Acceptance Inspection and Test \\ Methods}

Site Needs

Site: Hanford

Site ID\#: PW12
TFA Functional Area: Immobilization TFA Need ID\#: 677

slurries can be safely transported via cask or pipeline. Non-destructive techniques are needed to confirm that separated $137 \mathrm{Cs}$ waste product and its container meet the specifications for those materials.

Justifications:

Technical Justification: Product acceptance inspection and test results will provide part of basis for justifying payment to private contractors. Methods must be technically defensible in case of litigation.

Regulatory Justification: Product acceptance inspection and test results will provide part of basis for justifying payment to private contractors. Methods must be technically defensible in case of litigation.

ES\&H Justification: The secondary waste product specifications were developed in part to protect the safety of operators and to protect the environment. Failure to detect non-conforming products could lead to adverse environmental, safety and health impacts.

Cultural/Stakeholder Factors: Stakeholders continue to have concerns for the storage and disposal of radioactive wastes at Hanford.

\section{Other Justification:}

Consequences of Not Filling Need: Potential increases for inadequate secondary waste products slipping through acceptance process and upsetting later HLW immobilization, causing cost, safety, and environmental impacts. Technically indefensible inspection and test techniques could lead to losses should payments to private contractors be contested in courts.

Privatization Potential: High. Private companies have systems that can be adapted to Hanford applications.

Current Base Technology and Cost: None established. Some techniques are currently used by Hanford tank farm operations to assure that wastes received in the tanks meet tank specifications.

\section{Current Baseline Timeline:}

SUMMARY OF TFA RESPONSE: The TFA did not rate the technical response to this need separately. The TFA intends to satisfy this need through the technical response to Need ID\# 675. 


\begin{tabular}{lll}
\hline Tanks Focus Area & Need Title: Small-Scale Radioactive Demonstration of Phase I \\
Site Needs & Sludge Washing & \\
& & \\
& Site: Hanford & TFA Functional Area: Pretreatment \\
& Site ID\#: PW13 & TFA Need ID\#: 678 \\
\hline
\end{tabular}

SITE NEED:

Need Description: There is a need to demonstrate that the sludge washing and caustic leach process works at the larger bench scale (small pilot scale) with actual waste before embarking on deployment of the process as a baseline approach for supplying washed sludge to the Privatization Contractors for the Phase 1B High Level Waste Demonstration.

Waste stream: Single and Double Shell Tanks, Tank Farms

Functional Performance Requirements: Operating parameters must be developed for the PHMC process for delivering washed sludge complying with Envelope D specifications to each of the Privatization Contractors in accordance with the "Phase 1 High-Level Waste Pretreatment and Feed Staging Plan," WHC-SD-WM-ES-370, Rev.1 (Manuel et al), September 1996.

Schedule Requirements: This work is required to support the transfers scheduled to begin for Tank 241-AZ101 in June 2002 for Tank 241-AZ-102 in September 2003, and for Tank 241-AY-102 in November 2004. The schedules to support these are given in Manuel's document, September 1996. A mixer pump test in Tank 241AZ-101, Project W-151, will also include demonstrating the process steps for waste washing and caustic leaching. These tests are currently scheduled to be conducted in the October 1997 through September 1998. It would be highly beneficial to coordinate the bench scale tests proposed in this technology need with those full scale tests. This should include preceding the full scale test with a run of such solution through the bench scale test equipment if at all possible. Input to support the preparation of the Phase 2 Privatization Request for Proposal will be needed in the 2002 time frame.

Problem Description: Currently sludge wash laboratory data to support delivery of feed for HLW immobilization in Phase 1B Privatization are limited to that work done by PNNL (Lumetta and Rapko) and LANL (Tiemers) for the HLW Project. This small scale laboratory work is at the 5 gram/test level. Data are needed to support scaling the process up to full scale $(5 \times 109 \mathrm{~g})$; an intermediate scale test (large bench scale, small pilot scale) involving about a 15 gallon size vessel and a few hundred gallons of actual waste will provide the appropriate scale up information. Information is needed about the effects of temperature on such process steps as dilution and perhaps re-precipitation of solids, washing efficiency, leaching efficiency, and quantity of caustic needed. The various Privatization Phase 1 sludges need to be tested to support the full scale processing planned for tanks 241-AZ-101, 241-AZ-102, and 241-AY-102 (including material retrieved from tank 241-C106). Oxidation states of some of the chemical species (e.g. chromium) may need to be altered to ensure dissolution to support overall project objectives.

\section{Justifications:}

Technical Justification: Another need that can be addressed will be testing the various Phase 2 sludges to understand the requirements that must be addressed in the Phase 2 Privatization Request for Proposal. Such information will be essential for preparing a fair cost estimate of what is necessary to get the Phase 2 job done.

Regulatory Justification: Another need that can be addressed will be testing the various Phase 2 sludges to understand the requirements that must be addressed in the Phase 2 Privatization Request for Proposal. Such information will be essential for preparing a fair cost estimate of what is necessary to get the Phase 2 job done.

ES\&H Justification: Same as regulatory

Cultural/Stakeholder Factors: N/A

Other Justification: N/A 


\section{Tanks Focus Area Need Title: Small-Scale Radioactive Demonstration of Phase I

Site Needs

Site: Hanford

Site ID\#: PW13
TFA Functional Area: Pretreatment TFA Need ID\#: 678

Consequences of Not Filling Need: The Envelope D feed may contain more solids than would otherwise be possible; there may be more difficulty in meeting the Envelope D specifications. Another possible consequence is that the Project W-151 Process Test may be delayed because of inadequate data for preparing the safety documentation to support the operational readiness review. Similarly, the actual feed staging of Envelope D from Tank 241-AZ-101 to support privatization could be delayed because of safety documentation difficulties.

\section{Privatization Potential: N/A}

Current Base Technology and Cost: Satisfying this technical need is required to meet the current baseline and meeting the DOE's contractual commitments to deliver feed to the Phase 1 B Privatization Contractor(s) performing HLW immobilization.

\section{Current Baseline Timeline:}

SUMMARY OF TFA RESPONSE: The TFA separated this need into three parts. The TFA Need ID \# 678A and the title, "Settle Decant", identified the first part. The TFA rated \#33 the priority of the technical response to \#678A. The TFA proposes to provide funding in FY98-99, given available funding.

The second part was identified by the Need ID\# 678B and the title, "Pilot Plant." The TFA rated \#60 the priority of the technical response to \#678B. The TFA proposes to provide funding in FY98-00, given available funding.

The Need ID \# 678C and the title, "Solid/Liquid Separation-Hanford", identified the third part. The TFA rated $\# 34$ the priority of the technical response to \#678C. The TFA proposes to provide funding in FY98-99, given available funding. 


\begin{tabular}{lll}
\hline Tanks Focus Area & Need Title: Establish Retrieval Performance Evaluation Criteria \\
Site Needs & [Retr-1] & \\
& Site: Hanford & TFA Functional Area: Retrieval \& Closure \\
& Site ID\#: Retr 1 & TFA Need ID\#: 679 \\
\hline
\end{tabular}

SITE NEED:

Need Description: The Tri-Party Agreement (TPA) establishes an interim retrieval performance goal to leave no more than 360 cubic feet of waste in 75 foot diameter SSTs, and no more than 30 cubic feet in 20 foot diameter SSTs. This interim goal is intended to be finalized or modified over time based on demonstrations of retrieval technology, and on evaluation of cost, technical practicability, exposure of workers and public to radiation, and compliance with Nuclear Regulatory Commission requirements that will establish authority to regulate disposal of the radioactive component of residual waste.

A principal function of waste retrieval is to remove sufficient waste from tanks to permit tank closure. The TWRS EIS evaluated environmental impacts associated with retrieval of waste from SSTs using technologies that are expected to leave residual volumes of waste approximating the interim TPA retrieval performance goal. If residual waste must be retrieved from SSTs as part of closure operations, environmental impacts of such waste retrieval, including impacts on tank waste processing, have not been evaluated.

An additional aspect of establishing retrieval performance objectives concerns the amount of leakage of tank waste that would be allowable during retrieval operations. The amount of leakage that would be allowable depends on what will be done to remediate soil as a consequence of such leakage. Thus determination of allowable tank leakage during retrieval is related to and dependent on criteria for closing tank farms.

Evaluation of alternatives for tank farm closure, which would include evaluation of environmental impacts associated with retrieval of waste to the degree required for "clean closure" was not included within the scope of the TWRS EIS. The TWRS EIS stated that "sufficient information is not available to make final decisions on closure." The TWRS EIS states that the Hanford Tanks Initiative would "gather information and reduce uncertainties associated with tank closure" and that "information that would be gathered through the Hanford Tanks Initiative would be used to establish processes and criteria for future closure options."

In a report summarizing its review of the TWRS EIS, the Committee on Remediation of Buried and Tank Wastes, National Research Council, criticized DOE's and Ecology's decision to defer analysis of closure alternatives, because of the interrelationship of retrieval and closure. The Committee endorsed DOE's decision to address issues on retrieval and closure through the Hanford Tanks Initiative.

Several discrete technology needs must be satisfied to support decisions for tank closure alternatives. These needs include improvements to equipment and methods for tank heel removal, conditioning of wastes to slurries acceptable for transport, techniques to measure the residual waste volume following retrieval efforts, methods to capture samples of waste that are not directly below the riser, and methods to map contaminants in the vadose zone. These needs are expanded in the following paragraphs.

Need Title: SST Retrieval Equipment/System Development

Need Description: Performance and cost data comparing alternate and enhanced retrieval methods to the performance baseline of past-practice sluicing is needed. Data will be applied to the selection of retrieval systems for 1)Tank C-106 Heel Removal, 2) M\&I retrieval of SSTs during Privatization Phase I, 3) ISSTRS concept design technical input to the Privatization Phase II specification (TPA Milestone M-45-04A) and 5) performance assessment for SST closure. Supports maintaining core competency by providing expertise in the application of retrieval tools, regardless of the implementor.

Need Title: Waste Conditioning for Tank Heel Transfer

Need Description: The affects of the physical and chemical properties of waste on pipeline transfer, interim storage and subsequent transfer to pretreatment processed needs to be better understood so that waste conditioning requirements can be determined before any Single Shell Tank hard heels (including the tank 106-C heel) can be safely and efficiently transferred to a storage tank for later processing.

Need Title: Methods for Waste Heel Volume Determination Including Thickness and Profile

Site Needs Assessment

A.162

Appendix A - Site Needs Database 


\begin{tabular}{ll}
\hline Tanks Focus Area & Need Title: Establish Retrieval Performance Evaluation Criteria \\
Site Needs & {$[$ Retr-1] }
\end{tabular}

Site: Hanford

TFA Functional Area: Retrieval \& Closure

Site ID\#: Retr 1

TFA Need ID\#: 679

Need Description: Methods are needed to accurately determine the volume of residual waste in a tank for use in a tank closure assessment. Surface profile and heel thickness are needed to determine waste volume in tanks with unknown tank bottom flatness.

Functional Performance Requirements: Estimated requirement is (+/-) $40 \mathrm{cu}$. ft. (10\% op $360 \mathrm{cu}$. ft. -- target residual) (Will be negotiated based on available cost-effective technology/methodology).

Need Title: Sampling Methods for Residual Heels - Off Riser Axis

Need Description: Methods are needed to sample the residual waste in a tank for use in establishing retrieval performance evaluation criteria. Conventional sampling methods can prove ineffective due to little or no waste being located directly below the access riser. In addition, enough locations in the tank need to be sampled to show adequate characterization of residual waste for use in tank specific performance assessment work.

Need Title: Dilution Lab Tests

Need Description: During Phase I of privatization, TWRS will be retrieving double shell tank supernate. Many of these tank supernates are saturated with salts. The current plan is to dilute these supernates to ensure that these salts will not precipitate during transfer due to cooling. Precipitation can cause operational difficulties during transfer and can result in the transferred stream being $75 \%$ solids as contractually specified with the Privatization Contractors. However, the chemistry of these concentrated supernates is quite complex, and the dilution itself may cause precipitation. For example dilution may prevent sodium nitrate from precipitating, but may cause gibbsite (aluminum hydroxide) to precipitate. Thus it becomes important to understand the conditions which avoid precipitation. This task will verify thermodynamic models which help predict the occurrence of this precipitation.

Waste stream: Single Shell Tanks, Tank Farms

Functional Performance Requirements: These will be established through interaction with stakeholders and regulators as part of the task to establish retrieval performance objectives.

Schedule Requirements: Completion of definition of retrieval performance objectives is needed by FY2000 so that the results can be incorporated into the Privatization Phase II specification due to be completed in FY2003 and the first Single Shell Tank Closure Plan, due to be completed by November 2004 (TPA M-45-06T01).

Problem Description: Other than the retrieval performance goal provided in the Tri-Party Agreement, which is recognized by the Washington Department of Ecology and DOE in a memorandum of understanding as only an "interim" goal, no basis currently exists for defining retrieval performance objectives that address how much waste must be removed from SSTs and how much leakage during retrieval of SSTs will be allowable.

\section{Justifications:}

Technical Justification: This effort is required to establish retrieval system performance requirements relating to how much waste must be removed from SSTs, and how much waste may leak from SSTs during retrieval operations.

Regulatory Justification: This effort is required to establish retrieval system performance requirements relating to how much waste must be removed from SSTs, and how much waste may leak from SSTs during retrieval operations.

ES\&H Justification: Health and safety risks to workers and members of the public associated with alternatives for closing tank farms will be evaluated as part of the effort to address this technology need.

Cultural/Stakeholder Factors: The Washington Department of Ecology and DOE have signed a memorandum of understanding that commits to establishing retrieval performance objectives, as part of the effort to address

$\begin{array}{lll}\text { Site Needs Assessment } & \text { A.163 Appendix A - Site Needs Database }\end{array}$




\begin{tabular}{lll}
\hline Tanks Focus Area & Need Title: Establish Retrieval Performance Evaluation Criteria \\
Site Needs & [Retr-1] & \\
& Site: Hanford & TFA Functional Area: Retrieval \& Closure \\
& Site ID\#: Retr 1 & TFA Need ID\#: 679 \\
\hline
\end{tabular}

this technology need, through soliciting input from Indian Nations and stakeholders, through interaction with the Hanford Advisory Board, Community Leaders Network, and the Site Technology Coordinating Group.

\section{Other Justification: N/A}

Consequences of Not Filling Need: Establishing retrieval system performance objectives based solely on what is technologically achievable, without regard to practicality, cost, and health and safety risk, could lead to inappropriate allocation of site cleanup funds. Deferring establishment of retrieval performance objectives will increase contingency in Phase 2 Privatization proposals for retrieval of SST wastes, and will increase the likelihood of requiring multiple deployments of SST retrieval systems by the PHMC contractors during Phase 1 Privatization.

Privatization Potential: Retrieval system performance specifications will be provided to the Phase 2 Privatization Contractor.

Current Base Technology and Cost: No baseline technology or approach has been established for closing tank farms, or for establishing the degree of waste removal from tanks that will be sufficient to close tank farms.

\section{Current Baseline Timeline:}

SUMMARY OF TFA RESPONSE: The TFA separated this comprehensive need into three parts. The first part was identified as Need ID\# 679, and basically responds to the Hanford Tanks Initiative (HTI) requirements. The TFA rated the priority of the technical response to this need as \#5. The TFA is providing funding for FY97 and proposes to provide funding in FY98-00, given available funding. The response to this need also satisfies Need ID\# 660.

The second part was identified as Need ID\# 679A and titled, "SST Retrieval Equipment/System Development." It was rated priority \#13. The TFA is providing funding for FY97 and proposes to provide funding in FY98-00, given available funding.

The third part was identified as Need ID\# 679B and titled, "Waste Conditioning for Tank Heel Transfer." It was rated priority \#52. The TFA proposes to provide funding in FY98-00, given available funding.

The TFA considered the requirement for the Dilution Lab tests to be covered under the TFA's response to Need ID\# 671. 


\begin{tabular}{lll}
\hline Tanks Focus Area & Need Title: Initial Waste Mobilization Methods Needed to \\
Site Needs & Enhance Advanced Design Mixer Pump Retrieval for DST \\
& Site: Hanford & TFA Functional Area: Retrieval \& Closure \\
& Site ID\#: Retr 2 & TFA Need ID\#: 680 \\
\hline
\end{tabular}

\section{SITE NEED:}

Need Description: Complete retrieval of SY-102 is needed to prevent contamination of incoming supernates into TRU waste. Retrieval of DSTs using the baseline of two mixer pumps is expected to leave a considerable amount of hard sludge heel. While adequate for waste consolidation and pretreatment operations, 102-SY must be made considerably cleaner to act as the 200 West Area staging tank for SST stabilization supernates.

Therefore additional waste mobilization beyond mixer pumps must be deployed to adequately mobilize the TRU waste sludges. Mixer pump only mobilization of 102-SY is not expected to provide sufficient clean out of TRU sludge heel due to the shear strength, or resistance to mobilization, of the sludge (i.e., effective cleaning radius). Alternate or supplementary methods are needed to better mobilize sludge from certain DSTs. Other DSTs may contain hard heels and sludges and other waste types, waste which mixer pumps will not adequately mobilize. However, sample data has not been obtained from all DSTs to confirm this fact.

Waste stream: Double Shell Tanks, Tank Farms

Functional Performance Requirements: Complexed supernates from SSTs stabilization must not chemically absorb sufficient TRU material from residual TRU sludges in 102-SY to become TRU waste itself. Water addition to the tank for the purpose of retrieval or as a result of the process is limited by the cost and schedule of subsequent evaporation.

Schedule Requirements: 102-SY is scheduled to be placed in active service in FY1999 to be the 200 West Area terminus of SST supernates being transferred to the 200 East Area under the SST stabilization program (TPA Milestone M-41-00).

Problem Description: Methods to mobilize hard sludge that are more effective than baseline mixer pumps are needed. Methods are needed that minimize planned or inadvertent water addition during mobilization, replace mixer pumps or enhance mixer pump performance.

Proposed concepts: A sonic probe that uses low frequency sonic vibration can effectively lower the shear strength of the sludge. By reducing the strength of the sludge, the mixer pumps will provide adequate mobilization to meet the waste removal needs. The sonic probe was originally developed as an alternate to the mixer pump technology for mitigation of Tank 101-SY.

\section{Justifications:}

Technical Justification: This effort is required to ensure that the complexed supernates from the SSTs do not absorb TRU material from residual TRU sludges in 102-SY thus becoming TRU waste itself.

Regulatory Justification: This effort is required to ensure that the complexed supernates from the SSTs do not absorb TRU material from residual TRU sludges in 102-SY thus becoming TRU waste itself.

ES\&H Justification: Minimization of TRU wastes

CulturalStakeholder Factors: N/A

Other Justification: N/A

Consequences of Not Filling Need: Supernates from West Area SSTs will be exposed to TRU sludges and therefore, may become TRU wastes and require higher cost processing as HLW.

Privatization Potential: This effort will expand the baseline for retrieval of DST wastes.

Current Base Technology and Cost: Two mixer pumps

Site Needs Assessment A.165

Appendix A - Site Needs Database 


\begin{tabular}{lll}
\hline Tanks Focus Area & Need Title: Initial Waste Mobilization Methods Needed to \\
Site Needs & Enhance Advanced Design Mixer Pump Retrieval for DST \\
& Site: Hanford & TFA Functional Area: Retrieval \& Closure \\
& Site ID\#: Retr 2 & TFA Need ID\#: 680 \\
\hline
\end{tabular}

Current Baseline Timeline:

SUMMARY OF TFA RESPONSE: The TFA rated the priority of the technical response to this need as \#61. The TFA proposes to provide funding in FY98-99, given available funding. 


\begin{tabular}{ll}
\hline Tanks Focus Area & Need Title: Tank Leak Mitigation Systems for Underground \\
Site Needs & Single-Shell Waste Storage Tanks (SSTs) [Retr-4]
\end{tabular}

Site: Hanford

Site ID\#: Retr 4

TFA Functional Area: Safety

TFA Need ID\#: 681

SITE NEED:

Need Description: The use of past-practice sluicing for SST waste removal involves the addition of liquid to tanks and therefore increases the potential for waste leakage to the environment. Leakage mitigation applies to all SST retrieval, including PHMC retrieval during Phase I and preparation of the Phase II specification.

Leakage mitigation efforts and tools, that can be shown to provide cost-benefit and significant risk reduction over baseline methods, should be incorporated into retrieval system design and operating procedures. Existing mitigation techniques (i.e., the current baseline approach) must continue to be evaluated against potential/candidate mitigating technologies to ensure that the most cost-effective, risk reducing approach is applied. Periodic identification and evaluation of potential leakage mitigation tools for possible application during SST retrieval operations is required on a continuing basis.

Waste stream: Single Shell Tanks, Tank Farms

Functional Performance Requirements: The final leakage mitigation approach and requirements will be negotiated with DOE-RL and Ecology. Candidate mitigation systems will be evaluated by such criteria as overall cost-benefit and risk-reduction potential, ease of use and deployment, overall effectiveness, and capability to verify effectiveness. Mitigation systems should address the following types of issues:

- Maximizing in-tank and/or ex-tank opportunities to reduce or stop leakage prior to, during, or following sluicing

- Use of hardware systems that are deployable in or around the target tank to required locations that will facilitate use as designed

- Availability and/or deployability in order to operate during the time frame of need (e.g., at the time and location of a detected leak, or within the time frame of a sluicing campaign)

- Cost-benefit and risk-reduction when compared to the baseline approach and no-action scenario

- The mitigation tool/system must include a capability for installation vèrification and periodic performance verification while installed and/or in service

- The mitigation tool/system must utilize materials that are compatible with the waste (i.e., won't degrade), appropriate to the planned period of use, capable of "surviving" deployment

- Should not produce tank or tank waste conditions that preclude further attempts at waste retrieval or tank/tank farm closure, or that create additional, more complex retrieval problems or conditions.

Schedule Requirements: This need supports TPA milestones for submitting annual progress reports on the development of waste tank leak detection, monitoring, and mitigation (LDMM) activities. The second such report is due September 30, 1997 (TPA M-45-09B). TPA milestones M45-08A and B are also supported and require presentation of the leakage mitigation approach that will be used during sluicing of SSTs, and demonstration and evaluation of those tools that prove to be viable.

Problem Description: Mitigating systems that improve on the capabilities of the current baseline approach are needed. The objective is to prevent, curb, or eliminate the possibility or extent of liquid waste leakage from underground storage tanks into the surrounding soils. If cost-benefit, risk-reduction, and alternatives evaluations of new mitigating technologies determine that deployment, implementation, and operation is feasible, then further evaluation should be pursued. Such evaluations may include demonstrations and testing. Example concepts that could be evaluated include retrieval methods which minimize the potential for leakage, leak point and potential leak point location, "seek-and-seal" devices and methods, administrative approaches that maximize the use and coordination of currently available tools and methods, sheet barriers, close-coupled grout injection barriers, and dry-air containment barriers.

\section{Justifications:}

Technical Justification: Provisions for leakage mitigation are prerequisite to initiating actions to remove waste from leaking tanks. TPA Milestone M-45-08A requires measures for leak mitigation to be included in the

\begin{tabular}{lll}
\hline Site Needs Assessment & A.167 Appendix A-Site Needs Database
\end{tabular}




\title{
Tanks Focus Area Need Title: Tank Leak Mitigation Systems for Underground Site Needs

\author{
Site: Hanford \\ Site ID\#: Retr 4 \\ TFA Functional Area: Safety \\ TFA Need ID\#: 681
}

design of the initial SST retrieval task. This effort is required to ensure that the specification for initial SST waste retrieval, and the Phase II Privatization Contract, are adequate for bidders to make informed decisions and to show a minimum cost.

Regulatory Justification: Provisions for leakage mitigation are prerequisite to initiating actions to remove waste from leaking tanks. TPA Milestone M-45-08A requires measures for leak mitigation to be included in the design of the initial SST retrieval task. This effort is required to ensure that the specification for initial SST waste retrieval, and the Phase II Privatization Contract, are adequate for bidders to make informed decisions and to show a minimum cost.

ES\&H Justification: Leakage must not be allowed to occur to an extent that will preclude the use of available tools and methods for remediating the contaminated soil. The establishment and use of allowable leakage volumes (ALVs) is an important mitigation action since that approach sets operational limits within which soil remediation and closure can still proceed even in the event that leakage may occur. A viable approach to leakage mitigation during sluicing will contribute to the capability to ensure that leakage is managed below $\mathrm{ALVs}$, and to maintain overall safe operations during waste retrieval.

Cultural/Stakeholder Factors: Leakage detection and mitigation during waste retrieval are major issues of concern with Ecology and Hanford stakeholders. This concern is reflected in TPA milestones, review of the TWRS EIS, and in other public documentation.

Other Justification: N/A

Consequences of Not Filling Need: A position based upon current baseline mitigation tools and capabilities will be negotiated with Ecology. However, continued effort to seek new, or enhanced old methods and tools is a major Hanford stakeholder value that will be associated with approval to proceed. Phase II Privatization Contractors would have to put a larger contingency in their bids for retrieval of SSTs to negotiate this matter with Ecology, Hanford stakeholders, and the public by themselves.

Privatization Potential: Demonstration of candidate mitigation tools and methods will show where industry has the capabilities to perform now and where additional technology would be helpful.

Current Base Technology and Cost: Current baseline mitigation approach includes the following measures:

- Use of "smart sluicing" by Retrieval Operations to minimize aggravation of tank weak points

- Sluicing with appropriate diligence to determine, at the earliest possible time, if leakage is occurring

- Removal of water from tanks via interim stabilization when leakage rate and volume warrant

- Minimization of operational/system down-time during which leaks can proceed by providing availability of (backup) equipment and staff

- Designing retrieval systems and equipment for dependability and minimum maintenance.

\section{Current Baseline Timeline:}

SUMMARY OF TFA RESPONSE: The TFA rated the priority of the technical response to this need as \#62. The TFA proposes to provide funding in FY98-00, given available funding. 


\begin{tabular}{ll}
\hline Tanks Focus Area & Need Title: Alternative to Baseline Tank Waste Mixing Systems \\
[Retr-11]
\end{tabular}
Site Needs

Site: Hanford

Site ID\#: Retr 11

TFA Functional Area: Retrieval \& Closure TFA Need ID\#: 682

SITE NEED:

Need Description: Mixing system to homogenize and dilute slurry/supernate waste to support the following objectives: mobilization of settled solids heels; enhance and/or accelerate the dissolution of precipitated soluble salts; homogenize stratified waste layers; mobilization of problematic solids for removal from intermediate feed staging tanks; and to provide the capability to recover from receiving out of specification waste. Feed for Privatization Phase I Immobilization Demonstrations must be certified to comply with RFP waste envelope requirements. To accomplish this, the intermediate feed staging tanks contents must be well mixed before being sampled and transferred to the Privatization Phase contractors.

Waste stream: Double Shell Tanks, Tank Farms

Functional Performance Requirements: The waste solution to be mixed will be a dilute slurry/supernate with a maximum of $5 \%$ solids by volume. The system shall be capable of homogenizing dilute slurry/supernate and removing approximately $95 \%$ of settled solids heel from the tank. Proposed system will be installed into existing tank penetrations. System may be deployed into tanks currently storing wastes.

Schedule Requirements: Needed for Phase I feed beginning in FY2000.

Problem Description: Baseline mixing systems are designed for sludge mobilization. Historically, such mixing systems used at other DOE sites have had a short expected operational life. This situation has led to high life cycle costs related to removal and disposal costs. The system to be proposed should provide equipment that has a high reliability for the environment that it will operate in and also have an improved operational life expectancy.

\section{Justifications:}

Technical Justification: This activity will identify systems that more closely fit the demands of the mixing operation while providing the needed mobilization capabilities. The proposed system shall provide enhanced reliability.

Regulatory Justification: This activity will identify systems that more closely fit the demands of the mixing operation while providing the needed mobilization capabilities. The proposed system shall provide enhanced reliability.

ES\&H Justification: Less required replacement of failed equipment is ALARA.

\section{Cultural/Stakeholder Factors: N/A}

Other Justification: N/A

Consequences of Not Filling Need: Baseline mixing systems with lower reliability will be used with higher life cycle costs.

Privatization Potential: This task will show where industry has the capabilities to perform now and the potential for mobilization and retrieval success under Privatization Phase II.

Current Base Technology and Cost: Mixer pumps

\section{Current Baseline Timeline:}

SUMMARY OF TFA RESPONSE: The TFA rated the priority of the technical response to this need as \#63. The TFA proposes to provide funding in FY98-00, given available funding.

\begin{tabular}{lll}
\hline Site Needs Assessment & A.169 Appendix A-Site Needs Database
\end{tabular}




\begin{tabular}{lll}
\hline Tanks Focus Area & $\begin{array}{l}\text { Need Title: High Accuracy Psychrometric/Flow Measurements } \\
\text { for Determining Tank Evaporation Rates [Retr 13] } \\
\text { Site Needs }\end{array}$ \\
& Site: Hanford & TFA Functional Area: Safety \\
& Site ID\#: Retr 13 & TFA Need ID\#: 683 \\
\hline
\end{tabular}

SITE NEED:

Need Description: During waste retrieval and transfer of solids, a potential exists for the creation of "slurry growth" conditions (i.e., entrapped gases) in the receiver tank with a subsequent gas release event (GRE) similar to the behavior exhibited by Tank 101-SY. In order to monitor the waste for the presence of entrapped gases during a retrieval sequence, material balance calculations must account for the evaporative losses from the tank. This requires highly accurate psychrometric and flow measurement capabilities to detect the amount of entrapped gases.

Waste stream: Single Shell Tanks/Double Shell Tanks, Tank Farms

Functional Performance Requirements: The systems and components necessary for determining tank evaporative losses must be installed in either the tank dome area or the ventilation off gas system; must comply with Hanford tank farms design requirements for flammable gas conditions and must be capable of measuring the tank evaporative losses within $(+/-) 15 \%$.

Schedule Requirements: The technologies required to accurately determine tank evaporation rates are needed to support the retrieval of 106-C in the FY1997/98 time frame. Beyond this period, the most significant retrieval and transfer of solids will involve SST retrieval and DST waste consolidation activities. The initial SST retrieval systems will begin the design/construction phase in FY1999, complete in FY2003 and become operational in FY2004. The DST waste consolidation will involve the transfer of 102-SY solids beginning in FY1999. Therefore, the systems and components necessary for determining tank evaporative losses must be developed, tested and demonstrated prior to FY1999.

Problem Description: When entrapped gases are released during a GRE, the potential for a deflagration exists due to the presence of ignition sources in the tank. If the presence of entrapped gases can be detected and measured, then the retrieval activity can be managed in a way to minimize the consequences and risk of such an event.

\section{Justifications:}

Technical Justification: Slurry growth caused by entrapped gasses can be masked if the tank evaporative losses are not taken. into account during material balance calculations.

Regulatory Justification: Slurry growth caused by entrapped gasses can be masked if the tank evaporative losses are not taken into account during material balance calculations.

ES\&H Justification: Accident and consequence analyses show that the deflagration of entrapped gases corresponding to more than two inches of slurry growth in a DST exceeds risk evaluation guidelines.

Cultural/Stakeholder Factors: N/A

Other Justification: N/A

Consequences of Not Filling Need: Potential creation of GRE tanks that require active mitigation.

Privatization Potential: N/A

Current Base Technology and Cost: Manual psychrometrics/flow measurements

Current Baseline Timeline:

Site Needs Assessment

A. 170

Appendix A - Site Needs Database 
Tanks Focus Area Need Title: High Accuracy Psychrometric/Flow Measurements Site Needs for Determining Tank Evaporation Rates [Retr 13]

Site: Hanford

TFA Functional Area: Safety

Site ID\#: Retr 13 TFA Need ID\#: 683

SUMMARY OF TFA RESPONSE: The TFA rated the priority of the technical response to this need as \#47. The TFA proposes to provide funding in FY98-00, given available funding. 


\section{Tanks Focus Area Need Title: Multi-phase Moisture Flow in Arid Conditions Site Needs \\ Site: Hanford Site ID\#: SD1 \\ TFA Functional Area: Retrieval \& Closure TFA Need ID\#: 684}

\section{SITE NEED:}

Need Description: Moisture flow is the driving force for contamination release from waste and the transport of the contaminants. This flow is poorly understood under the arid conditions frequently found in arid Western sites used for waste disposal and especially for fractured media. In particular, for those sites where moisture barriers or diverters are used at arid sites, the theory and parameters describing liquid and vapor flow under very dry conditions need to be better understood.

Waste stream: Immobilized Low-Activity Tank Waste, Tank Farms

Functional Performance Requirements: 1) Simulate liquid and vapor phase moisture flow under very dry conditions to determine important parameters (such as unsaturated hydraulic conductivity, diffusion coefficient, effective porosity) and conditions over which they are important (e.g. moisture content and matrix potential values). 2) Measure the parameters over the ranges needed. 3) Compare simulations to actual laboratory/field measurements.

Material environments of interest include sand, gravel, concret, crushed glass, and fractured glass including aged specimens of fractured materials.

Schedule Requirements: For use in the Hanford Low-Level Tank Waste Performance Assessments such data and testing are needed by September 2000 . Preliminary versions of the performance assessments will need data by September 1998.

Problem Description: Computer codes are available to perform simulations. Specialized hydraulic measurement instruments are available to measure parameters. Great care must be given because of the small amounts of moisture involved in the measurements and because of the extreme non-linearity of the processes.

\section{Justifications:}

Technical Justification: Provide technical basis (particularly in very dry near-field conditions caused by shadows of moisture barriers) for moisture flow as part of the Hanford Low-Level Tank Waste Performance Assessment. Such information will also be of use in other waste management actions where moisture barriers are used in very dry conditions.

Regulatory Justification: Provide technical basis (particularly in very dry near-field conditions caused by shadows of moisture barriers) for moisture flow as part of the Hanford Low-Level Tank Waste Performance Assessment. Such information will also be of use in other waste management actions where moisture barriers are used in very dry conditions.

ES\&H Justification: Moisture flow is the main means for release of contaminants from waste and the transport of those contaminants to groundwater.

Cultural/Stakeholder Factors: Disposal of low-activity tank waste has the largest environmental impact of any intentional Hanford action.

Other Justification: Achieve better understanding of liquid and vapor phase flow when very dry conditions dominate flow.

Consequences of Not Filling Need: Conservative methods and data will be used in the performance assessment, likely requiring more stringent contaminant release specifications in the waste product request for proposal and requiring more expensive disposal facilities. Savings could mount to hundred's of millions of dollars. In addition, defensibility of performance assessment would be less increasing risk that disposal of tank waste would not occur. 
Privatization Potential: Information likely to be used at other arid DOE sites and at waste management sites in the Western United States which will have a moisture barrier.

Current Base Technology and Cost: Extrapolation of data at higher moisture contents.

Cost:

Waste: Immobilize waste in glass with required release rate based on simplified calculation

\section{Current Baseline Timeline:}

SUMMARY OF TFA RESPONSE: The TFA rated the priority of the technical response to this need as \#35. The TFA proposes to provide funding in FY98-00, given available funding. The following needs are considered covered within this response: $\# 687,688,689,690,692$, and 693 . Since the response to this need is broader than the need title would indicate, the TFA will manage this technical response under the name, "Tank Site Closure Technology." 


\section{Tanks Focus Area Need Title: Standard Method for Determining Waste Form Site Needs \\ Release Rate \\ Site: Hanford \\ TFA Functional Area: Immobilization \\ Site ID\#: SD2 TFA Need ID\#: 685}

SITE NEED:

Need Description: The release of radionuclides from a waste form and package to the environment results from the interactions between the waste form and water in the disposal system. For the disposal of immobilized lowactivity tank waste (ILAW), the waste form and package are expected to be in an extremely dry environment. In such an environment, the release rate is a sensitive function of physical (temperature, water content) and chemical environment ( $\mathrm{pH}$, amount and type of mineral and non-mineral species).

Waste forms are typically developed to minimize the rate of release as measured by a variety of test methods. Current ILAW product specifications require PCT testing and ANS 16.1 testing of the waste forms which involve testing the waste form in an environment where water is abundant and where chemical effects are minimized. These test methods will not be representative of the expected disposal system environment at Hanford. A release rate test method yielding results that can be related to the waste form release rate under expected service conditions is needed as a basis for Phase 2 ILAW product specifications.

Tests are also used to determine release data for use in the analysis for the assurance that long-term public health and safety will be protected using the proposed disposal method. Such tests must examine a wider set of environmental conditions that product acceptance tests and will form the basis of the Performance Assessment for the disposal action. As shown in the "Hanford Low-Level Tank Waste Interim Performance Assessment" (WHC-EP-0884), the contaminant release rate from the waste form is one of the few major factors in the assurance of public health and safety.

As part of the performance activity, the Pressurized Unsaturated Flow (PUF) test was developed (Proceedings of the American Ceramic Society and of Materials Research Society) by the Pacific Northwest National Laboratory to obtain contaminant release rates from waste form under dry conditions.

Waste stream: Immobilized Low-Activity Tank Waste, Tank Farms

Functional Performance Requirements: 1) Develop and standardize a waste form release rate method applicable to dry environments. The effort should compare results from this method to others.

2) Conduct sufficient tests (under a variety of geochemical and hydraulic conditions and using a variety of waste forms) to provide data to form a basis for Phase 2 waste form release rate specification.

3) Coordinate efforts with Hanford Low-Level Tank Waste Performance Assessment to ensure that environmental conditions are typical of Hanford.

Schedule Requirements: 1) For use in the Hanford Low-Level Tank Waste Performance Assessments such data and testing are needed by February 2001. Preliminary versions of the performance assessments will need data by January 1999.

2) A standard method for determining waste form release rate and supporting data is needed to prepare the ILAW product specifications for Phase 2 of the TWRS privatization beginning in approximately 2003.

Problem Description: Develop a standard waste form release rate test method that is relevant to expected performance in the disposal environment and that can be used as a ILAW product specification. The test should be accepted by a standards test organization such as the ASTM.

The test method must provide usable results within a 90-day time period such that the compliance of the waste form to the product specifications can be confirmed and payment to the private contractor authorized. The test method will be implemented in a production environment.

The test method must be suitable over a range of temperatures $(T=14$ to $90 \mathrm{oC})$, moisture conditions $(=0.1$ to $1.0)$, and $\mathrm{pH}(\mathrm{ph}=6.0$ to 12.0$)$ conditions for use in performance assessment activities.

Justifications:

Site Needs Assessment

A.174

Appendix A - Site Needs Database

TFA Need ID\#: 685 


\section{Tanks Focus Area} Site Needs
Need Title: Standard Method for Determining Waste Form Release Rate

Site: Hanford

Site ID\#: SD2
TFA Functional Area: Immobilization TFA Need ID\#: 685

Technical Justification: Numerous test methods including the MCC test, PCT, and ANS 16.1 have been used to determine waste form release rates. Current methods for measuring release rates from a waste form do not mimic the conditions that the waste form will experience in the disposal environment. A standardized test is needed.

Regulatory Justification: Numerous test methods including the MCC test, PCT, and ANS 16.1 have been used to determine waste form release rates. Current methods for measuring release rates from a waste form do not mimic the conditions that the waste form will experience in the disposal environment. A standardized test is needed.

ES\&H Justification: The long-term contaminant release rate is the driving factor in determining human health and environmental impact from the disposal of the low-activity fraction of the Hanford tank waste.

Cultural/Stakeholder Factors: Stakeholders are interested in the parameters which drive environmental impact rather than the parameters that are specified in a contract and only have a weak relationship to real-life performance.

\section{Other Justification:}

Consequences of Not Filling Need: Without data for long-term tests under expected conditions, the performance assessment will use conservative parameters which would require DOE to set tighter requirements on immobilization product vendors or on disposal facility design. Inadequate specification of release rates could lead to future environmental impacts.

Privatization Potential: Uses of glass as a waste form are in unsaturated media. Having a more suitable, standardized test would be of significant value in the DOE complex as well as in private industry.

Current Base Technology and Cost: Standardized tests are in fully emersed or saturated media (PCT, MCC) or in vapor (at high temperatures). Performance of tests at proper temperature, moisture, and pH is not currently possible but relies on extrapolation.

\section{Current Baseline Timeline:}

SUMMARY OF TFA RESPONSE: The TFA did not develop a separate technical response to this need. Instead, it has been captured in the TFA's response to Need ID\#670. 
Tanks Focus Area $\quad$ Need Title: Glass Monolith Surface Area

Site Needs

Site: Hanford

TFA Functional Area: Immobilization

Site ID\#: SD3

TFA Need ID\#: 686

SITE NEED:

Need Description: The contaminant release rate from glasses is proportional to the surface area reachable by moving moisture. As glass cools it experiences internal stresses and strains which may cause the glass to crack and hence increase the surface area on the glass. External stresses (for example, those caused by earthquakes) could also increase surface area.

In addition, cracks may expose imperfections in waste form (internal gas pockets, nucleation sites, devitrification regions) which may cause increased contaminant release rates. Relatively little is known about the long-term behavior of such cracks. Yet the total contaminant release must be known (or at least estimated) for thousands of years.

Waste stream: Immobilized Low-Activity Tank Waste, Tank Farms

Functional Performance Requirements:

1) Manufacture typical low-level waste glass monoliths using a variety of sizes and cooling methods.

2) Determine surface area and crack patterns.

3) Determine area reachable by moisture.

4) Accelerate aging and repeat measurements.

5) Determine unsaturated hydraulic properties of fractured and aged specimens.

Schedule Requirements: For use in the Hanford Low-Level Tank Waste Performance Assessments such data and testing are needed by September 2000. Preliminary versions of the performance assessments will need data by September 1998 .

Problem Description: Status of technology for measurement and aging not known.

\section{Justifications:}

Technical Justification: Contaminant release from the waste form is proportional to the surface area reachable by moving moisture. This release rate determines the impact from waste disposal using very slow-release waste forms.

Regulatory Justification: Contaminant release from the waste form is proportional to the surface area reachable by moving moisture. This release rate determines the impact from waste disposal using very slowrelease waste forms.

ES\&H Justification: The long-term contaminant release rate is the driving factor in determining human health and environmental impact from the disposal of the low-activity fraction of the Hanford tank waste.

Cultural/Stakeholder Factors: Stakeholders are interested in the parameters which drive environmental impact rather than the parameters that are specified in a contract and only have a weak relationship to real-life performance.

\section{Other Justification:}

Consequences of Not Filling Need: Without data, the performance assessment will use conservative parameters which would require DOE to set tighter requirements on immobilization product vendors or on disposal facility design, thus increasing costs. Better definition of contaminant release will lead to a performance assessment which can more easily be defended.

Privatization Potential: Methods could support the privatization vitrification technology industry by providing a means to quantify long-term performance of vitrified products.

Site Needs Assessment

A.176

Appendix A - Site Needs Database 
Tanks Focus Area Site Needs
Need Title: Glass Monolith Surface Area

Site: Hanford

Site ID\#: SD3
TFA Functional Area: Immobilization TFA Need ID\#: 686

Current Base Technology and Cost: Rule of thumb (based on very limited and probably inapplicable experience)

Current Baseline Timeline:

SUMMARY OF TFA RESPONSE: The TFA rated the priority of the technical response to this need as \#36. The TFA proposes to provide funding in FY98-00, given available funding. 


\section{Tanks Focus Area Need Title: Long-Term Testing of Surface Barrier Site Needs \\ Site: Hanford \\ Site ID\#: SD4 \\ TFA Functional Area: Retrieval \& Closure TFA Need ID\#: 687}

SITE NEED:

Need Description: Surface barriers are being used over many Hanford environmental restoration and waste management sites and more barriers are expected in the future. Such barriers are used to reduce moisture infiltration and plant and animal intrusion.

Short-term testing of barriers has occurred under project-sponsored activities, but long-term studies remain a funding orphan. Project-specific funding at Hanford ends in September 1997. Since the design life of the barrier is 1,000 years, need data on degradation to better understand the validity of the design life estimate.

Waste stream: Immobilized Low-Activity Tank Waste, Tank Farms

Functional Performance Requirements: Monitor performance of an existing barrier under both natural conditions and artificially applied increases in precipitation to reflect variability of natural conditions and possible human intrusion). Develop degradation experiments and perform them.

Schedule Requirements: For use in the Hanford Low-Level Tank Waste Performance Assessments such data and testing are needed by September 2000. Preliminary versions of the performance assessments will need data by September 1998. Closure will start occurring in 2005.

Problem Description: Short-term testing has been performed. Need continuing testing.

Justifications:

Technical Justification: The estimated natural recharge at the proposed tank waste disposal facility location is $3 \mathrm{~mm} /$ year. The specifications of the Hanford surface barrier are $0.5 \mathrm{~mm} /$ year for 1,000 years.

Regulatory Justification: The estimated natural recharge at the proposed tank waste disposal facility location is $3 \mathrm{~mm} /$ year. The specifications of the Hanford surface barrier are $0.5 \mathrm{~mm} /$ year for 1,000 years.

ES\&H Justification: See regulatory just above.

Cultural/Stakeholder Factors: A major environmental impact identified in the Hanford Remedial Action Environmental Impact Statement is the mining of materials for surface barrier construction from the McGee Ranch of the Hanford Site. The McGee Ranch area is a wildlife corridor which many see as vital in maintaining the unique shrub-steppe-biological community in this area.

\section{Other Justification:}

Consequences of Not Filling Need: The performance assessment may need to use conservative values or the facility design may be more expensive than necessary. In particular, more material than necessary may be used from an area of significant cultural value or the DOE may be forced to import suitable materials from a considerable distance.

Privatization Potential: Surface barriers are used at many DOE and commercial sites to reduce water infiltration. Research will aid many waste management areas, particularly those in arid and semi-arid Western states.

Current Base Technology and Cost: A cover is undergoing testing at the 200-BP-1 site at Hanford using environmental restoration funds. However, the funds are being greatly reduced and are scheduled to be eliminated after FY 1997.

\section{Current Baseline Timeline:}


Tanks Focus Area Need Title: Long-Term Testing of Surface Barrier Site Needs

Site: Hanford

Site ID\#: SD4

TFA Functional Area: Retrieval \& Closure TFA Need ID\#: 687

SUMMARY OF TFA RESPONSE: The TFA did not prepare a separate technical response for this need. Instead, it has been included under the response for Need ID\# 684 . 


\begin{tabular}{lll}
\hline Tanks Focus Area & Need Title: Testing of Sand-Gravel Capillary Barrier \\
Site Needs & & \\
& Site: Hanford & TFA Functional Area: Retrieval \& Closure \\
& Site ID\#: SD5 & TFA Need ID\#: 688 \\
\hline
\end{tabular}

STTE NEED:

Need Description: Water is the driving force behind releasing contaminants from waste forms and then carrying those contaminants to groundwater. Surface moisture barriers (such as the Hanford barrier) have a design life of a 1,000 years. Yet because of the dry conditions at Hanford, moisture infiltration should be minimized for thousands of years.

Unlike a surface barrier (which uses many of the same hydrologic principles), the capillary barrier diverts water away from the object underneath rather than storing the water until evaporation or plant transpiration removes the water. Thus the capillary barrier is expected to have a significantly longer life and be more effective than a surface barrier for moisture diversion.

Although the principles of sand-gravel capillary barriers are well established, such barriers (especially the ones the size needed for DOE applications) have not been extensively tested.

Waste stream: Immobilized Low-Activity Tank Waste, Tank Farms

Functional Performance Requirements: Design, construct, and operate a sand-gravel capillary barrier of significant extent. A variety of water input rates (ranging from those expected from the use of a surface barrier to those expected from crop irrigation) should be applied with moisture seepage through and around the barrier being collected. Effort should be expended to identify failure mechanisms.

Schedule Requirements: Such experiments should be started as soon as possible as such a barrier is seen as a key component in the design of the low-level Hanford tank waste disposal facility.

Problem Description: A sand-gravel capillary barrier consists of a layer of fine material having high conductivity (such as sand) over a layer of coarse material having low conductivity (such as gravel). These layers are slopped in order to encourage water runoff. Experiments are needed to determine the range of application as well as technical parameters such as the slope of the layers and the optimal types of materials in the layers.

\section{Justifications:}

Technical Justification: The "Hanford Low-Level Tank Waste Interim Performance Assessment" (WHC-EP0884) as well as earlier studies have identified the sand-gravel capillary barrier as a key component in the design of the disposal facility.

Regulatory Justification: The "Hanford Low-Level Tank Waste Interim Performance Assessment" (WHC-EP0884) as well as earlier studies have identified the sand-gravel capillary barrier as a key component in the design of the disposal facility.

ES\&H Justification: See regulatory just above

Cultural/Stakeholder Factors: Disposal of low-activity tank waste has the largest environmental impact of any intentional Hanford action.

\section{Other Justification:}

Consequences of Not Filling Need: Other facility design option must be identified or (more likely) the specifications for Phase 2 of Hanford TWRS Privatization must be significantly tightened. The latter could add hundreds of millions of dollars to the procurement costs. 
Tanks Focus Area Need Title: Testing of Sand-Gravel Capillary Barrier

Site Needs

Site: Hanford

Site ID\#: SD5

TFA Functional Area: Retrieval \& Closure TFA Need ID\#: 688

Privatization Potential: May have application to the design and construction of barriers over solid waste and especially hazardous waste landfills in the arid and semi-arid Western United States.

Current Base Technology and Cost: Theory is well understood. Limited field experience on related surface barriers.

Current Baseline Timeline:

SUMMARY OF TFA RESPONSE: The TFA did not prepare a separate technical response for this need. Instead, it has been included under the response for Need ID\# 684. 


\begin{tabular}{lll}
\hline Tanks Focus Area & Need Title: Moisture Dependence of Kd \\
Site Needs & & \\
& Site: Hanford & TFA Functional Area: Retrieval \& Closure \\
& Site ID\#: SD6 & TFA Need ID\#: 689 \\
\hline
\end{tabular}

SITE NEED:

Need Description: As contaminants travel from the waste disposal facility to the groundwater they interact with the soil. Such interaction can greatly delay and diminish the contaminant transport. Hanford studies (PNL-10722) have shown a moisture dependency of uranium adsorption to soils. More recent research has shown that the degree of uranium adsorption may increase or decrease, depending on the soil type, as soil moisture increases.

Measurements of this interaction (usually expressed as a $\mathrm{Kd}$ value) are normally performed with soils saturated with water. However, particularly in western sites, the soils are normally very dry.

Waste stream: Immobilized Low-Activity Tank Waste, Tank Farms

Functional Performance Requirements: Measure the interaction between important radiocontaminants having non-zero interactions (e.g. $\mathrm{U}$ ) in various soil types and under various conditions $(\mathrm{pH}$, redox) to determine $\mathrm{Kd}$.

Schedule Requirements: For use in the Hanford Low-Level Tank Waste Performance Assessments such data and testing are needed by September 2000. Preliminary versions of the performance assessments will need data by September 1998.

Problem Description: Equipment to perform measurements is available and preliminary work has been performed. A greater data base is needed along with the conceptual models to understand the data.

\section{Justifications:}

Technical Justification: Travel time (and amount of contaminant) are important in determining the impact from a disposal action. For many materials, the chemical interaction between the radiocontaminant and the soil eliminates the radiocontaminant from providing any significant impact.

Regulatory Justification: Travel time (and amount of contaminant) are important in determining the impact from a disposal action. For many materials, the chemical interaction between the radiocontaminant and the soil eliminates the radiocontaminant from providing any significant impact.

ES\&H Justification: See regulatory just above

Cultural/Stakeholder Factors: Disposal of low-activity tank waste has the largest environmental impact of any intentional Hanford action.

\section{Other Justification:}

Consequences of Not Filling Need: A conservative value for contaminant-soil interaction will have to be assumed requiring more stringent waste form performance or more costly facility design. Cost savings may mount to hundreds of millions of dollars.

Privatization Potential: Uranium is a common radiocontaminant. Understanding its interaction will significantly affect many waste disposal and environmental restoration activities.

\section{Current Base Technology and Cost:}

Current Baseline Timeline: 
Site Needs

Site: Hanford

Site ID\#: SD6
TFA Functional Area: Retrieval \& Closure TFA Need ID\#: 689

SUMMARY OF TFA RESPONSE: The TFA did not prepare a separate technical response for this need. Instead, it has been included under the response for Need ID\# 684 . 


\begin{tabular}{lll}
\hline Tanks Focus Area & Need Title: Getter Materials \\
Site Needs & & \\
& Site: Hanford & TFA Functional Area: Retrieval \& Closure \\
& Site ID\#: SD7 & TFA Need ID\#: 690 \\
\hline
\end{tabular}

SITE NEED:

Need Description: In order to meet the contaminant release specifications for the disposal of Hanford lowactivity tank waste, radiocontaminants are physically trapped in glass. However, only a few of these radioelements drive the performance assessment. If these key radioelements could be chemically trapped after their release from glass, then the performance of the waste disposal system could be significantly improved. Hydraulic properties of getter materials (original, loaded, and discharged) need to be measured to fully understand waste disposal performance in the presence of getters. The use of getter materials in the Savannah River Site's disposal of the Saltstone waste was an important consideration in the approval of that site's disposal of tank waste.

Waste stream: Immobilized Low-Activity Tank Waste, Tank Farms

Functional Performance Requirements: For the conditions expected to occur in the Hanford low-level tank waste disposal facility ( $\mathrm{pH}$ around 10 , various chemical species), identify and measure the geochemical and hydraulic properties of a material that can chemically trap technetium (and preferably selenium). The material must be low in cost because large quantities could be used and the disposal site should not represent an attractive natural resource following site closure. The getter material should not introduce any additional environmental hazard.

Schedule Requirements: For use in the Hanford Low-Level Tank Waste Performance Assessments such data and testing are needed by September 2000. Preliminary versions of the performance assessments will need data by September 1998.

Problem Description: Although limited effort to identify such getter materials (Pacific Northwest and Sandia National Laboratories) has been performed, no material has had sufficient testing to be selected.

Instrumentation to determine properties is available. It is the identification of the material that has proved difficult.

\section{Justifications:}

Technical Justification: If technetium (and selenium to a lesser extent) can be chemically trapped, then the requirements of the disposal facility and of the waste form can be lessened.

Regulatory Justification: If technetium (and selenium to a lesser extent) can be chemically trapped, then the requirements of the disposal facility and of the waste form can be lessened.

ES\&H Justification: See regulatory just above

Cultural/Stakeholder Factors: Disposal of low-activity tank waste has the largest environmental impact of any intentional Hanford action.

\section{Other Justification:}

Consequences of Not Filling Need: This potentially very useful design option for the disposal facility will not be available. Containment of the wastes will have to be performed by physical entrapment.

Privatization Potential: Technetium is normally the most important radiocontaminant in the contamination of groundwater. Inexpensive getter materials may be an important aid in any future waste management facility.

\section{Current Base Technology and Cost:}

\section{Current Baseline Timeline:}




\section{Tanks Focus Area $\quad$ Need Title: Getter Materials}

\section{Site Needs}

Site: Hanford

Site ID\#: SD7

TFA Functional Area: Retrieval \& Closure TFA Need ID\#: 690

SUMMARY OF TFA RESPONSE: The TFA did not prepare a separate technical response for this need. Instead, it has been included under the response for Need ID\# 684. 


\section{Tanks Focus Area Need Title: In-Situ Testing of Glass Release Site Needs \\ Site: Hanford \\ Site ID\#: SD8 \\ TFA Functional Area: Immobilization TFA Need ID\#: 691}

SITE NEED:

Need Description: Most testing of waste form performance is done under controlled laboratory conditions that differ from the field conditions actually expected to occur. A field experiment will allow scale-up questions to be explored and enhanced confidence to be generated in the expected performance of the entire disposal system (facility and waste form).

Waste stream: Immobilized Low-Activity Tank Waste, Tank Farms

Functional Performance Requirements: Design, construct, and operate a small scale, highly instrumented model of the disposal system using a low-level glass waste form (preferably one of those proposed by the TWRS privatization vendors).

Schedule Requirements: For use in the Hanford Low-Level Tank Waste Performance Assessments such data and testing are needed by September 2000.

Problem Description: Because of the very small release rate expected, development of instrumentation and methods under field conditions will be needed.

\section{Justifications:}

Technical Justification: Laboratory experiments allow the determination of parameters in the computer simulations. However, the only way to test the entire system is to perform a field experiment.

Regulatory Justification: Laboratory experiments allow the determination of parameters in the computer simulations. However, the only way to test the entire system is to perform a field experiment.

ES\&H Justification: See regulatory just above

Cultural/Stakeholder Factors: Disposal of low-activity tank waste has the largest environmental impact of any intentional Hanford action.

\section{Other Justification:}

Consequences of Not Filling Need: Must rely on computer simulations based on laboratory-generated data.

Privatization Potential: Little

Current Base Technology and Cost:

Current Baseline Timeline:

SUMMARY OF TFA RESPONSE: The TFA rated the priority of the technical response to this need as \#67. The TFA proposes to provide funding in FY99-00, given available funding. 
Tanks Focus Area Site Needs
Need Title: Field Measurements of Vadose Zone Hydraulic Properties

Site: Hanford

Site ID\#: SD9
TFA Functional Area: Retrieval \& Closure TFA Need ID\#: 692

\section{SITE NEED:}

Need Description: Assessments of waste disposal require the knowledge of hydraulic properties in the unsaturated sediments (the vadose zone). Typically, these properties are inferred or estimated from small cores or particle size distributions obtained from a drilled borehole. Field measurements of hydraulic properties will eliminate the uncertainty when extrapolating laboratory small-scale laboratory measurements.

Waste stream: Immobilized Low-Activity Tank Waste, Tank Farms

Functional Performance Requirements: Design, construction, and operate a device to measure hydraulic properties in the vadose zone under dry condition (moisture contents less than $10 \%$ ). Measurement of variables such as water content and matrix potential, which are used to calculate conductivity, must be accurate (within $2 \%$ for moisture contents less than $10 \%$ ) and quick (seconds). The device must be portable and reusable.

Schedule Requirements: For use in the Hanford Low-Level Tank Waste Performance Assessments such data and testing are needed by September 2000.

Problem Description: Limited development has occurred at the Pacific Northwest National Laboratory on such a device.

\section{Justifications:}

Technical Justification: Samples measured in the laboratory are too small and come from cored samples which may not be representative of the field condition. Measurements in the field provide the best estimate of hydraulic properties.

Regulatory Justification: Samples measured in the laboratory are too small and come from cored samples which may not be representative of the field condition. Measurements in the field provide the best estimate of hydraulic properties.

ES\&H Justification: See Regulatory just above.

Cultural/Stakeholder Factors: Disposal of low-activity tank waste has the largest environmental impact of any intentional Hanford action.

\section{Other Justification:}

Consequences of Not Filling Need: Must rely on laboratory measurements and estimation procedures with higher level of uncertainty that inflates risk calculations.

Privatization Potential: Such instruments would be widely applicable to other DOE Sites and to other locations needing hydraulic property data.

Current Base Technology and Cost: Laboratory measurements, extrapolated to field conditions.

Current Baseline Timeline:

SUMMARY OF TFA RESPONSE: The TFA did not prepare a separate technical response for this need. Instead, it has been included under the response for Need ID\# 684. 


\section{Tanks Focus Area Need Title: Distribution of Recharge Rates Site Needs \\ Site: Hanford Site ID\#: SD10 \\ TFA Functional Area: Retrieval \& Closure TFA Need ID\#: 693}

\section{SITE NEED:}

Need Description: Recharge water is the primary means for dissolution and release of contaminants from the buried waste and transport of those contaminants to the groundwater. Estimation of these rates is difficult under arid conditions because the rates are very low. In addition, there are significant questions about the adequacy of the estimated recharge rates given the heterogeneity of the environmental processes, the effect of facility features, the uncertainty of climate, and the influence of humans. Furthermore, no attempt has been made to quantify the distribution of recharge rates to enable sounder estimates of the mean and range of rates to be expected during the lifetime of the facility.

\section{Waste stream: Immobilized Low-Activity Tank Waste}

Functional Performance Requirements:

1) Identify range of factors that affect recharge

2) Develop new and innovative methods to determine recharge rates in and around subsurface disposal facilities

3) Estimate recharge rates for a subset of the range of factors and correlate estimates from multiple methods.

4) Use estimates to quantify spatial and temporal distribution of recharge rates for the spatial and temporal extent of the disposal facility.

Factors of interest that can contribute to variable recharge rates include soil type, vegetation, facility and surface cover design, human activity, climate, and time.

Schedule Requirements: For use in the Hanford Low-Level Tank Waste Performance Assessments, such data and testing are needed by September 2000. Preliminary versions of the performance assessments will need data by September 1998.

Problem Description: Computer codes, hydraulic measurements, and tracer movement can be used to estimate recharge rates. These techniques are not often used in conjunction, and hardly ever to characterize the spatial distribution of recharge rates.

\section{Justifications:}

Technical Justification: Provide technical basis for characterizing the distribution of recharge rates in and around the Hanford Low-Level Tank Waste Disposal System. Such information will also be of use in other waste management actions involving subsurface disposal.

Regulatory Justification: Provide technical basis for characterizing the distribution of recharge rates in and around the Hanford Low-Level Tank Waste Disposal System. Such information will also be of use in other waste management actions involving subsurface disposal.

ES\&H Justification: Recharge water is the main means for dissolution/release of contaminants from waste and the transport of those contaminants to groundwater.

Cultural/Stakeholder Factors: Disposal of low-activity tank waste has the largest environmental impact of any intentional Hanford action.

Other Justification: Achieve better understanding of magnitude and variability of recharge rates in dry environments.

Consequences of Not Filling Need: Conservative methods and data will be used in the performance assessment, likely requiring more stringent contaminant release specifications in the waste product request for proposal and requiring more expensive disposal facilities. 
Tanks Focus Area Need Title: Distribution of Recharge Rates

Site Needs

Site: Hanford

Site ID\#: SD10
TFA Functional Area: Retrieval \& Closure TFA Need ID\#: 693

Privatization Potential: Information likely to be used at other arid DOE sites and at waste management sites in the Western United States where wastes are present, or will be disposed, in the subsurface.

Current Base Technology and Cost: Point estimates of recharge.

Current Baseline Timeline:

SUMMARY OF TFA RESPONSE: The TFA did not prepare a separate technical response for this need. Instead, it has been included under the response for Need ID\# 684 . 


\section{Distribution}

No. of

Copies

\section{OFFSITE}

J. Bell

Bell Consultants, Inc.

137 Bowsprit Lane

Kingston, TN 37763

J. Carberry

Dupont

Experimental Station

Building 249/119

PO Box 80249

Wilmington, DE 19880-0249

G. Choppin

Chemistry Department

Florida State University

$600 \mathrm{~W}$. College Ave

Tallahasee, FL 32306-3006

A. G. Croff

Martin Marietta Energy Systems Inc.

Oak Ridge National Laboratory

PO Box 2008

Oak Ridge, TN 37831-6178

R. C. Erdmann

PO Box 922

Grass Valley, CA 95945

D. W. Geiser, EM-50

U.S. Department of Energy

19901 Germantown Road

Germantown, MD 20874-1298
No. of

Copies

J. A. Gentilucci

JAG Technical Services, Inc.

127 Savannah Drive

Aiken, SC 29803

T. Gutmann

U.S. Department of Energy

Savannah River Operations Office

PO Box A

Aiken, SC 29802

T. J. Hirons

Los Alamos_DOE-FP

Los Alamos National Laboratory

PO Box 1663 MS J591

Los Alamos, NM 87545

E. W. Holtzscheiter

Westinghouse Savannah River Company

Savannah River Technology Center

Aiken, SC 29802

A. M. Jensen

Lockheed Martin Idaho Technologies

Company

PO Box 1625

Idaho Falls, ID 83415-5219

D. S. Kaback

Colorado Center for Environmental

Management

999 18th St, Ste 2750

Denver, CO 80202

B. R. Kowalski

Chemistry Department, BG-10

University of Washington

Seattle, WA 98195 
No. of

Copies

J. H. Lee

Sandia National Laboratories

PO Box 5800, MSIN 0734

Albuquerque, NM 87185-0726

B. Lewis

Westinghouse Savannah River Company

Building 703-8C, Room 7

PO Box 616

Aiken, SC 29802

P. W. Lurk, EM-542

U.S. Department of Energy

19901 Germantown Road

Germantown, MD 20874-1298

C. P. McGinnis

Oak Ridge National Laboratory

PO Box 2008

Oak Ridge, TN 37821-6273

C. S. Mims

U.S. Department of Energy

Oak Ridge Operations Office

PO Box 2001

Oak Ridge, TN $37830-8620$

J. Morin

Westinghouse Savannah River Company

PO Box 616

Aiken, SC 29802

J. R. Noble-Dial

U.S. Department of Energy

Oak Ridge Operations Office

PO Box 2001

Oak Ridge, TN $37830-8620$

K.G. Picha

U.S. Department of Energy EM-32

Office of Eastern Operations

19901 Germantown Road

343/TREV

Germantown, MD 20874-1290
No. of

Copies

W. Prindle

1556 Crestline Drive

Santa Barbara, CA 93105

J. K. Rice

Director, Environmental Programs

Sandia National Laboratories

PO Box 5800

Albuquerque, NM 87185-0726

W. W. Schulz

5314 Arbustos Court, NE

Albuquerque, NM 87111

L. H. Sullivan

Los Alamos National Laboratory

PO Box 1663

Los Alamos, NM 87545

J. Swanson

1318 Cottonwood

Richland, WA 99352

L. L. Talvarides

Syracuse University

334 Hinds Hall

Syracuse, NY 13244

T. R. Thomas

Lockheed Martin Idaho Technologies

Company

PO Box 1625 MSIN 3458

Idaho Falls, ID 83415-3423

M. C. Thompson

Westinghouse Savannah River Company

Building 773-A, C140

PO Box 616

Aiken, SC 29802

J. H. Valentine

Lockheed Martin Idaho

Technologies Company

PO Box 1625

Idaho Falls, ID 83415-3100 
No of

Copies

G. Vandegrift

Argonne National Laboratory

Building 205

9700 South Cass Avenue

Argonne, IL 60439

T. E. Weber

6622 West Victoria

Kennewick, WA 99336

M. Winokur

Waste Policy Institute

555 Quince Orchard Road

Suite 600

Gaithersburg, MD 20878

P. E. Woodall

U.S. Department of Energy

Idaho Operations Office

750 Doe Place (MS 1145)

Idaho Falls, ID 83402

\section{ONSITE}

\section{DOE-RL}

J.A. Frey

K8-50

J. M. Hennig

K8-50

C. S. Louie

B4-55

L. S. Mamiya

K8-50

B. M. Mauss
No. of

Copies

2 Waste Policy Institute

G. T. Bear

K8-50

P. A. Hummer

K8-50

\section{Pacific Northwest National Laboratory}

R. W. Allen

K9-69

E. G. Baker

P8-38

T. M. Brouns

K9-08

J. L. Buelt

P7-41

R. M. Ecker

K6-91

M. S. Hanson

K9-02

J. O. Heaberlin

K8-41

S. W. Heaberlin

K8-31

J. P. LaFemina

K9-91

J. M. Latkovich

P7-27

A. K. Lebold

K9-69

K. L. Manke

T. Palusziewicz

K9-69

R. K. Quinn

SEQUIM

S. N. Schlahta

K9-69

K9-69

P. Scott

R3-87

T. L. Stewart

K9-91

W. C. Weimer

P7-27

TFA Library (3)

K9-69

Information Release Office (7)

K1-06

Lockheed Martin Hanford Corporation

J. O. Honeyman

G3-21

Los Alamos National Laboratory

G. Eller

S7-53

Numatec Hanford Corporation

P. W. Gibbons

H5-61

Distr.3 